UNIVERSIDADE DE SÃO PAULO

INSTITUTO DE GEOCIÊNCIAS

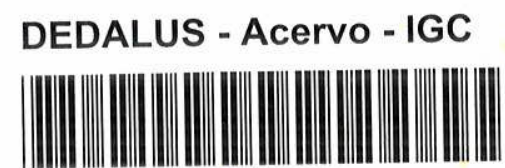

T.774

e.2.

30900005330

\title{
A PESOUISA E A METODOLOGIA DE ENSINO NAS ESCOLAS SUPERIORES DE GRADUAÇÃO EM GEOLOGIA NO PAÍS
}

Oscar Braz Mendonza Negrão

Orientador: Prof. Dr. Franco Levi

DISSERTAÇÃO DE MESTRADO

COMISSÃO EXAMINADORA

nome ass.

$\begin{array}{ll}\text { Presidente: } & \frac{\text { Dr. Franco Levi }}{\text { Examinadores: }} \frac{\text { Dr. Celso R.Beisiegel }}{\text { Dr. Josué C.Mendes }}\end{array}$

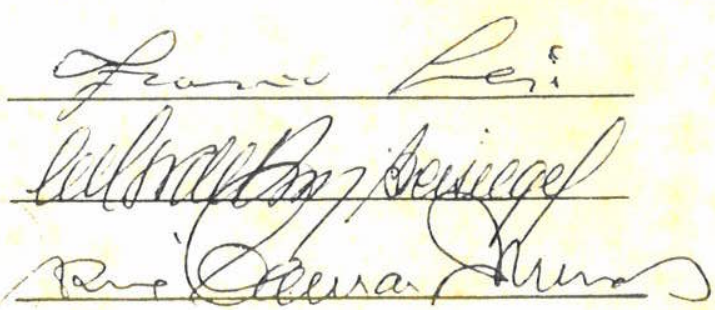


A Abelardo e Mercedes 
AGRADECIMENTOS

Exceto no fim do caminho, em que a redagăo obriga à dedicagão integral, o trânsito do trabalho esteve sempre mui to sujeito a solavancos e interrupgões. Não seria concluido sem a ajuda efetiva e competente, além do estimulo afetuoso, de vários profissionais, para minha ventura também amigos meus.

Ivan e Maria Helena ajudaram durante toda a Ionga construção.

Hilärio e Dorotéa abriram-me as portas de sua casa, de sua inteligência e de seu coracão, propiciando "exirio" altamente produtivo.

Silvia elaborou criticas e sugestões fundamentais, desviando generosamente muitas horas da redacão de sua própria tese.

Pedro Wagner Goncalves, Yokico e Lobão conferiram, corrigiram, diagramaram, poupando-me reservas preciosas de energia e tempo.

VZadimir, Mariley, EZiana, Thomas, Mariantonia, James e Hilton, auxiliaram de diferentes maneiras.

José Roberto bem mais do que datizografou, com rara eficiência e rapidez.

Franco, meu orientador, foi sempre paciente, tole rante e compreensivo. Não fosse essa postura, o trabalho ficaria inviabizizado.

A maior parte dos professores dos Cursos de Graduacão em Geologia valorizou a pesquisa diagnóstico elaborada pela Sociedade Brasileira de Geologia e Ministério da Educasão e Cultura, respondendo ao questionario proposto. Em seus depoimentos baseou-se este trabalho. 
A Sociedade Brasileira de Geologia (SBG) e o Ministerio de Educação e Cultura (MEC) realizaram, no ano de 1980, pesquisa diagnóstico acerca das diferentes populações que fazem parte do sistema de ensino de graduação na área de Geologia no País: as Unidades Universitärias, o professor, o aluno e o geólogo que atua fora da Universidade.

Foi escolhida para este estudo apenas uma das popula ções investigadas: os professores de disciplinas geológicas ou afins nos Cursos de Graduação em Geologia. Os professores foram divididos em dois grupos independentes, professores que desenvolvem e que não desenvolvem pesquisa.

Entre os dados disponíveis, havia värios que indicavam procedimentos de ensino do professor em sala de aula ou no campo. Tais procedimentos foram agrupados em diferentes conjuntos, indicando diferentes características metodológicas de ensino. O objetivo principal do trabalho é comparar os dois grupos de professores quanto à metodologia de ensino que uti1izam, tomando-se por referência as mencionadas características metodológicas. Outro objetivo é determinar a associação entre possibilidades de desenvolvimento de pesquisa por parte dos professores e aspectos ligados a sua situação funcional e instituições a que pertencem.

A amostra utilizada abrangeu 297 professores, que cor respondem a $56,6 \%$ da população de professores de disciplinas geolögicas ou afins e a $94,6 \%$ do $\underline{n}$ amostral da pesquisa reali zada por SBG e MEC. O instrumento de coleta de dados foi o questionärio da mesma pesquisa, aproveitando-se tambëm as res postas jä existentes.

os dados pertinentes foram organizados e analisados em tabelas de contingência de dupla e tripla entrada. Aplicou -se a prova estatística do $x^{2}$ para determinar a significância de diferenças entre os dois grupos de professores quanto aos referidos procedimentos de ensino. 
Os resultados demonstram não haver diferença signifi. cativa entre os dois grupos de professores ao tomar-se por re ferência as diversas características metodolögicas de ensino. Esta situação pode estar condicionada por aspectos administra tivos da Universidade e curriculares do Curso de Graduação em Geologia, e ainda pela pröpria política que definiu a criação dos primeiros Cursos de Geologia.

A anâlise dos resultados confirma a associação entre possibilidades de desenvolvimento de pesquisa e um conjunto de variāveis ligadas à situação funcional dos professores e Instituição a que encontram-se vinculados. 
During 1980 the Sociedade Brasileira de Geologia (SBG) and the Ministërio da Educação e Cultura (MEC) undertook a survey on undergraduate education in Geology in the universities of Brazil. The survey involved four populations: under graduate students in Geology, their professors, the institu tions (departments or schools) involved in undergraduate education in Geology, and geologists working outside the university.

Only one population was investigated in the present study: the professors of geology courses involved in undergra duate education. The professors were divided into two indepen dent groups, those who are involved in research and those who are not. Part of the available data concerned teaching procedures in the classroom and in the field, which were grouped into different combinations indicating different methodological characteristics of teaching. The main purpose of the research was to compare the teaching methodologies of the two groups of professors. Another purpose was to analyse the rela tionships between the possibility to do research and the career status of the professor and the characteristics of his institution.

The sampled population includes 297 professors, corresponding to $56,6 \%$ of the population of university geology professors and to $94,6 \%$ of those who answered the survey un dertaken by the SBG and MEC. The pertinent data drawn from the SBG/MEC questionnaires were analysed and organized into contingency tables with double and triple inputs. The $x^{2}$ statistical test was used to determine the significance of diffe rences in teaching procedures between the two groups of professors.

The results show that there are no significant diffe rences in methodological characteristics of teaching between the two groups. This situation may be the result of hiring 
practices and administrative aspects of Brazilian universities as well as partiy due to the nature of the undergraduate curriculum in Geology. Another cause may be related to the reasons behind the creation of the various schools of Geology in the country.

Analysis of the results confirms the hypothesis that research possibilities are associated with certain variables of career status of the professor and of his institution. 


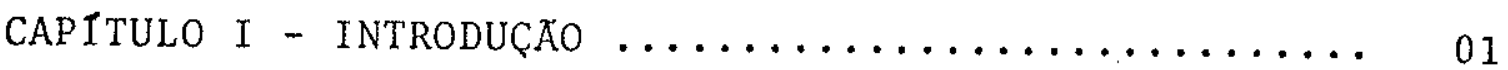

I.1 - A Metodologia de Ensino na Formação do Geólogo.. 01

I.2 - Origens do Movimento de Inovação ............ 11

I.3 - Conceito de Inovação em Metodologia de Ensino .. 14

I.4 - A Metodologia de Ensino Utilizada nos Cursos de Geologia ........................... 15

I.5 - Ensino e Pesquisa, Quais as Relações? 17

CAPITULO II - DEFINIÇÃO DO PROBLEMA, HIPOTESES E

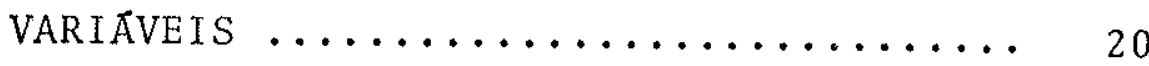

II.1 - Definição do Problema ................ 21

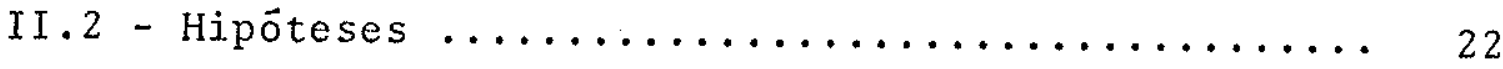

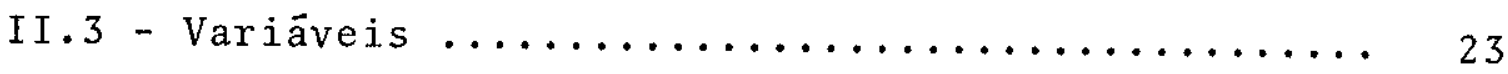

CAPITULO III - PROCEDIMENTO METODOLOGICO ......... 28

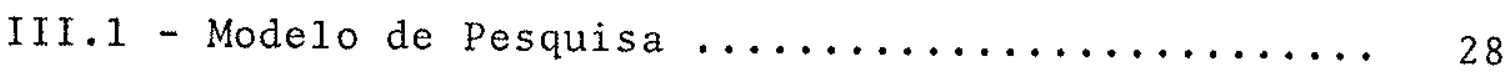

III.2 - População e Amostra ................ 31

III.3 - Coleta de Dados ................... 35

III.3.1 - Instrumento Utilizado na Coleta de Dados ........................ 35

III.3.2 - Procedimento de Coleta de Dados .... 38

III.4 - Tratamento dos Dados .............. 40

III.4.1 - Codificação e Computação ........ 41

III.4.2 - Prova Estatística ........... 41 
CAPITULO IV - DESCRIÇAO E ANALISE DOS RESULTADOS ( 1 a

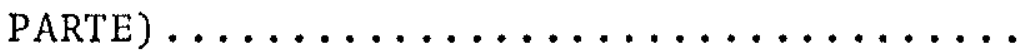

IV.1 - Os Professores e as Atividades de Pesquisa....

IV.1.1 - Tipo de Unidade Universitária e Periodo de Início de Funcionamento de Curso de Geologia.................. 42

IV.1.2 - Regime de Trabalho............. 46

IV.1.3 - Atividades profissionais Externas à Unidade Universitäria........... 48

IV.1.4 - Nível de Contratação............ 49

TV.1.5 - Título obtido.............. 52

IV.1.6 - Tempo de Serviço na Unidade Universitâa

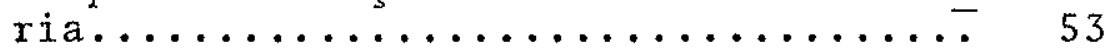

IV.2 - Fatores que Condicionam as Possibilidades de Pesquisa........................... 54

IV.2.1 - Regime de Traba1ho............. 54

IV.2.Ia - Regime de trabalho e tipo de Unidade Universitäria......

IV.2.1b - Regime de trabalho e periodo de inicio de funcionamento

de Curso de Geologia....... 56

IV.2.2 - Atividades Profissionais Externas à Unidade Universitäria.............

IV.2.2a - Atividades profissionais externas e tipo de Unidade Uni

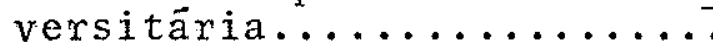

IV.2.2b - Atividades profissionais externas e periodo de inicio de funcionamento de Curso de Geologia...............

IV.2.3 - Nível de Contratação............. 60

IV.2.3a - Nivel de contratação e tipo de Unidade Universitāria.... 60

IV.2.3b - Nîvel de contratação e perío do de início de funcionamento de Curso de Geologia.....

IV. $2.4-$ Titulo obtido............... 65

IV.2.4a - Título obtido e tipo de Inidade Universitäria........ 65

IV.2.4b - Titulo obtido e período de início de funcionamento de Curso de Geologia.......... 
IV. 2.5 - Tempo de Serviço............ 70

IV.2.5a - Tempo de serviço e tipo de de Unidade Universitäia.... 70

IV.2.5b - Tempo de serviço e período de início de funcionamento de Curso de Geologia....... 70

IV.3 - Principais Tendências de Grupo............ 73

IV.3.1 - Tendências Conforme Tipo de Unidade Universitäria................ 73

IV.3.2 - Tendências Conforme Período de Início de Funcionamento de Curso de Geologia. 74

IV.3.3 - Conjunto de Tendências dos professores dos Grupos A e B.............. 75

CAPTTULO V - DESCRIÇAO E ANÁLISE DOS RESULTADOS (2 PARTE)

V.I - Descrição e Anâlise dos Procedimentos de Ensino.

V.1.1 - Procedimento de Ensino no 1......... 78

V.1.2 - Procedimento de Ensino $n^{\circ} 2 \ldots \ldots \ldots . \ldots . . . .60$

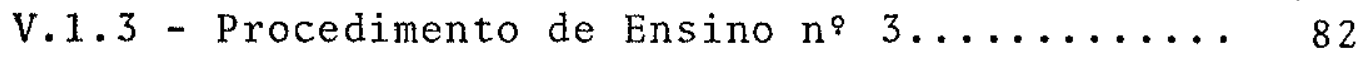

V.1.4 - Procedimento de Ensino ${ }^{\circ} 4 \ldots \ldots \ldots \ldots . \ldots 84$

V.1.5 - Procedimento de Ensino n०5........ 86

V.1.6 - Procedimento de Ensino $n^{8} 6 \ldots \ldots \ldots 88$

V.1.7 - Procedimento de Ensino $n: 7 \ldots \ldots . \ldots 90$

V.1.8 - Procedimento de Ensino ${ }^{\circ} 8 \ldots \ldots \ldots . \ldots . . \ldots 9$

V.1.9 - Procedimento de Ensino n: $\ldots \ldots \ldots . \ldots . . .94$

V.1.10-Procedimento de Ensino $n^{\circ} 10 \ldots \ldots 96$

V.1.11 - Procedimento de Ensino ${ }^{\circ} 11 \ldots \ldots . \ldots . . . .98$

V.1.12 - Procedimento de Ensino ${ }^{\circ} 12 \ldots \ldots \ldots \ldots 100$

V.1.13-Procedimento de Ensino $n^{\circ} 13 \ldots \ldots \ldots 102$

V.1.14 - Procedimento de Ensino $n^{\circ} 14 \ldots \ldots \ldots 104$

V.1.15 - Procedimento de Ensino n: 15........ 106

V.1.16 - Procedimento de Ensino $n^{\circ} 16 \ldots \ldots \ldots \ldots 108$

V.1.17-Procedimento de Ensino ${ }^{\circ} 17 \ldots \ldots \ldots \ldots 110$

V.1.18 - Procedimento de Ensino $n^{\circ} 18 \ldots \ldots \ldots \ldots 112$ 
V.2 - Sinopse dos Resultados - Procedimentos de Ensino Individuais ......................... 114

V.2.1 - Semelhanças entre os Grupos A e B ..... 114

V.2.2 - Diferenças entre os Grupos A e B ...... 115

V.3 - Caracterização da Metodologia de Ensino ....... 115

V.3.1 - Tipo de Aprendizagem ............. 118

V.3.2 - Forma de Obtenção de Conhecimentos .... 119

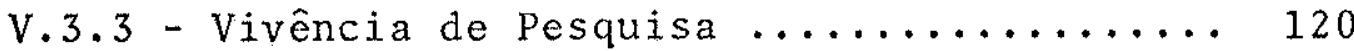

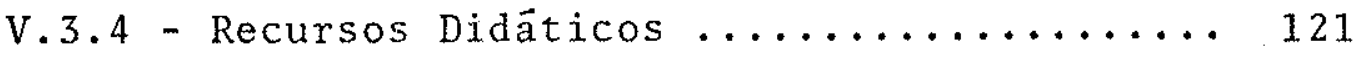

V.3.5 - Amplitude de Conceitos .............. 122

V.4 - A Metodologia de Ensino Utilizada Pelos Professo

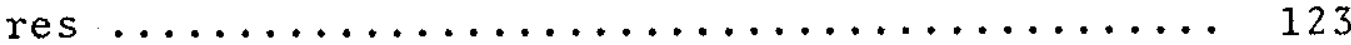

V.4.1 - Tipo de Aprendizagem ............ 123

V.4.2 - Forma de Obtenção de Conhecimentos .... 125

V.4.3 - Vivência de Pesquisa ................. 126

V.4.4 - Recursos Didáticos ................ 127

V.4.5 - Amplitude de Conceitos ............. 128

V.5 - Sinopse dos Resultados - Características Metodo-

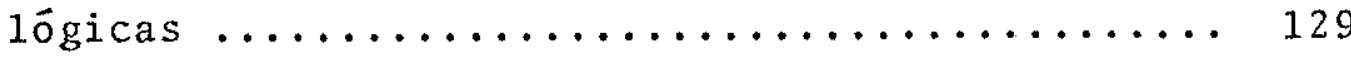

V.6 - Perfil do Professor Segundo Suas Características Metodológicas ....................... 130

CAPITULO VI - CONCLUSOES ................... 132

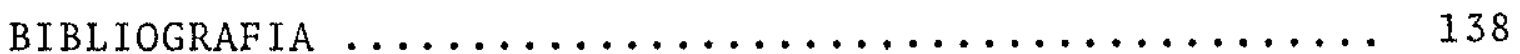

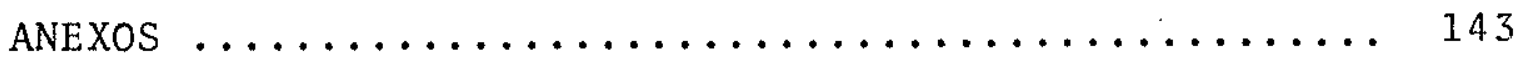

ANEXO 1 - Questionärio do. Professor ......... 144

ANEXO 2 - Instruções para Aplicação dos Questionärios ..................... 171

ANEXo 3 - Tabelas de Contingência de Dupla e Tripla Entrada - Relaçóes Entre Variá veis na Subamostra de Professores das Unidades Universitärias Federais ... 
TAEELA III -1

População e Amostra de Professores - 1980 ..........

TABELA III-2

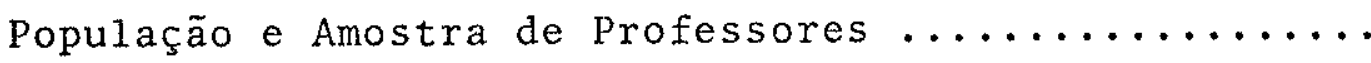

TABELA IV-1.

Tipo de Unidade Universitäria e Ano de Início de Funcionamento dos Cursos de Graduação em Geologia - 1980..

TABELA IV -2

Relação Entre Grupo e Tipo de Unidade Universitária -

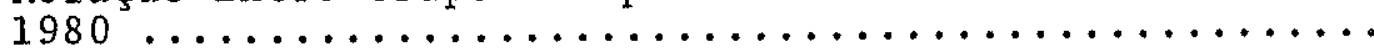

TABELA IV -3

Relação Entre Grupo e Período de Início de Funcionamen. to de Curso de Graduação em Geologia - 1980 ........

TABELA IV -4

Relação Entre Grupo e Período de Início de Funcionamen to de Curso de Graduação em Geologia na Subamostra de Professores das Unidades Universitärias Federais - 1980

TABELA IV -5

Relação Entre Grupo e Regime de Trabalho - 1980 .....

TABELA IV-6

Relação Entre Grupo e Exercicio de Atividades Profis sionais Externas a Unidade Universitāria - 1980 .....

TABELA IV-7

Relação Entre Grupo e Nível de Contratação - 1980 ...

TABELA IV -8

Relação Entre Grupo e Nïvel de Contratação na Subamostra de professores das Unidades Universitarias Fede-

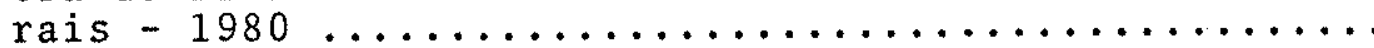

TABELA IV -9

Relação Entre Grupo e Título Obtido - $1980 \ldots \ldots \ldots \ldots$... 
TABELA IV- 10

Relação Entre Grupo e Tempo de Serviço na Unidade Uni-

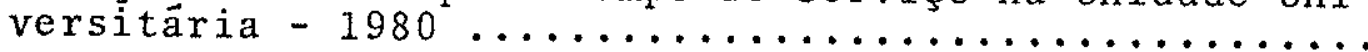

TABELA IV-11

Relação Entre Grupo e Tipo de Unidade Universitäria,

Controlando Pelo Regime de Trabalho - $1980 \ldots \ldots \ldots \ldots$.

TABELA IV -12

Relação Entre Grupo e Período de Início de Funcionamen to de Curso de Graduação em Geologia, Controlando Pelo

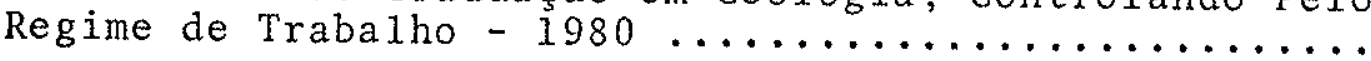

TABELA IV -13

Relação Entre Grupo e Tipo de Unidade Universitäria, Controlando PeloExercício de Atividades Profissionais

Externas - 1980

TABELA IV -14

Relação Entre Grupo e Período de Início de Funcionamen to de Curso de Graduação em Geologia, Controlando Pe10 Exercicio de Atividades Profissionais Externas à Unida

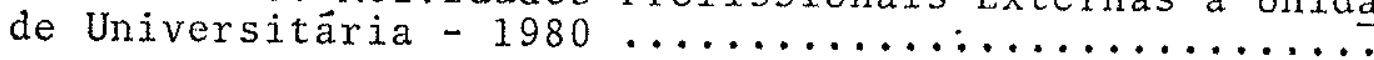

TABELA IV-15

Relação Entre Grupo e Tipo de Unidade Universitäria, Controlando Pelo Nível de Contratação - $1980 \ldots \ldots \ldots$

TABELA IV-16

Relação Entre Grupo e período de Início de Funcionamen to de Curso de Graduação em Geologia, Controlando Pe1o

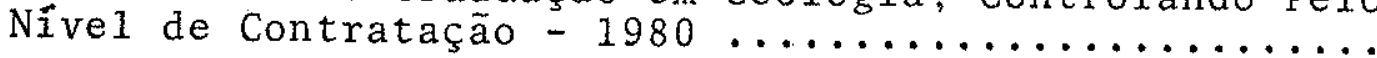

TABELA IV -17

Relação Entre Grupo e período de Início de Funcionamen to de Curso de Graduação em Geologia, Controlando Pe1o Nível de Contratação, na Subamostra de Professores das Unidades Universitärias Federais $-1980 \ldots \ldots \ldots \ldots \ldots$

TABELA IV-18

Relação Entre Grupo e Tipo de Unidade Universitäria, Controlando Pelo Título Obtido $-1980 \ldots \ldots \ldots \ldots \ldots \ldots$

TABELA IV -19

Relação Entre Grupo e Período de Início de Funcionamen to de Curso de Graduação em Geologia, Controlando Pe1o

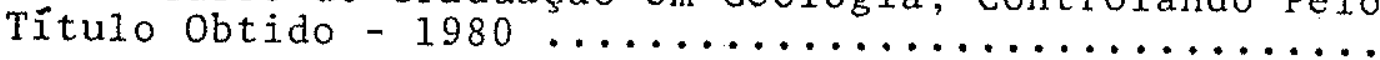


TABELA IV-20

Relação Entre Grupo e Tipo de Unidade Universitäria,

Controlando Pelo Tempo de Serviço - 1980 ..........

TABELA IV -21

Relação Entre Grupo e Período de Início de Funcionamento de Curso de Graduação em Geologia, Controlando Pelo Tempo de Serviço na Unidade Universitäria - $1980 \ldots \ldots$

TABELA V-1

Frequência do Procedimento: "Costumo Dar a Maior Parte de Minhas Aulas de Forma Expositiva" nos Grupos A e B 1980

TABELA $V-2$

Frequência do Procedimento: "Valorizo o Conhecimento de Detalhes ou Infuimações Especificas Sobre o Conteüdo de Minha Disciplina" nos Grupos A e B - 1980 ..........

TABELA $\mathrm{V}-3$

Frequência do Procedimento: "Apresento a Matëria Como um Corpo de Conhecimentos Acabado" nos Grupos A e B -

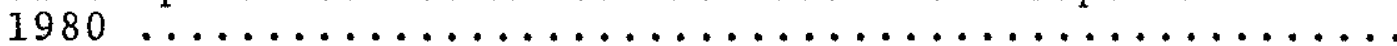

TABELA V-4

Frequência do Procedimento: "Durante as Aulas Expositivas Exploro as Questões Levantadas Pelos Alunos" nos

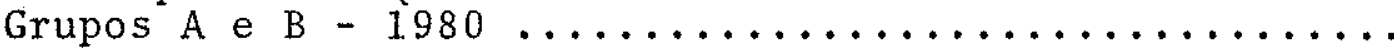

TABELA V-5

Frequência do Procedimento: "Estimulo os Alunos a Emiti rem Julgamento Sobre Questões Polêmicas" nos Grupos A e

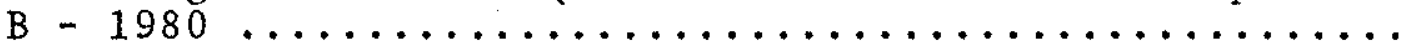

TABELA V-6

Frequência do Procedimento: "Estimulo a Memorização de Conhecimentos" nos Grupos A e B $-1980 \ldots \ldots \ldots \ldots \ldots \ldots$

TABELA $\mathrm{V}-7$

Frequência do Procedimento: "Proponho Problemas ou Ques tões Polêmicas Para os Alunos Discutirem" nos Grupos A

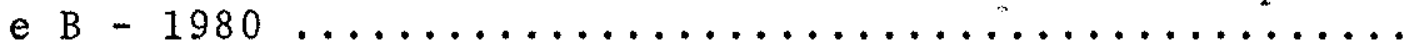

TABELA $\mathrm{V}-8$

Frequência do Procedimento: "Utilizo Somente Apostilas"

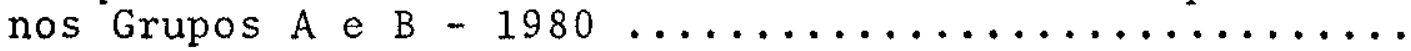


TABELA $\quad \mathrm{V}-9$

Frequência do Procedimento: "Incentivo os Alunos a

Construirem Maquetes, Mapas, Modelos, etc." nos Grupos

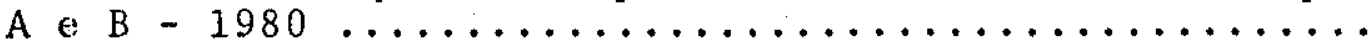

TABELA V-10

Frequência do Procedimento: "Procuro Incentivar os Alu nos a Captarem os Principais Conceitos e Princípios $\overrightarrow{\mathrm{e}}$ perceberem Interrelações" nos Grupos A e B - 1980 ....

TABELA $V-11$

Frequência do Procedimento: "Organizo e Oriento Traba1hos e Discussões de Grupo" nos Grupos A e B - 1980 ..

TABELA $\quad V-12$

Frequência do Procedimento: "Procuro Relacionar os Temas do Meu Programa com os Fatos da Realidade" nos Gru

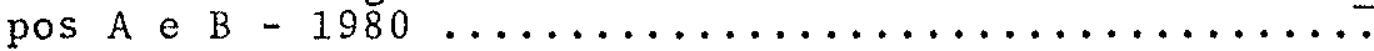

TABELA V-13

Frequência do Procedimento: "Em Minhas Exposições Apresento as Värias Visões ou Concepções a Respeito de um Assunto" nos Grupos A e B - 1980 ..............

TABELA V-14

Frequência do Procedimento: "Costumo Aceitar Sugestões dos Alunos Quanto a Modificações no Conteúdo do Progra ma" nos Grupos A e B $-1980 \ldots \ldots \ldots \ldots \ldots \ldots \ldots$

TABELA V-15

Frequência do Procedimento: "Incentivo os Alunos a For mularem Hipóteses e a Coletarem Dados Para Testar Es= tas Hipöteses" nos Grupos A e B - 1980 ............

TABELA V-16

Frequência do Procedimento: "Utilizo um Onico LivroTexto" nos Grupos A e B $-1980 \ldots \ldots \ldots \ldots \ldots \ldots \ldots$

TABELA $V-17$

Frequência do Procedimento: "Promovo Trabalhos de Campo, Com Roteiros de Pesquisa" nos Grupos A e B - 1980

TABELA V-18

Frequência do Procedimento: "Utilizo Materiais AudioVisuais (Mapas, Figuras, etc.)" nos Grupos A e B-1980

TABELA V-19

Distribuição dos Procedimentos de Ensino nas Caracterís ticas Metodológicas e Respectivas Categorias ......... 
Relação Entre Grupo e Regime de Trabalho na Subamostra de Professores das Unidades Universitärias Fede-

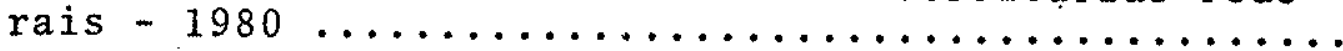

TABELA $3-2$

Relação Entre Grupo e Exercício de Atividades Profissionais Externas na Subamostra de Professores das Uni dades Universitärias Federais $-1980 \ldots \ldots \ldots \ldots \ldots \ldots$

TABELA 3-3

Relação Entre Grupo e Título Obtido na Carreira Universitäria na Subamostra de Professores das Unidades Universitärias Federais $-1980 \ldots \ldots \ldots \ldots \ldots \ldots \ldots \ldots$

TABELA $3-4$

Relação Entre Gípo e Tempo de Serviço na Unidade Uni versitaria na Subamostra de Professores das Unidades Universitärias Federais $-1980 \ldots \ldots \ldots \ldots \ldots \ldots \ldots$

TABELA 3-5

Relação entre Grupo e Período de Início de Funciona mento de Curso de Graduação em Geologia, Controlando pelo Regime de Trabalho, na Subamostra de Professores das Unidades Universitärias Federais - $1980 \ldots \ldots$....

TABELA 3-6

Relação Entre Grupo e Período de Início de Funciona mento de Curso de Graduação em Geologia, Controlando pelo Exercício de Atividades Profissionais Externas, na Subamostra de Professores das Unidades Universitä-

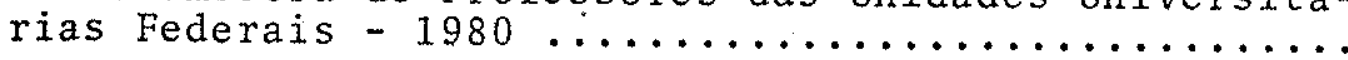

TABELA $3-7$

Relação Entre Grupo e Período de. Início de Funciona mento de Curso de Graduação em Geologia, Controlando pelo Titulo Obtido, na Subamostra de Professores das Unidades Universitärias Federais $-1980 \ldots \ldots \ldots \ldots \ldots$

TABELA $3-8$

Relação Entre Grupo e Período de Início de Funciona mento de Curso de Graduação em Geologia, Controlando pelo Tempo de Serviço, na Subamostra.de Professores das Unidades Universitárias Federais $-1980 \ldots \ldots \ldots$. 
C A P P I T T U L L 0 O I

INTRODUCAO

I.1 - A METOdologia de ENSino NA FORMAÇÃO DO GEOLOGO

O período de 1979-1982, na comunidade geológica, apre sentou grande efervescência no que tange ao debate das questões educacionais. Em torno da pesquisa diagnöstico das condi ções de formação do geólogo brasileiro, levada a efeito pela Sociedade Brasileira de Geologia (SBG) e pela Secretaria de Ensino Superior (SESU) do MEC (SBG/MEC, 1981), desenvolveramse inumeras atividades (Encontros, Seminärios e Simpösios de Ensino) e foram produzidos textos sobre o assunto que, de cer ta forma, inauguraram a literatura sobre ensino de Geologia no país. Como decorrência, nota-se profundo questionamento das principais características que cercam os Cursos de Geologia no país, tanto materiais quanto filosóficas e pedagögicas, apontando para significativas modificações. Foi estabelecido um perfil ideal do geólogo brasileiro, que na realidade écons tituído por diretrizes a nortear tais mudanças. Reproduz-se a seguir os cinco traços que compõem o perfil ideal do geólo go $(1)$ :

"a) Deverá ter uma formação polivalente voltada para as ne cessidades do País na ärea de Geologia, que o capacite a enfrentar, muitas vezes sozinho, trabalhos de campo em äreas di versificadas e problemas de natureza diversa.

b) Deverā ter uma formação científica que o capacite a desenvolver atividades profissionais com caräter inovador e não

( 1 ) SOCIEDADE BRASILEIRA DE GEOLOGIA/MINISTERIO DA EDUCAÇAOO E CULTURA - 1981 - A Formação do Geólogo nas Universidades Brasileiras, um Retrato de Duas Decadas. MEC, Brasilia, pp. 161 e 162 . 
somente habilitä-1o para a simples aplicação de metodologias estabelecidas em outros paises, muitas vezes inadequadas à nossa realidade.

c) Deverá ter uma postura crîtica perante sua atuação profissional e perante os principais problemas que afetam os setores estratëgicos da economia nacional.

d) Deverâ ter uma formação independente das diretrizes governamentais com caracteristicas imediatistas, obedecendo a um planejamento que retrate a projeção das necessidades do país previstas a médio e longo prazo.

e) Deverá ser um profissional com participação social e po 1itica junto a entidades de classe e outras agremiações políticas" (2).

A possibilidade de se atingir o perfil ideal está ob viamente condicionada a uma sërie de caracteristicas curriculares, tanto de ordem programätica quanto metodológica, como $\vec{e}$ possivel depreender da anälise dos traços expostos. Este fa to é exaustivamente reconhecido pelos autores de diversas teses apresentadas ao I Simpósio Nacional Sobre o Ensino de Geo logia no Brasil (3). A proposta de novo currículo mínimo de Geologia, por sua vez, aprovada recentemente pela comunidade no II Simpósio de Ensino (4) estä assentada em bases epistemo lógicas e psico-pedagógicas, o que significa dizer, segundo paschoale e Outros (1981), que "um currículo que pretenda for

( 2 ) Uma das contestações que se poderia fazer ao perfil ideal proposto é que seus itens não são suficientes para caracterizar o géólogo. Entretanto, são considerados necessärios, segundo opiniões e decisões de parcela expressiva da comunidade geológica, emanadas por ocasião da referida pesquisa diagnóstico e da Mesa Redonda Sobre Ensino de Geologia, desenvolvida no XXXI Congresso Brasileiro de Geo logia, em 1980 .

( 3 ) SOCIEDADE BRASILEIRA DE GEOLOGIA - 1981 - Teses ao I Simpósio Nacional sobre o Ensino de Geologia no Brasil . S.B.G., Belo Horizonte, I. eI: $268 \mathrm{pp}$.

( 4 ) SOCIEDADE BRASILEIRA DE GEOLOGIA - 1982 - Documento Fina1 do II Simpösio Nacional sobre o Ensino de Geologia no Brasi1. S.B.G., Sáo Paulo, versao preliminar, $58 \mathrm{pp}$. 
mar um geólogo com as características preconizadas no perfil ideal, deve refletir ao longo de sua organização, seleção de conteủdo e de experiências de aprendizagem, a complexidade e riqueza da Geologia enquanto ärea do conhecimento e prätica cientifica" $(5)$.

Os citados autores procuram, no trabalho em questão, estabelecer bases epistemolögica e psico-pedagógica para um currículo que viabilize o perfil ideal do geólogo(6) . Na cons trução da base epistemológica, levam em consideração trabathos de autores como: Hagner, Chamberlin, Gruza, Romanovskiy, Van Bemmelen, Leonov e Potapova. No plano epistemolögico, apös discutirem aspectos diversos ligados ao objeto e método da in vestigação geolögica, concluem apresentando o seguinte proces so para a cognição da Terra pela Geologia (segundo Potapova, $1968)^{(7)}$ :

"O processo de cognição da Terra pela Geologia é vis to como uma sequência dos seguintes estägios, que se repetem em níveis cada vez mais altos:

(1) descoberta e estudo de processos naturais contemporâ neos por värias ciências naturais e tecnológicas;

(2) descoberta de traços de processos similares no passado geológico;

(3) estudo das condições, tempo, lugar e leis do desenvolvimento dos processos naturais com base na síntese existente das ciências que tratam da história da Terra e o suplemento do conhecimento do processo histörico-geológico com base nos dados recëm-obtidos;

(5) PASCHOALE, C. e Outros - 1981 - Uma base para a Elabora ção do Currículo de Geologia. in Teses ao I Simpósio Nacional sobre o Ensino de Geologia no Brasil. S.B.G., Belo Horizonte, p. 30 .

(6) Estas bases foram aprovadas pela comunidade geológica durante o I Simpósio Nacional sobre o Ensino de Geologia no Brasil, em 1981, e constituiram o fundamento da proposta do Novo Currículo Mínimo para os Cursos de Geologia, apro vado no II Simpósio Nacional sobre o Ensino de Geologia no Brasil, realizado em 1982 .

( 7 ) paschOALE, C. e Outros - 1981 - idem, ibidem, p. 37. 
(4) predição do futuro curso de desenvolvimento dos proces sos geológicos com base na anälise dos dados disponiveis e sua relação com o desenvolvimento geral do processo histórico-geo lögico".

Os mesmos autores tratam a seguir da base psico-peda gógica que deve sustentar o currículo. Neste aspecto, trans creve-se também. as conclusões a que chegam e que, de certa forma, constituem a síntese da base psico-pedagógica propos ta:

"(1) o binômio prätica-conteủdo ê indissociävel;

(2) o conteủdo dentro do currículo não é tido como um fim em si mesmo, mas como um meio de se atingir, associando-se 'à prätica de Geologia como ciência, os objetivos de formação profissional;

(3) o conhecimento geológico deve ser apresentado, desde o inicio, preservando-se todas as suas caracteristicas como produto de uma prätica cientifica singular e complexa;

(4) as atividades de aprendizagem não devem se centrali zar no livro-texto;

(5) a organização do conteüdo deve ter, sempre como base, a prätica da Geologia enquanto ciência, ou seja, a introdução de qualquer conteüdo deve estar sempre justificada;

(6) finalmente, o currículo deve ser centrado em proble mas concretos (onde o campo desempenha o papel deflagrador e centralizador de aquisição, sistematização e crítica do conhe cimento geológico) que são apresentados, desde o início, com suas reais características e que serão tratados de modo cada vez mais complexo e rico ao longo do Curso, sofisticando-se, cada vez mais, o repertörío, a prätica de Geologia enquanto ciência e a crítica ao conhecimento e prática geológicas. A aprendizagem $\hat{e}$ centrada no estudante, que desempenha papel de agente (não mais paciente) do processo de ensino-aprendizagem" ( 8).

Estabelecendo-se relação entre as formulações conclu sivas das duas bases apresentadas, parece evidente a proposi-

(8) Paschoale, C. e Outros - 1981 - op. cit., p. 40. 
ção de uma metodologia de ensino que, ao invës de interpretar a ciência geológica para o estudante, permita-lhe vivenciä-1a, praticando o processo de cognição da Terra desenvolvido pela Geologia, através de investigações criativas em contato direto com o objeto a ser conhecido, liberando-se da noção de que "os processos mentais são uma função do conteüdo, antes que uma função dos processos cognitivos aplicados a este conteü do" (Taba, 1976) (9).

As idéias apresentadas, relativas à metodologia de ensino na formação do geólogo, são reforçadas em diversos trá balhos de caräter mais específico, reunidos nos volumes de te ses apresentadas ao I Simpósio de Ensino de Geologia(10).

Amaral (1981), ao descrever uma experiência de inova ção programática e metodolögica no campo do ensino de Geolo gia Introdutória no nível superior, destaca que o curso em questão adotou um planejamento da aprendizagem cujo "plano de aula, considerado na sua escala global, previa um ensino com procedimentos predominante e progressivamente abertos, com acentuada valorização e estímulo ao raciocínio pröprio do estudante, mesmo que isso implicasse em perda de rigor nos conceitos adquiridos. Tal diretriz metodológica estava em harmonia com a próprịa preocupação formativa relativa ao conteúdo. Em resumo, enquanto ao aluno cabia o papel ativo de agente de sua pröpria aprendizagem, ao professor cabia a função de orga nizador, coordenador e facilitador do processo"(11).

Ainda Amaral (1981, a), em outro trabalho em que ana iisa a citada experiência de inovação educacional, esclarece melhor a postura metodológica adotada:

"Na sala de aula, a metodologia de ensino e as relações professor-aluno adotadas tambëm originaram uma situação nova. A dinâmica de grupo, incorporada como mëtodo de ensino

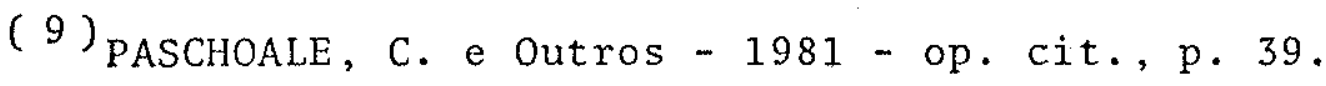

(10) SOCIEDADE BRASILEIRA DE GEOLOGIA - 1981 - op. cit.

(11) AMARAL, Ivan A. do - 1981 - A Geologia Introdutória na Uni versidade - Anälise de um Modelo de Curso. In Teses ao I Simpósio Nacional sobre o Ensino de Geologia no Brasil. S.B.G., Belo Horizonte, p. 52 . 
e não como tẻcnica auxiliar, foì responsävel pela diluição de uma das formas mais clássicas de autoritarismo: o do conhecimento e de quem o transmite na situação escolar (o professor). Deixou-se de apresentar o conhecimento cientifico como verdade absoluta, para mosträ-1o em sua real condição de mode1o transitório de uma realidade, geralmente contestado dentro da própria comunidade cientifica. Estimulou-se o estudante a ana lisā-1o criticamente, a formular suas próprias objeçöes. Para tanto foi necessäria a retração da palavra do professor, subs tituindo-a por outras formas de veiculação de informações. Foi necessärio mudar o conceito de um professor proprietário único de uma única verdade para o de um "coordenador e/ou facili tador da aprendizagem" (12).

Fujita e Outros (1981), ao analisarem o problema da metodologia de ensino em Geologia, demonstram a estreita rela ção existente entre os diferentes traços do perfil ideal do geólogo e a metodología de ensino a ser adotada nos Cursos de Geologia. Baseando-se tambëm em Taba, bem como em Aeb1i, Dewey, Turra, Mascellani e outros autores, transcrevem uma sërie de idéias relativas à participação intelectual ativa do estudante no processo de aprendizagem, adaptando-as ao contexto do ensino de Geologia, tais como: "O desenvolvimento da criativi dade individual e coletiva, juntamente com o processo sistemä tịco de experimentação, são fundamentais para a formação cien tífica do geólogo, pois valorizam e criam no individuo potencialidades que nortearão a sua capacidade de implementar novas idéias e concepções, necessärias à criação de uma tecnolo gia nacional"(13). Preconizam que o ensino incorpore a postura não dogmática da prōpria ciência: "(..) o ensino não deve apresentar uma única hipötese que explique um certo fenômeno geolögico. Pelo conträrio, deve-se desenvolver, comos alunos,

(12) AMARAL, Ivan A. do - 1981a - Uma Estratëgia de Implementa ção para as Mudanças Fropostas no Ensino de Geologia. In op. cit., p. 183.

(13) FUJITA, H. H.; GONÇALVES, P. W. ; CAIUBY, S. C. S. $-1981-$ Metodologia de Ensino em Geologia. In op. cit., p. 105 e 106 . 
as värias hipóteses possíveis. A ênfase é habilitar o geólogo (aluno) para que ele possa desenvolver seus próprios raciocínios na abordagem dos problemas"(14). Sustentam que a postura receptiva do estudante nas situações de ensino é inadequada para se atingir as metas expostas, propondo que "O nosso ensino deve propiciar situaçöes onde a aprendizagem seja fruto da interação entre os alunos. Isto propicia maior sociabilização e participação dos alunos; quando as experiências de aprendizagem são bem organizadas, destas interações decorre um apren dizado de fato" e "Para melhor aproveitamento do curso e concretização do perfíl do geỏlogo (proposto pela pesquisa da SBG/MEC-SESu), deve-se dar ênfase à centralização do processo de aprendizagem no aluno, com uma efetiva interação professor -aluno; e aluno-aluno"(15). Apresentam a seguir uma diversida de de recursos didáticos (materiais e metodolỏgicos) e as for mas de utilização que consideram adequadas para a concretização das diretrizes metodológicas sugerïdas.

Carneiro e Outros (1981), ao demonstrarem o papel e a importância do trabalho de campo na formação do geólogo, ini ciam afirmando que "o geólogo é antes de tudo umcientista"(16). Continuam, demonstrando que "os conhecimentos geológicos são obtidos no campo, jä que ninguém pode descrever e interpretar um fenômeno natural, sem observā-10" e concluindo que "a pratica, em Geología, realiza-se fundamentalmente no campo"(17). Com isso, querem os autores estabelecer uma relação da Geologia com as demais ciências, porëm realçando as peculiaridades da mesma. Aplicando tais idêias à situação de ensino, indagam acerca da maneira de se desenvolver espirito crítico e pensamento lógico no aprendiz. A resposta, segundo suas próprias palavras, é "Obviamente ninguém pode criticar uma teoria semana lisar evidências, sem ir à fonte de sua elaboração, que foi,

(14) FUJITA, H. H. e Outros - 1981 - op. cit., p. 106.

(15)FUJITA, H. H. e Outros - 1981 - op. cit., p. 109 e 110.

(16) CARNEIRO, C. D. R. e Outros - 1981 - A Introdução do Aluno às Atividades de Campo. In op. cit., p. 215.

(17) CARNEIRO, C. D. R. e Outros - 1981 - idem, ibidem, p. 216. 
sem düvida, a natureza. Como o que se pretende $\vec{e}$ a formação de um cientista ou um profissional criativo, capaz de desenvolver o conhecimento, esse requisito $\vec{e}$ imprescindivel"(18). Prosseguem criticando as posturas que defendem que o ensino de campo deva se desenvolver apenas nos ültimos anos do Curso e em disciplinas específicas. Criticam tambēm a circunscrição das atividades de campo aos simples papéis de ilustração ou de aplicação de conhecimentos teoricamente adquiridos; ".. propõem também que papëis de motivação e geração de problemas pa ra tais atividades sejam prioritários em relação aos demais, permitindo que "o aluno desempenhe um papel ativo, atravës do treino de observação e interpretação de feições no campo, ella boração e teste de hipöteses e modelos" (19). Concluem apresen tando alguns exemplos bem sucedidos em que estas inovações no ensino de campo foram adotadas e bem sucedidas.

Desempenho de papel ativo do estudante $\vec{e}$ proposta tambêm formulada por Fujita e Outros (1981) ao se referirem ao ensino por redescoberta. Neste caso, destacam o desenvolvi mento, por parte do estudante, de processos experimentais e de hipóteses na solução de problemas ${ }^{(20)}$. Conforme se verá adiante, a experimentação em laboratório e as atividades inte lectuais correspondentes desempenham papel fundamental no ensino orientado para a descoberta.

Gonçalves e Outros (1981), tomando como base um dos itens fundamentais do perfil do geoblogo preconizado, a poliva lência, discutem alguns requisitos necessärios para alcançar tal meta. Um deles seria que "a prática que o aluno deve ter em seu curso de graduação deve ser coerente com a prätica que se espera de um geólogo polivalente" (21). A polivalência, segundo os autores, implicaria, entre outras coisas, em: postura critica; contato direto com a comunidade, com a realidade

(18) CARNEIRO, C. D. R. e Outros - 1981 - op. cit., p. 216.

(19) CARNEIRO, C. D. R. e Outros - 1981 - idem, ibidem, p. 222.

(20) FUJTTA E OUTROS - 1981 - op. cit.; p. 107.

(21) GONÇALVES, P. W. e Outros - 1981 - A Questão da Formação polivalente - Uma Prätica Social. In op. cit., p. 229. 
geológica e com seus problemas concretos; consciência do papel do profissional na sociedade e da importância da ciência para a solução dos problemas existentes; visão multidisciplinar da realidade. Citando Mascellani (1976), propõem que "os problemas devem, pois, ser projetos de ação efetiva, levando - aluno a realizar efetivamente as operações que estão na base das noções ou idẻias a assimilar" (22).

Finalmente, destacam-se alguns trabalhos, tambëm pro duzidos na comunidade geológica, que, coerentemente con tudo o que foi at $\vec{e}$ agora apresentado, negam o livro-texto como recurso didático vâlido ou, então, propōem renovação profunda em suas formas de uso nas situações de ensino, deslocando-o da posição de centro do processo para outra meramente secundä ria.

Avanzo (1.981) posicionou-se frontalmente contra o i vro dids̈tico ("Não acredito em livros didäticos, ou melhor di zendo, acredito que eles só atrapalham (...)", porque "o 1ivro didätico surge apenas como um volteado simplificado em tor no de problemas que deveriam ser atacados diretamente, o que sö traz desvantagens, cria o häbito de se contentar apenas com superficialidades, de se fingir erudição e conhecimento, e de sempre procurar subterfügios para não encarar de frente a realidade da vida"(23). Concordam com ele paschoale e Outros (1981). Todavia, Amaral (1981), e Fujita e Outros (1981) posicionam-se de forma mais moderada, acreditando que o livro didătico deva ser utilizado de maneira crítica, de preferên cia diversos num mesmo curso, servindo como fonte de informações articulada com outros recursos e atividades de aprendiza gem ou, então, como propõem Amaral e Negrão (1981), o 1ivro didătico ideal deveria renunciar ao seu caräter de compendio, incorporando uma metodologia de ensino adequada ao conteúdo que veicula e que remeta o estudante a outras situações de aprendizagem que, entre outras coisas, eytrapolem os limites

(22) Gonçalves, P. W. e Outros - 1981 - op. cit., p. 231. (23) AVANZO, P. E. - 1981 - Se Eu Fosse Escrever um Livro de Geologia Introdutöria. Ediçao mimeografada, Salvador, p. 99 . 
do conteúdo por ele veiculado ${ }^{(24)}$.

A revisão ora elaborada demonstra o consenso nas reflexões feitas na comunidade geológica, acerca da importância da metodologia de ensino na formação do geólogo e de quais de veriam ser as características dessa metodologia de modo a per mitir a viabilização do chamado perfil ideal do geólogo. Pode se, agora, alinhar os principais caracteres dessa metodologia, nunca esquecendo que na sua maioria são interdependentes, che gando alguns a se confundirem parcialmente. Não obstante, estes caracteres serão apresentados de forma individualizada com vistas a melhor esquematização.

1. Deve proporcionar ao aluno condições de praticar o pensamento científico, seja atravês da vivência de procedimentos usuais na pesquisa, seja atravês da valorização de problemas e apresentação não dogmätica do conhecimento, evitando apresentá-lo de forma cristalizada.

2. Deve desenvolver procedimentos que promovam interações professor-aluno e aluno-aluno, em especial esta ültima, atravês de tëcnicas de dinâmica de grupo, onde os alunos desempenhem papel ativo na elaboração de conceitos e resolução de pro blemas.

3. Deve evitar estímulo à memorização pura e simples dos conhecimentos, à valorização de detalhes que não contribuam para a percepção de idêias e princípios unificadores, bem como de suas interrelações, devendo estes sim ser enfatizados.

4. Deve procurar contato permanente com a realidade, seja atravês de exemplos, seja através de problemas reais a serem equacionados e solucionados na situação de aprendizagem.

5. Deve procurar a diversificação dos recursos didâticos, sejam eles materiais ou metodológicos, em particular as ativi dades de campo voltadas para uma perspectiva de pesquisa.

6. Deve valorizar a aprendizagem dos processos de obtenção de conhecimentos em detrimento dos conhecimentos em si, produ tos destes processos.

(24) AMARAL, Ivan A. do e NEGRAO, O. B. M. - 1981 - Os Livros-Texto o Sua Adequação ao Ensino de Geologia Introdutó ria no Níve1 Superior. In op. cit., p. 239. 
I. 2 - ORIGENS DO MOVIMENTO DE INOVAÇAO

As características básicas do movimento de inovação de metodologia de ensino e de conteủdo dos. Cursos de Ceologia no país constituixam preocupação de inümeros trabalhos elaborados na década de 70 , sobre o ensino de Geologia no secundärio e terceiro grau. Dentre eles, podem ser citados: Amaral e Outros (1973), Avanzo (1974), Ladeira e Salomão (1974) e Mace do $(1974)^{(25)}$.

Essa perspectiva de inovação, por sua vez, tem origem nos esforços de inovação no ensino de Ciências, particular mente intensa nos Estados Unidos, a partir do final da década de 50. Nessa ocasião, principalmente sob o patrocinio da $\mathrm{Na-}$ tional science Foundation, foram iniciados värios projetos de ensino que se popularizaram atravës das siglas dos grupos ou comitês que os produziram (26). E, dentre eles, o conhecido ESCP (Earth Science Curriculum Project) (27).

Tais projetos, formulados para o ensino corresponden te ao primeiro e segundo graus no Brasil, apresentavam características comuns de inovação que se consubstanciavam, de um lado, na revisão de conteūdo das disciplinas e, de outro, em pressupostos especificos de metodologia de ensino. A mais notävel de suas características, conforme Ruegg (1967), é a "ên

(25) AMARAL, I. A. do e Outros - 1973 - A Tecnologia Educacional e o Ensino de Geociências. Comunicação apresentada na I I CONTECE, Sao Paulo.

AVANZO, P. E. - 1974 - "Geociências: Uma Nova Maneira de Ver a Terra". In Geologia: Ciência Tëcnica, n 4, CEPEGE-IGUSP. São Paulo, p. 7-24.

LADEIRA, E. A. e SALOMAO, E. P. - 1974 - "Técnicas de Ensino Aplicadas à Geologia". In SICEG (1978), Ouro Prem to, p. 213-239.

MACEDO, A. B. - 1974 - "Novos Métodos de Ensino em Geociências". In Geologia: Ciência Técnica, n?5, CEPEGE-IGUSP, São Paulo, p. 38-55.

(26) SHULMAN, L. S. e TAMIR, P. - 1973 - "Research on Teaching in the Natural Sciences". In TRAVERS, R. M. W. (Ed.), - Second Handbook of Research on Teaching. Rand McNally College Publishing Co, Chicago, p. 1098 e 1099.

(27) ESCP (Earth Science Curriculum Project) - 1973-1977 - Investigando a Terra. McGraw-Hill do Brasil/FUNBEC, Sáo Paulo, 1973 (19 Vol.) $, 435 \mathrm{pp}, 1977$ (2\% Vol.) $238 \mathrm{pp}$. 
fase constante na apresentação da ciência como um permanente inquêrito, o que significa salientar o fascínio da constante descoberta ao invēs da monótona aquisição de conheci mentos" (28).

As caracteristicas de conteúdo e de metodologia de ensino desses projetos propiciaram a distinção entre os denominados curriculos e cursos tradicionais e os cursos modernos. De acordo com Klopfer $(1971)^{(29)}$ :

"Os cursos tradicionais de ciência se concentram no conhecimento de fatos, leis e teorias científicas e em aplica ções tecnológicas, enquanto os cursos mais novos enfatizam na tureza, estrutura e unidade da ciência e os processos de investigarão cientifica. Os programas tradicionais tratam de abranger um grande nümero de temas enquanto os programas modernos nreferem a profundidade à extensão. Nos cursos tradi cionais o ensino ocorre, em grande parte, mediante o método de aulas expositivas e se busra a confirmaçäo nos exercícios de laboratōrio que não são essenciais aos cursos, enquanto que os programas modernos empregam investigações orientadas para a descoberta como base para a elaboração dos cursos".

Assim, tomandn-se como exemplo o caso do ESCP, a informação é colocada em plano secundārio e apenas utilizada quando integrada num todo organizado e correspondente à estru tura do conhecimento geolögico. Neste caso, a estrutura estä referida a temas unificadores tais como: compreensão de esca1a, universalidade da transformação, adaptação, uniformidade dos processos $(30)$.

A importância da estrutura já havia sido referida

(28) RUEGG, N. R. - 1967 - "Os Novos Currículos e os Conceitos Bäsicos da Ciência". In Boletim CECTSP, n 6, Março, Säo Paulo, p. 1 .

(29) KLOPFER,L. E. - 1971 - Evaluation of Learning in Science. In BLOOM, B. S.; HASTINGS, J. T.; MADAUS, G. F. - Hand book on Formative and Summative Evaluation of Student Learning. McGraw-Hill Inc., New York, p. 565.

(30) ESCP (Earth Science Curriculum Project) - 1978 - Guia do Professor. McGraw-Hill do Brasil/FUNBEC. Sãn Paulo, Vol. 1, p. 3-5. 
por Bruner (1978), ao relatar os resultados da conferência de Woods Hole realizada em setembro de 1959 , nos EUA. Segundo es se autor $(31)$ :

"(..) o curriculo de uma dada matêria deve ser determinado pela compreensão mais fundamental que se possa atin gix, a respeito dos princípios bäsicos que dão estrutura a es sa matëria."

Outra caracteristica fundamental dos diversos projetos de ensino desenvolvidos na dêcada de 60 nos EUA refere-se à investigação realizada pelos alunos em substituição às aulas expositivas, conferências e demonstrações operadas pelo professor. Conforme Suchman $(1980)^{(32)}$ :

"Se o aluno tiver pouca oportunidade de tirar, do seu modo, as próprias conclusñes, acabará transformando-se num me ro consumidor de conhecimentos, perdendo o contato com os pro cessos reais da investigação através da qual os conhecimentos são criados e organizados".

Embora à investigação realizada pelos alunos, usualmente caracterizada como processo de ensino por redescoberta, corresponda um conceito repleto de ambiguidades, seu mais intuitivo significado está relacionado ao ensino minimamente guìdo ou dirigido pelo professor (Shulman e Tamir - 1973)(33).

Convém notar que, no ensino orientado para a desco berta, o laboratörio e as atividades intelectuais ligadas ao uso do laboratório desempenham papel fundamental. Entretanto, conforme salientam Shulman e Tamir (1973), o pape1 do laboratórìo não está baseado em evidências empíricas mas na opinião de pesquisadores, principalmente aqueles que participaram do desenvolvimento dos novos currículos de Ciências (34).

Finalmente, deve-se considerar, como o faz Bruner (1978), que o experimento ou a demonstração de laboratório, jun tamente com muitos outros recursos didäticos auxiliares, po-

(31) BRUNER, J. S. - 1978 - "O Processo da Educação". Cia Editora Naciona1, São Paulo, p. 27.

(32) SUCHMAN, J. R. - 1980 - "Investigação e Educação". In NEL SON, L. N. - O Ensino: Textos Escolhidos. Saraiva, São Paulo, p. 236 .

(33) SHULMAN, L. E. e TAMIR, P. - 1973 - op. cit., p. 1112. 
dem ajudar os alunos a captar a estrutura subjacente da matéque estão aprendendo ${ }^{(35)}$.

Em suma, são caracteristicas bäsicas dos diversos projetos de ensino renovado de ciências, a ênfase na estrutura da matëria, ensino por redescoberta - no qual o laboratório desempenha importante papel - e utilização de recursos didäticos auxiliares.

Tais caracteristicas certamente influenciaram as con cepções acerca do ensino de Geologia manifestas nos diversos estudos produzidos por autores brasileiros anteriormente cita dos neste trabalho.

I.3 - CONCEITO DE INOVAÇAO EM METODOLOGIA DE ENSINO

o termo "inovação" foi utilizado nesta pesquisa para indicar mudanças promovidas em disciplinas do currículo de Geo logia e tambëm movimentos que as antecederam e delas foram precursores. Falta, entretanto, estabelecer precisamente a conceituação de inovação em metodologia de ensino, uma vezque as relações entre o desenvolvimento (ou não) de pesquisa por parte dos professores de disciplinas geolôgicas e a metodologia de ensino utilizada por eles constituem o foco das preocu pações do presente trabalho.

Ferretti (1980) conceitua inovação em metodologia de ensino de três maneiras diferentes, de acordo com os aspectos en fatizados do processo educativo. Duas das conceituações propos tas por esse autor são aqui transcritas, excluindo-se a tercei ra, voltada especificamente para o ensino individualizado (36): "(..) inovar, em termos metodológicos, tem signifi-

(34) SHULMAN, L. E. e TAMIR, P. - 1973 - op. cit., p. 1119.

(35) BRUNER, J. S. - 1978 - op. cit., p. 78 e 80 .

(36) FERRETTI, C. J. - 1980 - "A Inovação na Perspectiva pedagôgica". In GARCIA, W. E. - 1980 - Inovação Educacional no Brasil - Problemas e Perspectivas. Cortez Edito ra e Autores Associados, Sao Paulo, p. 62 e 63. 
cado estruturar métodos de ensino que levem o aluno a utilizar habilidades intelectuais, a exercitar o pensamento refiexi vo na solução de problemas e tomada de decisões."

$$
\text { "(..) inovar, do ponto de vista da didätica, tem }
$$
significado criar mëtodos ou técnicas de ensino que favoreçam a integração de conteúdos e a integração social dos alunos, bem como estimulem a participação destes em outros niveis que não apenas o intelectual".

Depreende-se, tambëm de Ferretti (1980), que a aplicação efetiva das citadas inovações na metodologia de ensino implica em mudanças nas relaçōes profesșor-aluno e aluno -aluno. A primeira dessas mudanças é assim conceituada pelo mesmo autor $(37)$ :

"Do ponto de vista da relação prufessor-aluno, inovar tem significado a disposição intencional do primeiro para manter, com o segundo, contactos que se caracterizam pela coo peração, pela estimulação das capacidades, pelo desafio à par ticipação e pela atenção individualizada, contactos nos quais - professor $\vec{e}$ identificado como o facilitador da aprendizagem e o aluno como o sujeito desse processo."

Pode-se constatar, portanto, que as conceituações agora transcritas encontram-se claramente identificadas, tanto com itens do perfil ideal do geólogo quanto com idëias, pro postas e experiências de mudança anteriormente registradas neste trabalho.

I.4 - A METODOlogta de ENSINO UTILIZADA NOS CURSOS DE GEOLOGIA

Atē agora, exceto algumas experiências isoladas de inovação de ensino em Geologia, limitou-se a apresentar propostas metodolögicas, sem preocupação com a distância que guar

(37).FERRETTI, C. J. - 1980 - op: cịt, p. 66 e 67 
dam em relação à realidade. Essas propostas partem do pressuposto de que o geólogo, em suas atividades profissionais, cientificas ou técnicas, produz ou reproduz conhecimentos utili zando-se da metodologia de investigação geológica, assim como do princípio de que se aprende fundamentalmente fazendo ao in vés de recebendo os conhecimentos prontos. Uma questä́o fundamental que emerge é se o geólogo adquire, durante sua forma ção universitäria, a maneira peculiar da Geologia "pensar" e "abordar" a natureza. Outra, subsidiäria e decorrente da ante rior, é se a metodologia de ensino utilizada nos Cursos de for mação dos geólogos brasileiros e compatível com a metodologia de investigação geológica.

Um elemento que parece bastante indicativo da realidade em foco encontra-se no primeiro estudo de caráter acadêmico no Brasil, no âmbito da educação em Geologia, desenvolvi do por Amaral, em $1981^{(38)}$. Nesta pesquisa, o autor estuda o conteūdo e o enfoque de uma coleção de obras didáticas naárea de Geologia Introdutória, visando a caracterização e anälise crítica de diferentes linhas de conteủdo sobre o assunto. 0 que interessa, no caso, ê um dos pressupostos fundamentaís do trabalho, assim expresso:

"Por outro lado, é forçoso reconhecer, entre os diversos elementos que influem no planejamento e desenvolvimento dos conteúdos programáticos dos cursos, possivelmente ode maior importância é olivro-texto. Pode-se identificar sua in fluência nos seguintes aspectos:

- constituì ponto de referência para a definição dos pro gramas das disciplinas;

- serve de base para o desenvolvimento do conteúdo programático durante a execução do curso, atravês de leituras obrigatórias ou optativas por parte dos alunos, e consti tui fonte de referência preferencial para planos de aulas ou para a elaboração de apostilhas, sendo que estas raramente modificam a proposta fundamental de conteüdo

(38) AMARAL, I. A. do - 1981b - o Conteüdo e o Enfoque dos Livros de Geologia Introdutoria. Dissertação de mestrado apresentada à Universidade de São Paulo. 
nele contida;

- fornece orientação metodológica de ensino, no caso daque las obras que tambëm a incluem junto com o texto informa tìvo.

Em resumo, o livro-texto representa o mais significa tivo recurso didatico utilizado pelos docentes, condicionando muitas das demais decisões didâticas relativas ao curso, inclusive as de cunho metodolögico"(39).

Apesar de Amaral (1981, b) tambëm reconhecer que in $\vec{x}-$ meros fatores interferem no planejamento, produzindo no curso um resultado final bem diferente do previsto, não consubstanciariam suas palavras forte evidência da metodologia de ensino efetivamente adotada no âmbito geolögico? ${ }^{(40)}$. Se o autor estä correto em seu pressuposto, e sabendo-se que a maioria dos livros didáticos são do tipo compêndio, sendo raros os que incluem proposta ativa e diversificada de aprendizagem, pode- se deduzir que o ensino de Geologia se processa numa forma dissertativa, com um elenco reduzido de recursos didäticos, com poucas oportunidades de participação interativa dos alunos e de desenvolvimento de procedimentos científicos. Em outras palavras, o ensino efetivamente praticado estaria bem distante do ideaiizado, possivelmente com caracteristicas opostas a este.

I.5 - ENSINO E PESQUISA, QUAIS AS RELAÇOES?

Segundo dados coletados pela pesquisa diagnóstico de SBG/MEC (1981), anteriormente mencionada, mais de 70,0\% dos professores atuantes na época (1980) nos cursos de Geologia, alêm de outras atividades, entre elas ensino, realizavam pes

(39) AMARAL, I. A. do - 1981b - op. cit., p. 27 e 28 .

(40) AMARAL, I. A: do $-1981 \mathrm{~b}$ - op. cit., p. 202-204. 
quisa(41). Se se admitir que existe propensão destes docentes a transferirem as atitudes adquiridas como pesquisadores para as respectivas situações de ensino e, sendo eles a maioria en tre os docentes, provavelmente chegar-se-a a uma conclusão oposta à do item anterior, ou seja, o ensino oferecido nos Cur sos de Geologia propicia, via de regra, condições para o estú dante aprender a metodologia da investigação geolögica e tudo o mais que esteja vinculado a este tipo de aprendizagem. Nes ta mesma Iinha de raciocínio, o ensino dissertativo e afastado de uma perspectiva de investigação deve ser praticado por aqueles docentes que, por uma ou outra razão, não realizam pesquisa.

Ainda no estudo de SBG/MEC (1981), encontra-se material relativo à metodologia de ensino adotada pelos professores (42). Tanto no Questionärio do Professor quanto no do Aluno foi apresentada uma 1 ista com dezoito procedimentos de ensino e sua frequência de adoção por parte dosprofessores (43). Todavia, os resultados apresentados são indjscriminados, não distinguindo os professores que desenvolviam pesquisa dos que não a desenvolviam.

Foram feitas algumas tentativas (44) de interpretação dos resultados da pesquisa com relação ao assunto em foco, in clusive no prōprio Documento Final da Pesquisa(45). As conclú sões alcançadas, baseadas nos depoimentos dos professores e/ lou dos estudantes, foram desfavoráveis no que se refere à maioria dos procedimentos de ensino adotados. Todavia, além

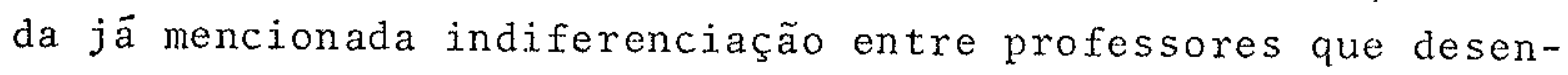

(41) SBG/MEC - 1981 - op. cit., p. 82 .

(42) SBG/MEC - 1981 - idem, ibidem, p. 76 e 77 .

(43) Os Questionários do Professor e do Aluno constituiram os instrumentos de coleta de dados das respectivas popula ções, não sendo publicados no relatörio final da referida pesquisa SBG/MEC. O Questionärio do Professor $\vec{e}$ apresenta do como Anexo neste trabalho.

(44)Ver: Cunha e Outros (1980); Paschoale e Outros (1981); Fu jita e Outros (1981); Santos e Outros (1981); Amara1 (1981a) (45) SBG/MEC - 1981 - op. cit., p. 175-183. 
volviam e não desenvolviam pesquisa na ëpoca, nota-se, em todas as tentativas, dificuldade de articulação entre os diversos procedimentos de ensino, de modo a agrupá-los segundo pos tuiras metodológicas mais amplas, que sirvam de parâmetro para avaliação mais consistente. 


\section{1 - DEFINIÇÃO DO PROBLEMA}

De acordo com a pesquisa diagnóstico acerca da forma ção do geölogo brasileiro, mais de 70,0\% dos professores entrevistados participava, na ëpoca, de pelo menos um projeto de pesquisa. ( 1$)$

Segundô â mesma pesquisa, as principais razões que levaram os professores a promover mudanças no conteüdo progra mático de suas disciplinas eram as seguintes: (a) necessidade de atualização de conteüdo $(17,5 \%)$ e (b) mudanças metodológicas $(9,5 \%)$. No tocante às mudanças de 1 ivro-texto das disci plinas, as principais razões apontadas foram: (a) necessidade de se adotar bibliografia mais atualizada $(16,5 \%)$ e (b) novas caracteristicas dos alunos $(5,0 \%)$. A "influência de novos pro jetos de pesquisa" não foi considerada importante em qualquer dessas mudanças, embora constituísse uma das alternativas de resposta. ( 2$)$

Não obstante as principais razöes apontadas para as referidas mudanças fossem relevantes, pareceu curioso o fato de projetos de pesquisa não terem influenciado ponderavelmente, uma vez que a maioria dos professores participava desses projetos.

Veriflcou-se logo a inviabilidade de descrever e explicar mudanças no conteüdo programático ou no livro-texto utilizado, em virtude da exiguidade de dados quanto à sua na-

( 1 ) SOCIEDADE BRASILEIRA DE GEOLOGIA/MINISTERIO DA EDUCAÇAO E CULTURA - 1981 - A Formação do Geölogo nas Universidades Brasileiras. MEC, Brasilia, p. 82 .

( 2 ) SOCIEDADE BRASTJETRA DE GEOLOGIA/MINISTERIO DA EDUCACAO E CULTURA - 1981 - idem, ibidem, p. 75. 
tureza e amplitude. Entretanto, foram essas reflexões iniciais que levaram ao interesse pela busca de relações entre pesquisa e ensino nas Unidades Universitārias que mantêm Curso de Graduação em Geologia ( 3 ). Tambëm nesta primeira etapa verificou-se que qualquer fosse o caminho escolhido, a investigação da relação desejada teria de incluir a divisão dos professores en trevistados em dois grupos distintos: professores que, na época, desenvolviam, e que não desenvolviam pesquisa.

Entre os dados disponíveis havia värios dados relacio nados à metodologia de ensino, consubstanciados em afirmações indicativas de procedimentos do professor em sala de aula ou no campo (4). As alternativas de resposta consistiam em medidas relativas de frequência de adoção dos citados procedimen tos de ensino (sempre, às vezes, nunca). O nümero relativamente elevado de afirmações de procedimentos (18), todas com as mesmas alternativas de resposta, o que permitiria melhor siste matização, levou, finalmente, à escolha de metodologia como as pecto de ensino a ser estudado.

Fazendo-se especulação prévia acerca dos dois grupos de professores cos que desenvolvem e que não desenvolvem pesquisa), admitiu-se que deveriam ser diferentes quanto à metodologia de ensino adotada. Assim, os professores que desen volvem pesquisa estariam mais voltados à metodologia caracte rística dos cursos modernos por duas razões: (a) poderiam, ao conträrio do outro grupo, transferir as atitudes adquiridas na pesquisa para as situações de ensino e (b) o fato de desenvolver pesquisa os faria mais suscetiveis à repercussão no Brasil do movimento de inovação iniciado nos Estados Unidos em fins da década de 50 .

Por outro lado, considerando que a pesquisa constitui uma das atribuições fundamentais da Universidade, o fato deper centual superior a $25,0 \%$ dos professores entrevistados não desenvolver pesquisa provocou a suposição de que existem fatores associados às possibilidades de desenvolvimento de pesquisa.

(3) Entende-se por Unidade Universitária o Instituto, Departa mento, ou congênere.

(4) SOCIEDADE BRASILEIRA DE GEOLOGIA/MINISTERIO DA EDUCAÇAO E CULTURA - 1981 - op. cit., p. 77. 
Decidiu-se investigar tambëm tal associação, uma vez que alguns desses fatores poderiam ser os funcionais e institucio nais - relacionados aos professores - cujas medidas constavain do acervo de dados...

Foi possível, então, chegar à formulação do problema investigado neste trabalho: "Determinar, no âmbito das Unidades Universitärias que mantêm Curso de Graduação em Geologia: (a) a associação entre possibilidades de desenvolvimento de pesquisa por parte dos professores e aspectos ligados a sua situação funcional e Instituição a que pertencem; (b) as diferenças entre professores que desenvolvem e professores que não desenvolvem pesquisa, tomando-se por referência um conjun to de caracteristicas metodológicas de ensino.

As características metodologicas foram estabelecidas a partir de classificação dos procedimentos de ensino. Esta classificação separa-os em subconjuntos, sendo que cada subconjunto contem procedimentos que atestam determinado aspecto de uma característica e procedimentos que atestam o aspecto conträrio da mesma característica metodolögica (ver Capítulo V) .

\section{II:2 - HIPOTESES}

$\mathrm{H}_{1}$ As possibilidades de desenvolvimento de pesquisa por par te dos professores dos Cursos de Graduação em Geologia no País estão associadas a um conjunto de variảveis funcionais e institucionais: tipo de Unidade Universitäria, período de início de funcionamento de Curso de Graduação em Geologia, regime de trabalho, atividades profissionais externas, nível de contratação, título obtido, tempo de serviço.

$\mathrm{H}_{2}$ A metodologia de ensino adotada pelos professores em Cur sos de Graduação em Geologia difere significativamente em função do desenvolvimento ou não de atividades de pes quisa. 
$\mathrm{H}_{2.1}$ Os professores que desenvolvem pesquisa (Grupo A) tendem a promover aprendizagem interativa, enquanto os professores que não desenvolvem pesquisa (Grupo B) tendem a promover aprendizagem receptiva.

$\mathrm{H}_{2.2}$ Os professores do Grupo A tendem a valorizar oprocesso de obtenção do conhecimento geolögico, enquan to os professores do Grupo B tendem a valorizar o conhecimento geológico propriamente dito, produto daquele processo.

$\mathrm{H}_{2.3}$ Os professores do Grupo A tendem a adotar comporta mento cientifico em suas aulas, enquanto os profes sores do Grupo B tendem a adotar comportamento não científico.

$\mathrm{H}_{2.4}$ Os professores do Grupo A tendem a utilizar diversos recursos didáticos enquanto os professores do Grupo B tendem a restringir a utilização desses re cursos.

$\mathrm{H}_{2.5}$ Os professores do Grupo A tendem a destacar princí pios e conceitos gerais, enquanto os professores do Grupo B tendem a destacar o conhecimento especí fico.

II.3-VARIÄVEIS

De acordo com as hipóteses estabelecidas, são as seguintes as variáveis incluídas no estudo: 


\begin{tabular}{|c|c|c|c|}
\hline HIPOTESE N & VARIAVEIS & $\begin{array}{l}\text { TIPO DE } \\
\text { VARIAVEL }\end{array}$ & $\begin{array}{l}\text { NTVEL DE } \\
\text { MENSURAÇAO }\end{array}$ \\
\hline \multirow{8}{*}{1} & a) Grupo & Dependente* & Nomina1 \\
\hline & b) Tipo de Unidade Universitäria & Independente* & Nominal \\
\hline & $\begin{array}{l}\text { c) Período de início de funciona- } \\
\text { mento de Curso de Geologia }\end{array}$ & Independente & Ordinal \\
\hline & d) Regime de trabalho & Interveniente $e^{* * \alpha}$ & Nomina1 \\
\hline & $\begin{array}{l}\text { e) Atividades profissionais exter } \\
\text { nas à Unidade Universitäria }\end{array}$ & Interveniente & Nominal \\
\hline & f) Nivel de contratação & Interveniente & Nominal \\
\hline & g) Título obtido & Interveniente & Nominal \\
\hline & h) Tempo de serviço & Interveniente & Intervalar \\
\hline \multirow{2}{*}{$2_{2.1}$} & a) Tipo de aprendizagem & Dependente & Nominal \\
\hline & b) Grupo & Independente & Nomina1 \\
\hline \multirow{2}{*}{22.2} & $\begin{array}{l}\text { Forma de obtenção de conheci- } \\
\text { mento }\end{array}$ & Dependente & Nominal \\
\hline & b) Grupo & Independente & Nominal \\
\hline \multirow{2}{*}{2.3} & a) Vivência de pesquisa & Dependente & Nominal \\
\hline & b) Grupo & Independente & Nominal \\
\hline \multirow{2}{*}{2.4} & a) Recursos didäticos & Dependente & Nominal \\
\hline & b) Grupo & Independente & Nominal \\
\hline \multirow{2}{*}{22.5} & a) Amplitude de conceitos & Dependente & Nominal \\
\hline & b) Grupo & Independente & Nominal \\
\hline
\end{tabular}

*Entende-se por variävel dependente o efeito presumível de outra variâ vel (ou outras variáveis) e que muda concomitantemente com mudanças nes ta(s) (Kerlinger, p. 35 e Engelhart, p. 24).

**Entende-se por variāvel independente a causa (ou uma das causas) presumivel da variävel dependente (Kerlinger, p. 35 e Engelhart, p. 24).

***Entende-se por variävel interveniente a que se encontra, numa sequência causal, entre uma causa "inicial" ou antecedente e o efeito final (Blalock, p. 20). 
II.3.1 - Descrição das variāveis

II.3.1a - Variäve1 central

E a variăvel grupo, sendo que hä dois grupos, o de professores que desenvolvem pesquisa (Grupo A) e o de professores que não desenvolvem pesquisa (Grupo B).

II.3.1b - Variāveis funcionais e institucionais ( 5 )

- Tipo de Unidade Universitäria: classificada, conforme a natureza da instituição mantenedora, em: federal, estadual e particular;

- Periodo de início de funcionaiiiento de Curso de Gra duação em Geologia: adotou-se três períodos para classificar esta variảvel, o primeiro anterior à Reforma Universitäria e que teve inicio com o funcionamento dos primeiros Cursos de Geologia (1957-1965); o segundo período situa-se após a implantação da Reforma e termina antes da ampliação do Curso de Geologia de quatro para cinco anos (1970-1973); e o terceiro e ûltimo depois dessa ampliação (1976-1977).

- Regime de trabalho: classificada em três categorias: a) tempo parcial ou hora-aula, abrangendo todos os profes sores em regime de dedicação parcial à Universidade ou rece bendo por hora-aula efetivamente dada; b) tempo integral, que inclui todos os que tem compromisso de 40 horas semanais com a Unidade Universitâria; c) tempo integral com dedicação exclusiva, englobando todos os contratos em RDIDP (Regime de De dicação Integral à Docência ou Pesquisa) ou RETIDE (Regime de

( 5 ) Todas as variâveis funcionais e institucionais foram consideradas intervenientes, à exceção das variāveis "tipo de Unidade Universitária" e "período de início de funcionamento de Curso de Graduação em Geologia" (variäveis independentes) porque geralmente são determinadas (ou influ enciadas) por estas variäveis independentes. Por exemplo, a categoria "tempo integral com dedicação exclusiva" da variâvel "regime de trabalho" é encontrada nas Unidades Universitärias püblicas (federais e estaduais) mas não nas particulares. 
Tempo Integral e Dedicação Exclusiva).

- Atividades profissionais externas à Inidade Uni-

versitária: classificada em duas categorias, segundo o exerci cio ou não dessas atividades.

- Níve1 de contratação: classificada em seǰs catego rias: auxiliar de ensino, assistente, adjunto, titular, visitante e colaborador.

- Título obtido: classificada em quatro categorias: graduado (bachare1 ou 1icenciado), mestre, doutor e livre-docente.

- Tempo de serviço: classificada em cinco categorias, conforme o número de anos trabalhados na unidade Universi tária: a) menos ảe 2 anos; b) de 2 a 5 anos; c) de 6 a 9 anos; d) de 10 a 13 anos; e) 14 anos ou mais.

II.3.Ic - Variäveis de caracterização metodológica

As cinco variäveis referentes à dimensão metodolôgi ca foram classificadas em duas categorias, as quais exprimem aspectos metodológicos opostos.

- Tipo de aprendizagem: a) aprendizagem interativa e b) aprendizagem receptiva. A aprendizagem interativa propicia o intercâmbio de idéias entre o professor e seus alunos e dos alunos entre si, enquanto a aprendizagem receptiva nãopro picia esse intercâmbio.

- Forma de obtenção de conhecimentos: a) processo e b) produto. As categorias "processo" e "produto" representam situações de ensino nas quais ocorrem, respectivamente, valorização da aprendizagem dos processos de obtenção do conhecimento geológico ou valorização do conhecimento geológico em si mesmo, produto desses processos.

- Vivência de pesquisa: a) comportamento científico e b) comportamento não científico. A categoria "comportamento cientifico" abrange duas posturas, não exclusivas, no ensino de Geologia: 1 $^{\text {a }}$ ) exposição de situações de pesquisa aos estudantes e $2^{a}$ ) promoção da vivência de situações de pesquisa pe- 
los estudantes. A categoria "comportamento não científico" significa ausência de ambas as posturas.

- Recursos didäticos: a) diversidade de recursos di. däticos e b) limitação de recursos didäticos. A primeira cate goria subentende diversificação de recursos de mesma natureza ou de natureza distinta. A segunda categoria significa restri ção de recursos didáticos, de mesma ou de naturezas diferen tes.

- Amplitude de conceitos: a) princípios e temas uni ficadores e b) conhecimento especifico. A primeira categoria significa destaque à essência e estrutura da.ciência e a segunda de fatos e informações particulares. 
III. I - MODELO DE PESQUTSA

A pretensão de reallzar descobertas välidas para determinada população implica na preocupação, por ocasião do planejamento e desenvolvimento da pesquisa, com a viabilidade de generalização de seus resultados. Neste caso, embora condi ção não necessäria, optou-se pela investigação de todos os contingentes da população escolhida para conferir consistência às possivveis generalizações.

os dados empiricos utilizados neste estudo foram extraídos de um subconjunto maior de informações obtidas através da pesquisa "A Formação do Geólogo nas Universidades Brasileiras", realizada pela Sociedade Brasileira de Geologia e Ministério da Educação e Cultura( 1 ).

Tal pesquisa pode ser classificada como sendo do tipo "survey". Segundo Kerlinger, um "survey" "estuda popula ções (ou universos) grandes ou pequenas, selecionando e estudando amostras dessas populações para descobrir a incidência, distribuição e interrelações de variäveis sociológicas e/ou psicológicas"'( 2$)$.

Hyman (1967) estabelece distinção entre "survey" des critivo e explicativo, afirmando que o primeiro "focaliza principalmente a medida precisa de uma ou mais variäveis dependentes"( 3$)$, enquanto o "survey" explicativo "estabelece

( 1 S SOCIEDADE BRASTLEIRA DE GEOLOGIA/MINISTERIO DA EDUCAÇAOO E CULTURA - 1981 - A Formação do Geölogo nas Universidades Brasileiras. MEC, Brasilia, $209 \mathrm{pp}$.

( 2 ) KERLINGER, F. N. - 1973 - Foundations of Behavioral Research. Holt, Rinehart and Winston, New York, p. 410.

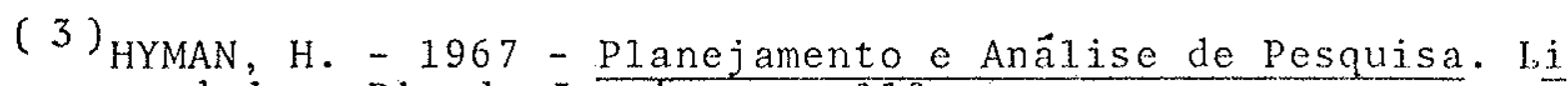
dador, Rio de Jañeiro, p. 110. 
com precisão a natureza da correlação entre um ou mais fenôme nos, ou variäveis dependentes, e uma ou mais causas, ou varia veis independentes" ( 4 ).

A mencionada pesquisa $S B G / M E C$ pretendeu ser um estudo abrangente dos diferentes universos que fazem parte do sis tema de ensino na ärea de Geologia: as Unidades Universitärias, o professor, o aluno e o profissional geólogo.

No que diz respeito às Unidades Universitärias, pesquisou-se as seguintes dimensões: (a) características gerais; (b) características dos cursos oferecidos; (c) caracteristicas do vestibular; (d) currículo e mudanças curriculares; (e) instalações, equipamentos e materiais didäticos; (f) taxas co bradas pela Unidade Universitāria; ( $g$ ) bolsas concedidas aos estudantes; (h) atıvidades extra-curriculares exercidas pelos estudantes; (i) convênios mantidos pela Unidade Universitária; (j) situação da pesquisa; (1) encontros científicos promovidos e (m) fatores que prejudicam ensino e pesquisa.

A pesquisa dos professores compreendeu as seguintes dimensões: (a) caracterîsticas gerais; (b) situação funcional; (c) atividades e cargos na Universidade; (d) formação acadêmica e tìtulação; (e) cursos de atualização e aperfeiçoa mento realizados; (f) atividades profissionais externas à Uni dade Universitāria; ( $g$ ) disciplinas ministradas e procedência dos alunos; (h) planejamento das disciplinas; . (i) mudanças ocorridas nas disciplinas; (j) metodologia de ensino adotada; (k) obstāculos às atividades didāticas; (1) opinião sobre o currículo atual; (m) opinião sobre o perfil ideal do geỏlogo; (n) participação em projetos de pesquisa e respectivas fontes de financiamento; (o) obstäculos às atividades de pesquisa e (p) participação em associações cientificas e profissionais.

A pesquisa dos estudantes incluiu as seguintes dimen. sões: (a) características gerais; (b) condições sócio-econômi cas; (c) condições de estudo; (d) instalações, equipamentos e materiais didáticos do Curso de Graduação; (e) situação do trabalho de campo e do estägio no Curso de Graduação; (f) par

(4) HYMAN, H. - 1967 - op. cit., p. 108 . 
ticipação em atividades docentes e de pesquisa na Unidade Uni versitäria; ( $g$ ) expectativas e decepções acerca do Curso de Graduação; (h) opinião sobre o currículo atual; (i) opinião acerca do perfil ideal do geólogo brasileiro; (j) opinião acerca das condiçöes necessärias para a formação do geólogo ideal; (1) opção profissional e capacitação oferecida pelo Curso de Graduação; (m) opinião acerca da metodologia de ensino adotada no Curso de Graduação e (n) participação nas decisões internas da Unidade Universitäria.

o estudo do universo dos profissionais englobou as seguintes dimensões: (a) características gerais; (b) cursos realizados e títulos obtidos; (c) trajetôria profissional; (d) opinião acerca do Curso de Graduação; (e) opinião acerca do perfil ideal do geölogo brasileiro; (f) opinião acerca de mudanças necessárias no Curso de Graduação; (g) opinião sobre mercado de trabalho e política mineral e (h) opinião acerca do pape1 da SBG no ensino de Geologia.

Portanto, pode-se considerar que o "survey" realizado por SBG e MEC abrangeu quatro populações, a saber: Unidades Universitárias que mantêm Curso de Graduação em Geolo gia, professores de disciplinas geológicas ou afins nesses cursos $^{(5)}$, alunos dos $3^{\circ}, 4^{\circ}$ e $5^{\circ}$ ano nos mesmos cursos, e pro fissionais geólogos de empresas püblicas e privadas.

A abrangência dos dados coletados, considerando estas quatro populações, permitiu que se descrevesse incidência e distribuição de um conjunto amplo de variáveis, mas nem sem pre que se estudasse em profundidade a interrelação entre sub conjuntos de variáveis. Assim, tal pesquisa caracteriza-se co mo "survey descritivo", poìs limitou-se à descrição de um con junto extenso de varia áveis, sem contudo explorar eventuais correlações ou relações de causa e efeito.

A pretensão deste trabalho consiste em aprofundar e entender melhor algumas das referidas interrelaçöes, daí ter-se escolhido apenas um dos universos investigados - os prom

(5) Entende-se por disciplinas geológicas ou afins todas as in cluídas nas categorias de "introdutorias" "fundamentais" ou "profissionalizantes" na classificação proposta por Cú nha e Outros (1981). 
fessores de disciplinas geológlcas ou afins nos cursos de Gra duação em Geologia - e selecionado algumas variảveis para ve rificar eventuais correlações e tentar explicä-1as. Neste sen tido, o presente estudo avançaria para o modelo do tipo "sur vey explicativo".

As variảveis selecionadas para exame neste estudo são pertinentes às seguintes dimensões do universo dos profes sores: características gerais, situação funcional, formação acadêmica e titulação, atividades profissionais externas à Uni dade Universitäria, e metodologia de ensino. As variäveis cor respondentes a esta ültima dimensão foram denominadas "variä veis de caracterização metodolögica" e as demais "variāveis funcionais e institucionais".

III.2 - POPULAÇÃO E AMOSTRA

A pretensão da pesquìsa "A Formação do Geólogo nas Universidades Brasileiras" era incluir no estudo toda a população de professores universitários que se dedicam ao magiste rio de disciplinas geolögicas ou afins nos Cursos de Gradua ção em Geologia no país. Entretanto, só foi possível abranger $59,8 \%$ dessa população $(6)$.

Não sendo atingida toda a população, ficou definido que os $59,8 \%$ de professores respondentes constituiriam apenas uma amostra do universo pesquisado. Assim, a amostra daquele estudo apresenta uma característica inusual no "survey", isto

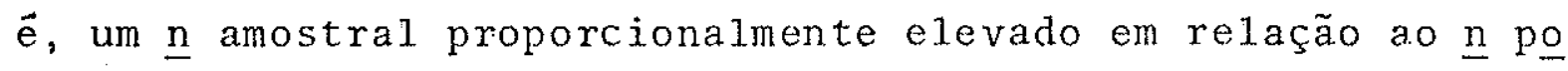
pulacional.

A TABELA III-1 apresenta população e amostra de professores da pesquisa em referência, discriminadas segundo cada Universidade.

Face às características peculiares da citada amos-

(6) SOCIEDADE BRASILEIRA DE GEOLOGIA/MINISTERIO DA EDUCAÇAO E CULTURA - 1981 - op. cit., p. 19 e 24. 
TABELA III-1

POPULAÇAO E AMOSTRA DE PROFESSORES - 1980*

\begin{tabular}{|c|c|c|c|}
\hline \multirow[b]{2}{*}{ UNIVERSIDADE } & \multirow{2}{*}{ 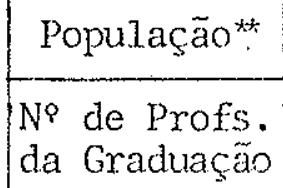 } & \multicolumn{2}{|c|}{ Anostra } \\
\hline & & $\begin{array}{l}\text { No de Profs. } \\
\text { amostrados }\end{array}$ & $\left\{\begin{array}{l}: \text { sobre a } \\
\text { populaçäo }\end{array}\right.$ \\
\hline 01. Universidade do Amazonas (FUA) & 17 & 11 & 64,7 \\
\hline 02. Univ. Fed. do Parä (UFPa) & 24 & 24 & 100,0 \\
\hline 03. Univ. Fed. do Cearä (UFCe) & 31 & 08 & 25,8 \\
\hline 04. Univ. de Fortaleza (UNIFOR) & 20 & 14. & 70,0 \\
\hline $\begin{array}{l}\text { 05. Univ. Fed. do Rio Grande do } \\
\text { Norte (UFRiv) }\end{array}$ & 23 & 12 & 52,2 \\
\hline 06. Univ. Fed. de Pernambuco (UFPe) & 34 & 16 & 47,1 \\
\hline 07. Univ. Fed. da Rahia (UFBa) & 52 & 21 & 40,4 \\
\hline 08. Univ. Fed. de Minas Gerais (UTMG) & 34 & 14 & 41,2 \\
\hline 09. Univ. Fed. de Ouro Preto (UFOP) & 17 & 13 & 76,5 \\
\hline 10. Univ. Fed. do Rio de Janeiro (UFR.J) & 36 & 17 & 47,2 \\
\hline 11. Univ. Est. do Rio de Janeiro (UERJ) & 08 & 08 & 100,0 \\
\hline $\begin{array}{l}\text { 12. Univ, Fed. Rural do Rio Janeiro } \\
\text { (UFRRJ) }\end{array}$ & 16 & 13 & 81,2 \\
\hline 13. Universidade de São Paulo (USP) & 54 & 20 & 37,0 \\
\hline 14. Univ. Est. Paulista (UNESP) & 31. & 21 & 67,7 \\
\hline 15. Univ. Fed. do Paranā (UFPR) & 19 & 18 & 94,7 \\
\hline $\begin{array}{l}\text { 16. Univ. Fed. do Rio Grande do Sul } \\
\text { (UFRS) }\end{array}$ & 44 & 36 & 81,8 \\
\hline $\begin{array}{l}\text { 17. Univ. Fed. do Vale do Rio dos } \\
\text { Sinos (UNISTNOS) }\end{array}$ & 22 & 16 & 72,7 \\
\hline 18. Universidade de Brasilia (UnB) & 27 & 20 & 74,1 \\
\hline 19. Univ. Fed. de Mato Grosso (FUFMT) & 16 & 12 & 75,0 \\
\hline TOTAL & 525 & 314 & 59,8 \\
\hline
\end{tabular}

*SEgundo SOCIEDADE BRASILETRA DE GEOLOGIA/MINTSIIRIO DA EDUCACAO E CUT,TU RA - 1981 - A Formacão do Geólogo nas Universidades Brasileiras. MEC, Brasilja, p. 24 , modif.

* População de professores que ministram disciplinas geolôgicas ou afins nos Cursos de Graduação en Geologia. 
tra, convëm tecer alguns comentärios a respeito de sua confiabi lidade e representatividade. Segundo Blalock (1973), o grau de confiança nos resultados da amostra é tambëm função do tipo de amostragem probabilistica delineado. Pretendendo atingir toda a população, a pesquisa realizada por $S B G$ e MEC näo definiu amos tragem alguma a priorj. Definida a posteriorj, a amostra rãotem, portanto, representatividade estatistica na perspectiva proba bilistica. Mas, do ponto de vista qualitativo, inclui repre sentantes de todos os contingentes populacionais existentes, pois constitui-se de professores das 19 Unidades Universitärias que mantêm Curso de Graduação em Geologia no país.

Ainda no dizer de Blalock (1973): "Não havendo varia ção em outros fatores, quanto maior a amostra, maior serä a confiança de que os resultados da amostra estarão pröximos dos nümeros verdadeiros para a população" 7 ).

Embora o tamanho não defina por si sö a qualidade de una amostra, no caso da pesquisa em questão ele constitui um atributo em favor de sua confiabilidade, na medida em que abrangeu quase $60,0 \%$ da população.

Feitos esses comentârios, pode-se passar à descrição da amostra utilizada neste estudo. Trabalhoumse com um total de 297 professores que corresponden a $94,6 \%$ daquele $\underline{\text { n }}$ amostral da pesquisa realizada por $S B G$ e MEC e a $56,6 \%$ da população de prom fessores de disciplinas geológjcas ou afins (TABELA III-2).

Como se pode observar, foram excluidos 17 professores por um dos seguintes motivos: (a) não terem respondido às questões utilizadas nesta pesquisa, ou tê-lo feito de maneira incompleta; (b) não terem respondido se desenvolviam ou não pesquisa, requisito considerado indispensavel ao tratamento de dados adotado; (c) pertencerem ao Centro de Geologia Eschwege que, embora vinculado à Universidade, vivencia apenas parcela da problemätica inerente aos cursos de graduação (8)

( 7 ) BLALOCK, Jr., H. M. - 1973 - Introduçãoãpesquisa Social. Zahar Editores, Rio de Janeiro, p. 65.

( 8 ) o Centro de Geologia Eschwege ê örgão suplenentar do Instituto de Geociências da Universidade Federal de Minas Ge rais e dedica-se a cursos de mapeamento geológico, desen = volvidos na forma de estägios para alunos de graduação e estägios de aperfeiçoamento. 
e (d) terem respondido ao questionärio em mais de uma Unidade Universitäria. Neste ültimo caso adotou-se o critério de apro veitar o questionärio correspondente à unidade com menor per centual de respondentes.

TABELA III -2

POPULAÇAO E AMOSTRA DE PROFESSORES

\begin{tabular}{|c|c|c|c|}
\hline \multirow[b]{2}{*}{ UNIVERSIDADE } & População* & \multicolumn{2}{|c|}{ Amostra } \\
\hline & $\begin{array}{l}\text { No de Profs. } \\
\text { da Graduação }\end{array}$ & $\begin{array}{l}\text { No de Profs. } \\
\text { amostrados }\end{array}$ & $\begin{array}{l}0 \text { sobre a } \\
\text { população }\end{array}$ \\
\hline 01. Universidade do Amazonas (FUA) & 17 & 11 & 64,7 \\
\hline 02. Univ. Fed. do parä (UFPa) & 24 & 24 & 100,0 \\
\hline 03. Univ. Fed. do Cearä (UliCe) & 31 & 08 & 25,8 \\
\hline 04. Univ. de Fortaleza (UNIFOR) & 20 & 13 & 65,0 \\
\hline $\begin{array}{l}\text { 05. Univ. Fed. do Rio Grande do Norte } \\
\text { (UFRN) }\end{array}$ & 23 & 11 & 47,8 \\
\hline 06. Univ. Fed. de Pernambuco (UFPe) & 34 & 16 & 47,1 \\
\hline 07. Univ. Fed. da Bahia (UFBa) & 52 & 19 & 36,5 \\
\hline 08. Univ. Fed. de Minas Gerais (UFMG) & 34 & 12 & 35,3 \\
\hline 09. Univ. Fed. de Ouro Preto (UFOP) & 17 & 13 & 76,5 \\
\hline $\begin{array}{l}\text { 10. Univ. Fed. do Rio de Janeiro } \\
\text { (UFRJ) }\end{array}$ & 36 & 17 & 47,2 \\
\hline $\begin{array}{l}\text { 11. Univ. Est. do Rio de Janeiro } \\
\text { (UERJ) }\end{array}$ & 08 & 06 & 75,0 \\
\hline $\begin{array}{l}\text { 12. Univ, Fed, Rural do Rio de } \\
\text { Janeiro (UFRRJ) }\end{array}$ & 16 & 11 & 68,8 \\
\hline 13. Universidade de São Paulo (USP) & 54 & 19 & 35,2 \\
\hline 14. Unj.v. Est. Paulista (UNESP) & 31 & 21 & 67,7 \\
\hline 15. Univ. Fed. do Paranä (UFPR) & 19 & 17 & 89,5 \\
\hline $\begin{array}{l}\text { 16. Univ. Fed. do Rio Grande do SuI } \\
\text { (UFRS) }\end{array}$ & 44 & 31 & 70,5 \\
\hline $\begin{array}{l}\text { 17. Univ. Fed. do Vale do Rio dos } \\
\text { Sinos (UNISINOS) }\end{array}$ & 22 & 16 & 72,7 \\
\hline 18. Universidade de Brasília (UnB) & 27 & 20 & 74,1 \\
\hline 19. Univ. Fed. de Mato Grosso (FUFMT) & 16 & 12 & 75,0 \\
\hline TOTAL & 52.5 & 297 & 56,6 \\
\hline
\end{tabular}

*População de professores que ministram disciplinas geolögicas ou afins nos Cursos de Graduação em Geologia (SBG/MEC, 3981). 
Como se depreende da comparação entre as TABELAS III-1 e III-2, a representatividade descrita para a amostra de professores da pesquisa realizada por SBG e MEC é conserva da na amostra utilizada neste estudo. Quanto ao tamanho, a di ferença entre uma e outra é relativamente pequena, conforme indicado pelos pexcentuais mencionados. Assim, pode-nse afirmar que as duas amostras apresentam praticamente as mesmas qualidades e limitações.

III.3 - COLETA DE DADOS

III.3.3. - Instrumento Utilizado na Coleta de Dados

Conforme se salientou anteriormente, o presente estu do foi realizado a partir dos dados da pesquisa "A Formação do Geölogo nas Universidades Brasileiras". Assim sendo, o ins trumento utilizado foi o mesmo.

O questionärio original (ver ANEXO 1), respondido pe los professores de disciplinas geológicas ou afins nos cursos de Graduação em Geologia continha 50 questões, incluindo questões fechadas (do tipo mültipla-escolha) e questões abertas, a serem completadas pelo respondente.

Alëm dos dados iniciais de identificaçäo da Unidade Universitäria (por exemplo. Instituto de Geociências da Uni versidade Federal de Minas Gerais), dentre as 50 questões mencionadas foram utilizadas neste estudo as seguintes:

1. Atualmente você está envolvido em atividades ou programas de pesquisa?

a) Não

b) Sim. Em quantos programas?

b1) apenas um

b2) dois

b3) mais de dois 
2. Hä quanto tempo trabalha nesta Unidade Universitäria?
a) Menos de 2 anos
b) De 2 a 5 anos
c) De 6 a 9 anos
d) De 10 a 13 anos
e) De 14 a 17 anos
f) Mais de 17 anos

3. Nesta Unidade Universitária você è contratado emnível de: (Unidades Estaduais) (Unidades Federais e particulares)
a) MSI
a) Auxiliar de Ensino
b) MS2
b) Assistente
c) MS3
c) Adjunto
d) MS4
d) Titular
e) MS5
e) Outro. Qual?
f) MS6

4. Em que regime de trabalho você é contratado?
a) Hora/aula. Especifique o nümero de horas/aula por se mana:
b) Regime de tempo parcial. Especifique o nümero de horas:
c) Regime de turno completo.
d) Regime de tempo jntegral.
e) Reglme de tempo integral com dedicação exclusiva.

5. Qua1 dos seguintes cursos você possui? (Marque apenas o ni. vel mais alto)
a) Universitärio completo (Bacharelado)
b) Universitärio completo (Licenciatura)
c) Universitário completo (Bacharelado e Licenciatura)
d) Mestrado incompleto
e) Mestrado completo
f) Doutorado incompleto
g) Doutorado completo
h) Livre Docêncìa incompleta
i) Livre Docência completa 
6. Se você exerce qualquer atividade profissional (seja ou não vinculada ao campo da Geologia) fora desta Unidade Universitária, quantas horas de trabalho semanal dedica a esta atividade?

a) Até 10 horas semanais

b) De 10 a 20 horas semanais

c) De 21 a 30 horas semanais

d) Mais de 30 horas semanais

x) Não exerço nenhuma atividade profissional fora desta Unidade Universitária.

7. Apresentamos, abaixo; uma lista de afirmações que representam diferentes maneiras de dar aula e orientar os traba thos dos alunos. Faça un círculo em torno da letra $A, B, C$ de acordo com a frequência com que você costuma adotar este ou aquele procedimento. Se por qualquer razão você não puder decidir a respeito de determinada afirmação, faça um círculo em torno do ponto de interrogação (?). Náo deixe nenhum item sem resposta.

\begin{tabular}{|c|c|c|c|c|}
\hline AFTRMACOES & Sempre & As vezes & Nunca & $\begin{array}{l}\text { Não sei } \\
\text { decidix }\end{array}$ \\
\hline $\begin{array}{l}\text { 1. Costumo dar a maior parte de minhas au- } \\
\text { las de forma expositiva. }\end{array}$ & $A$ & $B$ & $\mathrm{C}$ & ? \\
\hline $\begin{array}{l}\text { 2. Valorizo o conhecimento de detalhes ou } \\
\text { informaçóes especificas sobre o conteü- } \\
\text { do de minha disciplina. }\end{array}$ & A & B & $\mathrm{C}$ & $?$ \\
\hline $\begin{array}{l}\text { 3. Apresento a matéria como um corpo de co } \\
\text { nhecimentos acabado. }\end{array}$ & A & B & $\mathrm{C}$ & ? \\
\hline $\begin{array}{l}\text { 4. Durante as aulas expositivas exploro as } \\
\text { questões levantadas pelos alumos. }\end{array}$ & A & B & $\mathrm{C}$ & $?$ \\
\hline $\begin{array}{l}\text { 5. Estimulo os alunos a emitirem julgamen- } \\
\text { tos sobre questöes polêmicas. }\end{array}$ & A & B & $\mathrm{C}$ & ? \\
\hline 6. Estimulo a memorização de corthecimentos. & A & $B$ & $\mathrm{C}$ & $?$ \\
\hline $\begin{array}{l}\text { 7. Proponho problemas ou questões polêni - } \\
\text { cas para os alumos discutirem. }\end{array}$ & A & B & $\mathrm{C}$ & ? \\
\hline 8. Utilizo somente apostilas. & A & $B$ & $\mathrm{C}$ & $?$ \\
\hline
\end{tabular}




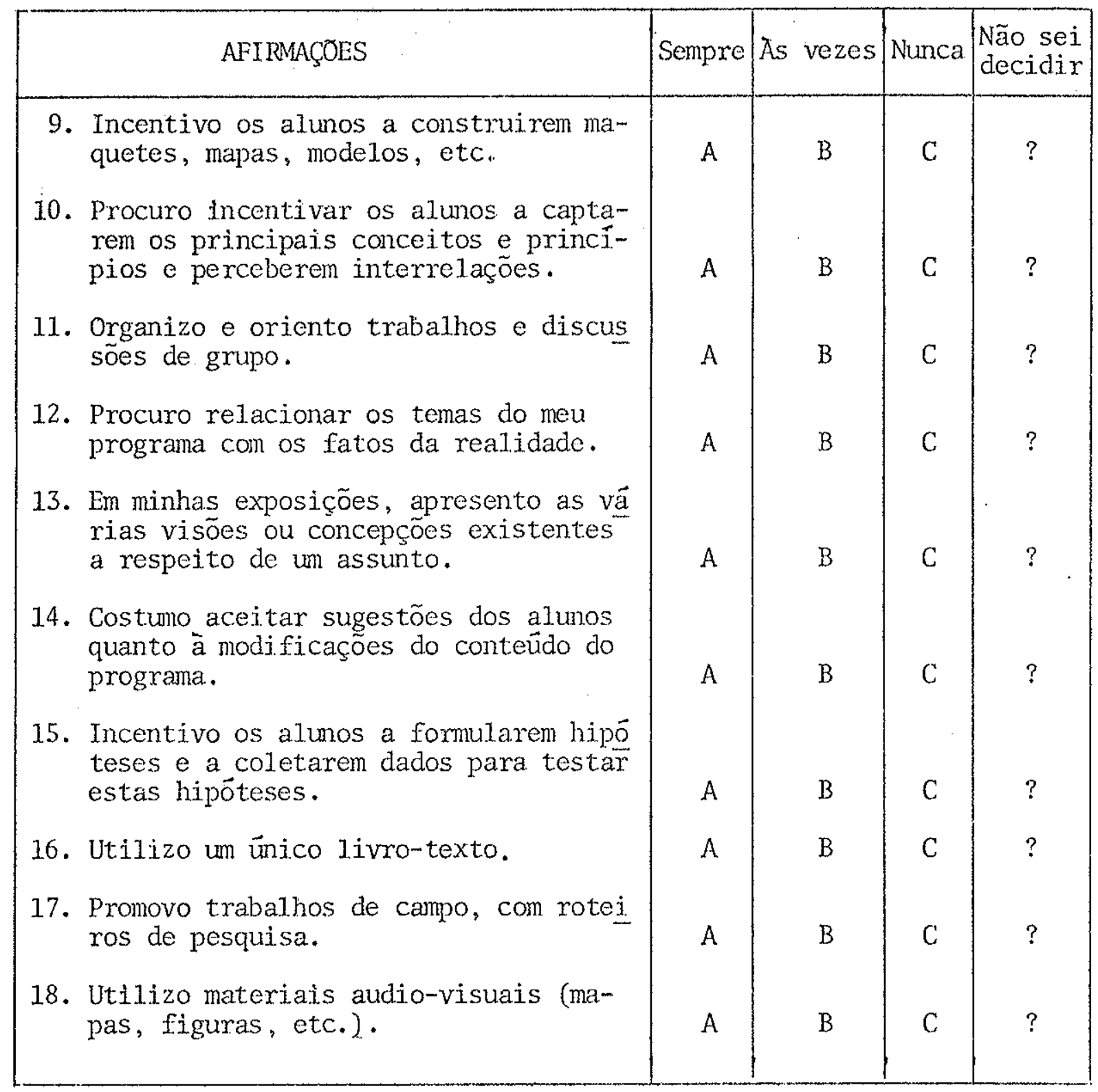

III.3.2 - Procedimento de Coleta de Dados

Quando da realização da pesquisa promovida por SBG e MEC, os questionärios tinham sido aplicados diretamente pelos membros da Comissão Nacional de Ensino ou da Comissão de Ensi no do Núcleo de São Paulo da SBG, tendo sido visitados todos os Cursos de Geologia do País, nos 13 Estados em que estão distribuídos, cada um durante o período de dois dias a três. dias. 
o procedimento dos aplicadores foi padronizado através de um Folheto de Instruções (ver ANEXO 2), onde constavam os diversos passos a serem dados, e atraves de discussões em reunião da Comissão Nacional de Ensino da SEG.

De um modo geral, a aplicação dos questionärios deu-se de acordo com a seguinte ordeni de eventos:

a) envio de carta ao responsävel pelo Curso de Geologia (Djre tor de Instituto, Chefe de Departamento, etc.) explicando- The as finalidades gerais da pesquisa, solicitando sua co laboração e informando-o da época de aplicação;

b) entrevista com o Diretor para detalhamento das finalidades da pesquisa e apresentação do questionärio a ser aplicado;

c) estabelecimento, de comum acordo, de horîrios adequados pa ra entrevistas do aplicador com grupos deprofessores;

d) entrevistas do aplicador com os professores para exposiçāo das finalidades da pesquisa e orientação para o preenchi mento do questionärio;

e) preenchimento do questionärio pela maioria dos professores contactados;

f) devolução do questionáxio preenchido, pessoalmente ao apli cador ou posteriormente pelo correio.

Os principais problemas que afetaram o plano ideal de aplicação foram: a) ausência de diversos professores por motivos de licença mêdica, trabalho de campo, viagem ao exterior, pös-graduação em outro Estado e regime de tempo parcial; b) não devolução do Questionärio por parte de diversos profes sores; c) insuflciência do prazo de três dias de permanência do aplicador na unidade, para superação das dificuldades apon tadas. 
III.4 - TRATAMENTO DOS DADOS

Considerando as finalidades especificas deste traba1ho, preferiu-se refazer o tratamento de dados em todas as suas etapas, adequando-as, quando fosse o caso, a essas finalidades.

\section{III.4.1 - Codificação e Computação}

o estabelecimento de cỏdigos numëricios deu-se a partir da combinação de alternativas de resposta em cada questão. Por exemplo, as respostas acerca de regime de trabalho dos professores foram codificadas da seguinte maneira: (1) Re gime de tempo parcial ou hora-aula; (2) Regime de tempo integra1; (3) Regime de tempo integral com dedicação exclusiva. Neste caso, o cỏdigo (1) englobou três alternativas de respos ta:: hora-aula, regime de tempo parcial e regime de turno com pleto.

A seguir, passou-se à preparação das "fichas código" para gravação em fita magnëtica. Uma vez obtida a listagem dos resultados, fez-se a necessäria conferência para identifi cação de erros na gravação e providenciou-se sua correção.

A etapa seguinte foi a elaboração de tabelas de con tingência de dupla e tripla entrada, de acordo com o seguinte programa: SPSS Batch System.

\section{4.2 - Prova Estatistica}

Para testar estatisticamente as diferentes categorias de resposta que os professores dos dois Grupos A e $B$ forne ceram em relação a cada procedimento de ensino, foi utilizada a prova do $X^{2}$.

A justificativa para aplicação dessa prova em tal si tuação é fornecida por siegel (1977).

"Quando os dados da pesquisa se apresentam sob forma 
de frequencias em categorias discretas, pode-se aplicar a pro va do $x^{2}$ para determinar a significância de diferenças entre dois grupos independentes. A mensuração pode ser ate mesmo em escala nominal" $(9)$.

As categorias de resposta submetidas à prova do $\mathrm{x}^{2}$ no presente estudo são nominais: "sempre", "às vezes" e "nunca".

O nível de significância escolhido para se determi nar os valores críticos de $\mathrm{x}^{2} \overline{\mathrm{e}} \alpha=0,05$.

(9) SIEGEL, S. - 1977 - Estatística Não-Paramëtrica. McGraw-Hill do Brasil, Saopaulo, p. 117 . 
DESCRICAO E ANALISE DOS RESULTADOS ( $1 \stackrel{\text { a }}{\text { PARTE})}$

Neste Capitulo ê investigada a relação entre grupo (professores que desenvolvem e que não desenvolvem pesquisa) e algumas variảveis ligadas à função dos professores e às Uni dades Universitärias a que pertencem.

São descritas e analisadas tabelas de contingência de dupla e tripla entrada. Nas tabelas de dupla entrada a variävel central (grupo) è relacionada com todas as demais e nas de tripla entrada com cada uma das variảveis independen tes, utilizando-se variāveis de controle.

Eventualmente, por uma ou outra razão, conforme se verä, julgou-se conveniente apresentar a relação em exame, se ja em tabelas de contingência de dupla ou tripla entrada, na subamostra de professores das Unidades Universitärias federais.

Os resultados finais consistem na apresentação das principais tendências de grupo, estabelecendo, em primeiro $1 \underline{u}$ gar, as tendências do Grupo A relacionadas ao tipo de Unidade Universitária e período de início de funcionamento dos Cursos de Geologia. Finalmente, são estabelecidas as tendências em conjunto dos Grupos A e B, para efeito de comparação.

IV. 1 - OS PROFESSORES E AS ATIVIDADES DE PESQUTSA

IV.1.1 - Tipo de Unidade Universitária e periodo de Inicio de Funcionamento de Curso de Geologia

As Unidades Universitárias que abrigam Curso de Graduação em Geologia foram classificadas em três tipos: federal, estadual e particular (TABELA IV-1). 
TABELA IV -1

TIPO DE UNIDADE UNTVERSITARIA E ANO DE INICIO DE FUNCIONAMENTO DOS CURSOS DE GRADUAÇAO EM GEOLOGIA - 1980

\begin{tabular}{|l|l|c|}
\hline \multicolumn{1}{|c|}{ UNIVERSIDADE } & $\begin{array}{l}\text { TIPO DE UNIDADE } \\
\text { UNIVERSITARIA }\end{array}$ & $\begin{array}{c}\text { INICIO DE } \\
\text { FUNCIONAMENTO }\end{array}$ \\
\hline Universidade Federal de Pernambuco & Federal & 1957 \\
Universidade Federal de Ouro Preto & Federal & 1957 \\
Universidade de São Paulo & Estadual & 1957 \\
Universidade Federal do Rio Grande do Sul & Federal & 1957 \\
Universidade Federal da Bahia & Federal & 1958 \\
Universidade Federal do Rio de Janeiro & Federal & 1958 \\
Universidade Federal do Parä & Federal & 1964 \\
Universidade de Brasilia & Federal & 1965 \\
Universidade Estadual Paulista & Estadual & 1970 \\
Universidade Federal do Cearä & Federal & 1970 \\
Universidade Federal Rural do R. de Janeiro & Federal & 1970 \\
Universidade Federal de Minas Gerais & Federa1 & 1973 \\
Universidade Federal do Paraná & Federal & 1973 \\
Universidade de Fortaleza & Particular & 1973 \\
Universidade do Vale do Rio dos Sinos & Particular & 1973 \\
Universidade do Amazonas & Federal & 1976 \\
Universidade Federal do Rio Grande do Norte & Federal & 1976 \\
Universidade Federal do Mato Grosso & Federal. & 1976 \\
Universidade do Estado do Rio de Janeiro & Estadual & 1977 \\
\hline
\end{tabular}

Possuem curso de graduação em Geologia: 14 Unidades Universitärias federais, 3 estaduais e 2 particulares. A distribuição dos professores que desenvolvem ou não desenvolvem pesquisa, segundo o tipo de unidade Universitäria, consta da TABELA IV -2 .

Verifica-se que nas Unidades Universitärias püblicas (federais e estaduais) ocorre predominio do Grupo A (professo res que desenvolvem pesquisa) enquanto nas particulares hä $1 \underline{i}$ geira predominância do Grupo B (professores que não desenvolvem pesquisa). Alëm disso, nota-se que as unidades estaduais levam nitida vantagem èm relaçäo às federais quanto a porcen- 
tagem de professores do Grupo A. Este resultado encontra reforço no fato das três unidades estaduais se encontrarem em São Paulo e Rio de Janeiro, reconhecidamente os Estados que dispõem de mais recursos na maior parte dos setores.

TABELA IV-2

RELAÇAOO ENTRE GRUPO E TIPO DE UNIDADE UNIVERSTTARIA - $1980^{*}$

\begin{tabular}{|c|c|c|c|c|c|c|}
\hline \multirow{2}{*}{$\begin{array}{c}\text { TIPO DE UNIDADE } \\
\text { UNIVERS ITARIA }\end{array}$} & \multicolumn{2}{|c|}{ GRUPO A* } & \multicolumn{2}{c|}{ GRUPO B** } & \multicolumn{2}{c|}{ TOTAL } \\
\cline { 2 - 7 } & $\mathrm{N}$ & $\frac{\circ}{\circ}$ & $\mathrm{N}$ & $\%$ & $\mathrm{~N}$ & $\%$ \\
\hline FEDERAL & 166 & 74,8 & 56 & 25,2 & 222 & 100,0 \\
\hline ESTADUAI & 40 & 87,0 & 6 & 13,0 & 46 & 100,0 \\
\hline PART I CULAR & 13 & 44,8 & 16 & 55,2 & 29 & 100,0 \\
\hline TOTAL & 219 & 73,7 & 78 & 26,3 & 297 & 100,0 \\
\hline
\end{tabular}

*Dados adaptados de: SOCIEDADE BRASILEIRA DE GEOLOGIA/MINISTERIO DA EDUCAÇÃ E CULTURA - 1981 - A Formação do Geólogo nas Universidades Brasileiras, um Retrato de Duas Décadas. MEC, Brasilia, 209 pp.

**GRUPO A: Professores que desenvolvem pesquisa

GRUPO B: Professores que não desenvolvem pesquisa

Outro critério escolhido para exame de distribuição dos grupos è o período de início de funcionamento de Curso de Graduação em Geologia (TABELA IV-1). Este critério permite es tabelecer três períodos bem distintos: desde o in icio dos pri meiros Cursos de Geologia até a sanção da Reforma Universitāria (1957 a 1965), desta reforma atë a amplìação do Curso de Geologia de quatro para cinco anos, acompanhada da reestruturação do currículo (1970 a 1973) e, finalmente, o período pos terior a essa ampliação (1976 a 1977). (1)

(1) Embora a Lei da Reforma Universitäria tenha sido sanciona da em 1968 e a ampliação do Curso de Geologia tenha ocorrido em 1975, os periodos foram velimitados de forma a abranger todos os anos em que algum Curso de Geologia teve início. O ültimo, da Universidade do Estado do Rio de Janeiro, teve inicio em 1977. 
0 primeiro período abrange 8 Unidades Universitárias, sendo 7 federais e 1 estadual; o segundo, 7 unidades, sendo 4 federais, 2 particulares e 1 estadual; o ültimo período abran ge apenas 4 unidades, sendo 3 federais e uma estadual. A distribuição dos grupos segundo tais períodos consta da TABELA IV -3 .

TABELA IV -3

RELAÇAO ENTRE GRUPO E PERIODO DE INICIO DE FUNCIONAMENTO DE CURSO DE GRADUAÇAO EM GEOLOGIA - 1980*

\begin{tabular}{|c|c|c|c|c|c|c|}
\hline \multirow{2}{*}{$\begin{array}{l}\text { INICIO DE } \\
\text { FUNCIONAMENTO }\end{array}$} & \multicolumn{2}{|c|}{ GRUPO $A^{\star *}$} & \multicolumn{2}{|c|}{ GRUPO $B^{* *}$} & \multicolumn{2}{|c|}{ TOTAL } \\
\hline & $\mathrm{N}$ & $\stackrel{0}{0}$ & $N$ & $\%$ & $\mathrm{~N}$ & $\%$ \\
\hline 1957 a 1965 & 136 & 85,5 & 23 & 14,5 & 159 & 100,0 \\
\hline 1970 a 1973 & 62 & 63,3 & 36 & 36,7 & 98 & 100,0 \\
\hline 1976 a 1977 & 21 & 52,5 & 19 & 47,5 & 40 & 100,0 \\
\hline TOTAL & 219 & 73,7 & 78 & 26,3 & 297 & 100,0 \\
\hline
\end{tabular}

*Dados adaptados de: SOCTEDADE BRASTLEIRA DE GEOLOGIA/MINISTERIO DA EDUCAÇAO E CULTURA - 1981 - A Formação do Geölogo nas Universidades Brasileiras, um Retrato de Duas Decadas. MEC, Brasilia, 209 pp.

**GRUPO A: Professores que desenvolvem pesquisa

GRUPO B: Professores que não desenvolvem pesquisa

Verifica-se sensivel decrëscimo das atividades de pes quisa do primeiro para o ültimo periodo. Enquanto no primeiro período dä-se predominio inquestionävel do Grupo A, no segundo essa vantagen diminui substancialmente, e no ültimo atinge -se praticamente a equivalência dos dois grupos.

Com base nos dados da TABELA IV-2, poder-se-ia supor que houvesse influência ponderävel das Unidades Universitárias estaduais e principalmente das particulares (cujos Cursos de Geologia tiveram início, ambos, no periodo de 1970 a 1973) nos resultados em exame. A TABELA IV-4 elimina tal influência, 
apresentando novamente a distribuição segundo periodo de início de funcionamento, mas agora na subamostra de professores das Unidades Universitärias federais exclusivamente.

TABELA IV -4

RELAÇAO ENTRE GRUPO E PERIODO DE INICIO DE FUNCIONAMENTO DE CURSO DE GRADUAÇAO EM GEOLOGIA NA SUBAMOSTRA DE PROFESSORES DAS UNIDADES UNIVERSITARIAS FEDERAIS - 1980*

\begin{tabular}{|cc|c|c|c|c|c|c|}
\hline \multirow{2}{*}{$\begin{array}{c}\text { INICIO DE } \\
\text { FUNCI ONAMENTO }\end{array}$} & \multicolumn{2}{|c|}{ GRUPO A** } & \multicolumn{2}{|c|}{ GRUPO B** } & \multicolumn{2}{|c|}{ TOTAL } \\
\cline { 2 - 8 } & $\mathrm{N}$ & $\%$ & $\mathrm{~N}$ & $\%$ & $\mathrm{~N}$ & $\%$ \\
\hline 1957 a 1965 & 117 & 83,6 & 23 & 16,4 & 140 & 100,0 \\
\hline 1970 & a 1973 & 31 & 64,6 & 17 & 35,4 & 48 & 100,0 \\
\hline 1976 & a 1977 & 18 & 52,9 & 16 & 47,1 & 34 & 100,0 \\
\hline & TOTAL & 166 & 74,8 & 56 & 25,2 & 222 & 100,0 \\
\hline
\end{tabular}

*Dados adaptados de: SOCIEDADE BRASILEIRA DE GEOLOGIA/MINISTERIO DA EDUCAÇAO E CULTURA - 1981 - A Formação do Geölogo nas Universidades Brasileiras, um Retrato de Duas Decadas. MEC, Brasilia, 209 pp.

**GRUPO A: Professores que desenvolvem pesquisa

GRUPO B: Professores que não desenvolvem pesquisa

Verifica-se que os percentuais dos grupos em cada pe ríodo são quase idênticos aos da TABELA anterior. Portanto, no segundo período (1970 a 1973), pretensamente o mais influenciado na TABELA IV-3, ocorreu compensação entre as influências das Unidades Universitārias particulares e da estadual. os percentuais nos demais períodos quase não foram afetados pela exclusão das respectivas Unidades Universitārias estaduais.

IV.1.2 - Regime de Trabalho

O regime de trabalho foi classificado em três catego 
rias: tempo parcial, tempo integral e dedicação exclusiva. A categoria tempo parcial abrange todas as alternativas do Ques tionário do professor que configuram dedicação parcial à Universidade. Estas alternativas são as seguintes: a) hora-aula (regime em que o professor é remunerado pelas horas-aula dadas); b) tempo parcial (remuneração segundo carga horāria se manal, independentemente das horas-aula) e c) turno completo (vinte e quatro horas semanais, também sem vinculação com o nümero de horas-aula). As demais categorias, tempo integral (quarenta horas semanais) e dedicação exclusiva (tempo integral com dedicação exclusiva), correspondem exatamente às do referido questionário. A TABELA IV-5 apresenta a distribuição dos Grupos A e B segundo as três categorias escolhidas para o regime de trabalho.

TABELA IV-5

RELAÇAO ENTRE GRUPO E REGIME DE TRABALHO - $1980^{*}$

\begin{tabular}{|r|c|c|c|c|c|c|}
\hline \multirow{2}{*}{$\begin{array}{c}\text { REGIME DE } \\
\text { TRABALHO }\end{array}$} & \multicolumn{2}{|c|}{ GRUPO A* } & \multicolumn{2}{|c|}{ GRUPO B** } & \multicolumn{2}{|c|}{ TOTAL } \\
\cline { 2 - 7 } & $\mathrm{N}$ & $\frac{0}{6}$ & $\mathrm{~N}$ & $\frac{\mathrm{N}}{0}$ & $\mathrm{~N}$ & $\%$ \\
\hline TEMPO PARCIAL OU HORA-AULA & 24 & 38,7 & 38 & 61,3 & 62 & 100,0 \\
\hline TEMPO INTEGRAL (40 horaS) & 79 & 76,0 & 25 & 24,0 & 104 & 100,0 \\
\hline DEDICAÇAO EXCLUSIVA & 116 & 89,2 & 14 & 10,8 & 130 & 100,0 \\
\hline TOTAL & 219 & 74,0 & 77 & 26,0 & $296^{* * *}$ & 100,0 \\
\hline
\end{tabular}

*Dados adaptados de: SOCIEDADE BRASILEIRA DE GEOLOGIA/MINISTEERTO DA EDU CAÇAO E CULTURA - 1981 - A Formação do Geölogo nas Universjdades Brasĩ leiras, um Retrato de Duas Decadas. MEC, Brasilia, 209 pp.

**GRUPO A: Professores que desenvolvem pesquisa

GRUPO B: Professores que não desenvolvem pesquisa

***O total de professores não atingiu o total da amostra porque um deles não respondeu acerca de seu regime de trabalho.

Verifica-se que o Grupo $B$ somente predomina no regi- 
me de tempo parcial, ocorrendo inversão de porcentagens nos regimes de tempo integral e dedicação exclusiva. Nesta última categoria o Grupo A ë predominante na razão aproximada $9: 1$.

IV.1.3 - Atividades Profissionais Externas à Unidade Universi $\underline{\text { tária }}$

Para esta variävel foram escolhidas duas categorias: a) exerce atividades profissionais externas e b) não exerce atividades profissionais externas. A primeira categoria abran ge as alternativas (a), (b), (c) e (d) da pergunta correspondente no Questionärio do Professor, as quais representam, res pectivamente, as seguintes cargas horärias de atividade exter na: atê dez horas semanais; dez a vinte horas semanais; vinte e uma a trinta horas semanais. A TABELA IV-6 exibe a distri buição dos Grupos A e B em função do exercício ou não de atividades externas à Unidade Universitärịa.

TABELA IV-6

RELAÇAO ENTRE GRUPO E EXERCICIO DE ATTVIDADES PROFISSTONATS EXTERNAS $\AA$ UNIDADE UNIVERSTTARIA - 1980*

\begin{tabular}{|c|c|c|c|c|c|c|}
\hline \multirow{2}{*}{$\begin{array}{l}\text { ATIVIDADES PROFIS } \\
\text { SIONAIS EXTERNAS }\end{array}$} & \multicolumn{2}{|c|}{ GRUPO $A^{* *}$} & \multicolumn{2}{|c|}{ GRUPO $B^{*-k}$} & \multicolumn{2}{|c|}{ TOTAL } \\
\hline & $N$ & $\%$ & $\mathrm{~N}$ & $\%$ & $\mathrm{~N}$ & $\%$ \\
\hline EXERCE & 47 & 56,0 & 37 & 44,0 & 84 & 100,0 \\
\hline NÃO EXERCE & 169 & 80,9 & 40 & 19,1 & 209 & 100,0 \\
\hline TOTAL & 216 & 73,7 & 77 & 26,3 & $293^{\text {xk-x }}$ & 100,0 \\
\hline
\end{tabular}

*Dados adaptados de: SOCIEDADE BRASILEIRA DE GEOLOGIA/MINISTERIO DA EDU CAÇÃO E CULTURA - 1981 - A Formaçäo do Geólogo nas Universidades Brasi leiras, un Retrato de Duas Decadas. MEC, Brasilia, 209 pp.

**GRUPO A: Professores que desenvolvem pesquisa

GRUPO B: Professores que não desenvolvem pesquisa

***O total de professores não atingiu o total da amostra porque alguns não responderam acerca de suas atividades profissionais externas à Unidade Universitäria. 
Verifica-se predominio do Grupo A nas duas categorias, mas muito maior na segunda, isto é, entre os professo res que não exercem atividades externas à sua unidade.

\section{IV.1.4 - Níve1 de Contratação}

Considerando que no Questionärio do Professor os niveis de contratação das unidades federais e particulares têm denominação diferente daqueles das unidades estaduais, decidiu-se pela junção de níveis equivalentes. Assim, das seis ca tegorias escolhidas, as quatro primeiras, auxiliar de ensino, assistente, adjunto e titular, todas alternativas das unjda des federais ou particulares, englobam tambëm, respectivamente, as seguintes alternativas das unidades estaduais: MSI;MS2 e MS3; MS4 e MS5; MS6. As demais categorias são: professor vi sitante e professor colaborador. A distribuição dos grupos se gundo o nível de contratação $\vec{e}$ apresentada na TABELA IV-7.

o Grupo A predomina em todos os niveis de contrata §ão, sendo este predomínio menor nos niveis auxiliar de ensino e assistente. Destaca-se o nivel de professor visitante, com relação entre os Grupos A e B superior a 9:1.

Considerando que hâ diferenças de orientação quanto a nivel de contratação entre os três tipos de Unidade universitāria estabelecidos nesta pesquisa, ë conveniente examinar a distribuição dos grupos segundo nível de contratação na sub amostra dos professores das Unidades Universitárias federais, - que é possível fazer na TABELA IV-8.

As porcentagens agora obtidas simplesmente confirmam os dados da TABELA anterior. A ünica diferença digna de nota $\vec{e}$ que o nivel de titular destaca-se agora junto ao de professor visitante quanto ao predominio do Grupo A. 
TABELA IV -7

RELAÇAO ENTRE GRUPO E NIVEL, DE CONTRATAÇAO - 1980*

\begin{tabular}{|c|c|c|c|c|c|c|}
\hline \multirow{2}{*}{$\begin{array}{c}\text { NIVEL DE } \\
\text { CONTRATAÇAO }\end{array}$} & \multicolumn{2}{|c|}{ GRUPO $A^{* * *}$} & \multicolumn{2}{|c|}{ GRUPO $\mathrm{B}^{* *}$} & \multicolumn{2}{|c|}{ TOTAL } \\
\hline & N & $\frac{0}{\partial}$ & $N$ & $\%$ & $\mathrm{~N}$ & $\frac{\circ}{0}$ \\
\hline AUXILIAR DE ENSINO & 40 & 61,5 & 25 & 38,5 & 65 & 100,0 \\
\hline ASSISTENTE & 58 & 68,2 & 27 & 31,8 & 85 & $1.00,0$ \\
\hline ADJUNTO & 55 & 83,3 & 11 & 16,7 & 66 & 100,0 \\
\hline TITULAR & 27 & 81,8 & 6 & 18,2 & 33 & 100,0 \\
\hline VISITANTE & 12 & 92,3 & 1 & 7,7 & 13 & 100,0 \\
\hline COLABORADOR & 25 & 78,1 & 7 & 21,9 & 32 & 100,0 \\
\hline TOTAL & 217 & 73,8 & 77 & 26,2 & $294^{* * x}$ & 100,0 \\
\hline
\end{tabular}

*Dados adaptados de: SOCIEDADE BRASILEIRA DE GEOLOGIA/MINISTERTO DA EDU CAÇAO E CULTURA - 1981 - A Formação do Geólogo nas Universidades Brasĩ leiras, um Retrato de Duas Decadas. MEC, Brasilia, $209 \mathrm{pp}$.

**GRUPO A: Professores que desenvolvem pesqui.sa

GRUPO B: Professores que não desenvolvem pesquisa

**O total de professores não atingiu o total da amostra porque alguns não responderam acerca de seu nivel de contratação. 
TABIILA IV -8

RELAÇAO ENTRE GRUPO E NTVEL DE CONTRATAÇAO NA SUBAMOSTRA DE: PROFESSORES DAS UNIDADES UNIVERSTTARIAS FEDERAIS - 1980 *

\begin{tabular}{|c|c|c|c|c|c|c|}
\hline \multirow{2}{*}{$\begin{array}{l}\text { NIVEL DE } \\
\text { CONTRATACXO }\end{array}$} & \multicolumn{2}{|c|}{ GRUPO $A^{* *}$} & \multicolumn{2}{|c|}{ GRUPO $B^{\star-k}$} & \multicolumn{2}{|c|}{ TOTAL } \\
\hline & $N$ & $\stackrel{0}{0}$ & N & $\stackrel{0}{0}$ & $N$ & $\frac{\circ}{0}$ \\
\hline AUXILIAR DE ENSINO & 31 & 58,5 & 22 & 41,5 & 53 & 100,0 \\
\hline ASSISTENTE & 32 & 64,0 & 18 & 36,0 & 50 & 100,0 \\
\hline ADJUNTO & 45 & 84,9 & 8 & $15, I$ & 53 & 100,0 \\
\hline TITULAR & 19 & 90,5 & 2 & 9,5 & 21 & 100,0 \\
\hline VISITANTE & 12 & 92,3 & 1 & 7,7 & 13 & 100,0 \\
\hline COLABORADOR & 25 & 83,3 & 5 & 16,7 & 30 & 100,0 \\
\hline TOTAL & 164 & 74,5 & 56 & 25,5 & $220^{k+k}$ & 100,0 \\
\hline
\end{tabular}

*Dados adaptados de: SOCIEDADE BRASILEIPA DE GEOLOGIA/MINISTERJO DA EDU CAÇAO E CULTURA -- 1981 - A Formação do Geölogo nas Universidades Brasĩ leiras, um Retrato de Duas Decadas. MEC, Brasilia, 209 pp.

**GRUPO A: Professores que desenvolvem pesquisa

GRUPO B: Professores que não desenvolvem pesquisa

***O total de professores näo atingiu o total da subamostra porque alguns não responderam acerca de seu nỉvel de contrataçăo. 
IV.1.5 - Título Obtido

A variävel "título" abrange quatro categorias: gra duado (bacharel ou licenciado), mestre, doutor e livre-docente... As alternativas do Questionärio do Professor que se refe rem a titulação incompleta foram reduzidas à categoria imedia tamente inferior. Assim, mestrado incompleto foj reduzido para graduação, doutorado incompleto para mestrado, e assim por diante. A distribuição dos grupos segundo o título ë apresentada na TABELA IV-9.

TABELA IV-9

RELAÇÃO ENTRE GRUPO E TITULO OBTIDO - 1980*

\begin{tabular}{|c|c|c|c|c|c|c|}
\hline \multirow{2}{*}{ TITULO } & \multicolumn{2}{|c|}{ GRUPO $A^{* \star}$} & \multicolumn{2}{|c|}{ GRUPO $B * *$} & \multicolumn{2}{|c|}{ TOTAL } \\
\hline & $N$ & $\stackrel{\circ}{0}$ & $\mathrm{~N}$ & $\%$ & $N$ & $\frac{0}{0}$ \\
\hline BACHAREL OU LICENCIADO & 62 & 56,9 & 47 & 43,1 & 109 & 100,0 \\
\hline MESTRE & 76 & 78,4 & 21 & 21,6 & 97 & 100,0 \\
\hline DOUTOR & 59 & 90,8 & 6 & 9,2 & 65 & 100,0 \\
\hline LIVRE-DOCENTE & 21 & 91,3 & 2 & 8,7 & 23 & 100,0 \\
\hline TOTAL & 218 & 74,1 & 76 & 25,9 & $294 \% *$ & 100,0 \\
\hline
\end{tabular}

* Dados adaptados de: SOCIEDADE BRASILEIRA DE GEOLOGIA/MINISTERIO DA EDU CAÇÃO E CULTURA - 1981 - A Formaçäo do Geólogo nas Universidades Brasĩ leiras, um Retrato de Duas Decadas. MEC, Brasilia, 209 pp.

**GRUPO A: Professores que desenvolvem pesquisa

GRUPO B: Professores que não desenvolvem pesquisa

***O total de professores não atingiu o total da amostra porque alguns não responderan acerca de seu título.

As Unidades Universitärias federais e estaduais conferem conotação diferente à livre-docência, o que obriga exame com reservas da categoria de livremdocente. Entre as demais 
categorias, porem, $\vec{e}$ possivel perceber nitida distinção nas porcentagens, havendo aumento do predominio do Grupo A quanto mais elevado for o título. o "livre-docente" apresenta a mesma relação de porcentagens do "doutor".

IV.1.6 - Tempo de Servico na Unidade Universitäria

As categorias utilizadas para a variáve1 "tempo de serviço" nesta pesquisa repetiram as do Questionärio do professor, exceto a ültima (14 anos ou mais), que abrange as a1ternativas "de 14 a 17 anos" e "mais de 17 anos", visando a evitar excessiva fragmentação da amostra. A TABELA IV-10 apre senta a distribuição dos Grupos A e B segundo tempo de serviço.

TABELA IV-10

RELAÇAO ENTRE GRUPO E TEMPO DE SERVIÇO NA UNIDADE UNIVERSTTARIA - $1980^{*}$

\begin{tabular}{|c|c|c|c|c|c|c|}
\hline \multirow{2}{*}{ TEMPO DE SERVIÇO } & \multicolumn{2}{|c|}{ GRUPO $A^{* \star}$} & \multicolumn{2}{|c|}{ GRUPO $B^{*-k}$} & \multicolumn{2}{|c|}{ TOTAL } \\
\hline & $N$ & $\stackrel{\circ}{0}$ & $\mathrm{~N}$ & $\%$ & $N$ & $\stackrel{0}{0}$ \\
\hline MENOS DE 2 ANOS & 37 & 54,4 & 31. & 45,6 & 68 & 100,0 \\
\hline 2 a 5 ANOS & 68 & 76,4 & 21 & 23,6 & 89 & 100,0 \\
\hline 6 a 9 ANOS & 43 & 82,7 & 9 & 17,3 & 52 & 100,0 \\
\hline 10 a 13 ANOS & 28 & 82,4 & 6 & 17,6 & 34 & 100,0 \\
\hline 14 ANOS OU MAIS & 43 & 79,6 & 11 & 20,4 & 54 & 100,0 \\
\hline TOTAL & 21.9 & 73,7 & 78 & 26,3 & 297 & 100,0 \\
\hline
\end{tabular}

*Dados adaptados de: SOCIEDADE BRASILEIRA DE GEOLOGIA/MINISTERIO DA EDUCAÇAO E CULTURA - 1981 - A Formação do Geólogo nas Universidades Brasileiras, um Retrato de Duas Decadas. MEC, Brasilia, 209 pp.

**aruPO A: Professores que desenvolvem pesquisa

GRUPO B: Professores que não desenvolvem pesquisa 
Observa-se predomînio do Grupo A em todas as categorias, mas na primeira delas (menos de 2 anos) a vantagem desse grupo é bem menor que nas demais.

IV.2 - FATORES QUE CONDICIONAM AS POSSIBILIDADES DE PESQUISA

As variāveis examinadas nas TABELAS anteriores deste Capítulo podem, todas elas, constituir-se em fatores que influenciam as possibilidades de desenvolvimento de pesquisa por parte dos professores. O estabelecimento das relações entre grupo (professores que desenvolvem ou não pesquisa) e variäveis independentes, introduzindo-se variảveis de controle, permitirá detectar as variāveis que devem efetivamente influenciar no desenvolvimento de pesquisa.

IV.2.1 - Regime de Trabalho

IV.2.1a - Regime de Trabalho e Tipo de Unidade Universitäria

A relação entre os conjuntos dos professores que desenvolvem pesquisa (Grupo A) e dos que não desenvol vem (Grupo B) e tipo de Unidade Universitária, utilizando-se regime de trabalho como variāvel de controle, é apresentada na TABELA IV-11.

Encontram-se em regime de tempo parcial ou hora-aula 58,6\% dos professores das unidades particulares con tra apenas $23,9 \%$ das estaduais e 15,4\% das federais.

Nas unidades federais o Grupo B predomina na categoria de tempo parcial ou hora-aula, ocorrendo inver são de porcentagens nas categorias de tempo integral e dedica ção exclusiva.

Nas unidades estaduais, embora a vantagem do Grupo B na categoria "tempo parcial" não possa ser levada. 
TABELA IV-1I

RELAÇAO ENTRE GRUPO E TIPO DE UNIDADE UNIVERSITARIA, CONTROLANDO PELO REGIME DE TRABALHO - 1980*

\begin{tabular}{|c|c|c|c|c|c|c|c|c|c|c|c|c|c|c|}
\hline \multirow{3}{*}{$\begin{array}{l}\text { TIPO DE UNIDADE } \\
\text { UNIVERSITARIA }\end{array}$} & \multicolumn{4}{|c|}{$\begin{array}{l}\text { TEMPO PARCIAL } \\
\text { OU HORA-AULA }\end{array}$} & \multicolumn{4}{|c|}{$\begin{array}{c}\text { TEMPO INTEGRAL } \\
(40 \text { horas })\end{array}$} & \multicolumn{4}{|c|}{$\begin{array}{l}\text { DEDICACĀAO } \\
\text { EXCEUSIVA }\end{array}$} & \multirow{2}{*}{\multicolumn{2}{|c|}{ TOTAL }} \\
\hline & \multicolumn{2}{|c|}{ GRUPO $A^{* *}$} & \multicolumn{2}{|c|}{ GRUPO $B^{* *}$} & \multicolumn{2}{|c|}{ GRUPO A } & \multicolumn{2}{|c|}{ GRUPO B } & \multicolumn{2}{|c|}{ GRUPO A } & \multicolumn{2}{|c|}{ GRUPO B } & & \\
\hline & $\mathrm{N}$ & $\%$ & $\mathrm{~N}$ & $\%$ & $\mathrm{~N}$ & $\stackrel{\circ}{0}$ & $\mathrm{~N}$ & $\%$ & $\mathrm{~N}$ & $\frac{\partial}{\partial}$ & N & $\%$ & N & $\%$ \\
\hline FEDERAL & 11 & 32,4 & 23 & 67,6 & 64 & 78,0 & 18 & 22,0 & 91 & 86,7 & 14 & 13,3 & 221 & 74,7 \\
\hline ESTADUAL & 5 & 45,5 & 6 & 54,5 & 10 & 100,0 & 0 & 0,0 & 25 & 100,0 & 0 & 0,0 & 46 & 15,5 \\
\hline PARTICULAR & 8 & 47,1 & 9 & 52,9 & 5 & 41,7 & 7 & 58,3 & 0 & 0,0 & 0 & 0,0 & 29 & 9,8 \\
\hline TOTAL & 24 & 8,1 & 38 & 12,8 & 79 & 26,7 & 25 & 8,4 & 116 & 39,2 & 14 & 4,7 & $296^{*}$ & 100,0 \\
\hline
\end{tabular}

*Dados adaptados de: SOCIEDADE BRASILEIRA DE GEOLOGIA/MINISTERIO DA EDUCAÇÃo E CULTURA - 1981 - A Formação do GEó1ogo nas Universidades Brasileiras, un Retrato de Duas Décadas. MEC, Brasilia, $209 \mathrm{pp}$.

**GRUPO A: Professores que desenvolvem pesquisa

GRUPO B: Professores que não desenvolvem pesquisa

***O total de professores não atingiu o total da amostra porque um deles não respondeu acerca de seu regime de trabalho. 
em conta, face aos pequenos valores absolutos envolvidos, $\vec{e}$ notävel que todos os professores do Grupo B estejam nessa categoria, sendo o Grupo A absoluto nas demais.

Nas unidades particulares não hä represen tantes em regime de tempo integral com dedicação exclusiva. Comparando-se os regimes de tempo integral e tempo parcial, ob serva-se que não hä diferença substancial entre as porcenta gens dos grupos nos dois regimes.

Portanto, o regime de tempo integral parece associado ao desenvolvimento de pesquisa pelos professores das unidades püblicas e o tempo parcial parece dificultâ-1o. Nas unidades particulares o regime de trabalho parece não exer cer influência quanto às atividades de pesquisa.

IV.2.1b - Regime de Trabalho e Período de Início de Funcionamento de Curso de Geologia

A influência do regime de trabalho na rela ção entre grupo e Curso de Geologia, segundo seu período de início de funcionamento, pode ser observada na TABELA IV-12.

Nos três períodos considerados o Grupo $B$ predomina na categoria de tempo parcial, ocorrendo inversão de porcentagens nas demais categorias. Nota-se, porēm, perda relativa de importância do tempo integral (comparando-se opri meiro período com os démais) e da dedicação exclusiva (comparando-se o primeiro, segundo e terceiro períodos) para desenvolvimento de pesquisa, progressivamente dos cursos antigos para os recentes.

Portanto, o regime de tempo parcial parece dificultar as atividades de pesquisa nos três períodos considerados e os de tempo integral e dedicação exclusiva favorecê -1as. Todavia, estes dois ültimos regimes parecem termaior ín fluência nos cursos mais antigos (1.957 a 1965), do que naque les criados nos demais períodos. 
TABELA IV -12

RELAÇAO ENTRE GRUPO E PERIODO DE INICIO DE FUNCIONAMENTO DE CURSO DE GRADUACAO EM GEOLOGIA, CONTROLANDO PELO REGIME DE TRABALHO - 1980*

\begin{tabular}{|c|c|c|c|c|c|c|c|c|c|c|c|c|c|c|}
\hline \multirow{3}{*}{$\begin{array}{l}\text { INICIO DE } \\
\text { FUNCIONAMENTO }\end{array}$} & \multicolumn{4}{|c|}{$\begin{array}{l}\text { TEMPO PARCIAL } \\
\text { OU HORA-AULA }\end{array}$} & \multicolumn{4}{|c|}{$\begin{array}{l}\text { TEMPO INTEGRAL } \\
\text { (40 horas) }\end{array}$} & \multicolumn{4}{|c|}{$\begin{array}{l}\text { DEDICACAOO } \\
\text { EXCLUSIVA }\end{array}$} & \multirow{2}{*}{\multicolumn{2}{|c|}{ TOTAL }} \\
\hline & \multicolumn{2}{|c|}{ GRUPO $A^{* *}$} & \multicolumn{2}{|c|}{ GRUPO $B^{* *}$} & \multicolumn{2}{|c|}{ GRUPO A } & \multicolumn{2}{|c|}{ GRUPO B } & \multicolumn{2}{|c|}{ GRUPO A } & \multicolumn{2}{|c|}{ GRUPO B } & & \\
\hline & $N$ & $\%$ & $\mathrm{~N}$ & $\%$ & $\mathrm{~N}$ & $\frac{\circ}{0}$ & $N$ & $\%$ & $N$ & $\%$ & $N$ & 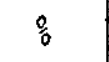 & $\mathrm{N}$ & $\because$ \\
\hline 1957 a 1965 & 10 & 43,5 & 13 & 56,5 & 50 & 89,3 & 6 & 10,7 & 76 & 95,0 & 4 & 5,0 & 159 & 53,7 \\
\hline 1970 a & 11 & 36,7 & 19 & 63,3 & 20 & 60,6 & 13 & 39,4 & 31 & 88,6 & 4 & 11,4 & 98 & 33,1 \\
\hline 1976 a & 3 & 33,3 & 6 & 66,7 & 9 & 60,0 & 6 & 40,0 & 9 & 60,0 & 6 & 40,0 & 39 & 13,2 \\
\hline TOTAL & 24 & 8,1 & 38 & 12,8 & 79 & 26,7 & 25 & 8,4 & 116 & 39,2 & 14 & 4,7 & $296^{6}$ & 100,0 \\
\hline
\end{tabular}

*Dados adaptados de: SOCIEDADE BRASILEIRA DE GEOLOGIA/MINISTERIO DA EDUCAÇÃo E CULTURA - 1981 - A Formaçāo do Geölogo nas Universidades Brasileiras, um Retrato de Duas Décadas. MEC, Brasília, 209 pp.

**GRUPO A: Professores que desenvolvem pesquisa

GRUPO B: Professores que não desenvolvem pesquisa

***0 total de professores não atingiu o total da amostra porque um deles não respondeu acerca de seu regime de trabalho. 
IV.2.2 - Atividades Profissionais Externas à Unidade Universi täria

\section{IV.2.2a - Atividades Profissionais Externas e Tipo de Unidade Universitäria}

A TABELA IV-13 apresenta a influência de atividades profissionais externas na relação entre grupo e ti po de Unidade Universitäria.

Nas unidades estaduais e particulares o exercício de atividades externas está associado principalmente ao Grupo A e nas federais aparece em proporção equivalente nos dois grupos. A ausência de atividades profissionais exter nas esta associada ao Grupo A nas unidades püblicas e ao Grupo $B$ nas particulares.

Enquanto $58,6 \%$ dos professores das unida des particulares declaram exercicio de atividade profissional externa, apenas $28,3 \%$ das estaduais e $24,8 \%$ das federats o fá zem.

Nas unidades particulares, o desenvolvimen to de pesquisa pode estar associado a atividades externas, pois a maioria $(76,9 \%)$ dos professores do Grupo A as possuem. Nas unidades püblicas o panorama é oposto: nas federais ape nas $17,2 \%$ dos professores desse grupo declaram atividade externa e nas estaduais apenas 22,50 .

A distribuição dos professores do Grupo B $\vec{e}$ equilibrada entre os que declaram exercício ou não de ativi dade externa. Apenas nas unidades estaduais isto não acontece, ficando inconclusivos os resultados em face dos valores absolutos muito pequenos.

Nas unidades püblicas, a variação de por centagens da primeira categoria (exerce atividades profissionais externas) para a segunda (não exerce atividades profissionais externas) sugere que o desenvolvimento de pesquisa pa rece dificultado pelas atividades profissionais externas. Nas unidades particulares, a inversão de porcentagens da primeira categoria para a segunda sugere que o desenvolvimento de pes quisa parece favorecido pelo exercicio deatividades externas. 
TABELA IV -13

RELACAO ENTRE GRUPO E TIPO DE UNTDADE UNIVERSITARIA, CONTROLANDO PELO EXERCTCIO DE ATIVIDADES PROFISSIONATS EXTERNAS - 1980*

\begin{tabular}{|c|c|c|c|c|c|c|c|c|c|c|}
\hline \multirow{3}{*}{ ATIVIDADES PROFISSIONAIS } & \multicolumn{4}{|c|}{ EXERCE ATIVIDADES EXTERNAS } & \multicolumn{4}{|c|}{ NAOO EXERCE ATIVIDADES EXTERNAS } & \multirow{2}{*}{\multicolumn{2}{|c|}{ TOTAL }} \\
\hline & \multicolumn{2}{|c|}{ GRUPO $A^{* *}$} & \multicolumn{2}{|c|}{ GRUPO $\mathrm{B}^{* *}$} & \multicolumn{2}{|c|}{ GRUPO $A^{* *}$} & \multicolumn{2}{|c|}{ GRUPO $B * *$} & & \\
\hline & N & $\%$ & N & $\%$ & $N$ & $\%$ & N & $\because$ & $\mathrm{N}$ & $\stackrel{\circ}{\circ}$ \\
\hline FEDERAL & 28 & 51,9 & 26 & 48,1 & 135 & 82,3 & 29 & 17,7 & 218 & 74,4 \\
\hline ESTADUAL & 9 & 69,2 & 4 & 30,8 & 31 & 93,9 & 2 & 6,1 & 46 & 15,7 \\
\hline PARTICULAR & 10 & 58,8 & 7 & 41,2 & 3 & 25,0 & 9 & 75,0 & 29 & 9,9 \\
\hline TOTAL & 47 & 16,0 & 37 & 12,6 & 169 & 57,7 & 40 & 13,7 & $293 *$ & 100,0 \\
\hline
\end{tabular}

*Dados adaptados de: SOCIEDADE BRASILEIRA DE. GEOLOGIA/MTNISTERIO DA EDUCAÇão E CULTURA - 1981 - A Formação do Geó1ogo nas Universidades Brasileiras, um Retrato de Duas Décadas. MEC, Brasília, 209 pp.

**GRUPO A: Professores que desenvolvem pesquisa

GRUPO B: Professores que não desenvolvem pesquisa

***O total de professores não atingiu o total da amostra porque alguns não responderam acerca de suas atividades profissionais externas à unidade üiversitäria. 
IV.2.2b - Atividades profissionais Externas e Período de Início de Funcionamento de Curso de Geo $\operatorname{logia}$

A relação entre grupo e Gurso de Geologia, segundo seu período de início de funcionamento, controlando pelo exercício ou não de atividades profissionais externas à Unidade Universitāria, pode ser observada na TABELA IV-14.

$\mathrm{Na}$ categoria "exerce atividades externas"

- Grupo A predomina apenas no primeiro periodo (1957 a 1965), sendo igual ou muito próximo ao Grupo B nos demais períodos. Vale registrar que embora os percentuais do terceiro período pouco difiram do primeiro, seus valores absolutos pequenos im pedem que se aponte predominância do Grupo A.

Na categoria "não exerce atividades externas" hä predominância absoluta do Grupo A no primeiro perïodo $(93,3 \%)$, bastante diminuida no segundo $(71,7 \%)$. No terceiro e ultimo período (1976 a 1977) os Grupos A e B são equivalentes.

Em resumo, atividades profissionais externas parecem constituir obstäculo ao desenvolvimento de pesqui sa nas Unidades Universitäias dos primeiro e segundo periodos, deixando aparentemente de ter importância naquelas do ter ceiro período.

IV. 2.3 - Nivel de Contratação

IV.2.3a - Nịve1 de Contratação e Tipo de Unidade Un versitäria

A influência de nível de contratação na re lação entre grupo e tipo de Unidade Universitäria é apresenta da na TABELA IV-15. Considerando que as categorias de professor visitante e colaborador são representadas quase exclusiva mente nas unidades federais e que não configuram posição defi nida na carreira universitäria, restringir-se-ā o exame às quatro categorias restantes.

Nas unidades püblicas, o Grupo A predomina 
TABELA IV-14 RELAČAO ENTRE GRUPO E PERTODO DE INICIO DE FUNCIONAMENTO DE CURSO DE GRADUAÇAO EM GEOLOGIA, CONTROLAN
DO PELO EXERCICIO DE ATIVIDADES PROFISSIONAIS EXTERNAS A UNIDADE UNIVERSITARIA - 1980*

\begin{tabular}{|c|c|c|c|c|c|c|c|c|c|c|}
\hline \multirow{3}{*}{$\begin{array}{l}\text { ATIVIDADES PROFISSIO- } \\
\text { NAIS EXTERNAS } \\
\text { INICIO DE } \\
\text { FUNCIONAMENTO }\end{array}$} & \multicolumn{4}{|c|}{ EXERCE ATIVIDADES EXTERNAS } & \multicolumn{4}{|c|}{ NAO EXERCE ATIVIDADES EXTERNAS } & \multirow{2}{*}{\multicolumn{2}{|c|}{ TOTAL }} \\
\hline & \multicolumn{2}{|c|}{ GRUPO A** } & \multicolumn{2}{|c|}{ GRUPO B** } & \multicolumn{2}{|c|}{ GRUPO $A^{* *}$} & \multicolumn{2}{|c|}{ GRUPO $B^{* *}$} & & \\
\hline & $\mathrm{N}$ & $\%$ & $\mathrm{~N}$ & $\%$ & $N$ & $\%$ & $N$ & $\%$ & $N$ & $\because$ \\
\hline 1957 a 1965 & 22 & 61,1 & 14 & 38,9 & 112 & 93,3 & 8 & 6,7 & 156 & 53,2 \\
\hline 1970 a 1973 & 19 & 50,0 & 19 & 50,0 & 43 & 71,7 & 17 & 28,3 & 98 & 33,4 \\
\hline 1976 a 1977 & 6 & 60,0 & 4 & 40,0 & 14 & 48,3 & 15 & 51,7 & 39 & 13,3 \\
\hline TOTAL & 47 & 16,0 & 37 & 12,6 & 169 & 57,7 & 40 & 13,7 & $293^{*+* *}$ & 100,0 \\
\hline
\end{tabular}

*Dados adaptados de: SOCIEDADE BRASHLEIRA DE GEOLOGIA/MINISTERIO DA EDUCAÇO E CULTURA - 1981 - A Formação do Geölogo nas Universidades Brasileiras; um Retrato de Duas Décadas. MEC, Brasilia, 209 pp.

**GRUPO A: Professores que desenvolvem pesquisa

GRUPO B: Professores que não desenvolvem pesquisa ** 0 total de professores não atingiu o total da amostra porque alguns não responderam acerca de suas atividades profis-
sionais externas à Unidade Universitária. 
TABELA IV-15

RELAÇAOO ENTRE GRUPO E TIPO DE UNIDADE UNIVERSITARIA, CONTROLANDO PELO NIVEL DE CONTRATAÇO - 1980*

\begin{tabular}{|c|c|c|c|c|c|c|c|c|c|c|c|c|c|c|c|c|c|c|c|c|c|c|c|c|c|c|}
\hline \multirow{3}{*}{ 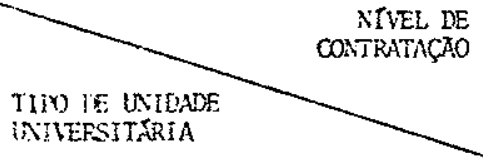 } & \multicolumn{4}{|c|}{ AUXILIAR DE ENSINO } & \multicolumn{4}{|c|}{ ASSISTENTE } & \multicolumn{4}{|c|}{ ADJuNTO } & \multicolumn{4}{|c|}{ TITULAR } & \multicolumn{4}{|c|}{ VISTTANTE } & \multicolumn{4}{|c|}{ COLABCRADOR } & \multirow{2}{*}{\multicolumn{2}{|c|}{ THAL }} \\
\hline & \multicolumn{2}{|c|}{ GRUPO $A^{* *}$} & \multicolumn{2}{|c|}{ GRUPO $B^{*}$} & \multicolumn{2}{|c|}{ GRUPO A. } & \multicolumn{2}{|c|}{ CRUPO B } & \multicolumn{2}{|c|}{ GRUPO A } & \multicolumn{2}{|c|}{ GRIPO B } & \multicolumn{2}{|c|}{ GRUPO A } & \multicolumn{2}{|c|}{ GRifOO 3} & \multicolumn{2}{|c|}{ GRUPO A } & \multicolumn{2}{|c|}{ GRUPO B } & \multicolumn{2}{|c|}{ GRUPO A } & \multicolumn{2}{|c|}{ GRIPO B } & & \\
\hline & $\mathrm{N}$ & s & $\mathrm{N}$ & $:$ & $\mathrm{N}$ & $\xi$ & $\mathrm{N}$ & $\varepsilon$ & $\mathrm{N}$ & : & $\mathrm{N}$ & $\&$ & $\mathrm{~N}$ & 8 & $\mathrm{~N}$ & 8 & $\mathrm{~N}$ & $:$ & $\mathrm{N}$ & 8 & $\mathrm{~N}$ & 8 & $\mathrm{~N}$ & q & $\mathrm{s}$ & $\$$ \\
\hline FEDEFNL & 31 & 58,5 & 22 & 41.5 & 32 & 64,0 & 18 & 36,0 & 45 & 84.9 & 8 & 15,1 & 19 & 90,5 & 2 & 9,5 & 12 & 92,3 & 1 & 7,7 & 25 & 83,3 & 5 & 16,7 & 220 & 74.8 \\
\hline ESTARUAL & 6 & 66,7 & 3 & 33,3 & 20 & 95,2 & 1 & 4,8 & 8 & 88,9 & $i$ & 11,1 & 6 & $100,0 \mid$ & 0 & 0.0 & 0 & 0.0 & 0 & 0,0 & 0 & 0,0 & 0 & 0.0 & 45 & 15,3 \\
\hline PATtarar & 3 & 100,0 & 0 & 0.0 & 6 & 42,9 & 8 & 57,1 & 2 & 50.0 & 2 & 50,0 & 2 & 33,3 & 4 & 66,7 & 0 & 0,0 & 0 & 0,0 & 0 & 0,0 & 2 & 100,0 & 29 & 9,9 \\
\hline TOTAL & 40 & 13,6 & 25 & 8.5 & 58 & 19,7 & 27 & 9,2 & 55 & 18.7 & 11 & 3,7 & 27 & 9,2 & 6 & 2,0 & 12 & 4,1 & 1 & 0,3 & 25 & 8,5 & $?$ & 2,4 & $29+$ & 100,0 \\
\hline
\end{tabular}

* Dados adantados de: SOCIEDADE BRASILETRA DE GEOLOGIA/MINISTERIO DA EDUCAÇÃO E C.ULTURA - 1981 - A Formação do Geólogo nas Universidades Brasileiras, um Retrato de Duas Décadas. MiEC, Brasílìa, 209 pp.

* GRUPO A: professores que desenvolvem pesquisa

GRUPO B: Professores que não desenvolvem pesquisa

**0 total de professores nãn atingiu o total da amostra porque aiguns não respcnceram acerca de seu nível de contratação. 
em todas as categorias mas seu predomínio $\vec{e}$ maior nos níveis mais elevados de contratação. Nas unidades federais o predomí nio do Grupo A aumenta progressivamente do nivel mais baixo (auxiliar de ensino) para o mais alto (titular), ocorrendo va riação mais forte na passagem da categoria de assistente para adjunto. Nas unidades estaduais a progressäo não ë tão nítida, verificando-se a mudança mais brusca nos percentuais dos grupos na passagem de "auxiliar de ensino" para "assistente".

Nas unidades particulares, o desenvolvimen to de pesquisa parece desfavorecido pelo avanço na carreira. Embora os valores absolutos sejam pequenos, observa-se inversão de porcentagens nos grupos, do nível mais baixo (auxiliar de ensino) para o mais elevado (titular), ficando cada um dos demais (assistente e adjunto) com percentuais idênticos ou mui to pröximos nos dois grupos.

Em resumo, nas unidades püblicas o avanço na carreira parece favorecer o desenvolvimento de pesquisa, sendo nas unidades federais principalmente ao atingir-se o ní vel de adjunto e nas estaduais principalmente apôs alcançado - nivel de assistente. Nas unidades particulares parece ocorrer o conträrio, notando-se tendência para maior desenvolvi mento de pesquisa nos niveis de contratação mais baixos.

\section{IV.2.3b - Nível de Contratação e Período de Início de Funcionamento de Curso de Geologia}

A TABELA IV-16 apresenta a influência do nível de contratação na relação entre grupo e Curso de Geologia segundo seu período de início de funcionamento.

ocorre sempre predomínio da Grupo A, exceto na categoria "auxiliar de ensino" do terceiro período (1976 a 1977) em que verifica-se predominância do Grupo B.

No primeiro período (1957 a 1965) os dois nîveis de contratação majs baixos (auxiliar de ensino e assis tente) apresentam percentuais muito pröximos, ocorrendo omesmo com os dois níveis mais elevados (adjunto e titular).o pre dominio do Grupo A $\vec{e}$ maior nestas categorias.

No segundo período (1970 a 1973) a maior 
TABELA IV-16

RELAÇAO ENTRE GRUPO E PERIODO DE INICIO DE FUNCIONAMENTO DE CURSO DE GRADUAÇAO EM GEOLOGIA, CONTROLANDO PELO NIVEL DE CONTRATAÇAO - 1980*

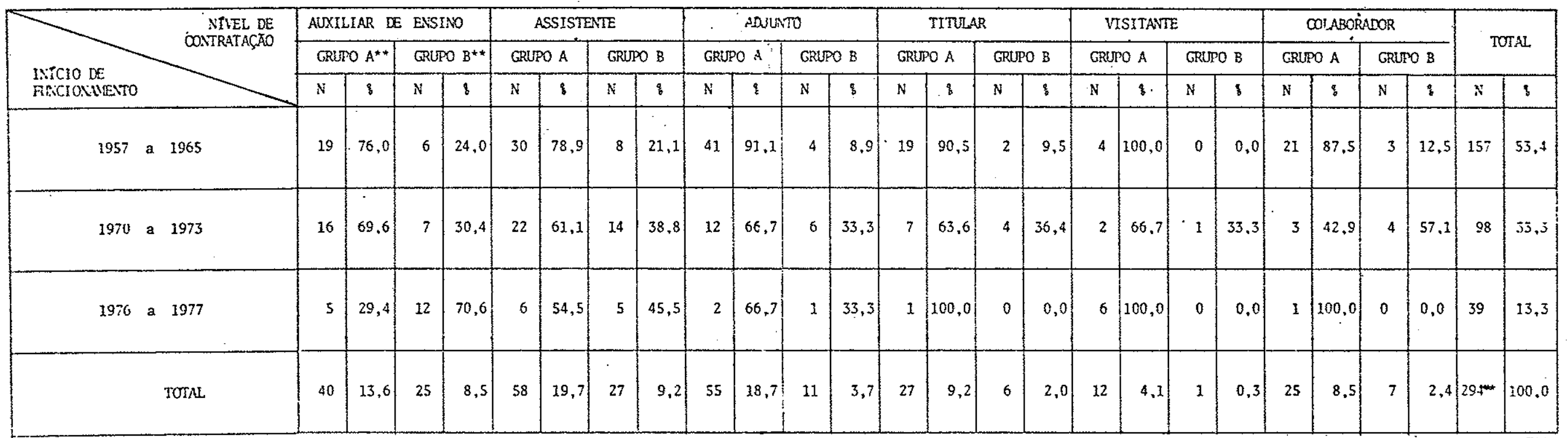

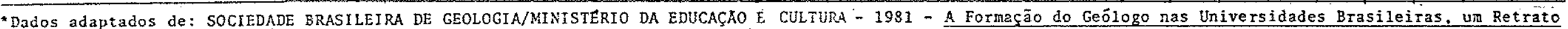
de Duas Decacas: MEC. Brasília, 209 pp.

*GRupo A: Professores que desenvolvem pesquisa

GRUTO B: Professores que năo desenvolvem pesquisa

$\cdots$ total de professores não atingiu o total da amostra porque alguras não respcnceram acerca de seu nível de contratação. 
vantagem do Grupo A encontra-se no nível de contratação mais baixo (auxiliar de ensino). Nos demais, os percentuais são mui to pröximos. Aqui pode-se suspeitar da influência dos cursos de unidades particulares, ambos iniciados no segundo período (1970 a 1973), pois foi visto que neles o desenvolvimento de pesquisa está mais associado ao menor nível de contratação que aos demais.

No terceiro período ocorre inversão de per centuais na passagem de auxiliar de ensino para assistente, fi cando o desenvolvimento de pesquisa associado ao nível mais elevado. Os demais níveis de contratação apresentam valores absolutos muito pequenos, não cabendo interpretação.

Em resumo, em dois dos períodos o desenvol vimento de pesquisa parece mais favorecido aos professores de níveis de contratação mais elevados, sendo no primeiro período a partir do nivel de adjunto e no terceiro a partir do nivel de assistente. Parece ocorrer o conträrio no segundo periodo, em que o desenvolvimento de pesquisa é mais favorecido no menor nível de contratação.

E possivel entender melhor o segundo perío do examinando a mesma relação em discussão na subamostra de professores das unidades federais (TABELA IV-17).

De fato, observa-se alteração substancjal dos percentuais somente no segundo período, em que agora o de senvolvimento de pesquisa parece mais favorecído nos níveis de adjunto e titular. (2)

IV. $2.4-$ Titulo Obtido

$\begin{aligned} \text { IV.2.4a }- & \text { Título Obtido e Tipo de Unidade Universitâa } \\ & \text { ría }\end{aligned}$

A TABELA IV-18 apresenta a influência do

(2) As tabelas de dupla e tripla entrada que estabelecem rela ções entre variäveis na subamostra de Unidades Iniversitâ rias federais, e que não foram utilizadas neste Capítulo, são apresentadas no ANEXO 3 deste trabalho. 
TABELA IV -17

RELAÇÃO ENTRE GRUPO E PERIODO DE INICIO DE FUNCIONAMENTO DE CURSO DE GRADUAÇAO EM GEOLOGIA, CONTROLANDO PELO NIVEL DE CONTRATAÇAO, NA SUBAMOSTRA DE PROFESSORES DAS UNIDADES UNIVERSITARIAS FEDERAIS - 1980*

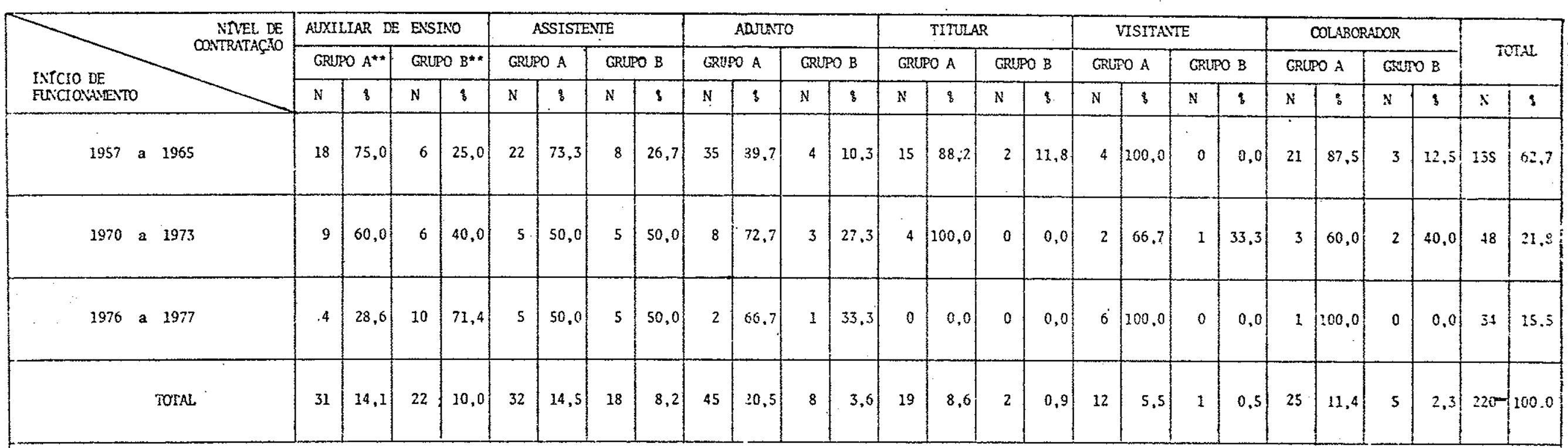

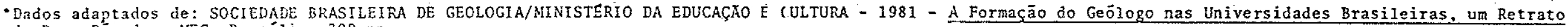
de Duas Décadas. MEC. Brasília, 209 pp.

- GRuro a: professores que desenvolvem pesquisa

GRupo B: protessores que não desenvol vem pesquisa

* o total de professores não atingiu o total da subanostra porque alguns não responderam acerca de seu nivel de contratação. 
TABELA IV-18

RELAÇÃO ENTRE GRUPO E TIPO DE UNIDADE UNIVERSITARIA, CONTROLANDO PELO TITULO OBTIDO - 1980*

\begin{tabular}{|c|c|c|c|c|c|c|c|c|c|c|c|c|c|c|c|c|c|c|}
\hline \multirow{3}{*}{$\begin{array}{l}\text { TIPO DE UNI DADE } \\
\text { UNIVERSITKRIA }\end{array}$} & \multicolumn{4}{|c|}{ BACHAREL OU LICENCIADO } & \multicolumn{4}{|c|}{ MESTRE } & \multicolumn{4}{|c|}{ DOUTOR } & \multicolumn{4}{|c|}{ LIVRE-DOCENTE } & \multirow{2}{*}{\multicolumn{2}{|c|}{ TOTAL }} \\
\hline & \multicolumn{2}{|c|}{ GRUPO $A^{* *}$} & \multicolumn{2}{|c|}{ GRUPO $B^{* *}$} & \multicolumn{2}{|c|}{ GRUPO A } & \multicolumn{2}{|c|}{ GRUPO B } & \multicolumn{2}{|c|}{ GRUPO A } & \multicolumn{2}{|c|}{ GRUPO B } & \multicolumn{2}{|c|}{ GRUPO A } & \multicolumn{2}{|c|}{ GRUPO B } & & \\
\hline & $\mathrm{N}$ & $\%$ & N & $\frac{\circ}{5}$ & $\mathrm{~N}$ & $\stackrel{0}{0}$ & $N$ & $\because$ & $\mathrm{N}$ & $\frac{\circ}{0}$ & $\mathrm{~N}$ & $\%$ & $\mathrm{~N}$ & $\%$ & $\mathrm{~N}$ & $\%$ & $\mathrm{~N}$ & $\because$ \\
\hline FEDERAL & 50 & 59,5 & 34 & 40,5 & 59 & 78,7 & 16 & 21,3 & 49 & 92,5 & 4 & 7,5 & 7 & 87,5 & 1 & 12,5 & 220 & 74,8 \\
\hline ESTADUAL & 5 & 71,4 & 2 & 28,6 & 11 & 91,7 & 1 & 8,3 & 10 & 90,9 & 1 & 9,1 & 14 & 93,3 & 1 & 6,7 . & 45 & 15,3 \\
\hline PARTICULAR & 7 & 38,9 & 11 & 61,1 & 6 & 60,0 & 4 & 40,0 & 0 & 0,0 & 1 & 100,0 & 0 & 0,0 & 0 & 0,0 & 29 & 9,9 \\
\hline TOTAL & 62 & 21,1 & 47 & 16,0 & 76 & 25,9 & 21 & 7,1 & 59 & 20,1 & $6^{\circ}$ & 2,0 & 21 & 7,1 & 2 & 0,7 & 294 & 100,0 \\
\hline
\end{tabular}

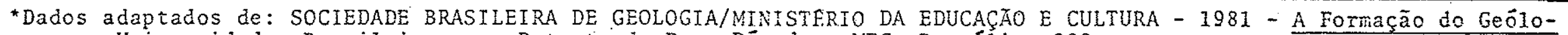
go nas Universidades Brasileiras, um Retrato de Duas Décadas. MEC, Brasília, 209 pp.

**GRUPO A: Professores que desenvolvem pesquisa

GRUPO B: Professores que não desenvolvem pesquisa

***0 tota1 de professores não atingiu o total da amostra porque alguns não responderam acerca de seu título. 
título obtido na relação entre grupo e tipo de Unidade Univer sitäria.

A exceção das categorias de graduado (bachare1 ou 1icenciado) e doutor, ambas nas unidades particulares, ocorre predomínio do Grupo A em todas as situações.

Nas unidades federais a vantagem do Grupo A aumenta de "graduado" para "mestre" e deste para "doutor". Ocorre diminuição dessa vantagem de "doutor" a "1ivre-docen te". Nas unidades estaduais verifica-se somente o primeiro au mento, estabilizando-se as porcentagens a partir do título de mestre.

Nas unidades particulares ocorre inversão de porcentagens de "graduado" para "mestre", com passagem de predominio do Grupo B para o Grupo A, embora deva-se registrar que os valores absolutos são pequenos na categoria de mestre. A categoria de doutor não pode ser considerada nas unidades particulares por haver apenas um representante.

Portanto, em todos os tipos de Unidade Uni versitäria o desenvolvimento de pesquisa parece mais favoreci do aos professores mais titulados. Nas unidades federais a as sociação mais forte com desenvolvimento de pesquisa ë atingida com o titulo de doutor ou 1ivre-docente. Nas demais unidades (estaduais e particulares), essa associação jä $\vec{e}$ alcançada com o titulo de mestre.

IV.2.4b - Titulo obtido e periodo de Início de Funcionamento de Curso de Geologia

A influência do título obtido, na relação entre grupo e curso, segundo seu período de início de funcionamento, é apresentada na TABELA IV-19.

observa-se que nos três períodos o maior predominio do Grupo A situa-se entre os professores com titulo de doutor ou Iivre-docente. Na categoria de mestre, o predomínio do Grupo A tambëm ê elevado nos dois primeiros períodos, ocorrendo equivalência entre os Grupos A e B no terceiro período. Entre os graduados, o Grupo A predomina somente nopri meiro período, equiparando-se ao Grupo B no segundo e sendo 
TABELA IV-19

RELAÇAO ENTRE GRUPO E PERIODO DE INICIO DE FUNCIONAMENTO DE CURSO DE GRADUAÇAO EM GEOLOGIA, CONTROLANDO PELO TITULO OBTIDO - 1980*

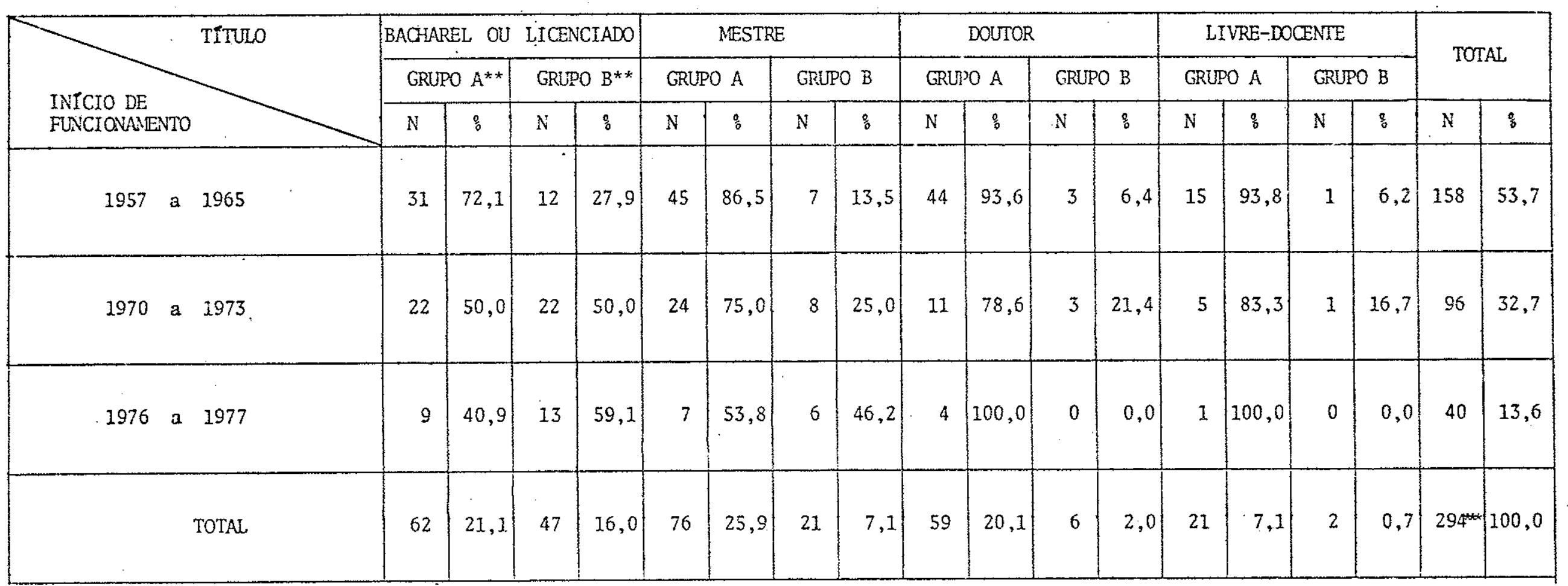

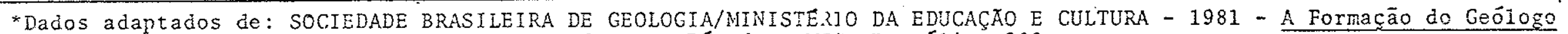
nas Universidades Brasileiras, um Retrato de Duas Décadas. MaC, Brasilia, 209 pp.

* GRUPO A: Processores que desenvolvem pesquisa

GRUPO B: Professores que não desenvolvem pesquisa

** O total de professores não atingiu o total da amostra porque iguns não responderam acerca dé seu título. 
sobrepujado por ele no terceiro período.

Em sintese, o desenvolvimento de pesquisa parece mais favorecido aos professores com título de doutor ou livre-docente nos cursos de qualquer periodo. Entre os que possuem o título de mestre a situação é pouco favorävel ape nas nos cursos de início mais recente (1976 a 1977). Para os apenas graduados o desenvolvimento de pesquisa somente $\vec{e}$ favo recido nos cursos mais antigos.

IV.2.5 - Tempo de Serviço

IV.2.5a - Tempo de Serviço e Tipo de Unidade Universitāiria

A TABELA IV-20 apresenta a influência do tempo de serviço na relação entre grupo e tipo de unjidade Uni versitária.

Nas unidades püblicas o Grupo A predomina em todas as categorias, sendo que o maior predomínio encontra -se nos intervalos superiores a dois anos de serviço. E notävel que nas unidades estaduais desenvolvem pesquisa todos os professores entrevistados com seis anos ou mais de servico.

Nas unidades particulares não há qualquer

destaque, sendo as porcentagens dos Grupos A e B iguais ou mui. to proximas em todas as categorias de intervalo estabelecidas. Portanto, nas unidades püblicas o desenvol. vimento de pesquisa parece mais favorecido depois de dois anos de serviço e nas unidades particulares não hâ, aparentemente, influência do tempo de serviço dos professores na realização ou não de pesquisa.

IV.2.5b - Tempo de Serviço e Período de Início de Fun cionamento de Curso de Geologia

$\mathrm{Na}$ TABELA IV-21 pode-se examinar a influên cia do tempo de serviço na relação entre grupo e Curso de Geo logia, segundo seu período de início de funcionamento. 
TABELA IV-20

RELAÇÃO ENTRE GRUPO E TTPO DE UNIDADE UNIVERSTTARIA, CONTROLANDO PELO TEMPO DE SERVIÇO - I980*

\begin{tabular}{|c|c|c|c|c|c|c|c|c|c|c|c|c|c|c|c|c|c|c|c|c|c|c|}
\hline \multirow{3}{*}{$\begin{array}{l}\text { TEMPO DE } \\
\text { SERVIÇO } \\
\text { TIPO DE UNIDADE } \\
\text { UNIVERSITARIA }\end{array}$} & \multicolumn{4}{|c|}{ MENOS DE 2 ANOS } & \multicolumn{4}{|c|}{2 a 5 ANOS } & \multicolumn{4}{|c|}{6 a 9 ANOS } & \multicolumn{4}{|c|}{10 a 13 ANOS } & \multicolumn{4}{|c|}{14 ANOS OU MAIS } & \multirow{2}{*}{\multicolumn{2}{|c|}{ TOTAL }} \\
\hline & \multicolumn{2}{|c|}{ GRUPO A** } & \multicolumn{2}{|c|}{ GRUPO B** } & \multicolumn{2}{|c|}{ GRUPO A } & \multicolumn{2}{|c|}{ GRUPO B } & \multicolumn{2}{|c|}{ GRUPO A } & \multicolumn{2}{|c|}{ GRUPO B } & \multicolumn{2}{|c|}{ GRUPO A } & \multicolumn{2}{|c|}{ GRUPO B } & \multicolumn{2}{|c|}{ GRUPO A } & \multicolumn{2}{|c|}{ GRUPO B } & & \\
\hline & N & s & N & $\frac{\circ}{6}$ & $\mathrm{~N}$ & $:$ & $N$ & $\because$ & $N$ & $\because$ & $\mathrm{N}$ & 8 & N & $:$ & N & 8 & $\mathrm{~N}$ & $\vdots$ & $\mathrm{N}$ & $\xi$ & $\mathrm{N}$ & $\frac{8}{8}$ \\
\hline FEDERAL & 28 & 56,0 & 22 & 44,0 & 52 & 81,3 & 12 & 18,8 & 32 & 84,2 & 6 & 15,8 & 25 & 83,3 & 5 & 16,7 & 29 & 72,5 & 11 & 27,5 & 222 & 74,7 \\
\hline ESTADUAL & 5 & 62,5 & 3 & 37,5 & 10 & 76,9 & 3 & 23,1 & 8 & 100,0 & 0 & 0,0 & 3 & 100,0 & 0 & 0,0 & 14 & 100,0 & 0 & 0,0 & 46 & 15,5 \\
\hline PARTICUI.AR & 4 & 40,0 & 6 & 60,0 & 6 & 50,0 & 6 & 50,0 & 3 & 42,9 & 4 & 57,1 & 0 & 0,0 & 0 & 0,0 & 0 & 0,0 & 0 & 0,0 & 29 & 9,8 \\
\hline TOTAL & 37 & 12,5 & 31 & 10,4 & 68 & 22,9 & 21 & 7,1 & 43 & 14,5 & 10 & 3,4 & 28 & 9,4 & 5 & 1,7 & 43 & 14,5 & 11 & 3,7 & 297 & 100,0 \\
\hline
\end{tabular}

*Dados adaptados de: SOCIEDADE BRASILEIRA DE GEOLOGIA/MINIST:RRIO DA EDUCAÇÁ E CULTURA - 1981 - A Formação do Geólogo
nas Universidades Brasileiras, um Retrato de Duas Décadas. IAEC, Brasília, 209 pp.

* GRUPO A: Professores que desenvolvem pesquisa

GRUPO B: Professores que não desenvolvem pesquisa 
TABELA IV-2I

RELAÇÃO ENTRE GRUPO E PERIODO DE INICIO DE FUNCIONAMENTO DE CURSO DE GRADUAÇAO EM GEOLOGIA, CONTROLANDO PELO TEMPO DE SERVICOO NA UNIDADE UNIVERSITARIA - $1980^{*}$

\begin{tabular}{|c|c|c|c|c|c|c|c|c|c|c|c|c|c|c|c|c|c|c|c|c|c|c|}
\hline \multirow{3}{*}{$\begin{array}{l}\text { TEMPO DE } \\
\text { SERVICO } \\
\text { INICIO DE } \\
\text { FUNCIONAMENTO }\end{array}$} & \multicolumn{4}{|c|}{ MENOS DE 2 ANOS } & \multicolumn{4}{|c|}{2 a 5 ANOS } & \multicolumn{4}{|c|}{6 a 9 ANOS } & \multicolumn{4}{|c|}{10 a 13 ANOS } & \multicolumn{4}{|c|}{14 ANOS OU MAIS } & \multirow{2}{*}{\multicolumn{2}{|c|}{ TOTAL }} \\
\hline & \multicolumn{2}{|c|}{ GRUPO $A^{\star *}$} & \multicolumn{2}{|c|}{ GRUPO $B^{* \star}$} & \multicolumn{2}{|c|}{ GRUPO A } & \multicolumn{2}{|c|}{ GRUPO B } & \multicolumn{2}{|c|}{ GRUPO A } & \multicolumn{2}{|c|}{ GRUPO B } & \multicolumn{2}{|c|}{ GRUPO A } & \multicolumn{2}{|c|}{ GRUPO B } & \multicolumn{2}{|c|}{ GRUPO A } & \multicolumn{2}{|c|}{ GRUPO B } & & \\
\hline & $\mathrm{N}$ & $\because$ & $\mathrm{N}$ & : & $\mathrm{N}$ & $\%$ & $\mathrm{~N}$ & $:$ & $\mathrm{N}$ & $\because$ & $\mathrm{N}$ & $\%$ & $\mathrm{~N}$ & $\frac{0}{5}$ & $\mathrm{~N}$ & $\frac{9}{8}$ & $\mathrm{~N}$ & $\%$ & $\mathrm{~N}$ & $\because$ & $\mathrm{N}$ & $\$$ \\
\hline 1957 a 1965 & 14 & 70,0 & 6 & 30,0 & 40 & 95,2 & 2 & 4,8 & 23 & 82,1 & 5 & 17,9 & 24 & 88,9 & 3 & $11 ; 1$ & 35 & 83,3 & 7 & 16,7 & 159. & 53,5 \\
\hline 1970 a 1973 & 15 & 55,6 & 12 & 44,4 & 21 & 60,0 & 14 & 40,0 & 16 & 76,2 & 5 & 23,8 & 4 & 66,7 & 2 & 33,3 & 6 & 66,7 & 3 & 33,3 & 98 & 33,0 \\
\hline 1976 a 1977 & 8 & 38,1 & 13 & 61,9 & 7 & 58,3 & 5 & 41,7 & 4 & 100,0 & 0 & 0,0 & 0 & 0,0 & 0 & 0,0 & 2 & 66,7 & 1 & 33,3 & 40 & 13,5 \\
\hline TOTAL. & 37 & 12,5 & 31 & 10,4 & 68 & 22,9 & 21 & 7,1 & 43 & 14,5 & 10 & 3,4 & 28 & 9,4 & 5 & 1,7 & 43 & 14,5 & 11 & 3,7 & 297 & 100,0 \\
\hline
\end{tabular}

* Dados adaptados de: SOCIEDADE BRASILEIRA DE GEOLOGIA/MINISTERJ O DA EDUCAÇAO E CULTURA - 1981 - A Formação do Geólogo nas Universidades Brasileiras, um Retrato de Duas Dëcadas. MEC, Brasilia, 209 pp.

* GRUPO A: professores que desenvolvem pesquisa

GRUPO B: Professores que não desenvolvem pesquisa 
o Grupo A somente é sobrepujado pelo Grupo $B$ entre os professores dos cursos mais recentes (1976 a 1977) com até dois anos de serviço.

Nos cursos do primeiro período (1957 a 1965) - maior predomínio do Grupo A ocorre logo no intervalo de 2 a 5 anos, decrescendo a seguir e estabilizando-se nos demais in tervalos.

No segundo período, o predomínio do Grupo A aumenta até o intervalo de 6 a 9 anos e diminui depois, mas esta queda não fica bem caracterizada em razão dos pequenos valores absolutos envolvidos.

No ûltimo período o Grupo A é inferior ao Grupo B no intervalo menor (até 2 anos), maior que o Grupo B no intervalo "2 a 5 anos" e absoluto em "6 a 9 anos". Os de mais intervalos estão insuficientemente representados.

Em resumo, nos cursos do primeiro período o desenvolvimento de pesquisa parece favorecido em qualquer intervalo, mas principalmente nos superiores a dois anos. Nos cursos dos segundo e terceiro períodos, o maior favorecimento ao desenvolvimento de pesquisa encontra-se no intervalo "6 a 9 anos".

IV.3 - PRINCIPAIS TENDENCIAS DE GRUPO

As relações dimensionadas entre a variável dependente (grupo) e as demais variāveis permitem estabelecer algumas tendências. Em primeiro lugar, são estabelecidas tendências do Grupo A conforme o tipo de Unidade Universitäria a que o professor está vinculado e, a seguir, conforme o período de início de funcionamento do Curso de Geologia. Finalmente, iden tifica-se o representante típico de cada Grupo A e B.

IV.3.1 - Tendências Conforme Tipo de Unidade Universitäria

Hä diferenças marcantes quanto a tendências dos pro- 
fessores que desenvolvem pesquisa entre Unidades Universita rias püblicas (federais e estaduais) e particulares. Antes de mais nada, o desenvolvimento de pesquisa apresenta-se muito mais associado às unidades püblicas que às particulares.

Os professores do Grupo A (professores que desenvolvem pesquisa) vinculados às Unidades Universitärias püblicas, tendem a:

- encontrar-se no regime de tempo integral (40 horas semanais) ou dedicação exclusiva;

- não exercer atividades profissionais externas à uni dade Universitäria;

- encontrar-se no nível de professor assistente ou mais elevado;

- ter tempo de serviço superior a dois anos.

os professores do Grupo A (professores que desenvo1vem pesquisa) vinculados às Unidades Universitárias particula res, tendem a:

- exercer atividades profissionais externas à Unidade Universitäria;

- encontrar-se no nível de auxiliar de ensino ou pro fessor assistente.

Quanto ao regime de trabalho e tempo de serviço, são variäveis que parecem não influir quanto ao desenvolvimento da pesquisa nas Unidades Universitärias particulares.

A ünica semelhança observada refere-se a título obti do, pois tanto nas Unidades Universitärias públicas quanto nas particulares, os professores do Grupo A tendem a possuir o título de mestre ou mais elevado.

\section{IV.3.2 - Tendências Conforme Periodo de Início de Funcionamen to de Curso de Geologia}

Considerando que as Unidades Universitärias püblicas somam 17, num total de 19 unidades, obviamente sua influência é predominante ou absoluta nos períodos estabelecidos para aná lise. Chegou-se a notar por vezes a influência das unidades particulares no segundo período (1970 a 1973), pois foi nele 
que ambas iniciaram os respectivos Cursos de Geologia.

o desenvolvimento de pesquisa encontra-se efetivamen te mais associado aos Cursos do primeiro período (1957 a 1965) e menos aos do terceiro (1976 a 1977), ficando o segundo perîodo (1970 a 1973 ) em posição intermediäria.

Os professores do Grupo A tendem a:

- possuir título mais elevado quanto mais recente o período de inicio de funcionamento do Curso;

- encontrar-se em regime de tempo integral ou dedicação ex clusiva nos três pexíodos, mas principalmente nas unidades Universitärias correspondentes ao primeiro período. A tendência do Grupo A para esses regimes de trabalho diminui no sentido dos cursos mais recentes;

- não exercer atividades profissionais externas, exceto nas unidades correspondentes ao terceiro periodo. Nestas os Grupos A e B se equivalem;

- apresentar tempo de serviço maior no segundo e terceiro períodos em relação ao primeiro período.

\section{IV.3.3 - Conjunto de Tendências dos Professores dos Grupos A e B}

Em função dos resultados examinados, é possível considerar representante típico do Grupo A o professor com as se guintes características:

- pertence a Unidade Universitäria pública cujo curso de Geologia teve início de 1957 a 1965 ;

- é contratado no regime de tempo integral ou dedicação ex clusiva ;

- não exerce atividades profissionais externas à sua Unida de Universitāria;

- encontra-se no nível de professor assistente ou mais ele vado;

- possui o título de mestre ou mais elevado;

- tem tempo de serviço superior a 2 anos.

o representante típico do Grupo B, por sua vez, apre senta as seguintes características: 
- pertence a Unidade Universitária particular,ou a unidade püblica cujo Curso de Geologia teve início em 1976 ou 1977;

- é contratado no regime de tempo parcial ou hora-aula;

- exerce atividades profissionais externas à sua Unidade Universitâria;

- possui apenas o título de bacharel ou licenciado;

- tem tempo de serviço inferior a dois anos.

As tendências verificadas confirmam a hipótese deque as possibilidades de desenvolvimento de pesquisa por parte dos professores dos Cursos de Graduação em Geologia estão associadas a diversas variāveis funcionais e institucionais. 


\section{A P I T U L $O$ O}

DESCRICAOO E ANALISE DOS RESULTADOS ( $2 \stackrel{a}{-}$ PARTE)

Este Capitulo inicia com a descrição e anālise dos resultados referentes a cada procedimento de ensino. A seguir, descreve-se a classificação dos procedimentos segundo posturas metodológicas mais amplas, denominadas característjcas me todolögicas e, finalmente, analisa-se os resultados à luz des sas características.

V.1 - DESCRIÇAO E ANALISE DOS PROCEDIMENTOS DE ENSINO

Os resultados referentes aos 18 procedimentos de ensino constantes no Questionärio do Professor estão apresentados na forma de tabelas de contingência de dupla entrada, con tendo medidas relativas de frequência quanto à adoção desses procedimentos pelos Grupos A (professores que desenvolvem pes quisa) e B (professores que não desenvolvem pesquisa). Á cada tabela corresponde um histograma para possibilitar comparação visual entre as frequências dos grupos em cada procedimento.

A determinação de significância de diferenças entre os Grupos A e B e feita atraves da prova estatistica do $x^{2}$. Em alguns procedimentos, a presença de frequência com valores nulos ou muito pequenos levou à combinação de categorias adja centes para permitir a aplicação da prova estatística.

Nos casos em que a aplicação da prova estatística re sulta em aceitação da hipótese nula, os valores de frequência dos Grupos A e B são somados, obtendo-se uma ünica tendência para a amostra de professores. Nos procedimentos em que a hipótese nula ê rejeitada, distingue-se as tendências dos Grupos A e B. 
V.1.1 - Procedimento de Ensino n० 1: "Costumo dar a major par te de minhas aulas de forma expositiva"

Como se depreende da observação da TABELA V-1 e tamm bëm do HISTOGRAMA correspondente, há predominância das respos tas "sempre" e "às vezes" para o procedimento de $n^{\circ} 1$, tanto para o Grupo A (professores que desenvolvem pesquisa) quanto para o Grupo B (professores que não desenvolvem pesquisa). Per cebe-se também que em ambos os Grupos A e B, a incidência das respostas "sempre" estā em torno de 50,0\%. Assim, a quase totalidade dos professores costuma dar suas aulas "sempre" ou "às vezes" de forma expositiva. Apenas uma minoria dos docentes nunca procede dessa maneira.

Aplicando-se a prova do $x^{2}$, obtem-se o valor de 3,16 . Para $g l=2$ e $\alpha=0,05, \mathrm{H}_{\mathrm{O}} \overrightarrow{\mathrm{e}}$ aceita,podendo-se afirmar que os Grupos A e B são equivalentes em relação ao procedimento em exame.

Pode-se consequentemente somar os valores absolutos de cada alternativa dos Grupos A.e B.

\begin{tabular}{|l|r|r|}
\cline { 2 - 3 } \multicolumn{1}{c|}{} & \multicolumn{2}{c|}{ TOTAL } \\
\cline { 2 - 3 } \multicolumn{1}{c|}{} & N & \multicolumn{1}{c|}{$\%$} \\
\hline SEMPRE & 147 & 49,5 \\
\hline AS VEZES & 128 & 43,1 \\
\hline NUNCA & 18 & 6,1 \\
\hline $\begin{array}{l}\text { NAO SABE OU } \\
\text { NAO RESPONDEU }\end{array}$ & 4 & 1,3 \\
\hline TOTAL & 297 & 100,0 \\
\hline
\end{tabular}

Verifica-se, portanto, tendência dos professores a desenvolverem suas disciplinas principalmente atravës de aulas expositivas, pois quase metade deles o faz "sempre" e $43,1 \%$ faz "às vezes". 
TABELA $V-1$

FREQUENCIA DO PROCEDIMENTO: "COSTUMO DAR A MAIOR PARTE DE MINHAS AULAS DE FORMA EXPOSITIVA" NOS GRUPOS A E B - 1980*

\begin{tabular}{|l|c|c|c|c|}
\hline \multirow{2}{*}{$\begin{array}{l}\text { FREQUENCIA DO } \\
\text { PROCEDIMENTO }\end{array}$} & \multicolumn{2}{|c|}{ GRUPO A** } & \multicolumn{2}{|c|}{ GRUPO B** } \\
\cline { 2 - 5 } & $\mathrm{N}$ & $\%$ & $\mathrm{~N}$ & $\%$ \\
\hline SEMPRE & 105 & 47,9 & 42 & 53,8 \\
\hline AS VEZES & 100 & 45,7 & 28 & 35,9 \\
\hline NUNCA & 11 & 5,0 & 7 & 9,0 \\
\hline $\begin{array}{l}\text { NAO SABE OU } \\
\text { NAO RESPONDEU }\end{array}$ & 3 & 1,4 & 1 & 1,3 \\
\hline TOTAL & 219 & 100,0 & 78 & 100,0 \\
\hline
\end{tabular}

*Dados adaptados de: SOCIEDADE BRASILEIRA DE GEOLOGIA/MINISTERIO DA EDUCAÇAO E CULTURA - 1981 - A Formação do Geólogo nas Universidades Brasileiras, um Retrato de Duas Dëcadas. MEC, Brasilia, 209 pp.

**GRUPO A: Professores que desenvolvem pesquisa

GRUPO B: Professores que não desenvolvem pesquisa

HISTOGRAMA V-1

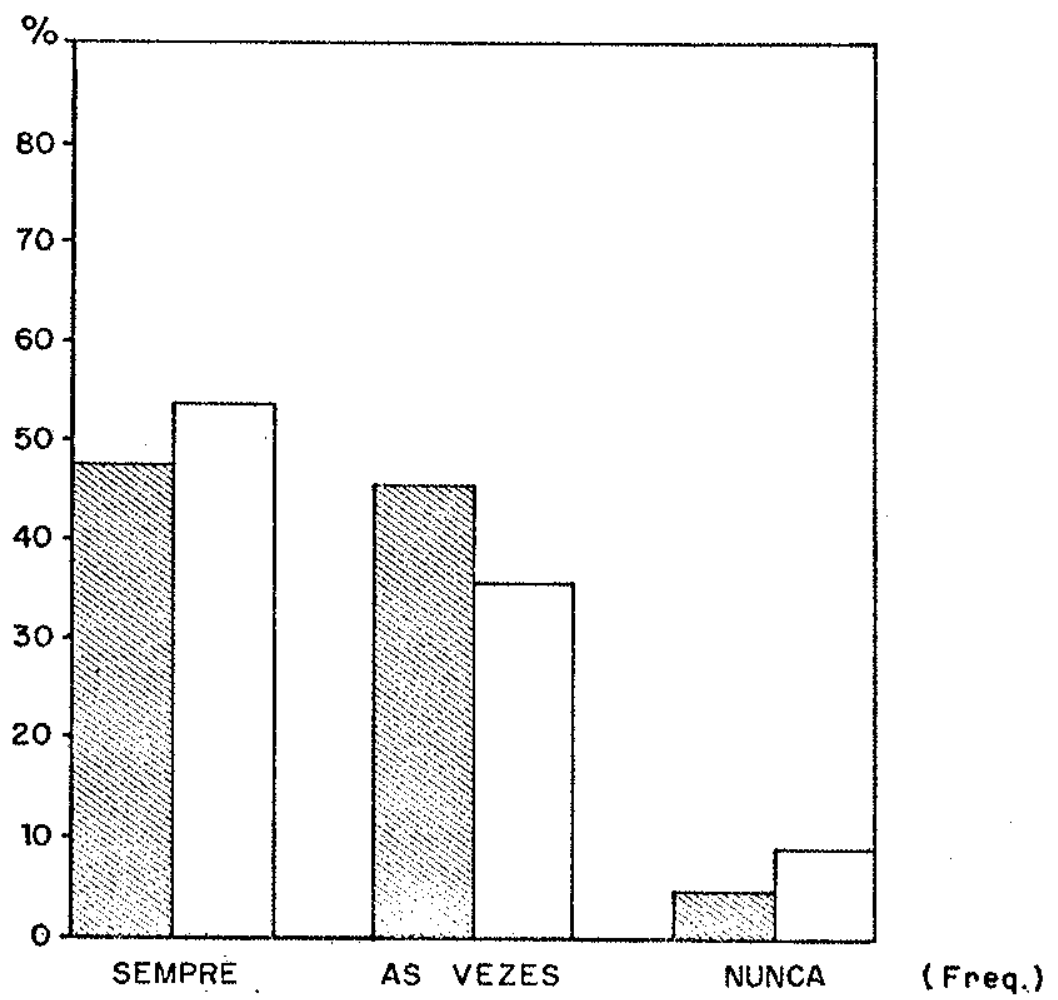

GRUPO A: Professores que desenvolvem pesquisa GRUPO B: Professores que não desenvolvem pesquisa 
V.1.2 - Procedimento de Ensino n8 2: "Valorizo o conhecimento de detalhes ou informações específicas sobre o conteu do de minha disciplina"

Neste caso, predominam as respostas "às vezes" e"sem pre". As porcentagens de "às vezes" são próximas de 50,0\% em ambos os grupos enquanto as respostas "sempre", tambëm nos dois grupos, situam-se pröximas de 33,0\% (TABELA e HISTOGRAMA $(-2)$.

A aplicação da prova do $x^{2}$ resultou na obtenção do valor 2,04. Para $g l=2$ e $\alpha=0,05, H_{0} \vec{e}$ aceita, sendo os Grupos A e B equivalentes quanto ao procedimento em questão. o resultado obtido permite somar os valores absolu tos das frequências dos Grupos A e B.

\begin{tabular}{|l|c|c|}
\hline \multirow{2}{*}{$\begin{array}{l}\text { FREQUENCTA DO } \\
\text { PROCEDIMENTO }\end{array}$} & \multicolumn{2}{|c|}{ TOTAL } \\
\cline { 2 - 3 } & $\mathrm{N}$ & $\%$ \\
\hline SEMPRE & 95 & 32,0 \\
\hline AS VEZES & 158 & 53,2 \\
\hline NUNCA & 22 & 7,4 \\
\hline $\begin{array}{l}\text { NAO SABE OU } \\
\text { NAO RESPONDEU }\end{array}$ & 22 & 7,4 \\
\hline TOTAL & 297 & 100,0 \\
\hline
\end{tabular}

Verifica-se que hâ tendência dos professores valorizarem o conhecimento de detalhes em suas respectivas discipli nas, mas nota-se que mais da metade entre eles adota tal procedimento somente "às vezes". 
TABELA $V-2$

FREQUENCIA DO PROCEDIMENTO: "VALORIZO O CONHECIMENTO DE DETALHES OU INFORMAÇOES ESPECTFICAS SOBRE O CONTEODO DE MINHA DISCIPLINA" NOS GRUPOS A E B - 1980*

\begin{tabular}{|l|c|c|c|c|}
\hline $\begin{array}{l}\text { FREQUENCIA DO } \\
\text { PROCEDIMENTO }\end{array}$ & \multicolumn{2}{|c|}{ GRUPO A** } & \multicolumn{2}{c|}{ GRUPO B** } \\
\hline N & 68 & 31,1 & 27 & 34,6 \\
\hline SEMPRE & 117 & 53,4 & 41 & 52,6 \\
\hline AS VEZES & 19 & 8,7 & 3 & 3,8 \\
\hline NUNCA & 15 & 6,8 & 7 & 9,0 \\
\hline $\begin{array}{r}\text { NAO SABE OU } \\
\text { NAO RESPONDEU }\end{array}$ & 219 & 100,0 & 78 & 100,0 \\
\hline TOTAL & & & & \multicolumn{1}{c|}{$\mathrm{B}^{*}$} \\
\hline
\end{tabular}

*Dados adaptados de: SOCIEDADE BRASILEIRA DE GEOLOGIA/MINISTERIO DA EDUCAÇAO E CULTURA - 1981 - A Formação do Geölogo nas Universidades Brasileiras, um Retrato de Duas Décadas. MEC, Brasilia, 209 pp.

**GRUPO A: professores que desenvolvem pesquisa

GRUPO B: Professores que não desenvolvem pesquisa

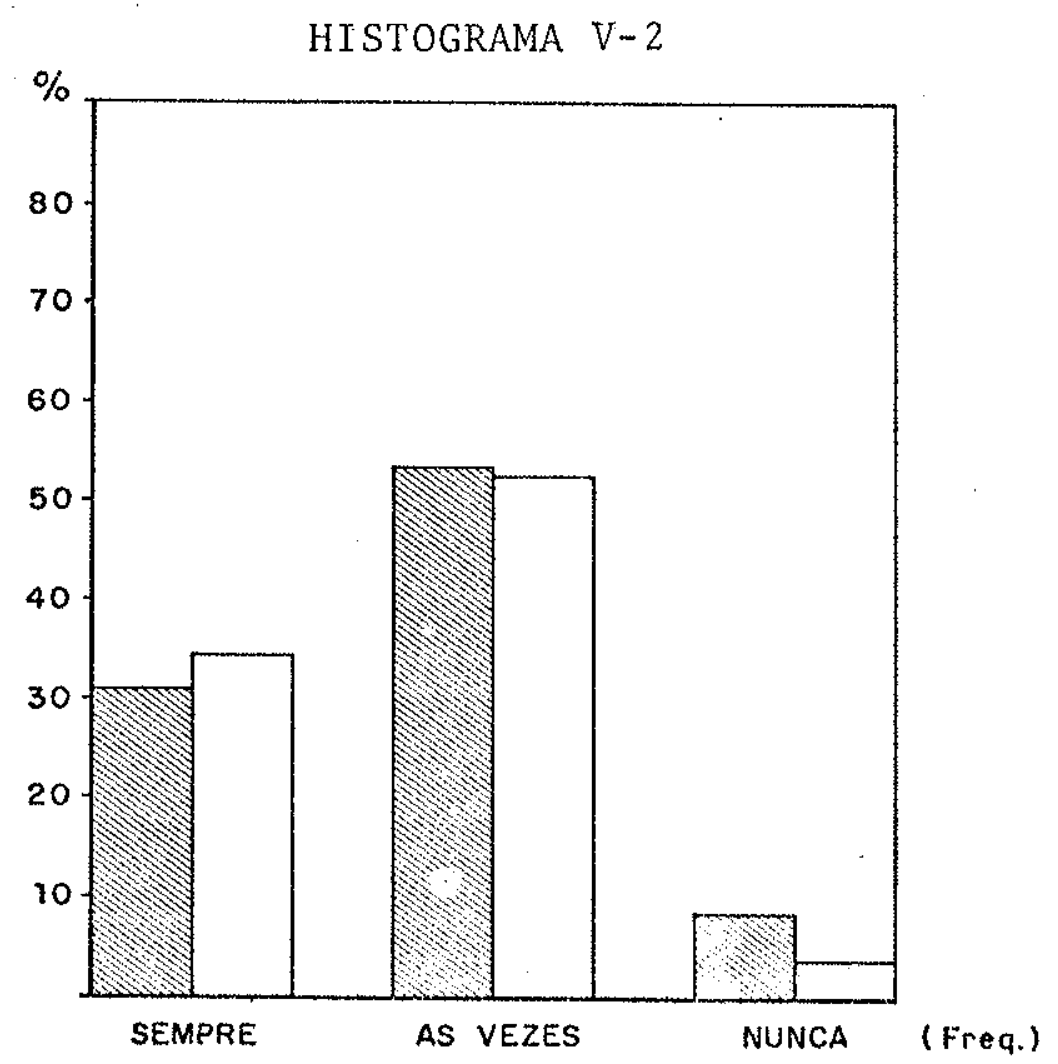

GRUPO A: Professores que desenvolvem pesquisa GRUPO B: Professores que não desenvolvem pesquisa 
V.1.3 - Procedimento de Ensino n' 3: "Apresento a matéria como um corpo de conhecimentos acabado"

Neste procedimento predominam as respostas "nunca", sendo que as porcentagens para os dois grupos situam-se em torno de $60,0 \%$ (TABELA e HTSTOGRAMA V-3).

A frequência de respostas "às vezes" apresenta-se me nor que as respostas "nunca" e, em ambos os Grupos, seu valor situamse em torno de $18,0 \%$. Poucos afirmam apresentar a materia "como um corpo de conhecimentos acabado". Vale ressaltar que cerca de $15,0 \%$ dos docentes não responderam à questão ou não souberam respondê-la.

Aplicando-se a prova do $x^{2}$ obteve-se o valor 3,20 . Pa ra $g l=2$ e $\alpha=0,05, H_{0} \vec{e}$ aceita, o que permite afirmar a eqüivalência dos Grupos $A$ e $B$ em relaçäo ao procedimento $n^{\circ} 3$ e, por conseguinte, reunir os valores de cada frequência.

\begin{tabular}{|l|c|c|}
\hline \multirow{2}{*}{$\begin{array}{l}\text { FREQUENCIA DO } \\
\text { PROCEDIMENTO }\end{array}$} & \multicolumn{2}{|c|}{ TOTAL } \\
\cline { 2 - 3 } & $\mathrm{N}$ & $\frac{0}{\circ}$ \\
\hline SEMPRE & 10 & 3,4 \\
\hline ȦS VEZES & 55 & 18,5 \\
\hline NUNCA & 187 & 63,0 \\
\hline $\begin{array}{l}\text { NAO SABE OU } \\
\text { NAO RESPONDEU }\end{array}$ & 45 & 15,2 \\
\hline TOTAL & 297 & 100,0 \\
\hline
\end{tabular}

Neste caso, a tendência dos professores é para nunca adotarem o procedimento, pois quase dois terços entre eles as sinalaram essa frequência. 
TABELA $\quad V-3$

FREQUENCIA DO PROCEDIMENTO: "APRESENTO A MATERIA COMO UM CORPO DE CONHECIMENTOS ACABADO" NOS GRUPOS A E B - 1980*

\begin{tabular}{|c|c|c|c|c|}
\hline \multirow{2}{*}{$\begin{array}{c}\text { FREQUENCIA DO } \\
\text { PROCEDIMENTO }\end{array}$} & \multicolumn{2}{|c|}{ GRUPO A** } & \multicolumn{2}{c|}{ GRUPO B** } \\
\cline { 2 - 5 } & $\mathrm{N}$ & $\frac{\circ}{0}$ & $\mathrm{~N}$ & $\%$ \\
\hline SEMPRE & 5 & 2,3 & 5 & 6,4 \\
\hline AS VEZES & 41 & 18,7 & 14 & 17,9 \\
\hline NUNCA & 141 & 64,4 & 46 & 59,0 \\
\hline $\begin{array}{l}\text { NAO SABE OU } \\
\text { NAO RESPONDEU }\end{array}$ & 32 & 14,6 & 13 & 16,7 \\
\hline TOTAL & 219 & 100,0 & 78 & 100,0 \\
\hline
\end{tabular}

*Dados adaptados de: SOCIEDADE BRASILEIRA DE GEOLOGIA/MINISTERTO DA EDUCAÇO E CULTURA - 1981 - A Formação do Geölogo nas Unj.versidades Brasileiras, um Retrato de Duas Décadas. MEC, Brasilia, 209 pp.

** GRUPO A: Professores que desenvolvem pesquisa

GRUPO B: Professores que näo desenvolvem pesquisa

HTSTOGRAMA V -3

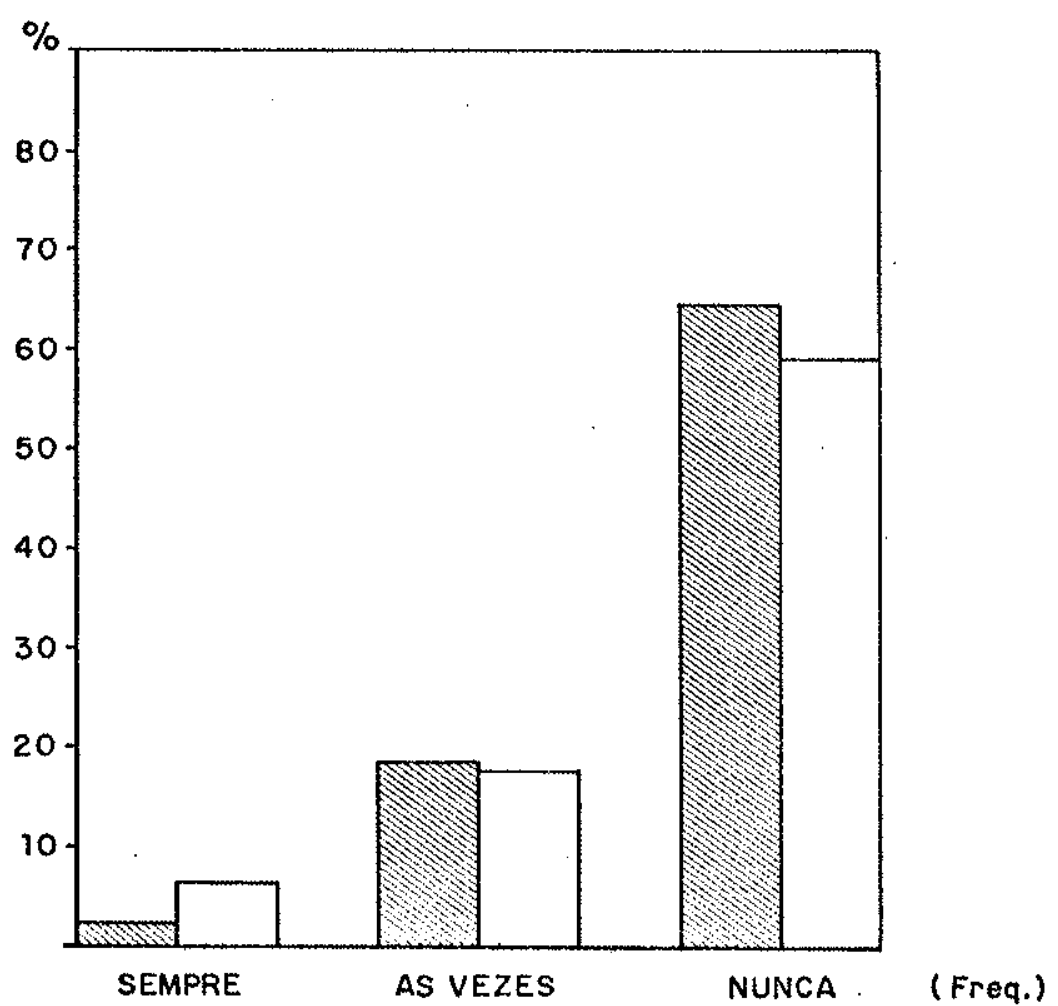

GRUPO A: Professores que desenvolvem pesquisa

GRUPO B: Professores que não desenvolvem pesquisa 
V.1.4 - Procedimento de Ensino n' 4: "Durante as aulas exposi tivas exploro as questões levantadas pelos alunos"

Em relação ao procedimento $n^{8} 4$, o total de respos tas é constituído quase integralmente pelas alternativas "sem pre" e "às vezes", totalizando, para cada um dos Grupos A eB, valores superiores a 96,0\%. Hä predomínio, nos dois Grupos, da afirmação dos professores de que sempre, durante as aulas expositivas, exploram as questões levantadas pelos alunos (TABE LA E HISTOGRAMA $V-4$ ).

Em virtude de mais de $20,0 \%$ do total de caselas conterem frequência inferior a 5 , deve-se combinar as categorias "às vezes" e "nunca" para aplicar validamente a prova do $x^{2}$. Tomada esta providência, a plicação da prova resulta no valor de 2,20. Para $g \ell=1$ e $\alpha=0,05, H_{0} \vec{e}$ aceita e, assim, os Grupos A e B podem ser considerados equivalentes quanto a este procedimento.

Somando-se as frequências dos Grupos A e B neste pro cedimento obtem-se:

\begin{tabular}{|c|c|c|}
\hline \multirow{2}{*}{$\begin{array}{l}\text { FREQUENCIA DO } \\
\text { PROCEDIMENTO }\end{array}$} & \multicolumn{2}{|c|}{ TOTAL } \\
\hline & $N$ & $\%$ \\
\hline SEMPRE & 187 & 63,0 \\
\hline AS VEZES & 101 & 34,0 \\
\hline NUNCA & 3 & 1,0 \\
\hline $\begin{array}{ll}\text { NAO } & \text { SABE OU } \\
\text { NAO } & \text { RESPONDEU }\end{array}$ & 6 & 2,0 \\
\hline TOTAL & 297 & 100,0 \\
\hline
\end{tabular}

A tendência dos professores é de explorar as questões levantadas pelos alunos, pois quase dois terços entre eles ado tam "sempre" este procedimento e um terço tambëm o adota "às vezes". 
TABELA V-4

FREQUENCIA DO PROCEDIMENTO: "DURANTE AS AULAS EXPOSTTIVAS EXPLORO AS QUESTOZS LEVANTADAS PELOS ALUNOS" NOS GRUPOS A E B - $1980^{*}$

\begin{tabular}{|l|c|c|c|c|}
\hline $\begin{array}{c}\text { FREQUENCIA DO } \\
\text { PROCEDTMENTO }\end{array}$ & \multicolumn{2}{|c|}{ GRUPO $\mathrm{A}^{* *}$} & \multicolumn{2}{c|}{ GRUPO B*\% } \\
\hline $\mathrm{N}$ & 131 & 59,8 & 56 & 71,8 \\
\hline SEMPRE & 80 & 36,5 & 21 & 26,9 \\
\hline AS VEZES & 2 & 0,9 & 1 & 1,3 \\
\hline NUNCA & 6 & 2,7 & 0 & 0,0 \\
\hline $\begin{array}{l}\text { NAO SABE OU } \\
\text { NAO RESPONDEU }\end{array}$ & 219 & 100,0 & 78 & 100,0 \\
\hline
\end{tabular}

*Dados adaptados de: SOCIEDADE BRASIILEIRA DE GEOLOGIA/MINISTERIO DA EDUCAÇAO E CULTURA - 1981 - A Formação do Geölogo nas Universidades Brasileiras, um Retrato de Duas Dëadas. MEC, Brasilia, 209 pp.

**GRUPO A: Professores que desenvolvem pesquisa

GRUPO B: Professores que não desenvolvem pesquisa

HTSTOGRAMA V-4.

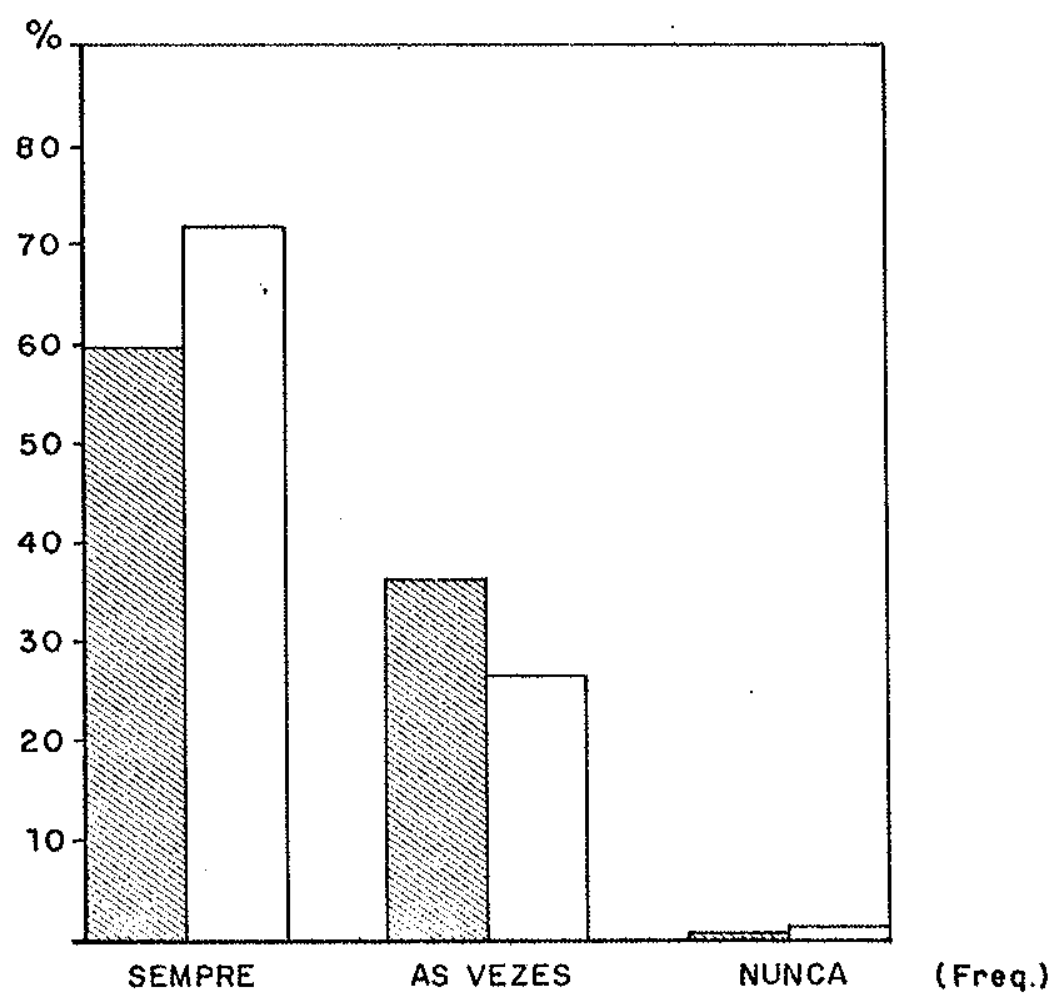

GRUPO A: Professores que desenvolvem pesquisa

GRUPO B: Professores que não desenvolvem pesquisa 
V.1.5 - procedimento de Ensino n? 5: "Estimulo os alunos a emi tirem julgamento sobre questões polêmicas"

Como no caso anterior, tambëm para este procedimento as respostas se concentram nas alternativas "sempre" e "às ve zes", totalizando, para cada um dos Grupos A e B, valores superiores a 90,0\%. Entretanto, as porcentagens de "sempre" e "às vezes" são agora bastante pröximas entre si, e com valores aproximados a 50,0\% (TABELA e HISTOGRAMA V-5).

A aplicação da prova do $X^{2}$ resulta no valor de 0,65 . Para $g \ell=2$ e $\alpha=0,05, H_{0}$ é aceita, significando que os Gru pos $A$ e $B$ são equivalentes.

Buscando caracterizar a tendéncia dos docentes neste procedimonto soma-se as frequências absolutas dos Grupos A e $B$ e monta-se o seguinte quadro:

\begin{tabular}{|c|c|c|}
\hline \multirow{2}{*}{$\begin{array}{l}\text { FREQUENCIA DO } \\
\text { PROCEDIMENTO }\end{array}$} & \multicolumn{2}{|c|}{ TOTAL } \\
\hline & $\mathrm{N}$ & $\%$ \\
\hline SEMPRE & 136 & 45,8 \\
\hline ȦS VEZES & 140 & 47,1 \\
\hline NUNCA & 6 & 2,0 \\
\hline $\begin{array}{l}\text { NAO } \cdot \text { SABE OU } \\
\text { NAO RESPONDEU }\end{array}$ & 15 & 5,1 \\
\hline TOTAL & 29.7 & $1.00,0$ \\
\hline
\end{tabular}

Portanto, a têndência dos professores ë estimular os alunos a emitirem julgamento sobre questões polêmicas, pois tal procedimento é às vezes ou sempre adotado por $92,9 \%$ dos professores. 
TABELA $V-5$

FREQUENCTA DO PROCEDTMENTO: "ESTTMUIOO OS ALUNOS A EMTTIREM JULGAMENTO SOBRE QUESTOOES POLEMI CAS"NOS GRUPOS A E B - 1980*

\begin{tabular}{|l|c|c|c|c|}
\hline \multirow{2}{*}{$\begin{array}{l}\text { FREQUENCIA DO } \\
\text { PROCEDTMENTO }\end{array}$} & \multicolumn{2}{|c|}{ GRUPO A** } & \multicolumn{2}{c|}{ GRUPO $\mathrm{A}^{* k}$} \\
\hline SEMPRE & 97 & 44,3 & 39 & 50,0 \\
\hline AS VEZES & 1.04 & 47,5 & 36 & 46,2 \\
\hline NUNCA & 5 & 2,3 & 1 & 1,3 \\
\hline $\begin{array}{r}\text { NAO SABE OU } \\
\text { NAO RESPONDEU }\end{array}$ & 13 & 5,9 & 2 & 2,6 \\
\hline TOTAL & 219 & 100,0 & 78 & 100,0 \\
\hline
\end{tabular}

*Dados adaptados de: SOCIEDADE BRASIJEIRA DE GEOLOGIA/MINISTERIO DA EDUCAÇAO E CULTURA - 1981 - A Formação do Geólogo nas Universidades Brasileiras, um Retrato de Duas Dëcadas. MEC, Brasilia, 209 pp.

**GRUPO A: Professores que desenvolvem pesquisa

GRUPO B: Professores que não desenvolvem pesquisa

HTSTOGRAMA V-5

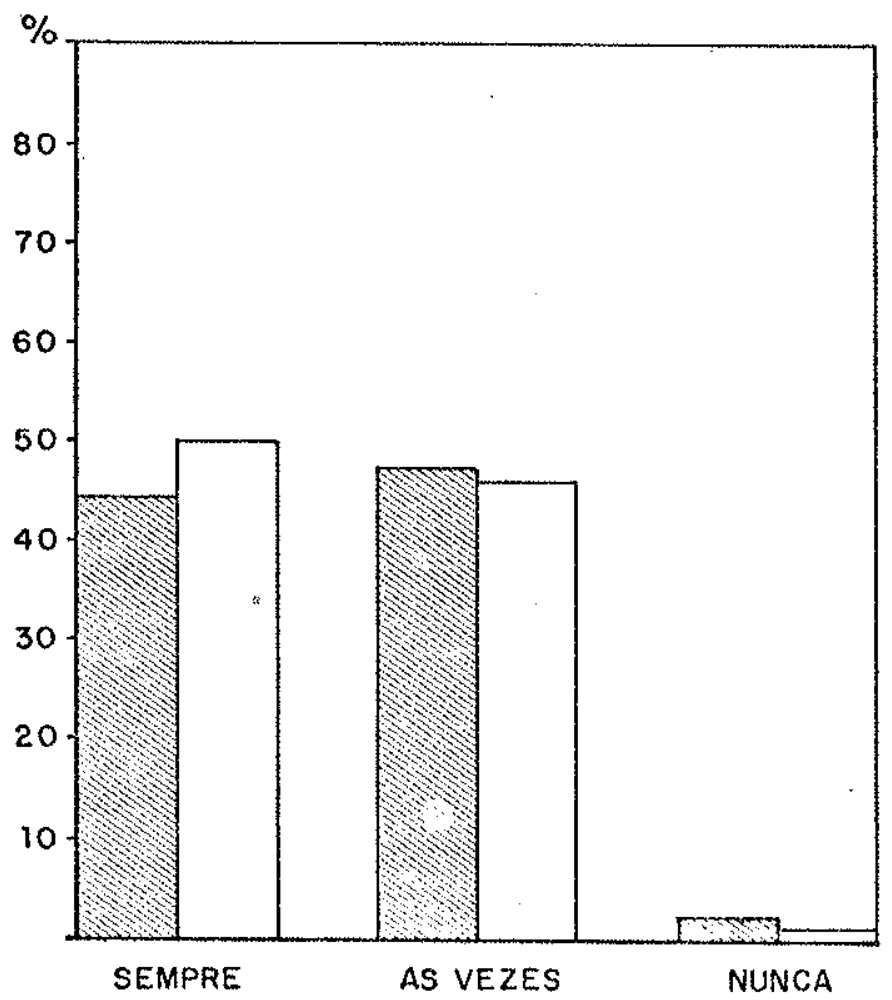

(Freq.)

GRUPO A: Professores que desenvolvem pesquisa

GRUPO B: Professores que não desenvolvem pesquisa 
V.1.6 - Procedimento de Ensino n" 6: "Estimulo a memorização de conhecimentos"

Neste caso, a maioria dos professores, tanto do Grupo A quanto do Grupo B, indicou que "às vezes" estimula a memorização de conhecimentos, abrangendo cerca de metade das respostas dadas a este procedimento. As respostas "nunca" foram escolhidas com frequências pröximas entre si, com valores em torno de 20,0\% (TABELA e HISTOGRAMA V-6).

Aplicando-se a prova do $\chi^{2}$ obtem-se o resultado 9,09 . Para $g l=2$ e $\alpha=0,05, H_{0} \vec{e}$ rejeitada, significando que $A$ e $B$ têm tendências diferentes neste procedimento de ensino.

o Grupo A na sua maioria $(56,6 \%)$. "às vezes" estimula a memorização de conhecimentos, sendo que menos de um quinto de seus membros "sempre" o faz. No Grupo B, apenas um terço dos componentes "sempre" estimula a memorização e menos da me tade $(43,6 \%)$ "às vezes" o faz.

Observa-se que os professores que desenvolvem pesqui sa estimulam menos a memorização de conhecimentos do que aque les que não desenvolvem pesquisa. 
TABELA $V-6$

FREQUENCTA DO PROCEDIMENTO: "ESTIMULO A MEMORIZACAO DE CONHECIMENTOS" NOS GRUPOS A E B - 1980*

\begin{tabular}{|l|c|c|c|c|}
\hline \multirow{2}{*}{$\begin{array}{c}\text { FREQUENCIA DO } \\
\text { PROCEDIMENTO }\end{array}$} & \multicolumn{2}{|c|}{ GRUPO $\mathrm{A}^{* *}$} & \multicolumn{2}{c|}{ GRUPO $3^{* *}$} \\
\cline { 2 - 5 } & $\mathrm{N}$ & $\frac{0}{6}$ & $\mathrm{~N}$ & $\%$ \\
\hline SEMPRE & 37 & 16,9 & 26 & 33,3 \\
\hline AS VEZES & 124 & 56,6 & 34 & 43,6 \\
\hline NUNCA & 45 & 20,5 & 15 & 19,2 \\
\hline $\begin{array}{r}\text { NAO SABE OU } \\
\text { NAO RESPONDEU }\end{array}$ & 13 & 5,9 & 3 & 3,9 \\
\hline TOTAL & 219 & 100,0 & 78 & $1.00,0$ \\
\hline
\end{tabular}

*Dados adaptados de: SOCTEDADE BRASILEIRA DE GEOLOGIA/MINISTERIO DA EDUCAÇAO E CULTURA - 1981 - A Formacão do Geölogo nas Universidades Brasileiras, un Retrato de Duas Dëcadas. MEC, Brasilia, 209 pp.

**GRUPO A: Professores que desenvolvem pesquisa GRUPO B: Professores que não desenvolvem pesquisa

\section{HISTOGRAMA V-6}

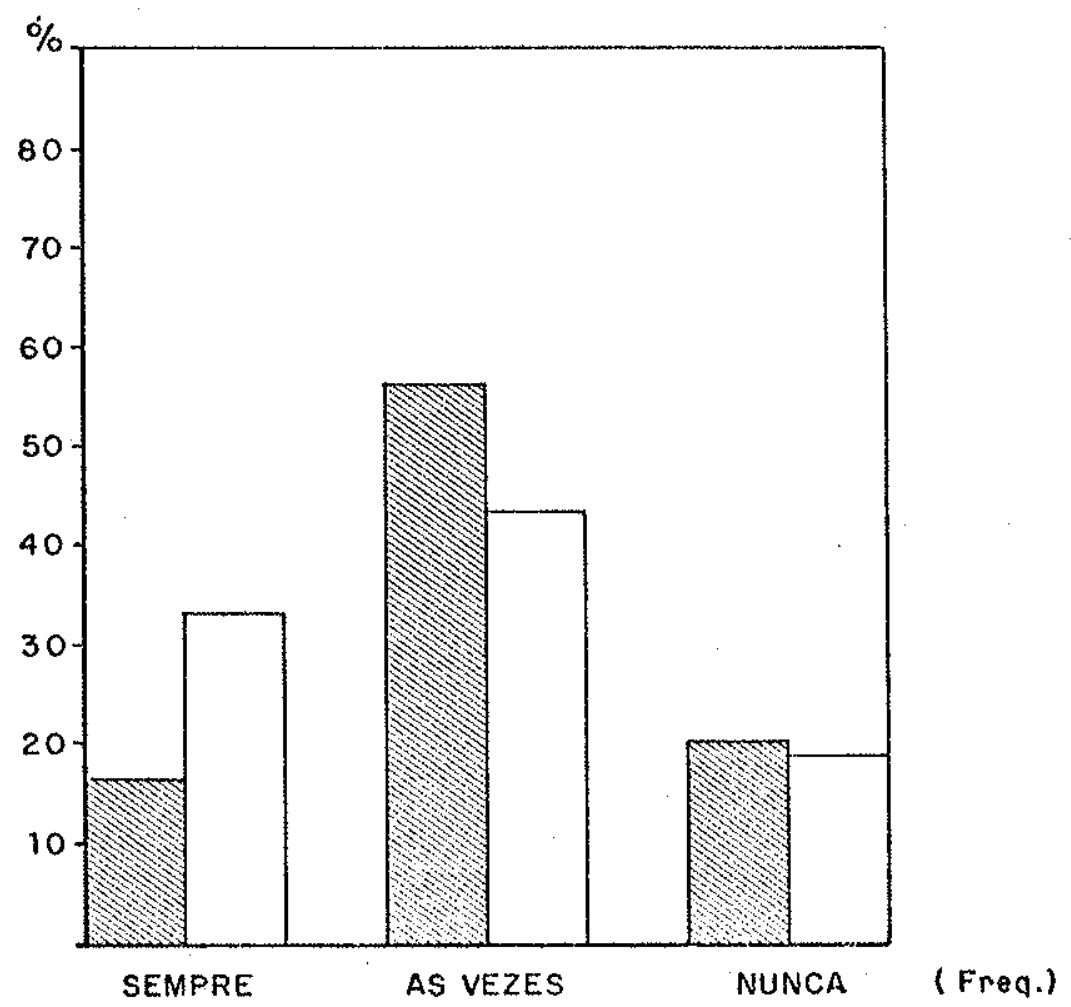

GRUPO A: Professores que desenvolvem pesquisa GRUPO B: Professores que não desenvolvem pesquisa 
V.1.7 - procedimento de Ensino n" 7: "Proponho problemas ou questões polêmicas para os alunos djscutirem"

Verifica-se que os percentuais dos Grupos A e B, quan do comparados entre si, são pröximos para todas as alternativas. As porcentagens de "às vezes" são predominantes em relação às demais, situando-se em torno de 65,0\% (TABELA e HISTOGRAMA V-7).

Aplicando-se a prova do $x^{2}$ obtem-se o valor 1,06. Pa ra $g l=2$ e $\alpha=0,05, H_{0} \vec{e}$ aceita, significando que os Grupos A e B são equivalentes quanto a este procedimento de ens no.

pode-se, assim, reunir os Grupos A e B num só, onde as frequências são as seguintes:

\begin{tabular}{|l|c|c|}
\hline \multirow{2}{*}{$\begin{array}{l}\text { FREQUENCTA DO } \\
\text { PROCEDIMENTO }\end{array}$} & \multicolumn{2}{|c|}{ TOTAL } \\
\cline { 2 - 3 } & $\mathrm{N}$ & \multicolumn{1}{|c|}{$\%$} \\
\hline SEMPRE & 67 & 22,6 \\
\hline AS VEZES & 193 & 65,0 \\
\hline NUNCA & 23 & 7,7 \\
\hline $\begin{array}{l}\text { NAO SABE OU } \\
\text { NAO RESPONDEU }\end{array}$ & 14 & 4,7 \\
\hline TOTAL & 297 & 100,0 \\
\hline
\end{tabular}

Portanto, verifica-se tendência dos professores a so mente "às vezes" propor problemas ou questões polêmicas para os alunos, pois apenas $22,6 \%$ deles adotam "sempre" tal procedimento. 
TABELA $\quad V-7$

FREQUENCIA DO PROCEDIMENTO: "PROPONHO PROBLEMAS OU QUESTOES POLEMI CAS PARA OS ALUNOS DISCUTIREM" NOS GRUPOS A E B - 1980*

\begin{tabular}{|l|c|c|c|c|}
\hline $\begin{array}{l}\text { FREQUENCIA DO } \\
\text { PROCEDIMENTO }\end{array}$ & \multicolumn{2}{|c|}{ GRUPO $\mathrm{A}^{* *}$} & \multicolumn{2}{c|}{ GRUPO $\mathrm{B}^{*-*}$} \\
\hline SEMPRE & $\mathrm{N}$ & $\%$ & $\mathrm{~N}$ & $\%$ \\
\hline AS VEZES & 139 & 63,5 & 54 & 69,2 \\
\hline NUNCA & 18 & 8,2 & 5 & 6,4 \\
\hline $\begin{array}{r}\text { NAO SABE OU } \\
\text { NAO RESPONDEU }\end{array}$ & 10 & 4,6 & 4 & 5,1 \\
\hline TOTAL & 219 & 100,0 & 78 & 100,0 \\
\hline
\end{tabular}

*Dados adaptados de: SOCTEDADE BRASILEIRA DE GEOLOGIA/MINISTERIO DA EDUCAÇAO E CULTURA - 1981 - A Formação do Geölogo nas Universidades Brasileiras, um Retrato de Duas Décadas. MEC, Brasilia, 209 pp.

**GRUPO A: Professores que desenvolvem pesquisa

GRUPO B: Professores que não desenvolvem pesquisa

\section{HTSTOGRAMA V-7}

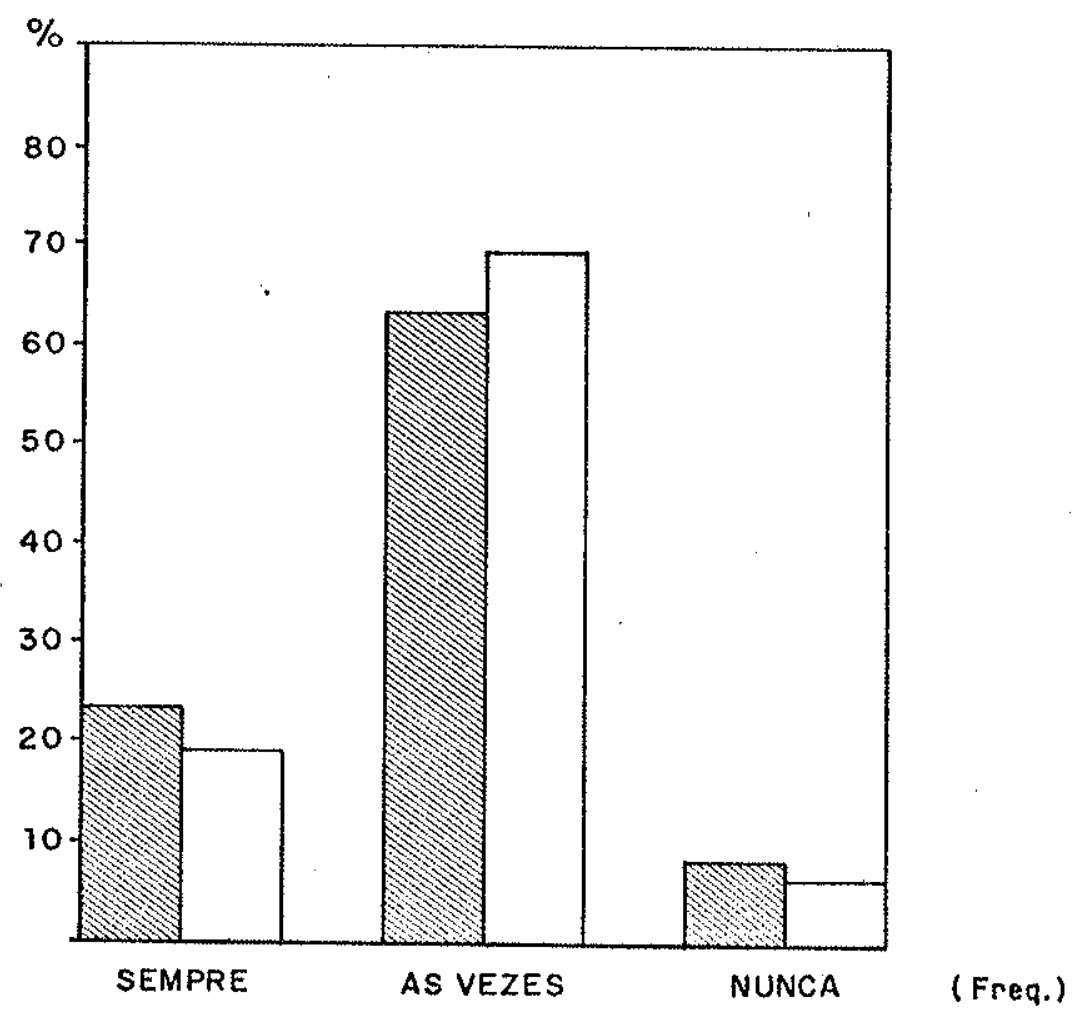

GRUPO A: Professores que desenvolvem pesquisa GRUPO B: Professores que não desenvolvem pesquisa 
V.1.8 - Procedimento de Ensino n 8: "Utilizo somente aposti1as"

As alternativas "nunca" e "às vezes" abrangem mais de $90,0 \%$ da amostra, sendo seus valores respectivamente $69,4 \%$ e 22,8\% para o Grupo A e 62,8\% e 30,8\% para o Grupo B. Nota- se tambëm que são pröximos os percentuais dos dois Grupos nessas alternativas (TABELA e HISTOGRAMA V-8).

Ap1icando-se a prova do $x^{2}$ obtem-se o valor 2,62 . Pa $\mathrm{ra} g \ell=2 \mathrm{e} \alpha=0,05, \mathrm{H}_{\mathrm{O}} \overrightarrow{\mathrm{e}}$ aceita, significando que, quanto ao procedimento em exame, os Grupos A e B são equivalentes.

Pode-se então somar as frequências dos dois Grupos citados:

\begin{tabular}{|l|r|r|}
\hline \multirow{2}{*}{$\begin{array}{l}\text { FREQUENCIA DO } \\
\text { PROCEDIMENTO }\end{array}$} & \multicolumn{2}{|c|}{ TOTAL } \\
\cline { 2 - 3 } & \multicolumn{1}{|c|}{$N$} & \multicolumn{1}{c|}{$\%$} \\
\hline SEMPRE & 8 & 2,7 \\
\hline AS VEZES & 74 & 24,9 \\
\hline NUNCA & 201 & 67,7 \\
\hline $\begin{array}{l}\text { NAO SABE OU } \\
\text { NAO RESPONDEU }\end{array}$ & 14 & 4,7 \\
\hline TOTAL & 297 & 100,0 \\
\hline
\end{tabular}

Verifica-se portanto que a tendência dominante entre os professores é a de não utilizar somente apostilas em suas disciplinas, pois cerca de dois terços entre eles "nunca" o faz e um quarto sỏ o faz "às vezes". 
TABELA V-8

FREQUENCIA DO PROCEDIMENTO: "UTILIZO SOMENTE APOSTILAS" NOS GRUPOS A E B - 1980*

\begin{tabular}{|l|c|c|c|c|}
\hline \multirow{2}{*}{$\begin{array}{l}\text { FREQUENCIA DO } \\
\text { PROCED IMENTO }\end{array}$} & \multicolumn{2}{|c|}{ GRUPO $A^{* *}$} & \multicolumn{2}{c|}{ GRUPO B } \\
\cline { 2 - 5 } & $N$ & $\%$ & $N$ & $\%$ \\
\hline SEMPRE & 7 & 3,2 & 1 & 1,3 \\
\hline AS VEZES & 50 & 22,8 & 24 & 30,8 \\
\hline NUNCA & 152 & 69,4 & 49 & 62,8 \\
\hline $\begin{array}{l}\text { NAO SABE OU } \\
\text { NAO RESPONDEU }\end{array}$ & 10 & 4,6 & 4 & 5,1 \\
\hline TOTAL & 219 & 100,0 & 78 & 100,0 \\
\hline
\end{tabular}

*Dados adaptados de: SOCIEDADE BRASILEIRA DE GEOLOGIA/MINISTERIO DA EDUCAÇAO E CULTURA - 1981 - A Formação do Geölogo nas Universidades Brasileiras, um Retrato de Duas Décadas. MEC, Brasilia, $209 \mathrm{pp}$.

${ }^{*}$ GRUPO A: Professores que desenvolvem pesquisa

GRUPO B: Professores que não desenvolvem pesquisa

$$
\text { HISTOGRAMA V-8 }
$$

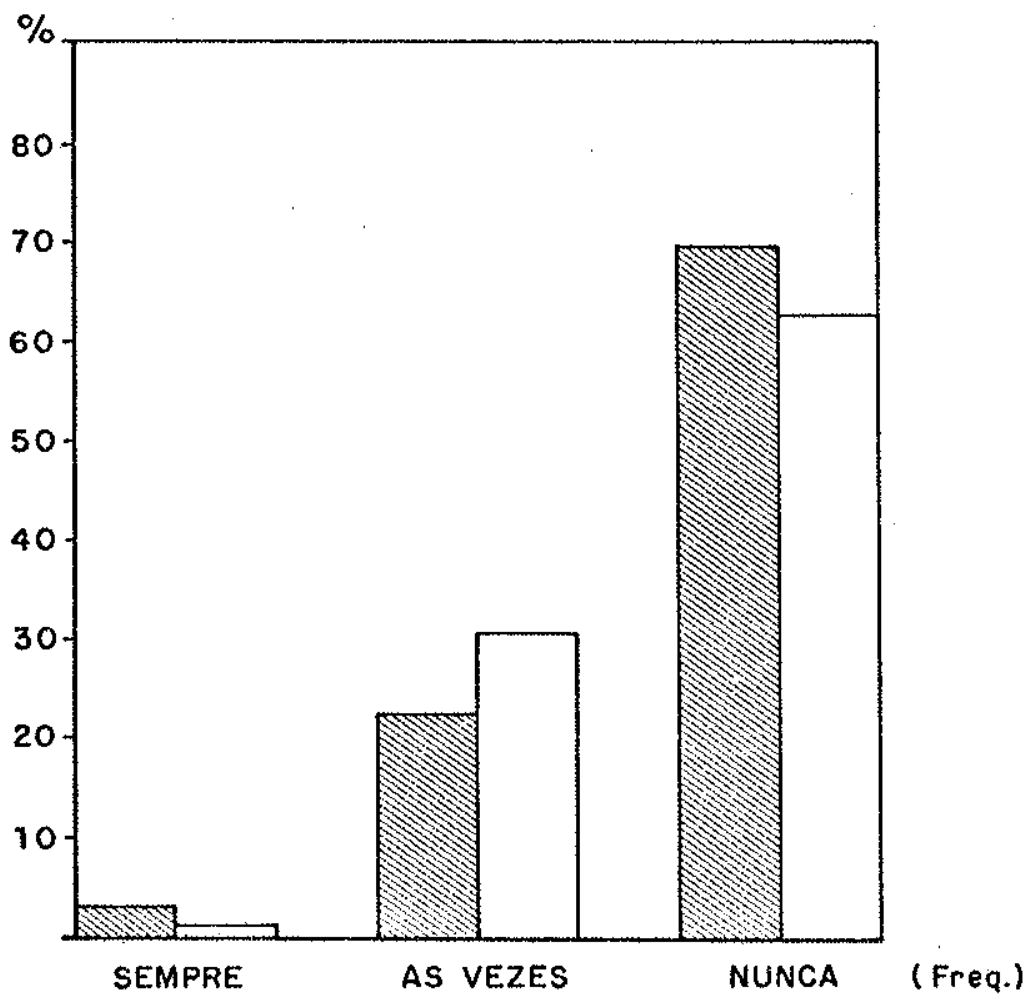

GRUPO A: Professores que desenvolvem pesquisa GRUPO B: Professores que não desenvolvem pesquisa 
V.1.'9 - Procedimento de Ensino n" 9: "Incentivo os alunos a construirem maquetes, mapas, modelos, etc.".

As alternativas "sempre" e "às vezes" abrangem aproximadamente $75,0 \%$ dos indivíduos em cada um dos grupos. Compa rando-se os percentuais dos dois grupos entre si e para cada alternativa, observa-se que são todos eles próximos. Há predo nínio da alternativa "às vezes", escolhida por aproximadamente 50,0\% dos respondentes de cada Grupo (TABELA e HISTOGRAMA $\mathrm{v}-9)$.

Aplicando-se a prova do $x^{2}$ obtem-se o valor $1 ; 41$. Pa ra $g l=2$ e $\alpha=0,05, H_{0} \vec{e}$ aceita, o que significa equiva 1.ência entre os Grupos A e B quanto ao procedimento de ensino em causa.

Soma-se portanto as frequências dos Grupos A e B para obter a tendência dominante neste procedimento:

\begin{tabular}{|c|c|c|}
\hline \multirow{2}{*}{$\begin{array}{l}\text { FREQUENCIA DO } \\
\text { PROCEDIMENTO }\end{array}$} & \multicolumn{2}{|c|}{ TOTAL } \\
\hline & $\mathrm{N}$ & $\because$ \\
\hline SEMPRE & 82 & 27,6 \\
\hline ȦS VEZES & 142 & 47,8 \\
\hline NUNCA & 43 & 14,5 \\
\hline $\begin{array}{ll}\text { NAO } & \text { SABE OU } \\
\text { NAO } & \text { RESPONDEU }\end{array}$ & 30 & 10,1 \\
\hline TOTAL & 297 & 100,0 \\
\hline
\end{tabular}

Verifica-se tendência dos docentes a incentivarem os alunos a construirem mapas e outros tipos de modelos, mas qua se metade entre eles adota tal procedimento somente "às vezes". 
TABELA V-9

FREQUENCIA DO PROCEDIMENTO: "INCENTTVO OS ALUNOS A CONSTRUIREM MAQUETES, MAPAS, MODELOS, ETC." NOS GRUPOS A E B - 1980*

\begin{tabular}{|l|c|c|c|c|}
\hline \multirow{2}{*}{$\begin{array}{l}\text { FREQUENCI A DO } \\
\text { PROCEDIMENTO }\end{array}$} & \multicolumn{2}{|c|}{ GRUPO $\mathrm{A}^{* *}$} & \multicolumn{2}{c|}{ GRUPO $\mathrm{B} * * *$} \\
\cline { 2 - 5 } & $\mathrm{N}$ & $\frac{0}{\circ}$ & $\mathrm{N}$ & $\frac{0}{\circ}$ \\
\hline SEMPRE & 57 & 26,0 & 25 & 32,1 \\
\hline AS VEZES & 108 & 49,3 & 34 & 43,6 \\
\hline NUNCA & 30 & 13,7 & 13 & 16,7 \\
\hline $\begin{array}{r}\text { NAO SABE OU } \\
\text { NAO RESPONDEU }\end{array}$ & 24 & 10,9 & 6 & 7,6 \\
\hline TOTAL & 219 & 100,0 & 78 & 100,0 \\
\hline
\end{tabular}

*Dados adaptados de: SOCIEDADE BRASILEIRA DE GEOLOGIA/MINISTERTO DA EDUCACZAO E CULTURA - 1981 - A Formação do Geölogo nas Universidades Brasileiras, um Retrato de Duas Dëadas. MEC, Brasilia, 209 pp.

**GRUPO A: Professores que desenvolvem pesquisa

GRUPO B: Professores que não desenvolvem pesquisa

HTSTOGRAMA V-9

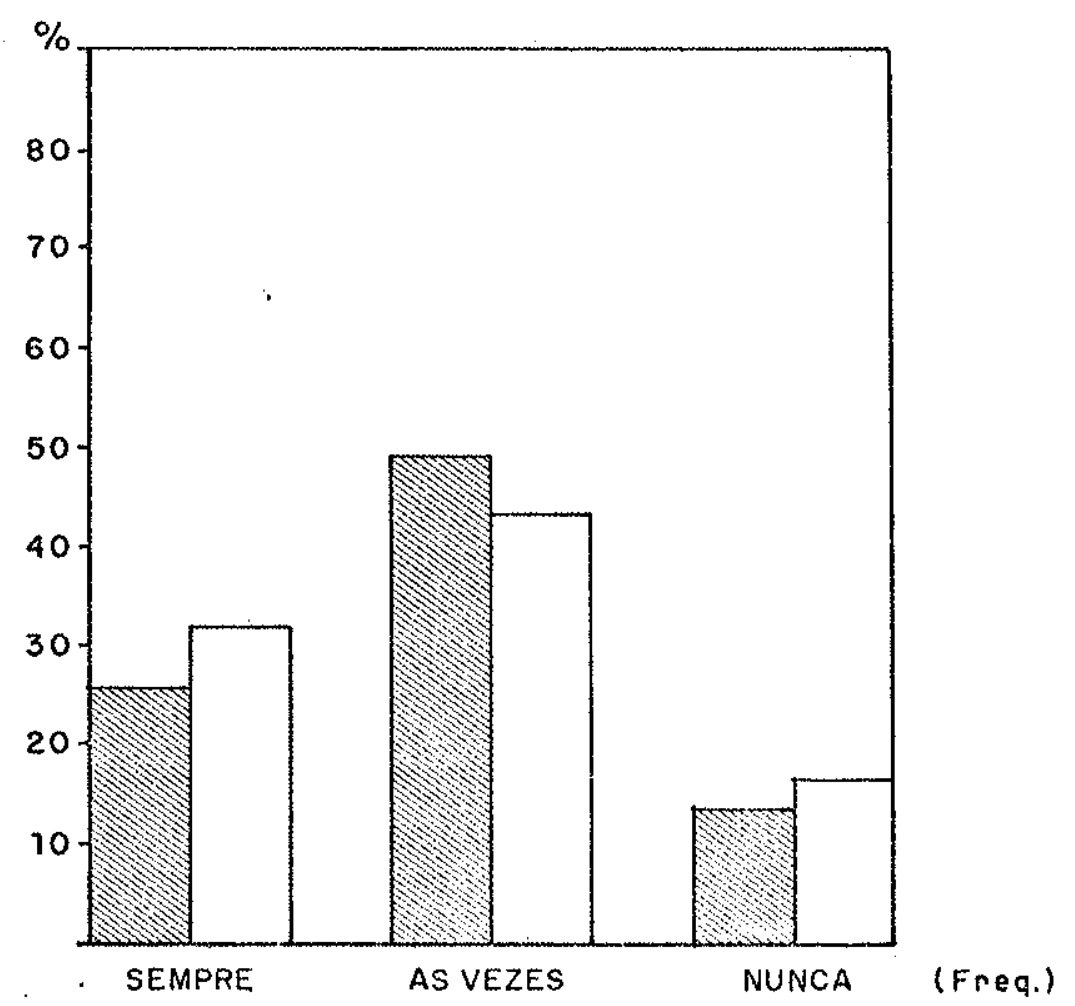

Fiv GRUPO A: Professores que desenvolvem pesquisa GRUPO B: Professores que não desenvolvem pesquisa 
V.1.10 - Procedimento de Ensino n" 10: "Procuro incentivar os alunos a captarem os principais conceitos e princi pios e a perceberem interrelaçōes"

A resposta "sempre" abrange cerca de $90,0 \%$ da amostra, sendo os percentuais pröximos entre si nos dois Grupos. Nenhum dos respondentes optou pela alternativa "nunca" (TABELA E HISTOGRAMA V-10).

Aplicando-se a prova do $x^{2}$ obtem-se o valor 0,24 . Pa ra $g l=1$ e $\alpha=0,05, H_{0} \vec{e}$ aceita, significando que os Grupos A e B têm a mesma tendência quanto ao procedimento em pau ta.

Reunindo-se as frequências dos Grupos A e B, obtem-se:

\begin{tabular}{|c|c|c|}
\hline \multirow{2}{*}{$\begin{array}{l}\text { FREQUENCIA DO } \\
\text { PROCEDIMENTO }\end{array}$} & \multicolumn{2}{|c|}{ TOTAL } \\
\hline & $\mathrm{N}$ & $\%$ \\
\hline SEMPRE & 265 & 89,2 \\
\hline AS VEZES & 29 & 9,8 \\
\hline NUNCA & 0 & 0,0 \\
\hline $\begin{array}{ll}\text { NAO } & \text { SABE OU } \\
\text { NAO } & \text { RESPONDEU }\end{array}$ & 3 & 1,0 \\
\hline TOTAL & 297 & 100,0 \\
\hline
\end{tabular}

Esta ê uma das tendências melhor definidas dos pro fessores, pois quase 90,0\% entre eles "sempre" incentiva os alunos a captarem os principais conceitos e principios e a perceberem interrelaçōes; não hä sequer um professor que "nun ca" age deste modo. 
TABELA V -10

FREQUENCIA DO PROCEDIMENTO: "PROCURO INCENTIVAR OS ALUNOS A CAPTAREM OS PRINCIPAIS CONCETTOS E PRINCIPIOS E PERCEBEREM INTERRELAÇOES" NOS GRUPOS A E B - 1980*

\begin{tabular}{|l|c|c|c|c|}
\hline \multirow{2}{*}{$\begin{array}{l}\text { FREQUENCIA DO } \\
\text { PROCEDIMENTO }\end{array}$} & \multicolumn{2}{|c|}{ GRUPO A** } & \multicolumn{2}{|c|}{ GRUPO $\mathrm{B}^{* *}$} \\
\cline { 2 - 5 } & $\mathrm{N}$ & $\frac{\mathrm{o}}{\mathrm{v}}$ & $\mathrm{N}$ & $\frac{\circ}{\mathrm{o}}$ \\
\hline SEMPRE & 194 & 88,6 & 71 & 91,0 \\
\hline AS VEZES & 23 & 10,5 & 6 & 7,7 \\
\hline NUNCA & 0 & 0,0 & 0 & 0,0 \\
\hline $\begin{array}{l}\text { NAO SABE OU } \\
\text { NAO RESPONDEU }\end{array}$ & 2 & 0,9 & 1 & 1,3 \\
\hline TOTAL & 219 & 100,0 & 78 & 100,0 \\
\hline
\end{tabular}

* Dados adaptados de: SOCIEDADE BRASILETRA DE GEOLOGIA/MINISTERIO DA EDUCACAO E CULTURA - 1981 - A Formação do Geölogo nas Universidades Brasileiras, um Retrato de Duas Décadas. MEC, Brasilia, $209 \mathrm{pp}$.

**GRUPO A: Professores que desenvolvem pesquisa

GRUPO B: Professores que não desenvolvem pesquisa

HISTOGRAMA V-10

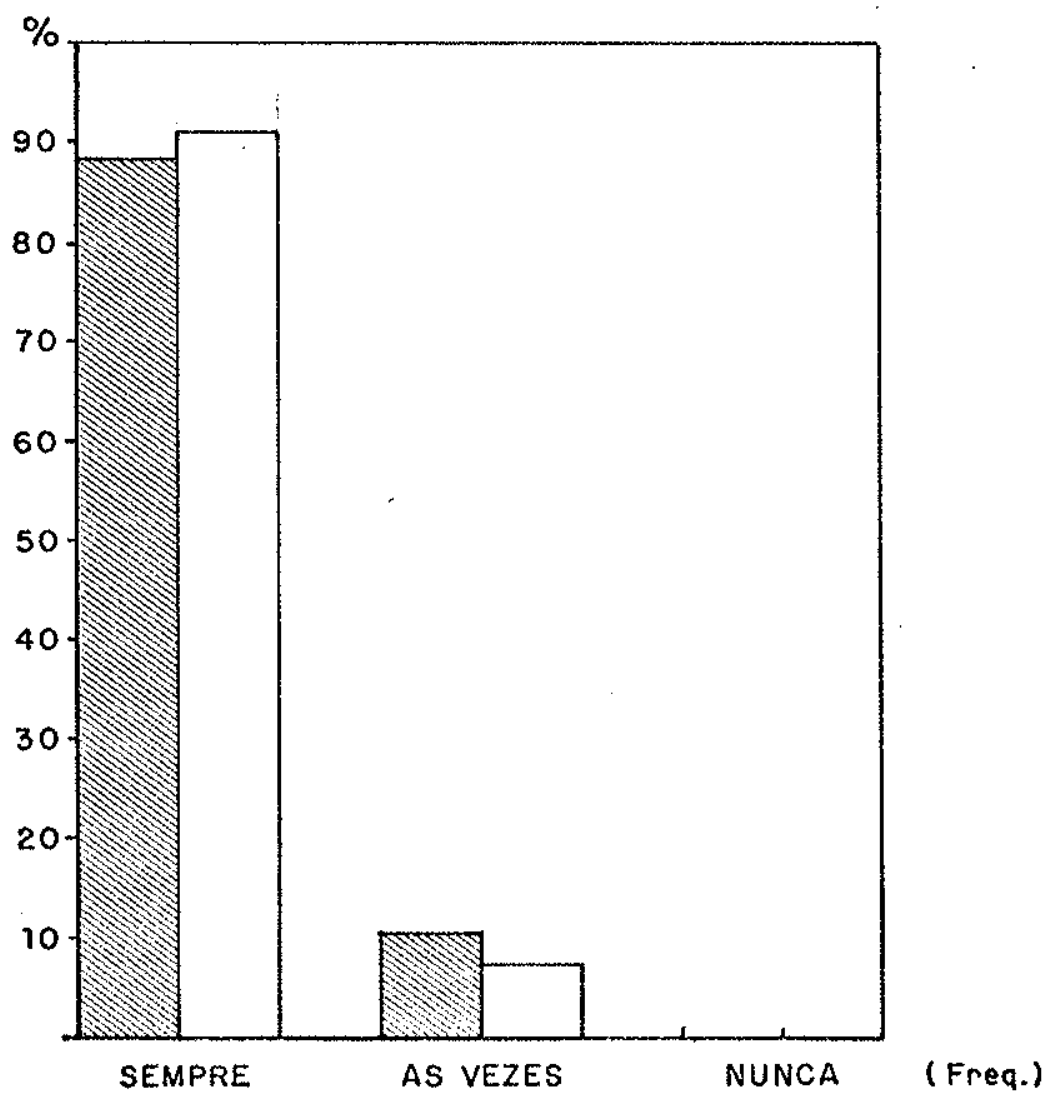

GRUPO A: Professores que desenvolvem pesquisa

GRUPO B: Professores que não desenvolvem pesquisa 
V.1.11 - Procedimento de Ensino n" 11: "Organizo e oriento trabalhos e discussões de grupo"

Neste caso, predomina a resposta "às vezes" com valo res pröximos a $60,0 \%$ para cada um dos Grupos. Vale ressaltar que para as demais alternativas de resposta os valores tambëm são pröximos entre si (TABELA e HISTOGRAMA V-11).

Ap1icando-se a prova do $X^{2}$ obtem-se o valor 1,54 . Pa ra $g l=2$ e $\alpha=0,05$ aceita-se $H_{0}$ e portanto, os Grupos $A$ e $B$ são equivalentes quanto a este procedimento de ensino.

Somando-se as frequências dos Grupos A e B obtem-se a tendência deste procedimento:

\begin{tabular}{|c|c|c|}
\hline \multirow{2}{*}{$\begin{array}{l}\text { FREQUENCTA DO } \\
\text { PROCEDIMENTO }\end{array}$} & \multicolumn{2}{|c|}{ TOTAL } \\
\hline & $N$ & $\%$ \\
\hline SEMPRE & 77 & 25,9 \\
\hline AS VEZES & 172 & 57,9 \\
\hline NUNCA & 37 & 12,5 \\
\hline $\begin{array}{ll}\text { NAO } & \text { SABE OU } \\
\text { NAO } & \text { RESPONDEU }\end{array}$ & 11 & 3,7 \\
\hline TOTAL & 297 & 100,0 \\
\hline
\end{tabular}

A tendência dos professores ê, portanto, somente "às vezes" organizar e orientar trabalhos e discussões de grupo, pois apenas $25,9 \%$ deles o faz "sempre". 
TABELA V-11

FREQUENCIA DO PROCEDIMENTO: "ORGANTZO E ORIENTO TRABALHOS E DISCUSSOES DE GRUPO" NOS GRUPOS A E B - $1980^{*}$

\begin{tabular}{|l|c|c|c|c|}
\hline \multirow{2}{*}{$\begin{array}{l}\text { FREQUENCIA DO } \\
\text { PROCEDIMENTO }\end{array}$} & \multicolumn{2}{|c|}{ GRUPO $\mathrm{A}^{* *}$} & \multicolumn{2}{c|}{ GRUPO $\mathrm{B}^{* *}$} \\
\cline { 2 - 5 } & $\mathrm{N}$ & $\frac{0}{0}$ & $\mathrm{~N}$ & $\%$ \\
\hline SEMPRE & 60 & 27,4 & 17 & 21,8 \\
\hline AS VEZES & 123 & 56,2 & 49 & 62,8 \\
\hline NUNCA & 29 & 13,2 & 8 & 10,3 \\
\hline $\begin{array}{l}\text { NAO SABE OU } \\
\text { NAO RESPONDEU }\end{array}$ & 7 & 3,2 & 4 & 5,1 \\
\hline TOTAL & 219 & 100,0 & 78 & 100,0 \\
\hline
\end{tabular}

*Dados adaptados de: SOCIEDADE BRASTLEIRA DE GEOLOGIA/MINISTERIO DA EDUCACAO E CULTURA - 1981 - A Formação do Geölogo nas Universidades Brasileiras, um Retrato de Duas Décadas. MEC, Brasilia, 209 pp.

* GRUPO A: Professores que desenvolvem pesquisa

GRUPO B: Professores que não desenvolvem pesquisa

\section{HT.STOGRAMA V-1I}

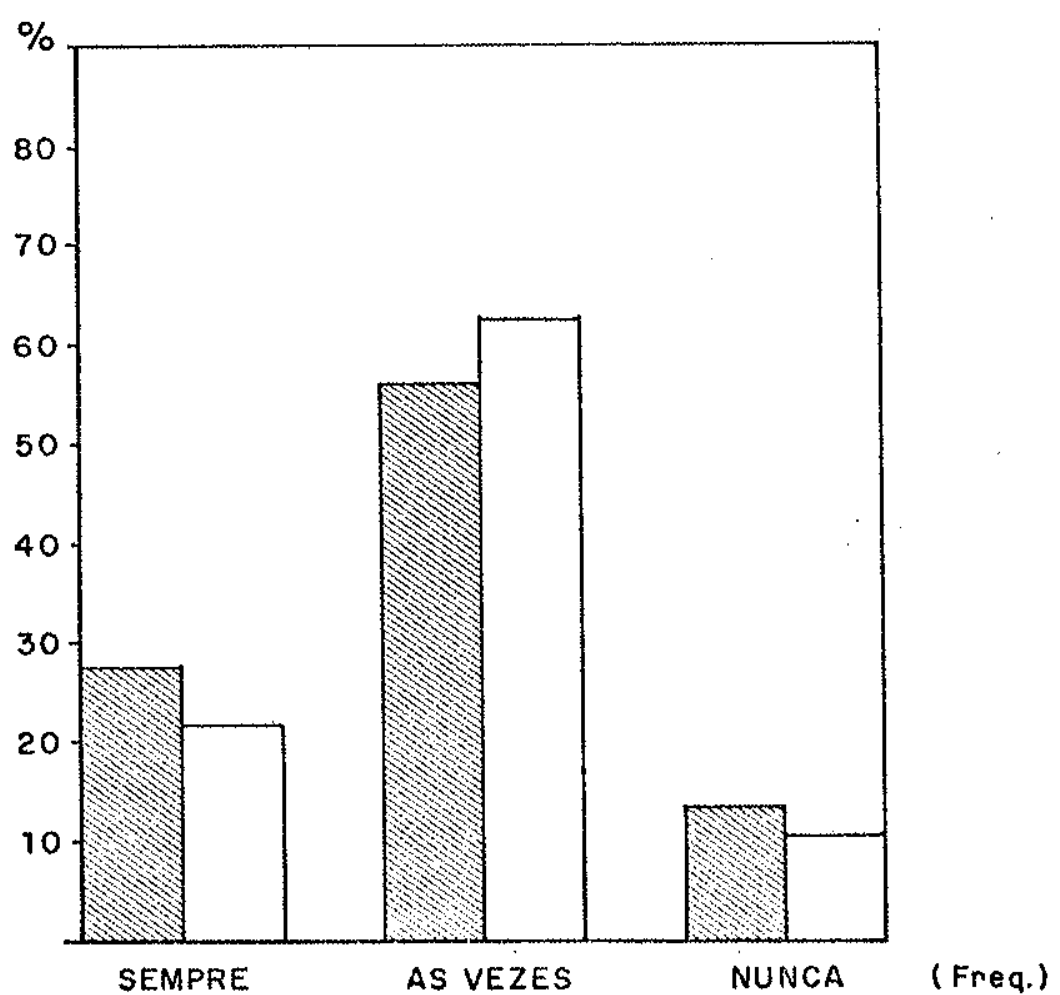

GRUPO A: professores que desenvolvem pesquisa

GRUPO B: Professores que não desenvolvem pesquisa 
V.1.12 - Procedimento de Ensino n: 12: "Procuro relacionar os temas do meu programa com os fatos da realidade"

As alternativas "sempre" e "às vezes" abrangem quase toda a amostra, com predominâncía da primeira alternativa nos dois grupos (TABELA e HISTOGRAMA $V-12$ ).

Aplicando-se a prova do $x^{2}$ obteve-se o valor $0,06 . \mathrm{p}_{\mathrm{a}}$ a $g l=1$ e $\alpha=0,05$ aceita-se $H_{0}$, significando que os Grupos $A$ e $B$ são equivalentes quanto a este procedimento.

Sendo os Grupos A e B equivalentes, pode-se somar os valores de suas frequencias para divisar-se a tendência dos docentes quanto ao procedimento em questão:

\begin{tabular}{|c|c|c|}
\hline \multirow{2}{*}{$\begin{array}{l}\text { FREQUENCIA DO } \\
\text { PROCEDIMENTO }\end{array}$} & \multicolumn{2}{|c|}{ TOTAL } \\
\hline & $N$ & $\%$ \\
\hline SEMPRE & 232 & 78,1 \\
\hline ÁS VEZES & 56 & 18,9 \\
\hline NUNCA & 0 & 0,0 \\
\hline $\begin{array}{ll}\text { NAO } & \text { SABE OU } \\
\text { NAO } & \text { RESPONDEU }\end{array}$ & 9 & 3,0 \\
\hline TOTAL & 297 & 100,0 \\
\hline
\end{tabular}

Verifica-se que a tendência dos professores è rela cionar os temas de seus programas com a realidade, pois cerca de $80,0 \%$ entre eles "sempre" adotam tal procedimento. 
TABELA $V-12$

FREQUENCIA DO PROCEDIMENTO: "PROCURO RELACIONAR OS TEMAS DO MEU PROGRAMA CON OS FATOS DA REALIDADE" NOS GRUPOS A E B - 1980*

\begin{tabular}{|l|c|c|c|c|}
\hline \multirow{2}{*}{$\begin{array}{c}\text { FREQUENCIA DO } \\
\text { PROCEDIMENTO }\end{array}$} & \multicolumn{2}{|c|}{ GRUPO A* } & \multicolumn{2}{c|}{ GRUPO B* } \\
\cline { 2 - 5 } & $\mathrm{N}$ & $\frac{1}{\circ}$ & $\mathrm{N}$ & $\%$ \\
\hline SEMPRE & 172 & 78,5 & 60 & 76,9 \\
\hline AS VEZES & 40 & 18,3 & 16 & 20,5 \\
\hline NUNCA & 0 & 0,0 & 0 & 0,0 \\
\hline $\begin{array}{r}\text { NAO SABE OU } \\
\text { NAO RESPONDEU }\end{array}$ & 7 & 3,2 & 2 & 2,6 \\
\hline TOTAL & 219 & 100,0 & 78 & 100,0 \\
\hline
\end{tabular}

*Dados adaptados de: SOCIEDADE BRASILEIRA DE GEOLOGIA/AINNISTERIO DA EDUCAC_AO E CULTURA - 1981 - A Formação do Geólogo nas Universidades Brasileiras, um Retrato de Duas Dëcadas. NEC, Brasilia, 209 pp.

**GRUPO A: Professores que desenvolvem pesquisa

GRUPO B: Professores que não desenvolvem pesquisa

HTSTOGRAMA V-12

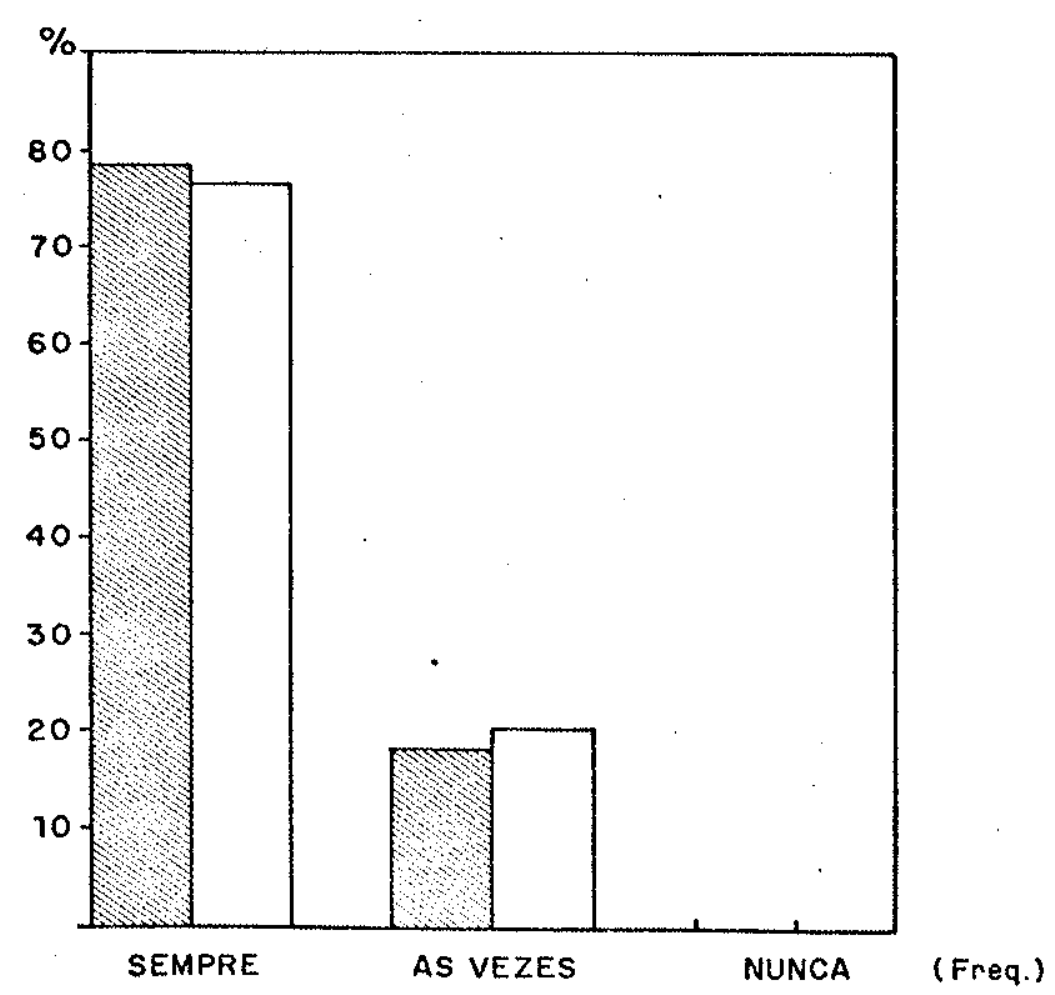

GRUPO A: Professores que desenvolvem pesquisa

GRUPO B: Professores que não desenvolvem pesquisa 
V.1.13 - Procedimento de Ensino n 13: "Em minhas exposições apresento as várias visões ou concepções a respeito de um assunto"

As alternativas "sempre" e "às vezes" abrangem quase toda a amostra, havendo predomínio da primeira sobre a segunda. Além disso, os percentuais de cada uma delas são próximos quando se comparam os dois Grupos entre si (TABELA e HISTOGRA MA V-13) .

A existência de casela zero obriga à combinação das categorias "às vezes" e "nunca" para permitir aplicação da pro va estatística. Aplicando-se a prova do $x^{2}$ obtem-se o valor 0,03 . Para $g l=1$ e $\alpha=0,05$ aceita-se $H_{0}$, significando que os Grupos A e B são equivalentes quanto a este procedimento.

Somando-se as frequências dos Grupos A e B obtem-se os seguintes resultados:

\begin{tabular}{|c|c|c|}
\hline \multirow{2}{*}{$\begin{array}{l}\text { FREQUENCIA DO } \\
\text { PROCEDIMENTO }\end{array}$} & \multicolumn{2}{|c|}{ TOTAL } \\
\hline & $\mathrm{N}$ & $\stackrel{0}{0}$ \\
\hline SEMPRE & 190 & 64,0 \\
\hline ÁS VEZES & 102 & 34,3 \\
\hline NUNCA & 1 & 0,3 \\
\hline $\begin{array}{ll}\text { NAOO } & \text { SABE OU } \\
\text { NAOO } & \text { RESPONDEU }\end{array}$ & 4 & 1,3 \\
\hline TOTAL & 297 & 100,0 \\
\hline
\end{tabular}

A tendência dos professores é apresentar as värias visões ou concepções a respeito do assunto em estudo, por oca sião de suas exposições, pois quase dois terços entre eles adotam "sempre" esse procedimento e cerca de um terço o fazem "às vezes". 
TABELA V-13

FREQUENCIA DO PROCEDIMENTO: "EM MINHAS EXPOSIÇOES APRESENTO AS VĀRIAS VISOES OU CONCEPÇðES A RESPEITO DE UM ASSUNTO" NOS GRUPOS A E B - 1980*

\begin{tabular}{|l|r|r|c|c|}
\hline \multirow{2}{*}{$\begin{array}{l}\text { FREQUENCIA DO } \\
\text { PROCEDIMENTO }\end{array}$} & \multicolumn{2}{|c|}{ GRUPO A** } & \multicolumn{2}{c|}{ GRUPO B** } \\
\cline { 2 - 5 } & $\mathrm{N}$ & $\%$ & $\mathrm{~N}$ & $\%$ \\
\hline SEMPRE & 141 & 64,4 & 49 & 62,8 \\
\hline AS VEZES & 74 & 33,8 & 28 & 35,9 \\
\hline NUNCA & 1 & 0,5 & 0 & 0,0 \\
\hline $\begin{array}{r}\text { NAO SABE OU } \\
\text { NAOO RE SPONDEU }\end{array}$ & 3 & 1,4 & 1 & 1,3 \\
\hline TOTAL & 219 & 100,0 & 78 & 100,0 \\
\hline
\end{tabular}

* Dados adaptados de: SOCIEDADE BRASILEIRA DE GEOLOGIA/MINISTERIO DA EDUCACÃo E CULTURA - 1981 - A Formação do Geólogo nas Universidades Brasileiras, um Retrato de Duas Décadas. MEC, Brasilia, 209 pp.

**GRUPO A: Professores que desenvolvem pesquisa

GRUPO B: Professores que não desenvolvem pesquisa

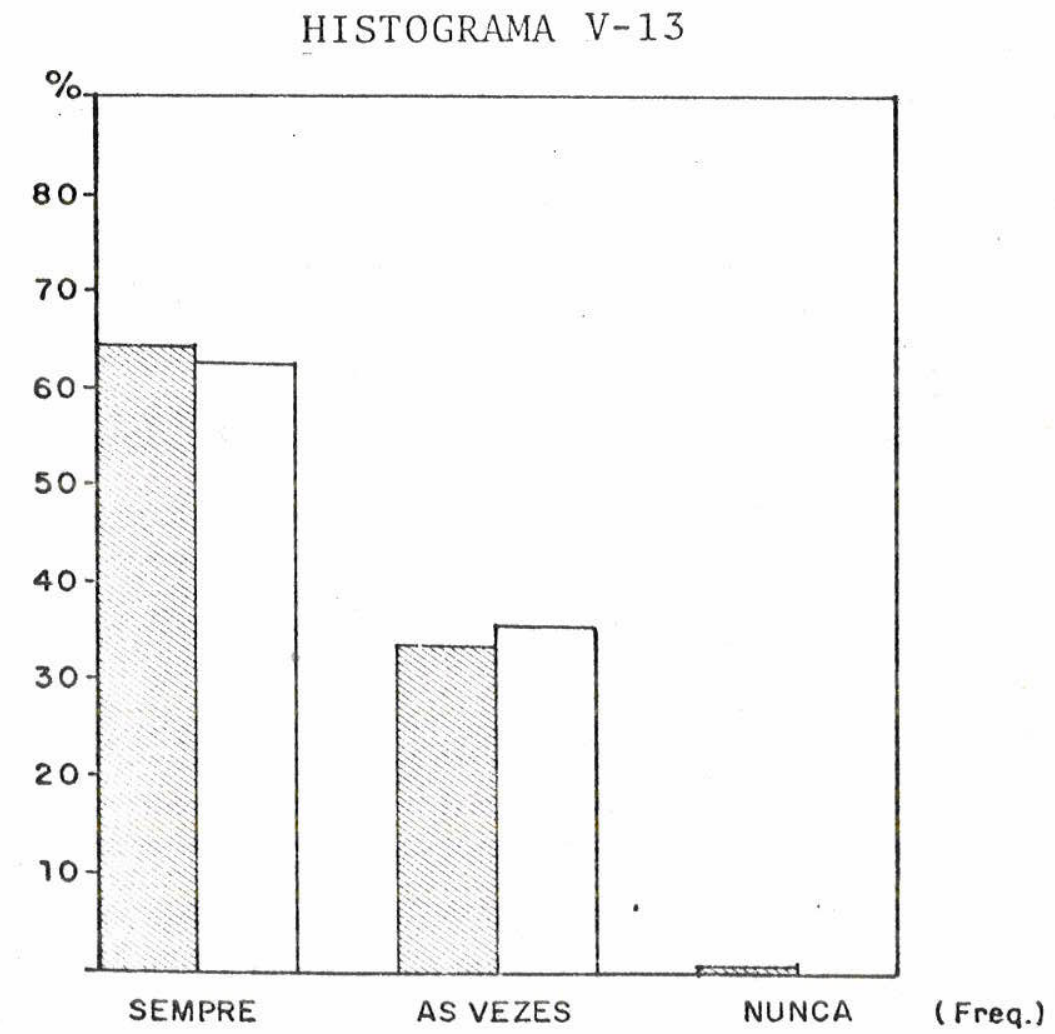

GRUPO A: Professores que desenvolvem pesquisa

GRUPO B: Professores que não desenvolvem pesquisa 
V.1.14 - Procedimento de Ensino n" 14: "Costumo aceitar suges tões dos alunos quanto a modificações do conteüdo do programa"

Ocorre predomínio da alternativa "às vezes" em ambos os Grupos, com valores pröximos a $65,0 \%$. A alternativa menos escolhida pelos respondentes dos dois Grupos foi "nunca" , com valores pröximos a 5,0\% (TABELA e HISTOGRAMA V-14).

Aplicando-se a prova do $\mathrm{x}^{2}$ obtem-se o valor 2,28 . Pa ra $g l=2$ e $\alpha=0,05$ aceita-se $H_{0}$, significando que os Grupos A e B são equivalentes quanto ao procedimento em exame.

Somando-se os valores das frequências dos dois Grupos (A e B), obtem-se os seguintes resultados:

\begin{tabular}{|l|c|c|}
\hline \multirow{2}{*}{$\begin{array}{l}\text { FREQUENCIA DO } \\
\text { PROCEDIMENTO }\end{array}$} & \multicolumn{2}{|c|}{ TOTAL } \\
\cline { 2 - 3 } & $\mathrm{N}$ & \multicolumn{1}{c|}{} \\
\hline SEMPRE & 53 & 17,8 \\
\hline AS VEZES & 180 & 60,6 \\
\hline NUNCA & 21 & 7,1 \\
\hline $\begin{array}{l}\text { NAO SABE OU } \\
\text { NAO RESPONDEU }\end{array}$ & 43 & 14,5 \\
\hline TOTAL & 297 & 100,0 \\
\hline
\end{tabular}

A tendência dos professores é somente "às vezes" aceitar sugestões dos alunos para modificação de conteũdo do programa, pois apenas $17,8 \%$ deles adota "sempre" tal procedimento. 
TABELA $\mathrm{V}-14$

FREQUENCIA DO PROCEDIMENTO: "COSTUMO ACEITAR SUGESTOES DOS ALUNOS QUANTO A MODIFICAÇOES NO CONTEUDO DO PROGRAMA" NOS GRUPOS A E B - 1980*

\begin{tabular}{|l|c|c|c|c|}
\hline \multirow{2}{*}{$\begin{array}{c}\text { FREQUENCIA DO } \\
\text { PROCEDIMENTO }\end{array}$} & \multicolumn{2}{|c|}{ GRUPO A** } & \multicolumn{2}{c|}{ GRUPO B** } \\
\cline { 2 - 5 } & $\mathrm{N}$ & $\%$ & $\mathrm{~N}$ & $\%$ \\
\hline SEMPRE & 42 & 19,2 & 11 & 14,1 \\
\hline AS VEZES & 127 & 58,0 & 53 & 67,9 \\
\hline NUNCA & 17 & 7,8 & 4 & 5,1 \\
\hline $\begin{array}{r}\text { NAO SABE OU } \\
\text { NAO RESPONDEU }\end{array}$ & 33 & 15,1 & 10 & 12,8 \\
\hline TOTAL & 219 & 100,0 & 78 & 100,0 \\
\hline
\end{tabular}

*Dados adaptados de: SOCIEDADE BRASILEIRA DE GEOLOGIA/MINISTERIO DA EDUCAÇAO E CULTURA - 1981 - A Formação do Geölogo nas Universidades Brasileiras, um Retrato de Duas Décadas. MEC, Brasilia, 209 pp.

**GRUPO A: Professores que desenvolvem pesquisa

GRUPO B: Professores que não desenvolvem pesquisa

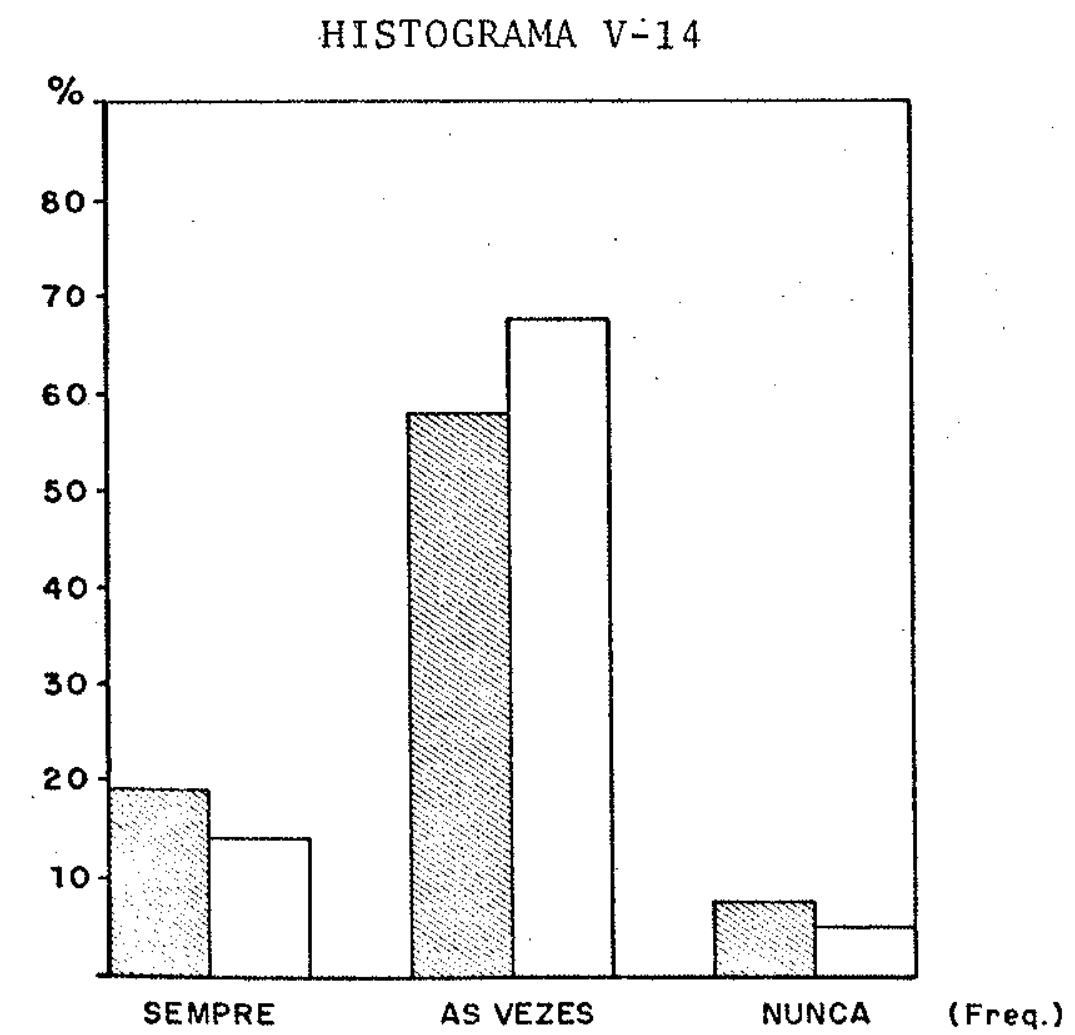

GRUPO A: Professores que desenvolvem pesquisa GRUPO B: Professores que não desenvolvem pesquisa 
V.1.15 - Procedimento de Ensino n" 15: "Incentivo os alunos a formularem hipóteses e a coletarem dados para testar estas hipóteses"

Observa-se predomínio da alternativa "às vezes", com valores da ordem de 50,0\% nos dois Grupos. Seguem-se a alternativa "sempre" com percentuais pröximos entre si, e "nunca", com o mesmo percentual nos dois Grupos (TABELA e HISTOGRAMA $\mathrm{V}-15)$.

Aplicando-se a prova do $x^{2}$ obtem-se o valor 0,50 . Pa ra $g l=2$ e $\alpha=0,05$ aceita-se $H_{0}$, significando que os Grupos A e B são equivalentes quanto a este procedimento. Isto permite que sejam somados os valores das frequências obtidas, originando os seguintes resultados:

\begin{tabular}{|c|c|c|}
\hline \multirow{2}{*}{$\begin{array}{l}\text { FREQUENCIA DO } \\
\text { PROCEDIMENTO }\end{array}$} & \multicolumn{2}{|c|}{ TOTAL } \\
\hline & $\mathrm{N}$ & $\%$ \\
\hline SEMPRE & 75 & 25,3 \\
\hline ȦS VEZES & 148 & 49,8 \\
\hline NUNCA & 38 & 12,8 \\
\hline $\begin{array}{ll}\text { NAO } & \text { SABE OU } \\
\text { NAO } & \text { RESPONDEU }\end{array}$ & 36 & 12,1 \\
\hline TOTAL & 297 & 100,0 \\
\hline
\end{tabular}

Pelo fato de praticamente metade dos professores somente "às vezes" incentivarem os alunos a formularem hipóte ses e a coletarem dados para testā-las, e somente um quarto deles fazerem-no "sempre", caracteriza-se a tendência de "às vezes" adotarem tal procedimento. 
TABELA $\mathrm{V}-15$

FREQUENCIA DO PROCEDIMENTO: "INCENTIVO OS ALUNOS A FORMULAREM HIPOTESES E A COLETAREM DADOS PARA TESTAR ESTAS HIPOTESES" NOS GRUPOS A E B - 1980*

\begin{tabular}{|l|c|c|c|c|}
\hline \multirow{2}{*}{$\begin{array}{c}\text { FREQUENCIA DO } \\
\text { PROCEDIMENTO }\end{array}$} & \multicolumn{2}{|c|}{ GRUPO A** } & \multicolumn{2}{c|}{ GRUPO B** } \\
\cline { 2 - 5 } & $\mathrm{N}$ & $\frac{\mathrm{N}}{\mathrm{N}}$ & $\mathrm{N}$ & $\frac{\mathrm{a}}{\mathrm{O}}$ \\
\hline SEMPRE & 58 & 26,5 & 17 & 21,8 \\
\hline AS VEZES & 108 & 49,3 & 40 & 51,3 \\
\hline NUNCA & 28 & 12,8 & 10 & 12,8 \\
\hline $\begin{array}{r}\text { NAO SABE OU } \\
\text { NAO RESPONDEU }\end{array}$ & 25 & 11,4 & 11 & 14,1 \\
\hline TOTAL & 219 & 100,0 & 78 & 100,0 \\
\hline
\end{tabular}

*Dados adaptados de: SOCIEDADE BRASIIEIRA DE GEOLOGIA/NINISTERIO DA EDUCAÇO E CULTURA - 1981 - A Formação do Geölogo nas Universidades Brasileiras, um Retrato de Duas Dëcadas. MEC, Brasiliza, $209 \mathrm{pp}$.

**GRUPO A: Professores que desenvolvem pesquisa

GRUPO B: Professores que não desenvolvem pesquisa

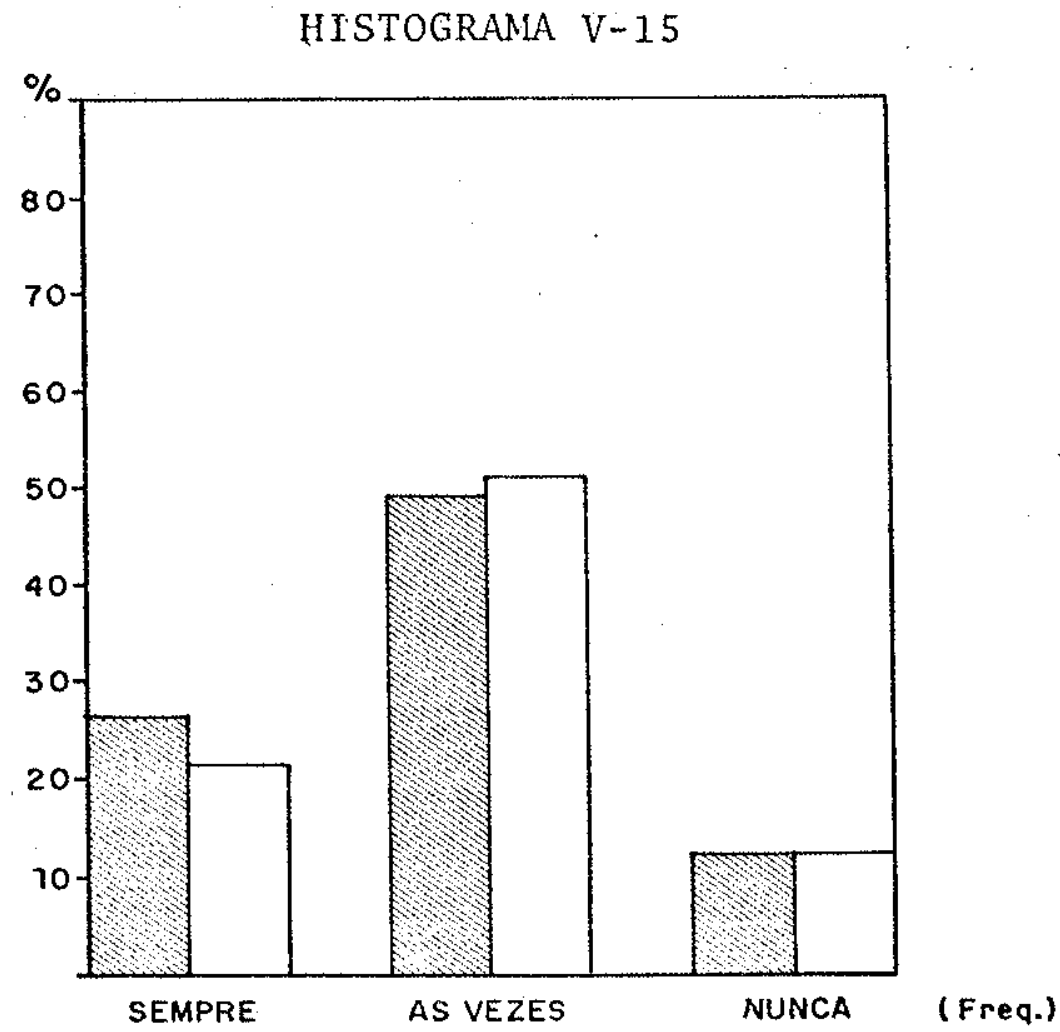

GRUPO A: Professores que desenvolvem pesquisa

GRUPO B: Professores que não desenvolrem pesquisa 
V.1.16 - Procedimento de Ensino n' 16: "Utilizo um único 1ivro-texto"

A alternativa "nunca" é predominante nos dois Grupos A e B, com valores muito próximos e em torno de 80,0\% (TABELA e HISTOGRAMA $V-16$ ).

Aplicando-se a prova do $x^{2}$ obtem-se o valor de 1,22 . Para $g l=2$ e $\alpha=0,05$, aceita-se $H_{0}$, significando que os Grupos A e B são equivalentes em relação a este procedimento de ensino.

Por conseguinte pode-se montar o quadro com a soma das frequências dos Grupos A e B para este procedimento:

\begin{tabular}{|c|c|c|}
\hline \multirow{2}{*}{$\begin{array}{l}\text { FREQUENCIA DO } \\
\text { PROCEDIMENTO }\end{array}$} & \multicolumn{2}{|c|}{ TOTAL } \\
\hline & $N$ & $\stackrel{\circ}{0}$ \\
\hline SEMPRE & 10 & 3,4 \\
\hline ȦS VEZES & 35 & 11,8 \\
\hline NUNCA & 239 & 80,5 \\
\hline $\begin{array}{l}\text { NAO SABE OU } \\
\text { NAO RESPONDEU }\end{array}$ & 13 & 4,4 \\
\hline TOTAL & 297 & 100,0 \\
\hline
\end{tabular}

Indubitavelmente, a tendência dos professores è para "nunca" adotarem um ünico livro-texto em suas disciplinas. 
TABELA $V-16$

FREQUENCIA DO PROCEDIMENTO: "UTILIZO UM ONICO LIVRO-TEXTO" NOS GRUPOS A E B - 1980*

\begin{tabular}{|l|c|c|c|c|}
\hline \multirow{2}{*}{$\begin{array}{c}\text { FREQUENCIA DO } \\
\text { PROCEDIMENTO }\end{array}$} & \multicolumn{2}{|c|}{ GRUPO A** } & \multicolumn{2}{c|}{ GRUPO B** } \\
\cline { 2 - 5 } & $\mathrm{N}$ & $\%$ & $\mathrm{~N}$ & $\%$ \\
\hline SEMPRE & 6 & 2,7 & 4 & 5,1 \\
\hline AS VEZES & 27 & 12,3 & 8 & 10,3 \\
\hline NUNCA & 178 & 81,3 & 61 & 78,2 \\
\hline $\begin{array}{l}\text { NAO SABE OU } \\
\text { NAO RESPONDEU }\end{array}$ & 8 & 3,7 & 5 & 6,4 \\
\hline TOTAL & 219 & 100,0 & 78 & 100,0 \\
\hline
\end{tabular}

*Dados adaptados de: SOCIEDADE BRASILEIRA DE GEOLOGIA/MINISTERIO DA EDUCAÇAO E CULTURA - 1981 - A Formacão do Geólogo nas Universidades Brasileiras, um Retrato de Duas Décadas. MEC, Brasilia, $209 \mathrm{pp}$.

**GRUPO A: Professores que desenvolvem pesquisa

GRUPO B: Professores que não desenvolvem pesquisa

HISTOGRAMA V-16

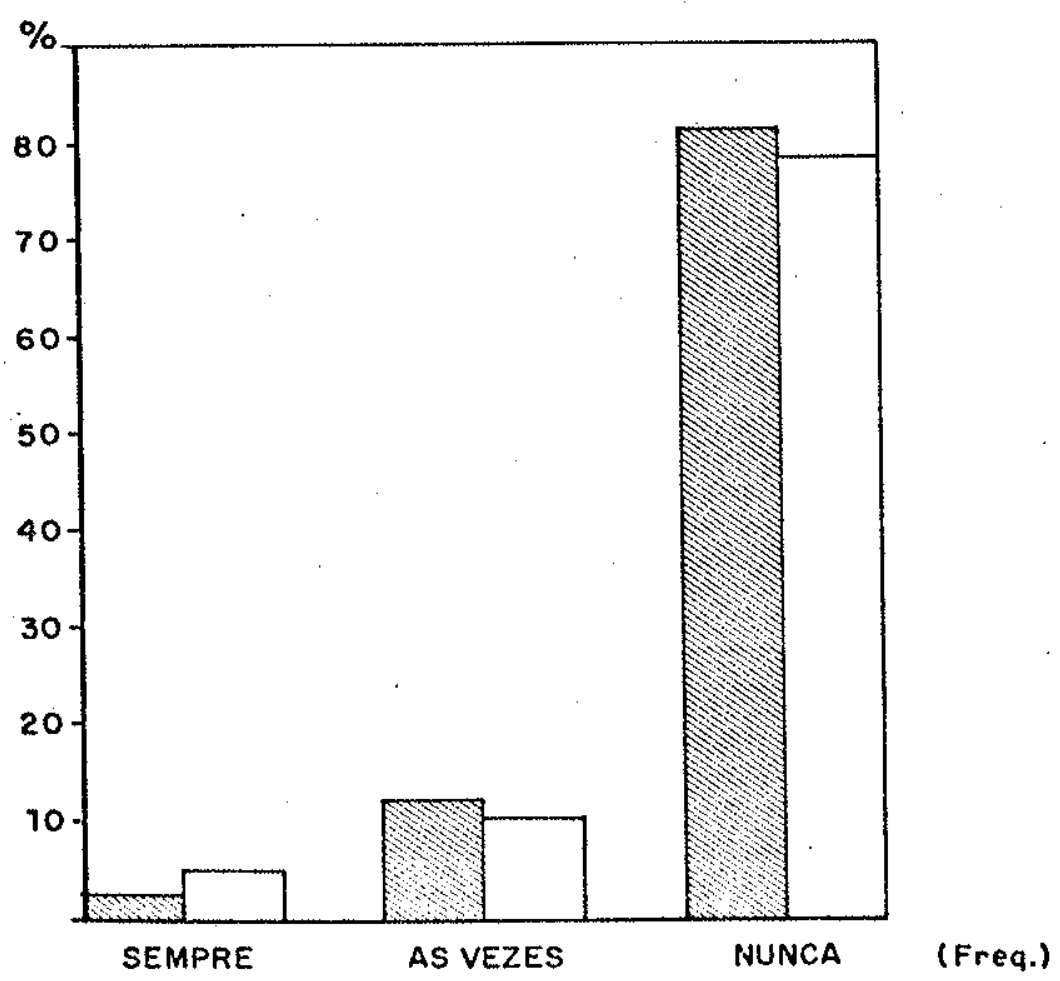

GRUPO A: Professores que desenvolvem pesquisa

GRUPO B: Professores que não desenvolvem pesquisa 
V.1.17: - Procedimento de Ensino n" 17: "Promovo trabalhos de campo, com roteiros de pesquisa"

Verifica-se predominio da alternativa "às vezes", com valores muito próximos nos dois grupos e da ordem de 40,0\%. Aproximadamente $30,0 \%$ dos docentes de cada Grupo escolheu a alternativa "sempre" (TABELA e HISTOGRAMA V-17).

Aplicando-se a prova do $x^{2}$ obtem-se o valor de 0,46 . Para $g l=2$ e $\alpha=0,05$ aceita-se $H_{0}$, significando que os Gru pos A e B são equivalentes.

Somando-se os valores das frequênctas dos Grupos A e $B$ neste procedimento, obtem-se o quadro abaixo:

\begin{tabular}{|c|c|c|}
\hline \multirow{2}{*}{$\begin{array}{l}\text { FREQUENCIA DO } \\
\text { PROCEDTMENTO }\end{array}$} & \multicolumn{2}{|c|}{ TOTAL } \\
\hline & $\mathrm{N}$ & $\%$ \\
\hline SEMPRE & 100 & 33,7 \\
\hline ȦS VEZES & 122 & 41,1 \\
\hline NUNCA & 45 & 15,2 \\
\hline $\begin{array}{ll}\text { NAO } & \text { SABE OU } \\
\text { NAO } & \text { RESPONDEU }\end{array}$ & 30 & 10,1 \\
\hline TOTAL & 297 & 100,0 \\
\hline
\end{tabular}

os professores tendem a promover trabalhos de campo com roteiros de pesquisa "às vezes" ou "sempre". 
TABELA V -17

FREQUENCIA DO PROCEDIMENTO: "PROMOVO TRABALHOS DE CAMPO, COM ROTEIROS DE PESQUISA" NOS GRUPOS A.E B - 1980*

\begin{tabular}{|l|c|c|c|c|}
\hline $\begin{array}{l}\text { FREQUENCIA DO } \\
\text { PROCED IMENTO }\end{array}$ & \multicolumn{2}{|c|}{ GRUPO A** } & \multicolumn{2}{c|}{ GRUPO B** } \\
\cline { 2 - 5 } & $\mathrm{N}$ & $\%$ & $\mathrm{~N}$ & $\%$ \\
\hline SEMPRE & 76 & 34,7 & 24 & 30,8 \\
\hline AS VEZES & 89 & 40,6 & 33 & 42,3 \\
\hline NUNCA & 32 & 14,6 & 13 & 16,7 \\
\hline $\begin{array}{l}\text { NAO SABE OU } \\
\text { NAO RESPONDEU }\end{array}$ & 22 & 10,0 & 8 & 10,3 \\
\hline TOTAL & 219 & 100,0 & 78 & 100,0 \\
\hline
\end{tabular}

*Dados adaptados de: SOCIEDADE BRASILEIRA DE GEOLOGIA/MINISTERIO DA EDUCAÇAO E CULTURA - 1981 - A Formação do Geölogo nas Universidades Brasileiras, um Retrato de Duas Décadas. MEC, Brasilia, 209 pp.

**GRUPO A: Professores que desenvolvem pesquisa

GRUPO B: Professores que não desenvolvem pesquisa

$$
\text { HISTOGRAMA } \mathrm{V}-17
$$

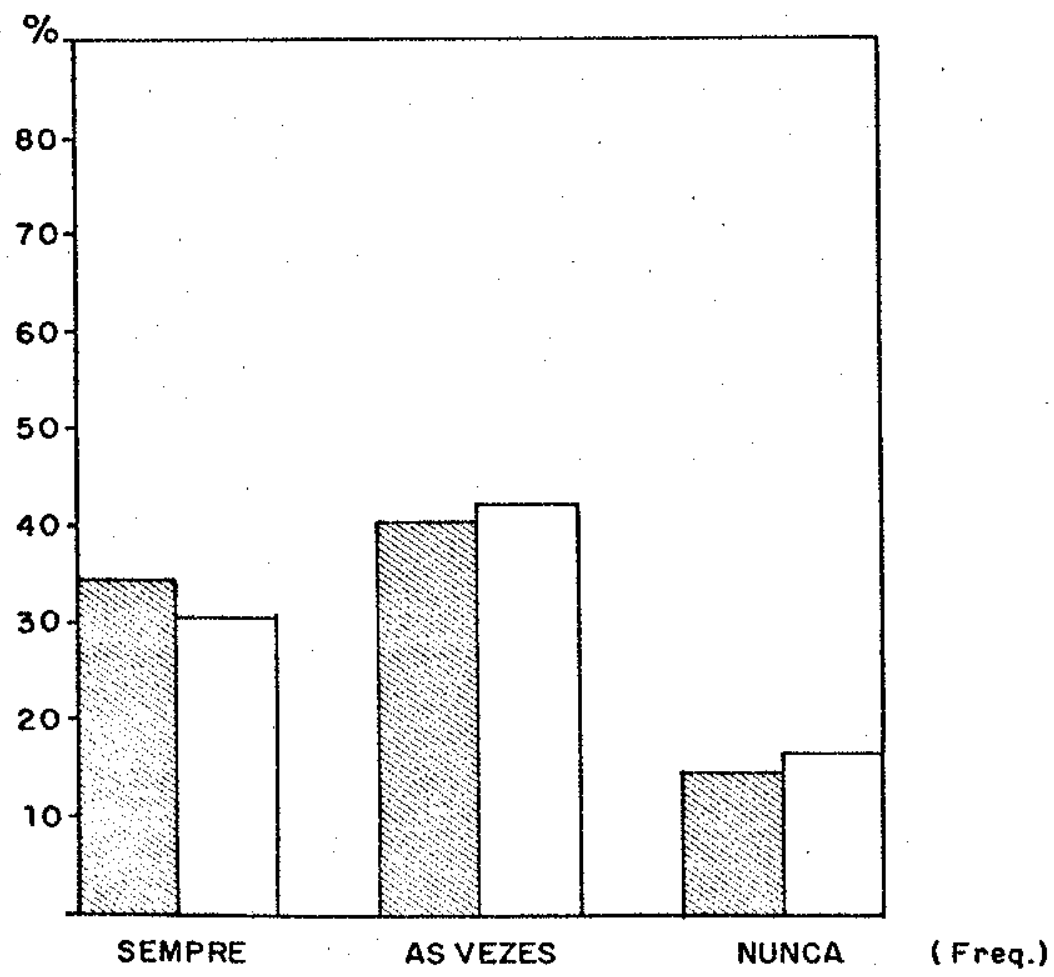

GRUPO A: Professores que desenvolvem pesquisa

GRUPO B: Professores que não desenvolvem pesquisa 
V.1.18 - Procedimento de Ensino n" 18: "Utilizo materiais audio-visuais (mapas, figuras, etc.)"

As alternativas "sempre" e "às vezes" abrangem 99,0\% da amostra (TABELA e HISTOGRAMA V-18).

A existência de frequência nula obrigou à combinação das categorias "às vezes" e "nunca" para permitir aplicação da prova estatística. Obteve-se o valor de 3,91 para o $x^{2}$. Pa ra $g l=1$ e $\alpha=0,05$ rejeita-se $H_{0}$, significando que os Gru pos A e B são distintos em relação a este procedimento de ensino.

No Grupo A observa-se relação de $3: 2$ entre as alternativas "sempre" e "às vezes" e, no Grupo B, a mesma relação é de 1:1. Logo, os professores que desenvolvem pesquisa apresentam tendência maior, do que aqueles que não a desenvolvem, para utilizar materiais audio-visuais em suas atividades de ensino. 
TABELA $\quad \mathrm{V}-18$

FREQUENCIA DO PROCEDIMENTO: "UTILIZO MATERIAIS AUDIO-VISUAIS (MAPAS, FIGURAS, ETC:)" NOS GRUPOS A E B - 1980*

\begin{tabular}{|l|c|c|c|c|}
\hline \multirow{2}{*}{$\begin{array}{l}\text { FREQUENCIA DO } \\
\text { PROCEDIMENTO }\end{array}$} & \multicolumn{2}{|c|}{ GRUPO $\mathrm{A}^{* *}$} & \multicolumn{2}{c|}{ GRUPO $\mathrm{B}^{* *}$} \\
\cline { 2 - 5 } & $\mathrm{N}$ & \multicolumn{1}{c|}{$\%$} & $\mathrm{~N}$ & $\%$ \\
\hline SEMPRE & 134 & 61,2 & 37 & 47,4 \\
\hline AS VEZES & 81 & 37,0 & 41 & 52,6 \\
\hline NUNCA & 4 & 1,8 & 0 & 0,0 \\
\hline $\begin{array}{l}\text { NAO SABE OU } \\
\text { NAO RESPONDEU }\end{array}$ & 0 & 0,0 & 0 & 0,0 \\
\hline TOTAL & 219 & 100,0 & 78 & 100,0 \\
\hline
\end{tabular}

*Dados adaptados de: SOCIEDADE BRASILEIRA DE GEOLOGIA/MINISTERIO DA EDUCAÇAO E CULTURA - 1981 - A Formação do Geólogo nas Universidades Brasileiras, um Retrato de Duas Dëcadas. MEC, Brasilia, $209 \mathrm{pp}$.

**GRUPO A: Professores que desenvolvem pesquisa

GRUPO B: Professores que näo desenvolvem pesquisa

HISTOGRAMA V-18

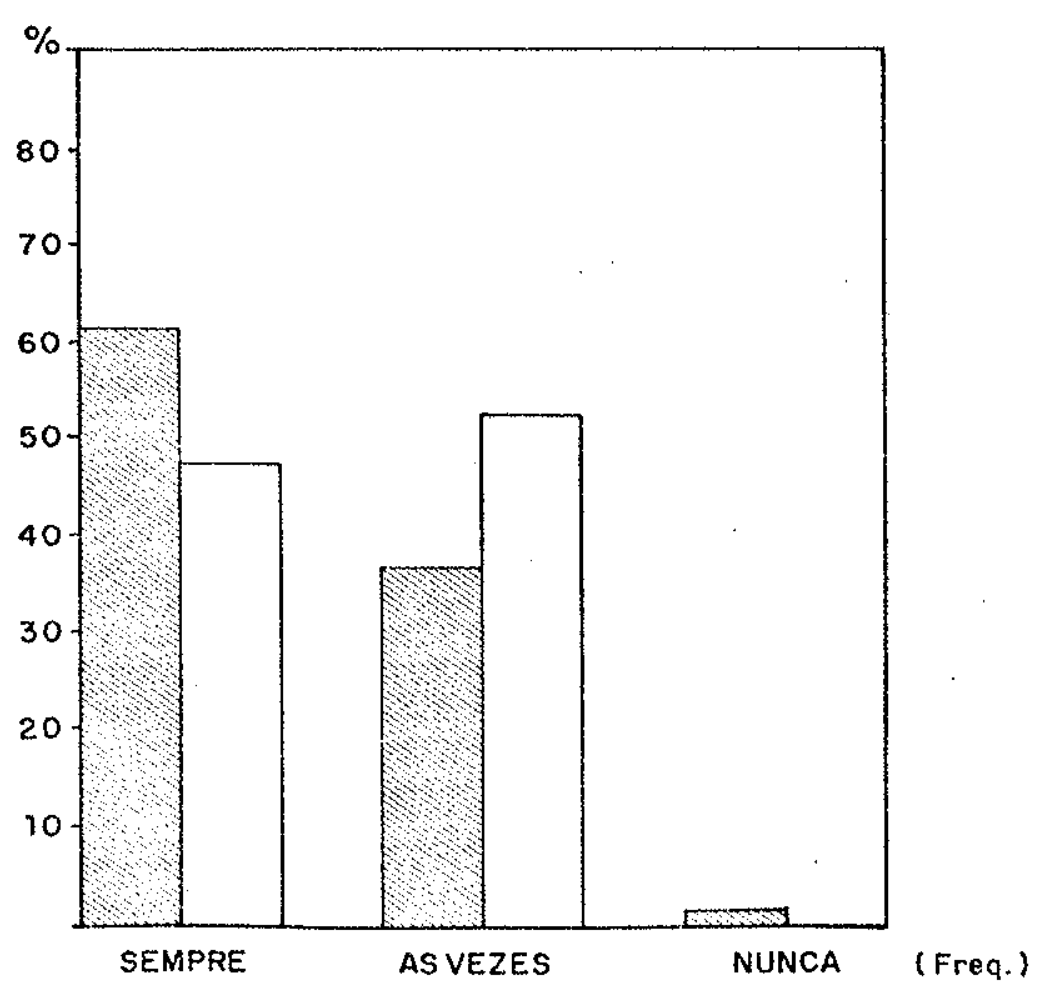

GRUPO A: Professores que desentolvem pesquisa GRUPO B: Professores que não desenvolven pesquisa 


\section{2 - SINOPSE DOS RESULTADOS - PROCEDIMENTOS DE ENSINO INDIVIDUAIS}

\section{V.2.1 - Seme1hanças entre os Grupos A e B}

Os Grupos A e B são semelhantes quanto à frequência de adoção dos seguintes procedimentos de ensino:

a) desenvolvimento de aulas expositivas;

b) valorização de detalhes ou informações especificas sobre o conteüdo;

c) apresentação da matéria na forma de conhecimento acabado;

d) exploração de questões dos alunos durante aulas exposi.tivas;

e) estímulo aos alunos ao julgamento de questões polêmicas;

f) proposição de problemas ou questões polêmicas para discussão pelos alunos;

g) utilização exclusiva de apostilas;

h) incentivo aos alunos à construção de modelos;

i) incentivo aos alunos à captação dos principais concei tos e princípios e de suas interrelações;

j) organização e orientaçāo de trabalhos e discussões de grupo;

k) relação dos temas do programa com os fatos da realida de ;

1) apresentação das vârias concepções a respeito de um mes mo assunto durante aulas expositivas;

m) receptividade a sugestões dos alunos quanto a modificações do conteủdo do programa;

n) incentivo aos alunos à formulação de hipóteses e coleta de dados para testä-las; 
o) utilização exclusiva de um ünico livro-texto;

p) promoção de trabalhos de campo, com roteiros de pesquisa.

V.2.2 - Diferenças entre os Grupos A e B

Os Grupos A e B distinguem-se nos seguintes procedimentos de ensino:

a) os professores do Grupo B tendem a estimular a memoriza ção de conhecimentos com mais frequência que os do Grupo A.

b) os professores do Grupo A tendem a utilizar recursos äu dio-visuais com mais frequência que os do Grupo B.

V. 3 - CARACTERIZAÇAO DA METODOLOGIA DE ENSINO

Os 18 procedimentos de ensino anteriormente apresentados foram selecionados, na elaboração da pesquisa de SBG/MEC, por se referirem a procedimentos usuais no ensino de Geologia no país. Alguns não são exclusivos do ensino de Geologia, como por exemplo, os de $n: 1,2$ e 11. Outros, são específicos do ensino de Geologia, de äreas afins ou das ciências denominadas naturais, como os de $n^{\circ} 2$ e 17 .

Tais procedimentos foram usados para se caracterizar a metodologia de ensino empregada pelos professores. Assim, o procedimento n: 3 - "Apresento a matëria como um corpo de co nhecimentos acabado" - é indicativo do tipo de tratamento que o professor confere ao conhecimento cientifico: um conjunto estätico ou dinâmico de conhecimentos.

Procedeu-se à classificação dos procedimentos de ensino segundo as características da metodologia de ensino que representam: tipo de aprendizagem, forma de obtenção de conhe cimentos, vivência de pesquisa, recursos didáticos, amplitude de conceitos. A cada uma dessas características foram atribuí 
das duas categorias, exprimindo aspectos metodológicos opos- . tos.

A TABELA V-19 apresenta as características metodológicas, suas categorias e os correspondentes procedimentos de ensino. Note-se que um mesmo procedimento pode representar ca racterísticas metodológicas distintas. Assim, o procedimento n' 15 - "Incentivo os alunos a formularem hipóteses e a cole tarem dados para testar essas hipóteses" - é indicativo tanto de "tipo de aprendizagem" quanto de "vivência de pesquisa".

Alêm disso, cada procedimento é também indicador da categoria metodológica oposta. Usando como exemplo o mesmo procedimento $n^{\circ} 15$, pode-se dizer que ele indica a existência de interação entre o professor e seus alunos (aprendizagem in terativa) no caso dos respondentes haverem assinalado as seguintes alternatịvas de resposta: "sempre"; "às vezes". Contu do, ele poderá caracterizar a inexistência de interaçäo entre - professor e seus alunos e, portanto, aprendizagem receptiva. Isto, para o caso dos professores que escolheram a alternativa "nunca".

Finalmente, não foram aproveitados, para a análise, os procedimentos de ensino $n^{\circ} 12$ e 14. Estes procedimentos se referem, especificamente, à vinculação do conteüdo programäti co com a realidade e à contribuição dos alunos para o planeja mento das disciplinas. Não havendo outros procedimentos para contrapor a eles, e eventualmente constituir novas caracterís ticas metodológicas, tiveram de ser excluidos.

A seguir, säo definidas as categorias correspondentes a cada uma das caracteristicas metodológicas. 
TABELA V-19

DISTRIBUIÇAOO DOS PROCEDIMENTOS DE ENSTNO NAS CARACTERISTICAS METODOLOGICAS E RESPECTIVAS CATEGORIAS

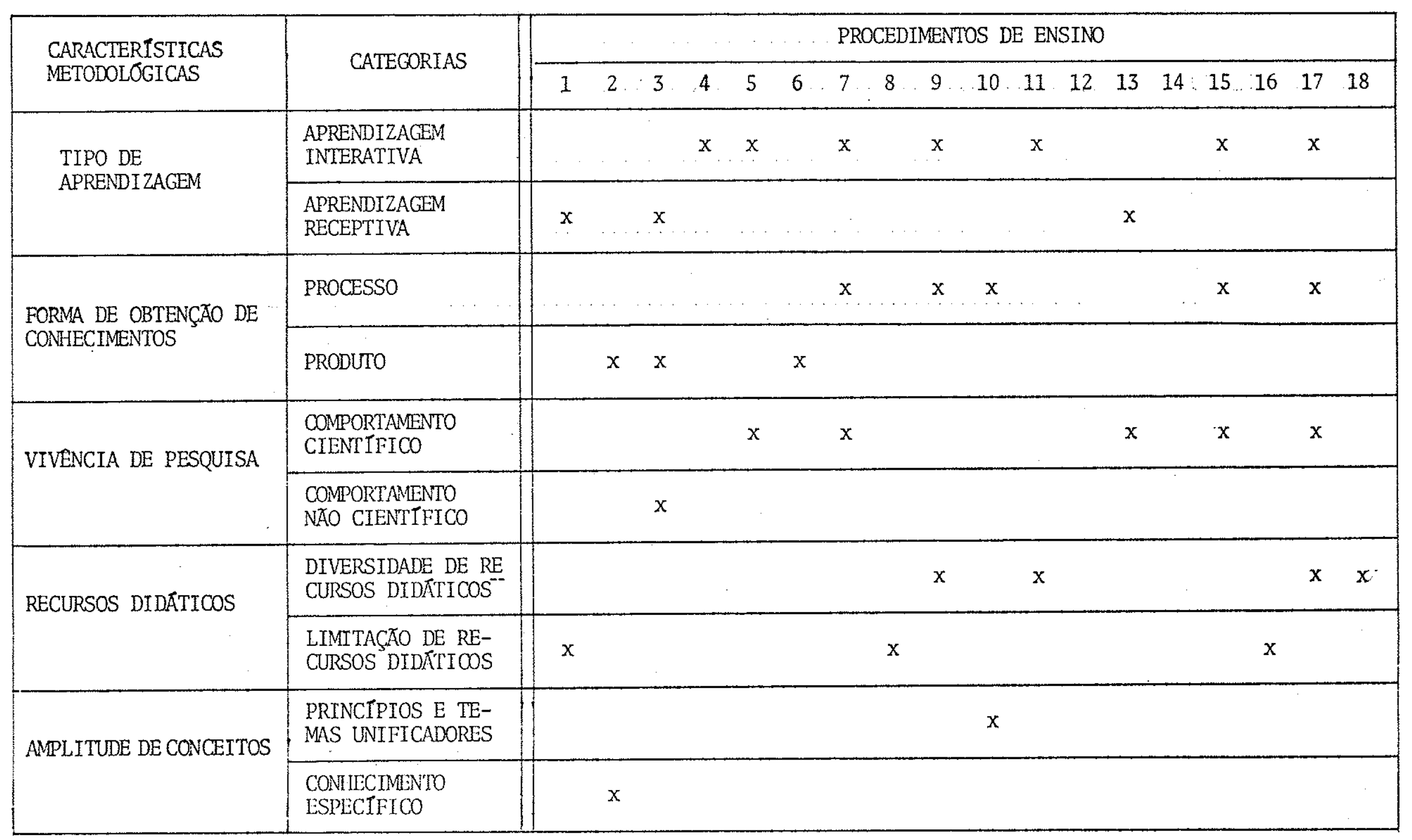


V.3.1 - Tipo de aprendizagem

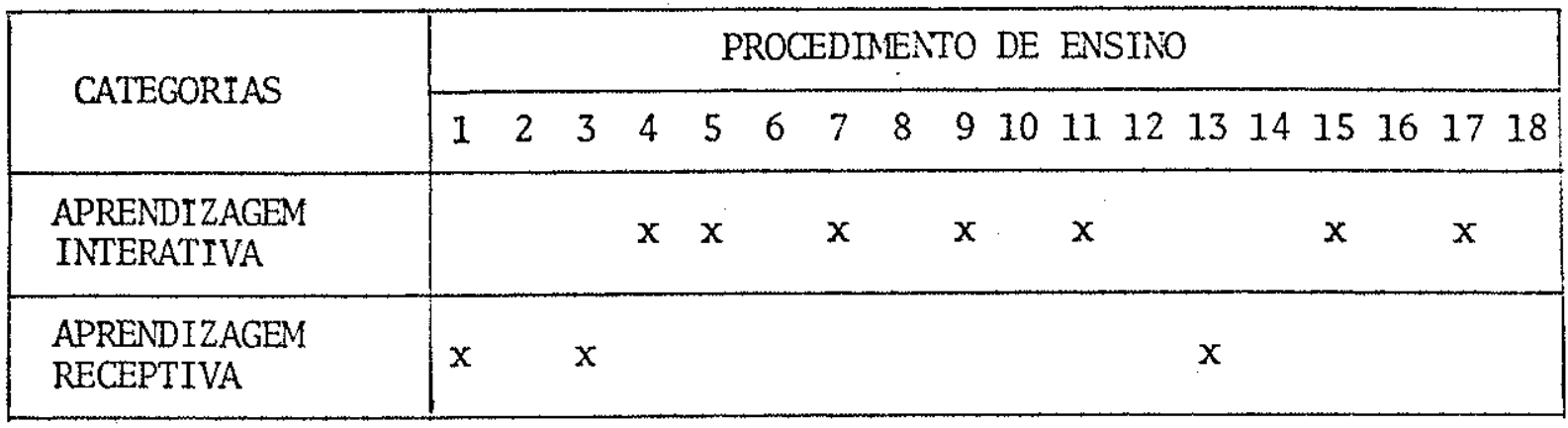

$\mathrm{Na}$ aprendizagem interativa o professor explora as questões propostas pelos alunos, propõe questões polêmicas pa ra discussão em classe, bem como estimula os alunos a emiti rem julgamentos sobre essas questões; incentiva os alunos na coleta de dados e na formulação de hipóteses; organiza e orienta trabalhos de grupo e de campo e discussões dos alunos en tre si; incentiva a construção de mapas ou de outros modelos. Todos esses procedimentos possibilitam o intercâmbio de idéias entre professor e seus alunos e dos alunos entre si. Esses pro cedimentos estão representados na tabela acima e correspondem às afirmações de n: 4, 5, 7, 9, 11, 15 e 17 .

$\mathrm{Na}$ aprendizagem receptiva o professor ministra a maior parte de suas aulas sob forma expositiva. Nelas, o conteúdo pode ser apresentado de maneiras opostas: nas suas diversas concepçóes contemporâneas ou diacrônicas, ou como corpo de conhecimentos acabado, isto $\vec{e}$, não sujeitos às transfor mações. Entretanto, em qualquer desses casos, a mera exposi ção de conhecimentos, na medida em que não propicia o inter câmbio de idéias entre o professor e os alunos e dos alunos entre si, representa aprendizagem receptiva. Os procedimentos de ensino correspondentes a essa categoria são os de $n^{\circ} 1,3$ e 13 . 
V.3.2 - Forma de obtenção de conhecimentos

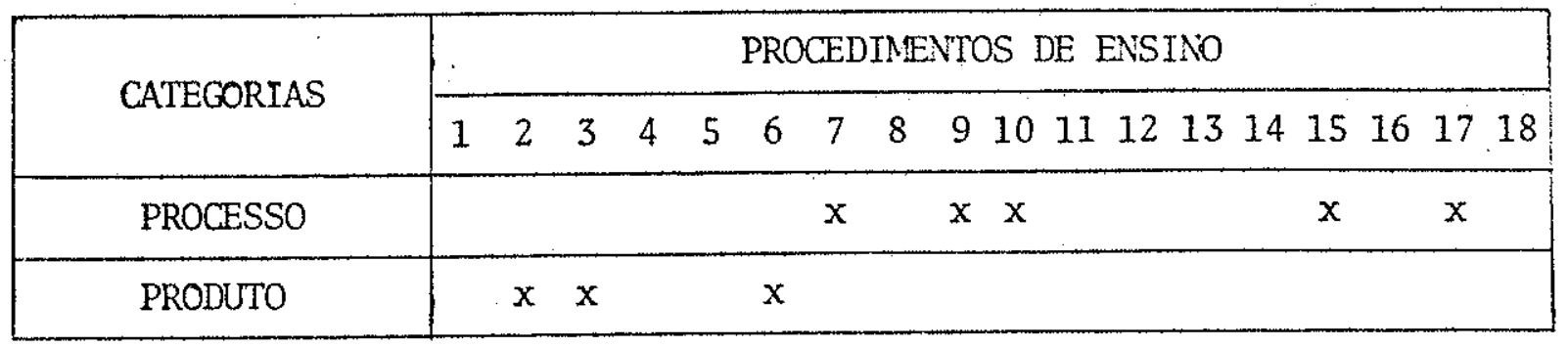

As categorias processo e produto representam situações de ensino nas quais ocorrem, respectivamente, a valorização da aprendizagem dos processos de obtenção do conhecimento geołógico ou valorização do conhecimento geológico em si mesmo, produto desse processo.

Assim, a característica metodológica processo $\vec{e}$ in dicada pelos procedimentos do professor quando: incentiva os alunos a formularem hipóteses e a coletarem dados para testar essas hipóteses; promove trabalhos de campo com roteiros de pesquisa; incentiva os alunos a perceberem interrelações entre os principais conceitos e principios; incentiva os alunos a construirem maquetes, mapas, modelos ou thes propõe problemas ou questões polêmicas para serem discutidas. Em todas essas situações pressupõe-se que o professor esta ensinando com portamentos usuais de investigação em geologia e/ou incenti vando seus alunos a executarem essas condutas de pesquisa. São correspondentes a essa categoria os procedimentos de ensino $n$ ? $7,9,10,15$ e 17 .

Por sua vez, a categoria produto refere-se, alëm das negativas dos procedimentos acima, às situações em que o professor: apresenta a matéria como corpo de conhecimentos acabado; estimula a memorização de conhecimentos; valoriza o conhecimento de detalhes ou informações específicas sobre o conteủdo de sua disciplina. A essa categoria correspondem os procedimentos de ensino de n? 2,3 e 6 . 
V.3.3 - Vivência de pesquisa

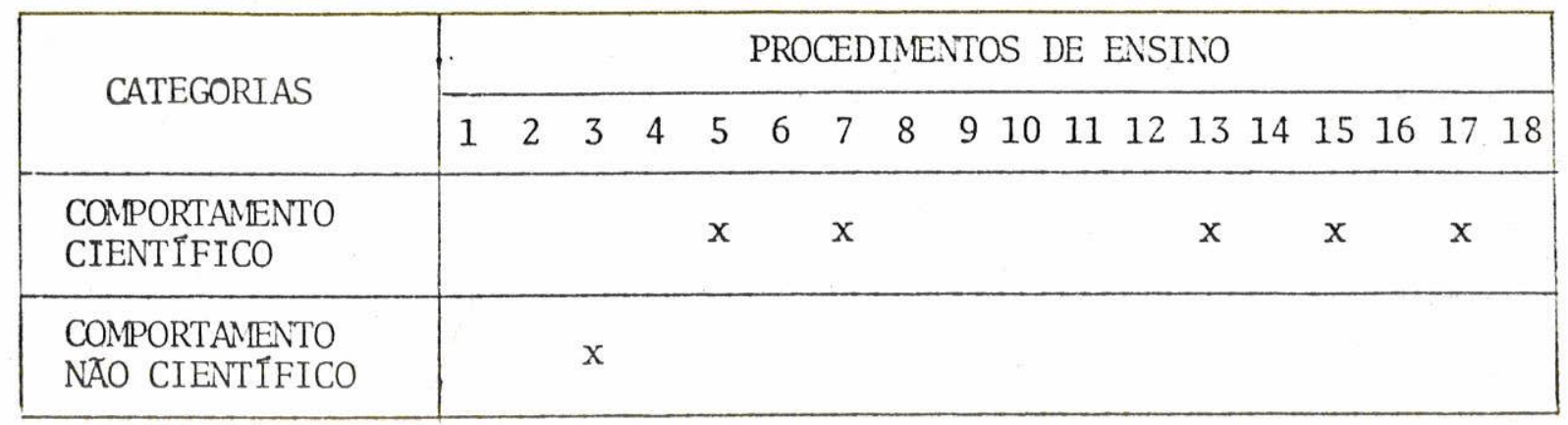

A categoria comportamento científico è indicada pelos procedimentos de ensino desenvolvidos pelo professor que incentiva seus alunos a formularem hipóteses e a coletarem da dos para testar essas hipóteses; promove trabalhos de campo com roteiros de pesquisa. E tambẻm indicado pelos procedimentos que traduzem comportamentos não dogmáticos, tais como: in centivar os alunos a emitirem julgamentos sobre questões polê micas ou expor as várias visões ou concepções existentes a respeito de um assunto. Essa categoria é representada pelos procedimentos de ensino de $n^{\circ}$ 5, 7, 13, 15 e 17 .

A categoria comportamento não científico, por sua vez, é indicada pelos procedimentos de ensino desenvolvidos pelo professor que não incentiva seus alunos a formularem hipóteses e a testā-las, não promove trabalhos de campo ou ofaz sem utilização de roteiros de pesquisa ou, então, que tradu zem comportamentos dogmäticos, como os de ensinar a matéria como um corpo de conhecimentos acabado. E correspondente a es sa categoria o procedimento de ensino de n: 3 além, é claro, dos procedimentos que correspondem à negação da categoria anterior. 
V.3.4 - Recursos didáticos

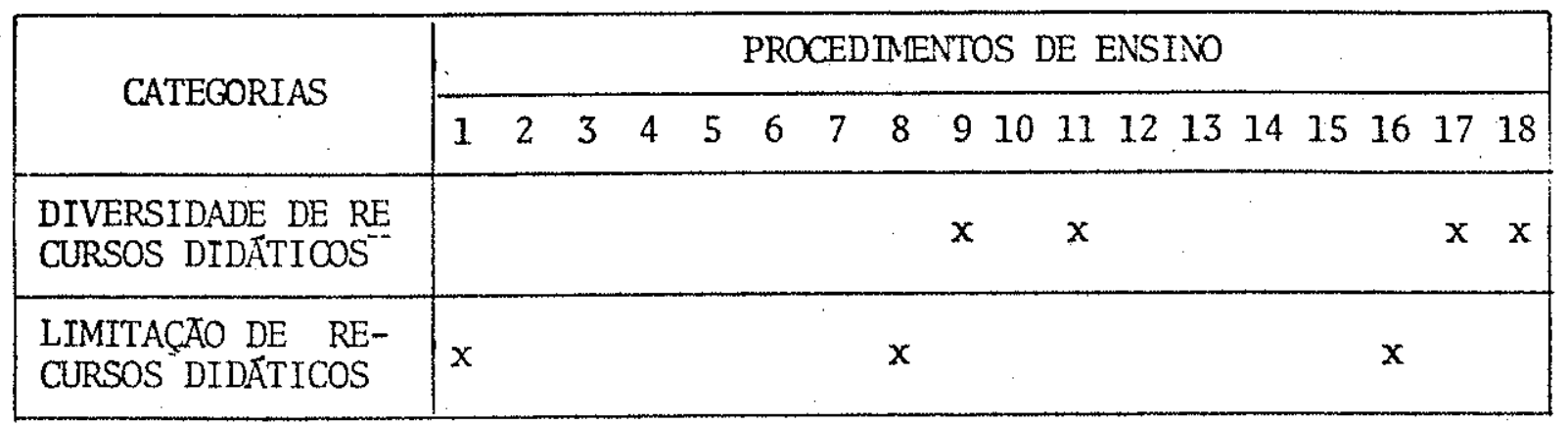

A categoria diversidade de recursos didäticos pode se manifestar de duas formas: mediante a diversificação de um ünico tipu de recurso, por exemplo, o uso de diversos recur sos audio-visuais, a construção de diferentes modelos, etc.; ou através da diversificação de recursos de natureza distinta, por exemplo, a utilização de roteiros de pesquisa, büssola, ma pas, etc., no trabalho de campo. São indicativos dessa catego ria os procedimentos de ensino de $\mathrm{n}^{\circ} 9,11,17$ e 18 .

A categoria limitação de recursos didáticos refere -se ao ensino restrito a praticamente um ünico tipo de recurso didático, por exemplo, restrição do ensino apenas a aulas expositivas; uso ou indicação exclusivamente de apostilas ou de um ünico livro-texto para fonte de informaçōes sobre o con teúdo. Essa categoria é representada pelos procedimentos de ensino de $n^{\circ} 1,8$ e 16 . 
V.3.5 - Amplitude de conceitos

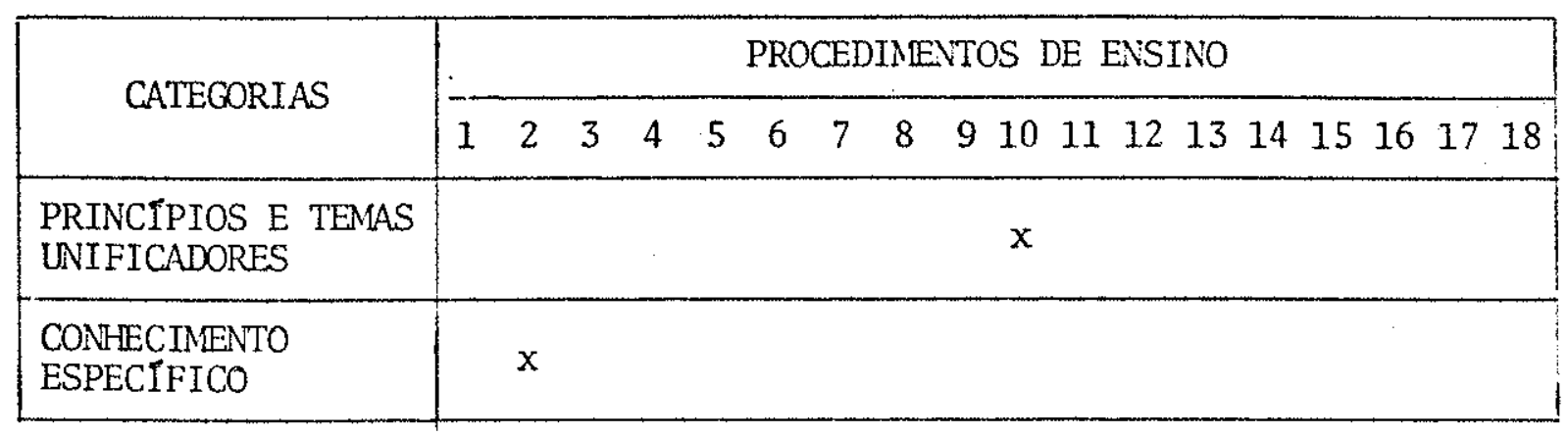

A categoria princípios e temas unificadores represen ta a preocupação do professor em destacar a essência e estrutura da ciência. Manifesta-se, por exemplo, no estímulo à cap tação, por parte dos alunos, dos princípios e conceitos mais importantes e das relações entre eles. Essa categoria tem como indicador o procedimento $\mathrm{n}: 10$.

A categoria conhecimento especifico representa 0 interesse do professor em destacar fatos e informações particulares. Está associada à valorização do conhecimento de deta Thes do conteúdo programático e o procedimento de ensino que a indica $\bar{e} \circ$ de $n^{\circ} 2$. 
o delineamento da metodologia de ensino utilizada pe los professores, feito com base nas categorias definidas no item V.3, ë apresentado a seguir. A sequência è a mesma para cada característica metodológica: 1istagem dos procedimentos de ensino correspondentes às suas categorias, tabela contendo os percentuais das alternativas de frequência dos mesmos procedimentos e, finalmente, descrição e anälise dos resultados. os procedimentos em que a tendência dos Grupos A e B é dife renciada foram tambëm incluídos, registrando-se, nesse caso, os percentuais dos dois grupos.

\section{V.4.1 - Tipo de Aprendizagem}

4. Durante as aulas expositivas exploro as questões levantadas pelos alunos.

5. Estimulo os alunos a emitirem julgamentos sobre questões polêmicas.

7. Proponho problemas ou questões polêmicas para os alunos discutirem.

9. Incentivo os alunos a construirem maquetes, mapas, mode los, etc.

11. Organizo e oriento trabalhos e discussões de grupo.

15. Incentivo os alunos a formularem hipóteses e a coleta rem dados para testar estas hipöteses.

17. Promovo trabalhos de campo, com roteiros de pesquisa.

1. Costumo dar a malor parte das minhas aulas de forma expositiva.

3. Apresento a matëria como um corpo de conhecimentos acabado.

13. Em minhas exposições, apresento as värias visões ou con cep̧ões existentes a respeito de um assunto. 


\begin{tabular}{|c|c|c|c|c|c|c|c|c|c|c|}
\hline \multicolumn{7}{|c|}{ TIPO DE APRENDI ZAGEM } \\
\hline CATEGORIA & \multicolumn{7}{|c|}{ APRENDIZAGEM INTERATIVA } & \multicolumn{2}{c|}{$\begin{array}{c}\text { APRENDIZAGEM } \\
\text { RECEPTIVA }\end{array}$} \\
\hline $\begin{array}{l}\text { Prequência do } \\
\text { Procedimento }\end{array}$ & 4 & 5 & 7 & 9 & 11 & 15 & 17 & 1 & 3 & 13 \\
\hline SEMPRE & 63,0 & 45,8 & 22,6 & 27,6 & 25,9 & 25,3 & 33,7 & 49,5 & 3,4 & 64,0 \\
\hline AS VEZES & 34,1 & 47,1 & 65,0 & 47,8 & 57,9 & 49,8 & 41,1 & 43,1 & 18,5 & 34,3 \\
\hline NUNCA & 1,0 & 2,0 & 7,7 & 14,5 & 12,5 & 12,8 & 15,2 & 6,1 & 63,0 & 0,3 \\
\hline
\end{tabular}

A alternativa "às vezes" é dominante na maior parte dos procedimentos de ensino correspondentes a aprendizagem in terativa (procedimentos $n^{\circ} 7,9,11,15$ e 17). No procedimento $n^{9} 4$, em que a iniciativa para interação não depende somen te do professor, mas também do aluno, predomina a alternativa "sempre". No procedimento $n^{\circ} 5$, as alternativas "sempre" e "às vezes" são praticamente equivalentes e, somadas, abrangem mais de $90 \%$ da amostra.

A alternativa. "sempre" $\vec{e}$ dominante nos procedimentos de ensino $n^{\circ} 1$ e 13, correspondentes a aprendizagem receptiva, enquanto a alternativa "nunca" predomina noprocedimento $n$ * 3 .

Verifica-se que os professores tendem a ser partidārios da aprendizagem receptiva através da dominância da altex nativa "sempre" nessa categoria e "às vezes" na categoria aprendizagem interativa. Entretanto, $\bar{e}$ fundamental assinalar que eles não parecem refratärios à aprendizagem interativa, o que $\vec{e}$ indicado principalmente pelo percentual das frequências "sempre" dos procedimentos $n^{8} 4$ e 5 e "nunca", do procedimento $n^{\circ} 3$. 
V.4.2 - Forma de Obtenção de Conhecimentos

7. Proponho problemas ou questões polêmicas para os alunos discutirem.

9. Incentivo os alunos a construirem maquetes, mapas, mode los, etc.

10. Procuro incentivar os alunos a captarem os principais conceitos e princípios e perceberem interrelaçōes.

15. Incentivo os alunos a formularem hipóteses e a coleta rem dados para testar estas hipóteses.

17. Promovo trabalhos de campo, com roteiros de pesquisa.

2. Valorizo o conhecimento de detalhes ou informações espe cíficas sobre o conteúdo de minha disciplina.

3. Apresento a materia como um corpo de conhecimentos acabado.

6. Estimulo a memorização de conhecimentos.

\begin{tabular}{|c|c|c|c|c|c|c|c|c|c|}
\hline \multicolumn{3}{|c|}{ FORMA DE OBTENÇAO DE CONHECIMENTOS } \\
\hline CATECORTA & \multicolumn{3}{|c|}{ PROCESSO } & \multicolumn{3}{|c|}{ PRODUTO } \\
\hline $\begin{array}{c}\text { Prequência do } \\
\text { Procedimento }\end{array}$ & 7 & 9 & 10 & 15 & 17 & 2 & 3 & $6-\mathrm{GA}$ & $6-\mathrm{GB}$ \\
\hline SEMPRE & 22,6 & 27,6 & 89,2 & 25,3 & 33,7 & 32,0 & 3,4 & 16,9 & 33,3 \\
\hline AS VEZES & 65,0 & 47,8 & 9,8 & 49,8 & 41,1 & 53,2 & 18,5 & 56,6 & 43,6 \\
\hline NUNCA & 7,7 & 14,5 & 0,0 & 12,8 & 15,2 & 7,4 & 63,0 & 20,5 & 19,2 \\
\hline
\end{tabular}

A exceção dos procedimentos de ensino n 10 e 3 , a alternativa "às vezes" é dominante em todos os demais, quer se refiram à categoria "processo", quer a "produto".

Portanto, considerando o conjunto de respostas, a tendência dos professores é não privilegiar qualquer das cate gorias desta caracteristica metodológica, revelando indefinição quanto à sua preferência. 
Tomadas isoladamente, ambas as respostas fornecidas aos procedimentos n: 10 e 3 favorecem a categoria "processo". Este favorecimento, porëm, revela-se duvidoso na medida em que se detecta incoerência de uma parcela dos respondentes: en quanto a alternativa "sempre" do procedimento 10 atinge quase $90 \%$, a mesma alternativa dos procedimentos 2 e 6 (este do Gru po B) atingem cerca de $1 / 3$ dos respondentes. A incoerência ad vem de se tratarem de procedimentos de natureza contrária.

\section{V.4.3 - Vivência de Pesquisa}

5. Estimulo os alunos a emitirem julgamentos sobrequestōes polêmicas.

7. Proponho problemas ou questões polêmicas para os alunos discutirem.

13. Em minhas exposições, apresento as värias visões ou con cepçöes existentes a respeito de um assunto.

15. Incentivo os alunos a formularem hipöteses e a coleta rem dados para testar estas hipóteses.

17. Promovo trabalhos de campo, com roteiros de pesquisa.

3. Apresento a matéria como um corpo de conhecimentos acabado.

\begin{tabular}{|c|c|c|c|c|c|c|}
\hline \multicolumn{7}{|c|}{ VIVENCIA DE PESQUISA } \\
\hline CATEGORTAS & \multicolumn{3}{|c|}{ COMPORTAMENTO CIENT IFICO } & NAO \\
\hline $\begin{array}{l}\text { Frequência do } \\
\text { Procedimento }\end{array}$ & 5 & 7 & 13 & 15 & 17 & 3 \\
\hline SEMPRE & 45,8 & 22,6 & 64,0 & 25,3 & 33,7 & 3,4 \\
\hline AS VEZES & 47,1 & 65,0 & 34,3 & 49,8 & 41,1 & 18,5 \\
\hline NUNCA & 2,0 & 7,7 & 0,3 & 12,8 & 15,2 & 63,0 \\
\hline
\end{tabular}

Na categoria "comportamento científico", a alternati 
va "às vezes" é dominante em três dos procedimentos de ensino (procedimentos $n^{\circ} 7,15$ e 17) e praticamente igual à alternativa "sempre" em um deles (procedimento $n^{\circ} 5$ ). O procedimento $n^{8} 13$ é o ünico em que predomina a alternativa "sempre".

No ünico procedimento de ensino correspondente à categoria "comportamento não científico" (procedimento n? 3 ), predomina a alternativa "nunca".

Pode-se classificar os procedimentos correspondentes à categoria "comportamento científico" em dois níveis: (a) ado ¿̧ão do comportamento científico frente aos alunos (procedimen to $n^{\circ}$ 13) e (b) promoção de adoção do comportamento científico pelos alunos (procedimentos n: $5,7,15$ e 17).

Indicam que o professor procede de acordo com o primeiro nivel a resposta ao procedimento $n^{\circ} 13$ e tambëm a alter nativa "nunca" correspondente ao procedimento $n^{\circ} 3$ da categoria "comportamento não científico". A promoção de adoção do comportamento cientifico $\vec{e}$ indicada em menor intensidade, face ao predominio de respostas "às vezes".

Verifica-se que os professores tendem a adotar comportamento cientifico frente aos alunos mas nem sempre a promover sua adoção pelos alunos.

\section{V.4.4- Recursos Didáticos}

9. Incentivo os alunos a construírem maquetes, mapas, mode los, etc.

11. Organizo e oriento trabalhos e discussōes de grupo.

17. Promovo trabalhos de campo, com roteiros de pesquisa.

18. Utilizo materiais âuio-visuais (mapas, figuras, etc.).

1. Costumo dar a maior parte das minhas aulas de forma expositiva.

8. Utilizo somente apostilas.

16. Utilizo um único livro-texto. 


\begin{tabular}{|c|c|c|c|c|c|c|c|c|}
\hline \multicolumn{8}{|c|}{ RECURSOS DIDATICOS } \\
\hline CATEGORIAS & \multicolumn{7}{|c|}{ DIVERSIDADE } & \multicolumn{2}{|c|}{ LIMITACAO } \\
\hline $\begin{array}{c}\text { Frequência do } \\
\text { Procedimento }\end{array}$ & 9 & 11 & 17 & $18 \mathrm{GA}$ & $18 \mathrm{~GB}$ & 1 & 8 & 16 \\
\hline SEMPRE & 27,6 & 25,9 & 33,7 & 61,2 & 47,4 & 49,5 & 2,7 & 3,4 \\
\hline AS VEZES & 47,8 & 57,9 & 41,1 & 37,0 & 52,6 & 43,1 & 24,9 & 11,8 \\
\hline NUNCA & 14,5 & 12,5 & 15,2 & 1,8 & 0,0 & 6,1 & 67,7 & 80,5 \\
\hline
\end{tabular}

Os percentuais das respostas, de maneira geral, favo recem a categoria "diversidade de recursos didäticos". Os úni cos indicadores de limitação são os percentuais correspondentes ao procedimento $n^{\circ} 1$, que revelam preferência dos professores pela adoção de aulas expositivas.

Examinando mais acuradamente as respostas fornecidas, nota-se que a tendência mais forte à diversidade de recursos didäticos dā-se, à exceção do $n^{\ominus} 1$, nos procedimentos que não explicitam qualquer atividade dos estudantes, isto $\vec{e}$, os de $\mathrm{n}$ : 18,8 e 16. Nos procedimentos 9,11 e 17 , em que a ativida de dos alunos é explicitada, predomina a resposta "às vezes".

Em resumo, os professores tendem a utilizar diversos recursos didäticos, mas com mais frequência aqueles que não dependem da promoção de atividades dos alunos.

\section{V.4.5 - Amplitude de Conceitos}

10. Procuro incentivar os alunos a captarem os principais conceitos e princípios e pexceberem interrelações.

2. Valorizo o conhecimento de detalhes ou informações especificas sobre o conteüdo de minha disciplina. 


\begin{tabular}{|c|c|c|}
\hline \multicolumn{3}{|c|}{ AMPLITUDE DE CONCEITOS } \\
\hline CATEGORIAS & PRINCIPIOS & CON.ESP \\
\hline $\begin{array}{c}\text { Frequencia do } \\
\text { Procedimento }\end{array}$ & 10 & 2 \\
\hline SEMPRE & 89,2 & $32 ; 0$ \\
\hline AS VEZES & 9,8 & 53,2 \\
\hline NUNCA & 0,0 & 7,4 \\
\hline
\end{tabular}

Quase 90\% dos professores "sempre" incentiva os alunos a captarem os principais conceitos e perceberem interrela ções. Uma parcela destes professores, conforme foi visto, entra em contradição ao assinalar a mesma alternativa para a va lorização de detalhes e informações específicas.

A mencionada contradição, aliada ao baixo percentual de respostas "nunca" correspondentes ao procedimento de ensino $n^{\circ} 2$, revelam indefinição dos professores quanto à caracte rística metodológica em questão.

V.5 - SINOPSE DOS RESULTADOS - CARACTERISTICAS METODOLOGICAS

As principais tendências dos docentes quanto às suas características metodológicas, independentemente de pertencerem ao Grupo A ou B, são as seguintes:

- Desenvolver aprendizagem receptiva. Nota-se, porém, que os professores manifestan tambëm disposição de atender aos alu nos em suas dificuldades. O interesse dos professores diminui no que se refere à proposição de problemas e trabalhos ao Cor po discente. 
- Adotar comportamento científico. Os professores adotam comportamento cientifico frente aos alunos, mas promovem a ado ção por eles desse comportamento com frequência muito menor.

- Utilizar diversos recursos didâticos. Entretanto, os recursos didáticos que incluem atividades dos alunos são muito menos utilizados.

Alêm dessas tendências, os professores manifestaram indefinição quanto às seguintes caracteristicas metodológicas: forma de obtenção de conhecimentos e amplitude de conceitos.

Assim, os professores valorizam, nas situações de en sino, tanto o processo de obtenção de conhecimentos quanto o produto, isto $\breve{e}$, o resultado desse processo. Da mesma forma, valorizam tanto conceitos e princípios gerais, que constituem a própria estrutura da ciência, quanto detalhes e informações específicas.

No que se refere às hipöteses de trabalho, estes resultados apenas formalizam o que $j \vec{a}$ era perceptivel no item V.1, onde os Grupos A e B foram constatados equivalentes em relação a quase todos os procedimentos de ensino: infirmam to das as hipóteses de trabalho relacionadas com metodologia de ensino (hipóteses 2.1 a 2.5). Assim, não é possível estabeledistinção entre os Grupos A e B atravēs de qualquer das carac terísticas metodológicas delineadas.

V.6 - PERFIL DO PROFESSOR SEGUNDO SUAS CARACTERISTICAS METODOLOGICAS

Algumas caracteristicas metodológicas e mesmo procedimentos de ensino isolados permitem divisar a importância que o professor atribui às suas atividades de ensino. Por exem plo, ao utilizar diversos recursos didaticos, atender aos alu nos em suas dưvidas ou apresentar as diferentes concepçōes acerca de um assunto, demonstra o professor interesse em trans mitir seus conhecimentos e sua experiência.

Todavia, a partir de outras características metodoló 
gicas e procedimentos, percebe-se que o professor tende a $1 i$ mitar a participação do aluno. Por exemplo, ao promover apren dizagem receptiva, adotar comportamento cientifico frente aos alunos mas pouco promovê-lo entre eles, ou utilizarmuitomais aqueles recursos didäticos que não incluem atividades dos alu nos. Portanto, tende a encarar o aluno mais como "paciente" do que "agente" do processo de ensino-aprendizagem, de acordo com a terminologia utilizada por Paschoale e Outros (1981, p. 40).

Entre todas as características metodológicas duas cha mam mais atenção, em virtude da manifesta indefinição dos pro fessores em relação a elas: "forma de obtenção de conhecimentos" e "amplitude de conceitos". Os depoimentos fornecidos in dicam mesma ênfase, de um lado à aprendizagem de processos de obtençäo de conhecimentos e da estrutura da ciência e, de outro, à aprendizagem de fatos e informações particulares.

o conjunto de resultados revela que as caracteristicas da metodologia de ensino empregada pelos professores são predominantemente aquelas dos chamados cursos tradicionais. 


\section{A P I T \\ CONCLUSOES}

1. Algumas variāveis 1 igadas à situação funcional dos professores e às respectivas instituiçōes propiciaram dis tinguir entre si os dois grupos considerados (professores que desenvolvem e que não desenvolvem pesquisa). Todavia, não foi possivel distinguí-1os ao tomar-se por referência caracteristicas metodológicas de ensino. Aparentemente, o fato de desen volver pesquisa não exerce influência quanto à adoção, pelos professores, da metodologia de ensino dos chamados cursos modernos.

Esta situação pode dever-se em parte a algumas carac teristicas administrativas atuais da Universidade no país. A contratação de professores ocorre em função de necessidades no âmbito do ensino, ou seja, disciplinas a serem ministradas. Entre as exigências contratuais, nenhuma estabelece a necessi dade de qualificação pedagögica. Uma vez ingresso na Universi dade, o professor assume compromisso com uma carga didática e sua carreira desenvolve-se apoiada nos trabalhos de pesquisa e nos cursos que realiza (mas näo nos que ministra). Em face de tais circunstâncias, o professor pode ser levado a acreditar que a qualidade de seu ensino independe de cuidados ao ní vel dos que ele dedica à sua pesquisa, não chegando, portanto, a assumir preocupações maiores quanto à metodologia de ensino que adota em suas disciplinas.

2. A politica que definiu a criação dos primeiros Cursos de Geologia deve ter contribuído tambëm para uma forma ção do geólogo desvinculada de maiores preocupações em rela ção à metodologia de ensino. Segundo Silva (1972), "(...) num periodo onde a tônica das discussões era a necessidade de for mação de pessoal técnico especializado compatível com um mercado de trabalho rapidamente crescente e diversificado, a cria ção da $\operatorname{CAGE}^{(1)}$ constituiu uma medida concreta para a supe 
ração dos problemas causados pela escassez de tëcnicos de nível superior no campo da Geologia"(2).

$\mathrm{Na}$ ëpoca, o Ensino de Geologia constituia aparente mente especialidade de pouco interesse. Forte evidência disso era a existência exclusivamente de Bacharelado em Geolo gia, não havendo Licenciatura. Tal direcionamento inicial se perpetuou, conforme indica o relato de Ladeira e Salomão (1978), que organizaram curso integrado de Geologia Estrutural e Estratigrafia no Departamento de Geociências da Universidade de Brasilia, a partir de 1971:

"Na realidade, grande parte, senão a maior parte das constatações e informaçōes que usamos no decorrer do curso, ou melhor, no planejamento do curso, na execução, são nada mais que reflexão sobre o ensino que nös tivemos, sobre a dificiên cia que este ensino nos trouxe, sobre de como ele poderia ter sido e, principalmente, quais as condições em que se teria que melhorar, ainda em nível incipiente, porëm como uma iniciativa välida, as qualidades deste ensino."(3)

"(...) encaramos todo o sistema, todo o trabalho ain da como uma fase preliminar, uma fase experimental e, principalmente, uma fase em que nós, com os nossos recursos e as nos sas limitações, jä não somos mais capazes de levar com força e vigor à frente sem contarmos com o auxíio de pedagogos, de psicólogos, enfim, de homens que em outros países costumam ser chamados de engenheiros educacionais, engenheiros de educação". (4)

(1) A CAGE (Campanha de Formação de Geólogos), instituída jun to ao Ministério da Educação e Cultura, foi criada através do Decreto 40.783 de $18 / 03 / 1957$.

( 2 ) SILVA, A. M. M. - 1972 - Geologia - Estudos e Perspecti vas de Trabalho. Fundação Carlos Chagas, Serie Profjssoes, n०4, Sáo paulo.

(3) LAdEIRA, E. A. e SAloná, E. P. - 1978 - Técnicas de Ensi no Aplicadas à Geologia. In SICEG, no 14/15, Ouro Pre to, p. 214.

( 4 ) LADEira, E. A. e SALOMÃo, E. P. - 1978 -idem, ibidem, p.213. 
Na primeira citação os autores revelam que sua proposta de curso era empírica, decorrendo basicamente de reflexão acerca do ensino que haviam recebido durante sua graduação. Na segunda, confessam a falta de instrumentos para prosseguir sozinhos no aperfeiçoamento do curso.

De fato, a carência nos aspectos psico-pedagógicos permanece atë a época atual, pois de acordo com a pesquisa SBG/MEC (1981) somente 12,8\% dos professores apenas gradua dos, supostamente em fase inicial de carreira, possuia Licenciatura (5). Além disso, não existe na Licenciatura nem na pós graduaçāo qualquer disciplina voltada para o ensino especifico de Geologia.

Todo esse panorama se compatibiliza com a tênue apli cação de inovações em metodologia de ensino por parte dos pro fessores de graduação em Geologia. E possível que prevaleça a "reprodução" no ensino das experiências assimiladas pelo professor em sua situação anterior de estudante. Ladeira e Salo mão (1978) acreditam que assim seja:

"Infelizmente no Brasjl o professor ainda não temuma profissão. O que se faz é improviso. O que se faz é pegar pes soas inexperientes e fazê-las professores, às custas de suas próprias experiências. Quase sempre estas experiências são re petitivas: nös apenas nos limitamos a desenvolver um trabalho exatamente como fomos ensinados. Nem sempre isto è satisfa torio." (6)

3. A preocupação dos chamados cursos modernos com a estrutura da matêria em estudo e os processos de investigaçäo cientifica estabelece entre ensino e pesquisa muito mais afinidade do que havia no passado. Não obstante, verificou-se que a tendência dos professores que desenvolvem pesquisa, tan to quanto os que não a desenvolvem, $\vec{e}$ adotar a metodologia de ensino característica dos cursos tradicionais.

( 5 ) SOCIEDADE BRASTLEIRA DE GEOLOGIA/MINISTERIO DA EDUCACÁO E CULTURA - 1981 - A Formaça do Geólogo nas Universidades Brasileiras. MEC, Brasilia, p. 70 .

(6) LADEIRA, E. A. e SALOMAO, E. P. - 1978 -op. cit., p. 213. 
E questionável a possibilidade de propiciar a todos os alunos situações originais com que se defronta o pesquisador, mas roteiros escritos de experimentos, por exemplo, se habilmente elaborados podem resultar em simulações üteis para introduzir os alunos à prática da pesquisa. A opção por soluções desse tipo por parte do professor implica na sua aceitam ção em enfrentar um novo problema: o da adequação de situações de ensino de Geologia à metodologia de pesquisa dessa ci ência.

A solução de tal problema não pode ser encaminhada somente com o concurso de pedagogos e psicólogos, por escapar thes as peculiaridades do conteủdo geológico e da correspon dente metodologia de pesquisa. Embora a assessoria desses pro fissionais seja indispensável, delineia-se como elemento mais apto o geólogo especializado em Ensino de Geologia, pois além de sua familiaridade com o conteủdo geológico e correspondente metodologia de pesquisa, dispõe de conhecimentos em psicopedagogia, atributos que o qualificam a elaborar as propostas de ensino mais adequadas em Geologia.

A disseminação de novas propostas de ensino entre os professores nos Cursos de Geologia constitui ainda outro problema. Há necessidade de capacitar os professores a compreender as novas propostas em suas relações com a pesquisa geológica e a ajusta-las conforme a realidade a que se destinam. Uma das alternativas aparentemente mais adequadas para capaci tá-los a tanto são os cursos de especialização e aperfeiçoa mento.

4. Um dos componentes essenciais na adoção de aspec tos de inovação em metodologia de ensino são as mudanças no relacionamento professor-aluno e aluno-aluno. Da parte do pro fessor, são esperadas as seguintes atitudes, entre outras:

atribuir ao aluno o papel de agente de sua pröpria aprendizagem e ao professor o de organizador, coordenador e facilita dor do processo (Amaral, 1981); propiciar situações em que a aprendizagem seja fruto da interação entre os alunos (Fujita e Outros, 1981); permitir que o aluno desempenhe um papel ati vo, através do treino de observação e interpretação de feições no campo (Carneiro e Outros, 1981); criar oportunidades 
aos alunos para tirarem, de seu modo, as próprias conclusões (Suchman, 1980).

Embora os professores não tenham se manifestado refratários à inovação, percebe-se que não adotam (ou fazem-no muito ligeiramente) as atitudes essenciais à sua concretização.

As respostas dos alunos acerca dos mesmos procedimen tos de ensino classificados no Capítulo $V$ não podem ser diretamente cotejadas com as dos professores, em parte por compre enderem alternativas diferentes (7). Verifica-se, entretanto, que aquelas respostas reforçam extremamente tanto a intensida de dos aspectos correspondentes aos cursos tradicionais quanto a falta das mencionadas atitudes, por parte do professor, que caracterizam a aplicação de inovações (SBG/MEC, 1981 , p. 107). (8)

5. O delineamento das caracteristicas metodológicas vigentes nas disciplinas geológicas e afins dos Cursos de Gra duação em Geologia foi elaborado exclusivamente a partir dos depoimentos dos professores dessas disciplinas. Este trabalho requer continuidade através de outras pesquisas para se ter idéia mais precisa das situaçōes ocorrentes em sala de aula.

professores e alunos desempenham papëis diferentes na atividade de ensino-aprendizagem e suas impressões a respeito podem também ser diferentes. A quantificação de seus de poimentos na pesquisa SBG/MEC (1981) aponta para isso, embo-

( 7 ) No Questionärio do Aluno da pesquisa SBG/MEC (1981), cons tavam os mesmos 18 procedimentos de ensino mencionados neste trabalho, tambëm referidos aos professores dos Cursos de Geologia. As alternativas de resposta oferecidas aos alunos, porem, eram diferentes: (a) A grande maioria dos professores; (b) Apenas um pequeno grupo; (c) Nenhum professor e (d) Näo sei decidir (SBG/MEC, 1981, p. 107).

( 8 ) por exemp1o, ao procedimento "Estimula os alunos a emitirem julgamento sobre questöes polêmicas". os alunos forne ceram as seguintes respostas: (a) A grande maioria dos professores: $8,2 \%$; (b) Apenas um pequeno grupo: $68,1 \%$; (c) Nenhum professor: $18,0 \%$; (d) Não sei decidir: 5,2\% (SBG/MEC, 1981, p. 107). Ao mesmo procedimento, os profes sores responderam: (a) Sempre: $45,8 \%$; (b) As vezes: 47,1 ; (c) Nunca: 2,0\%; (d) Não sabe ou não respondeu: $5,1 \%$ (Ver Capitulo $V$ deste trabalho e SBG/MEC, 1981, p. 77). 
ra não possam ser, tecnicamente, confrontados.

Alëm de pesquisa junto aos alunos, hä outras possibi lidades, adicionais ou alternativas, para coleta de opiniões acerca da metodologia de ensino em aplicação. Por exemplo, pro fessores ou monitores podem assistir as aulas e posteriormente transmitir suas impressões. 
AMARAL, I. A. do - 1981 - A Geologia Introdutöria na Universi dade - Anälise de um Modelo de Curso. In Teses ao Simpósio Nacional sobre o Ensino de Geologia no Brasil. SBG, Belo Horizonte, 1:45-56.

AMARAL, I. A. do - 1981a - Uma Estratégia de Implementação pạ ra as Mudanças Propostas no Ensino de Geologia. In Teses ao Simpósio Nacional sobre o Ensino de Geologia no Brasil. SBG, Belo Horizonte, 1:177-187.

AMARAL, I. A. do -1981 b - o Conteüdo e o Enfoque dos Livros de Geologia Introdutōria. Dissertação de Mestrado apresentada ao Instituto de Geociências da Universidade de São Paulo, São Paulo, $259 \mathrm{pp}$.

AMARAL, I. A. do e NEGRAO, O. B. M. - 1981 - Os Livros-texto e sua Adequação ao Ensino Superior de Geologia Introdutó ria no Nível Superior. In Teses ao Simpösio Nacional sobre - Ensino de Geologia no Brasil. SBG, Belo Horizonte, 2:235 -245 .

AVANzo, P. E. - 1974 - Geociências, uma Nova Maneira de Ver a Terra. Geologia, Ciência e Técnica, n 4, CEPEGE, IG/USP, São Paulo, p. 7-24.

AVANzo, P. E. - 1981 - Se eu Fosse Escrever um Livro de Geolo gia Introdutória. Texto mimeografado, Salvador, $100 \mathrm{pp}$.

BLALOCK Jr., H. M. - 1964 - Causal. Inferences in Nonexperimen tal Research. The Norton Library, New York, 200 pp.

BLALOCK Jr., H. M. - 1973 - Introdução à Pesquisa Social. Zahar Editores, Rio de Janeiro, $133 \mathrm{pp}$. 
BRUNER, J. S. - 1978 - o Processo da Educação. Cia Editora Na cional, São Paulo, $87 \mathrm{pp}$.

CARNEIRO, C. D. R.; FERNANDES, A. J.; RICCOMINI, C.; CAMPANHA, G. A. da C. - 1981 - A Introdução do Aluno às Atividades de Campo. In Teses ao Simpósio sobre o Ensino de Geologia no Brasil. SBG, Belo Horizonte, $\underline{2}: 215-228$.

COOPER, D. H. - 1958 - School Surveys. In Harris, C. W. - 1960 Encyclopedia of Educational Research. The MacMillan Company, New York, p. 1211-1216.

CUNHA, C. A. L. e OUTRos - 1980 - O Ensino na Formação do Geō1ogo. Contribuição à Mesa Redonda de Ensino de Geologia ño XXXI Congresso Brasileiro de Geologia/SBG. Edição mimeogra fada, $13 \mathrm{pp}$.

CUNHA, C. A. L.; ASSIS, E. F. de; LOPES, M. M. - 1981 - Uma

- Proposta de Classificação dos Currículos plenos. In Teses ao Simpósio Nacional sobre o Ensino de Geologia no Brasil. SBG, Belo Horizonte, 2:189-195.

ENGELHART, M. D. - 1972 - Methods of Educational Research. Rand McNally and Company, Chicago, $553 \mathrm{pp}$.

E.S.C.P. (Earth Science Curriculum Project) - 1978 - Guia do Professor. McGraw Hill do Brasil/FUNBEC, São paulo, Vo1.1, $573 \mathrm{pp}$.

E.S.C.P. (Earth Science Curriculum Project) - 1973 e 1977 Investigando a Terra. McGraw Hill do Brasil/FUNBEC, São Paulo, 1973 (1: vol.), 435 pp., 1977 (2\% vol.), 238 pp.

FERRETTI, C. J. - 1980 - A Inovação na Perspectiva Pedagōgica. In GARCIA, W. E. - 1980 - Inovação Educacional no Brasil Problemas e perspectivas. Cortez Editora e Autores Associa dos, São Paulo, p. 55-82. 
FUJITA, H. H.; GONÇALVEZ, P. W. ; CAIUBY, S. C. S. -1981 - Me todologia de Ensino em Geologia. In Teses ao Simpósio Nacional sobre o Ensino de Geologia no Brasil. SBG, Belo Horizonte, 1:101-122.

GONÇALVES, P. W.; CAIUBY, S. C. S.; SUGAWARA, W. A.; SHTMABUKURO, Y. - 1981 - A Questão da Formação Polivalente - Uma Prātica Social. In Teses ao Simpósio Nacional sobre o Ensi no de Geologia no Brasil. SBG, Belo Horizonte, 2:229-233.

HYMAN, H. - 1967 - Planejamento e Anä1ise de Pesquisa. Lida dor, Rio de Janeiro, $546 \mathrm{pp}$.

KERLINGER, F.N. - 1973. - Foundations of Behavioral Research. Holt, Rinehart and Winston Inc., New York, $741 \mathrm{pp}$.

KLOPFER, L. E. - 1971 - Evaluation of Learning in Science. In BLOOM, B. S.; HASTINGS, J. T.; MADAUS, G. F. - 1971 - Hand book on Formative and Summative Evaluation of Student Lear ning. McGraw Hill Inc., New York, p. 559-642.

LADEIRA, E. A. e SALOMAO, E. P. - 1974 - Técnicas de Ensino Aplicadas à Geologia. Conferência proferida na XV Semana de Estudos da SICEG. In SICEG (1978), XIV e XV Semanas de Estudos, Ouro Preto, p. 213-239.

MACEDo, A. B. - 1974 - Novos Mëtodos de Ensino em Geociências. Geologia, Ciência e Têcnica, $n^{\circ} 5$, CEPEGE, IG/USP, São Pau10, p. $38-55$.

PARTEN, M. - 1966 - Surveys, Pol1s, and Samples: Practical Procedures. Cooper Square Publishers, New York, 624 pp.

PASCHOALE, C.; SillVA, A. da; VASCONCELOS, A. C. B. C. de - 1981 - Uma Base para a Elaboração do Currículo de Geologia. In Teses ao Simpósio Nacional sobre o Ensino de Geolo gia no Brasil. SBG, Belo Horizonte, $1: 27-44$. 
PHILlips, B. S. - 1974 - Pesquisa Social - Estratégia e Täticas. Livraria Agir Editora, Rio de Janeiro, $460 \mathrm{pp}$.

RUEGG, N. R. - 1967 - Os Novos Currículos e os Conceitos Bási cos da Ciência. In Boletim CECISP $\mathrm{n}$ \% 6 , mar., $7 \mathrm{pp}$.

SANTOS, M. D. e OUTROS - 1981 - A Situação da Carreira Docente nos Cursos de Geologia das Universidades Brasileiras. In Teses ao Simpósio Nacional sobre o Ensino de Geologia no Brasil. SBG, Belo Horizonte, 1:133-139.

SIEGEL, S. - 1977 - Estatística Não-Paramëtrica. McGraw Hil1 do Brasil Ltda., São Paulo, $350 \mathrm{pp}$.

STlva, A. M. M. - 1972 - Geologia, Estudos e Perspectivas de Trabalho. Sërie Profissões, n: 4, Fundação Carlos Chagas, São Paulo, $82 \mathrm{pp}$.

SOCIEDADE BRASILEIRA DE GEOLOGIA - 1980 - O Ensino de Geolo gia no pais. Atas da Mesa Redonda realizada no XXXl Congres so Brasileiro de Geologia, Camboriü, SC.

SOCIEDADE BRASTLETRA DE GEOLOGIA/MINISTERIO DA EDUCAÇÃO E CUL TURA - 1981 - A Formação do Geólogo nas Universidades Brasileiras, um Retrato de Duas Décadas. MEC, Brasília, 209 pp.

SOCTEDADE BRASILEIRA DE GEOLOGIA - 1981 - Teses ao I Simpósio Nacional sobre o Ensino de Geologia no Brasil. Belo Hori zonte, I e II:268 pp.

SOCIEDADE BRASILEIRA DE GEOLOGIA - 1982 - Documento Final do I Simpösio Nacional Sobre o. Ensino de Geologia no Brasil. Belo Horizonte, $155 \mathrm{pp}$.

SOCIEDADE BRASILEIRA DE GEOLOGIA - 1982 - Documento Final do I Simpósio Nacional Sobre o Ensino de Geologia no Brasil. São Paulo, versão preliminar, $58 \mathrm{pp}$. 
SHULMAN, L. S. e TAMTR, P. - 1973 - "Research on Teaching in the Natural Sciences". In TRAVERS, R. M. W. (Ed.) - Second Handbook of Research on Teaching. Rand McNally College Publishing Co., Chicago, p. 1098 a 1148 .

SUCHMAN, J. R. - 1965 - Investigação e Educação. In NELSON,

L. N. - 1980 - O Ensino: Textos Escolhidos. Saraiva, São Paulo, p. $231-247$.

WITHEY, S. B. - 1957 - Survey Research Methods. In HARRIS, C. W. - 1960 - Encyclopedia of Educational Research. The MacMyllan Company, New York, p. 1447-1452. 


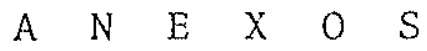


A $N$ E $X$

QUESTIONARIO DO PROFESSOR 
$\mathrm{MEC} / \mathrm{SESU}$ - CEETPS - SBG

A FORMACAO DOS GEOLOGOS

NAS UNIVERSIDADES BRASILEIRAS

Questionärio do Professor

Pesquisa planejada e executada pela Comissão Nacional de Ensino de Geologia da Sociedade Brasileira de Geologia

- 1980 - 


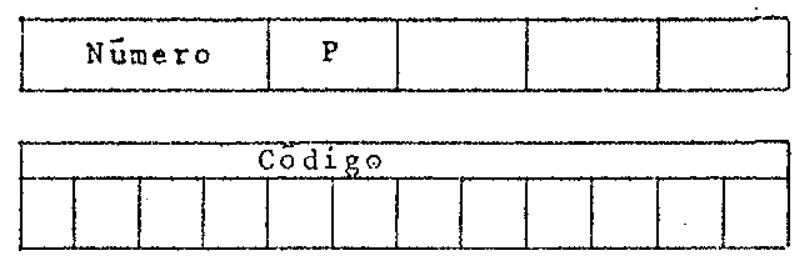

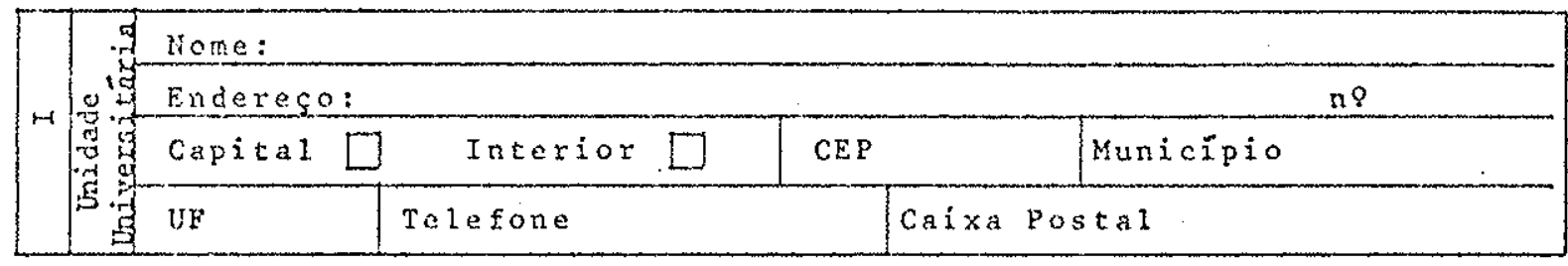

Instrucões para o preenchimento:

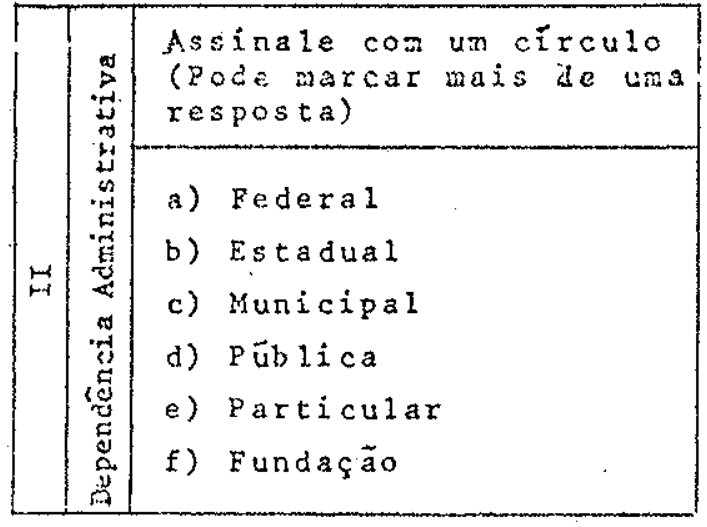

1. A sua colaboracäo respondendo a este ques tionärio sera de grande valia, preencha-o, portanto, com seriedade e honestidade.

2. Para responder às perguntas, trace uma circunferência ao redor da letra corres pondente à alternativa de sua resposta.

3. Marque apenas una alternativa em cada per gunta, a nao ser que as instruçöes nela contidas, indiquem o conträrio.

4. Quando as questões estiverem em aberto, procure responde-las con letra legivel, se possivel em letra de forma.

5. Sempre que o espaço destinado para respos ta năo for suficiente, continue no verso da folha.

6. Por favor, responda a todas as perguntas, não deixe nenhuma em branco.

7. Nos casos em que a pergunta não se apli car ao seu caso particular, assinale a al ternativa "X.N.S.A." (Näo se aplica).

8. A folha em branco no final deste questionário, fica à sua disposição para críti cas, comentarios ou para incluir informaçôes adicionais.

Muito obrigado

\begin{tabular}{|c|c|c|}
\hline \multirow{3}{*}{$\begin{array}{l}m \\
m\end{array}$} & \multirow{3}{*}{ 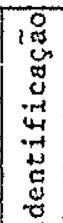 } & Nome do informate: (optativo) \\
\hline & & Departamento ou setor a que pertence: \\
\hline & & Disciplina(s) que oinistra: \\
\hline
\end{tabular}


1. Seu sexo:

a) Masculino..

b) Feminino.

P-I:

2. Sua idade (em anos completos):

a) Menos de 25 anos.

b) De 25 a 30 anos.

c) De 31 a 35 anos.

d) De 36 a 40 anos.

e) De 41 a 45 anos.

f) De 46 a 50 anos.

g) Mais de 50 anos.

3. Hä quanto tempo trabalha nesta Unidade Universitäria?
a) Menos de 2 anos.
b) De 2 a 5 anos.
c) De 6 a 9 anos.
d) De 10 a 13 anos.
e) De 14 a 17 anos.
f) Mais de 17 anos.

4. Nesta Unidade Universitäria você ẻ contratado em nível de: (Unidades Estaduais)

(Unidades Federais
a) $M S_{1}$
b) $\mathrm{HS}_{2}$
c) $\mathrm{MS}_{3}$
d) $\mathrm{MS}_{4}$
e) $\mathrm{MS}_{5}$
f) $\mathrm{MS}_{6}$

e Particulares)

a) Auxiziar de Ensino.

b) Assistente.

c) Adjunto.

d) Titular.

e) outro. Qual? 


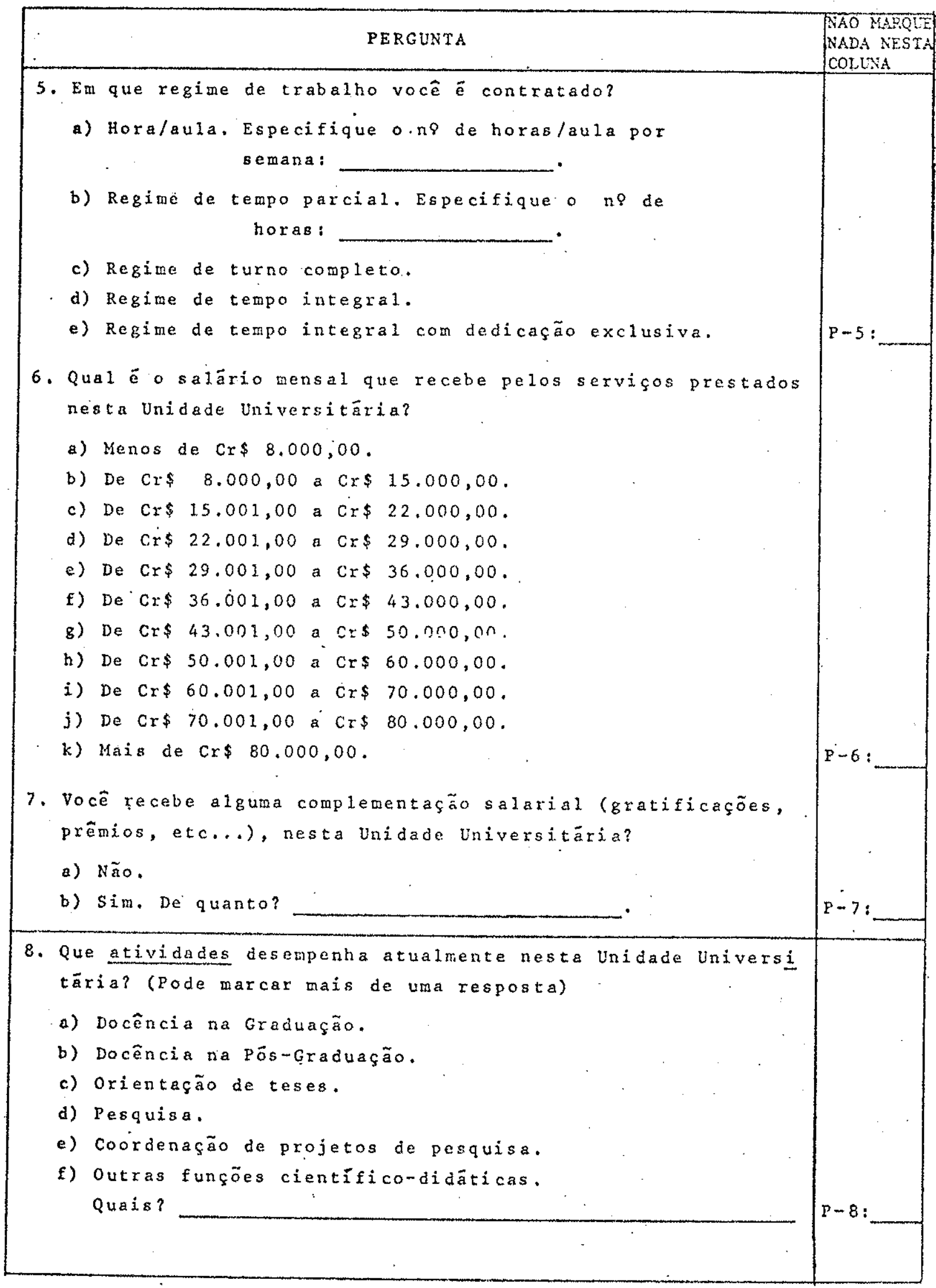




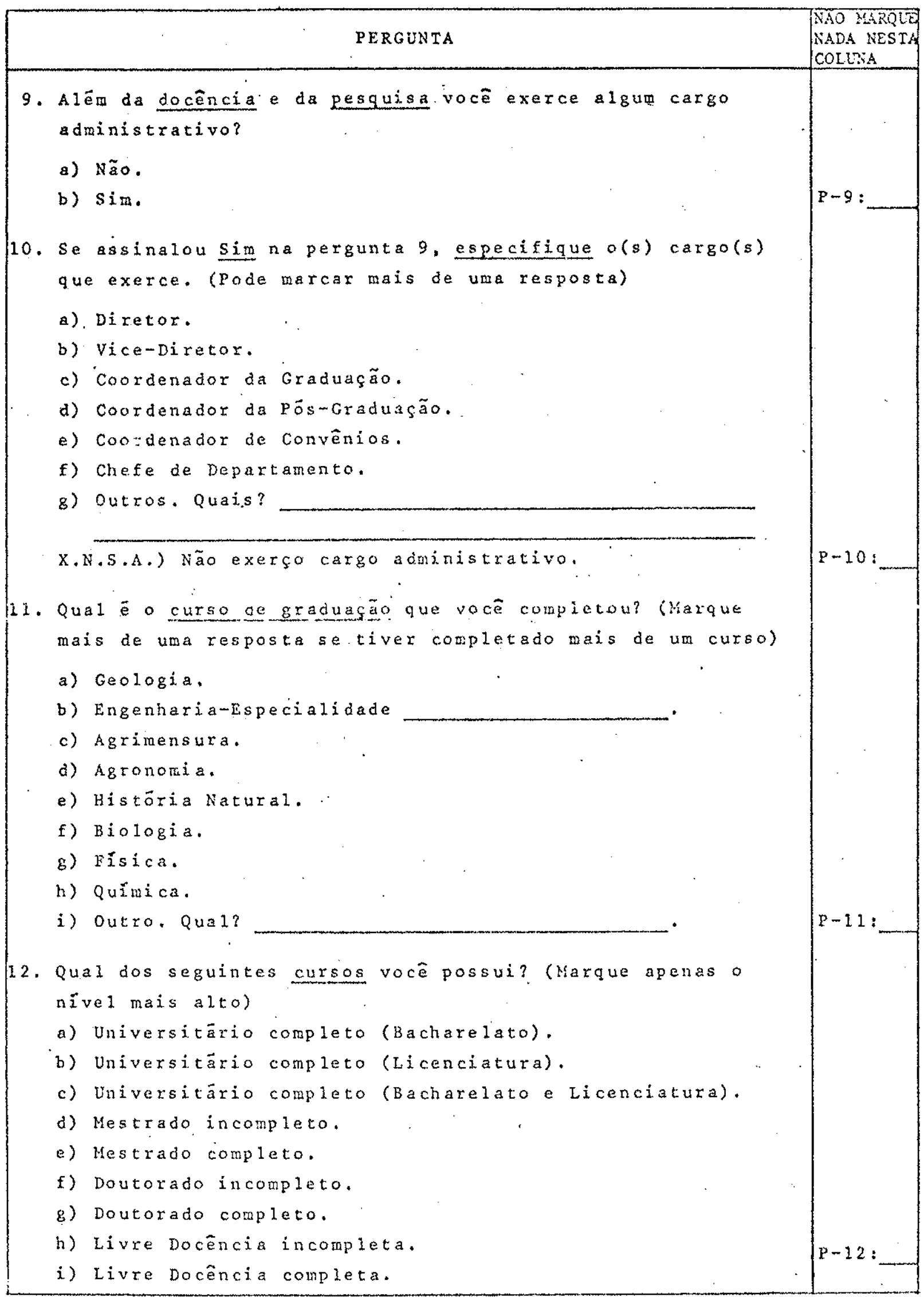




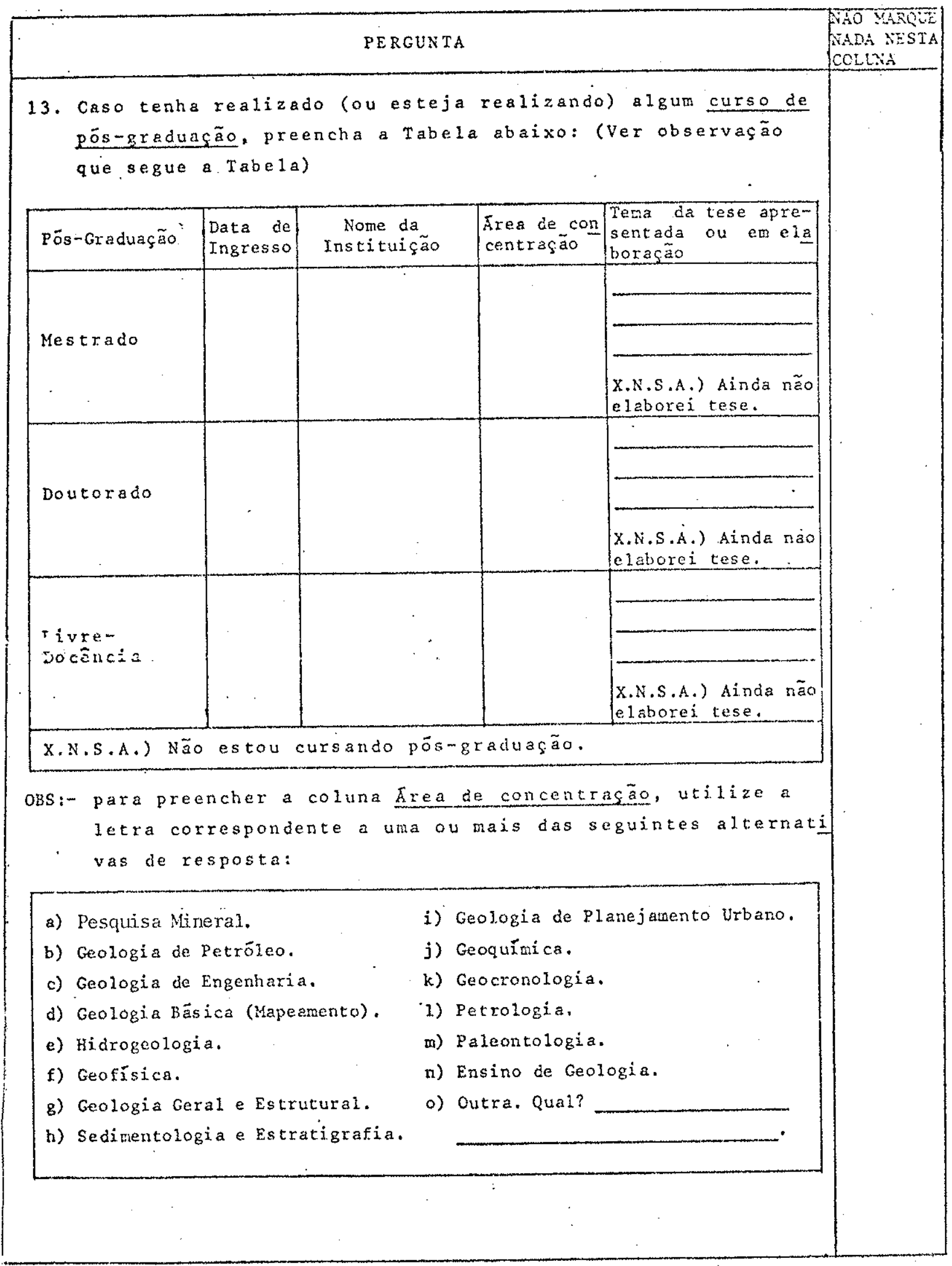




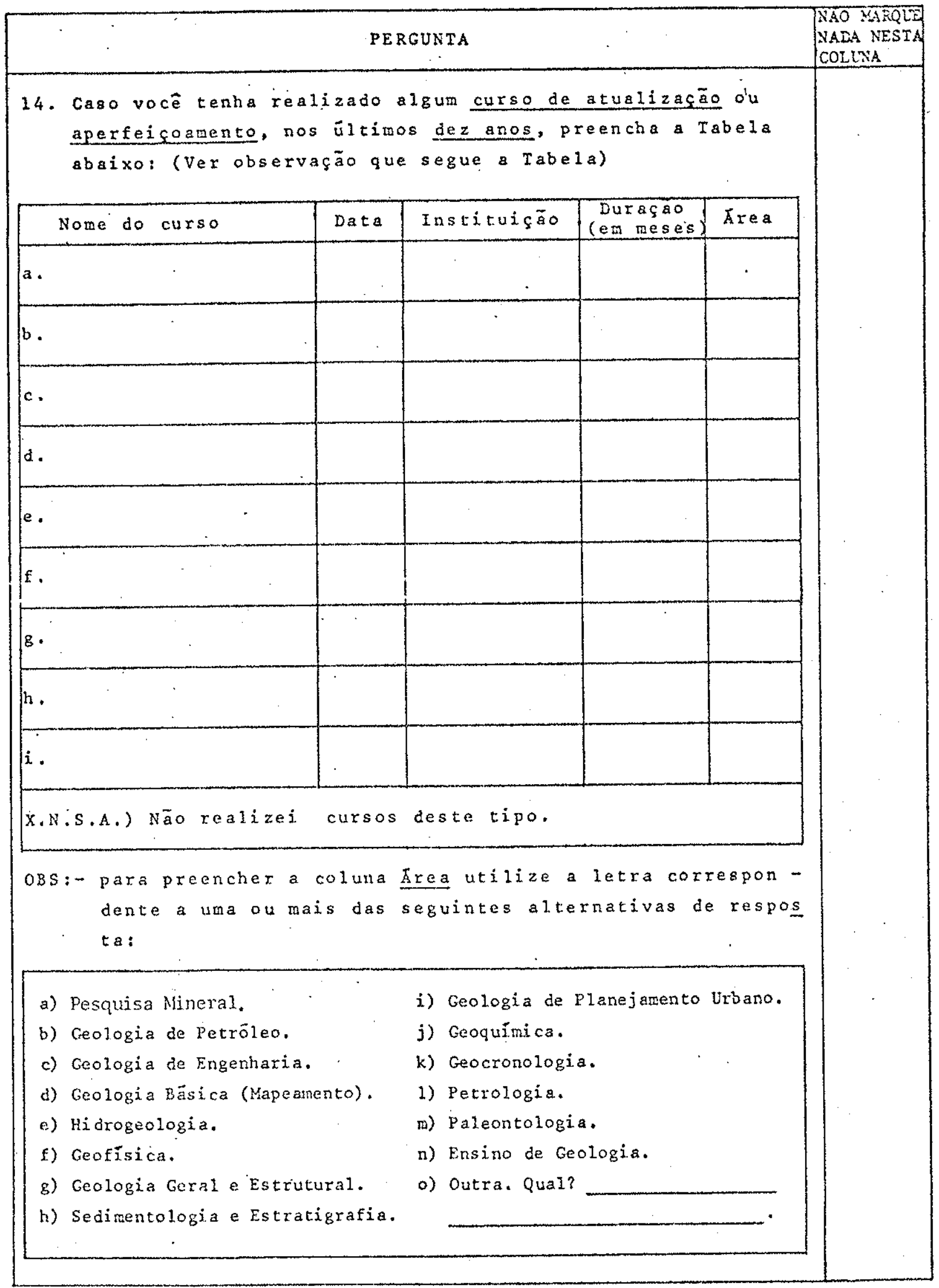




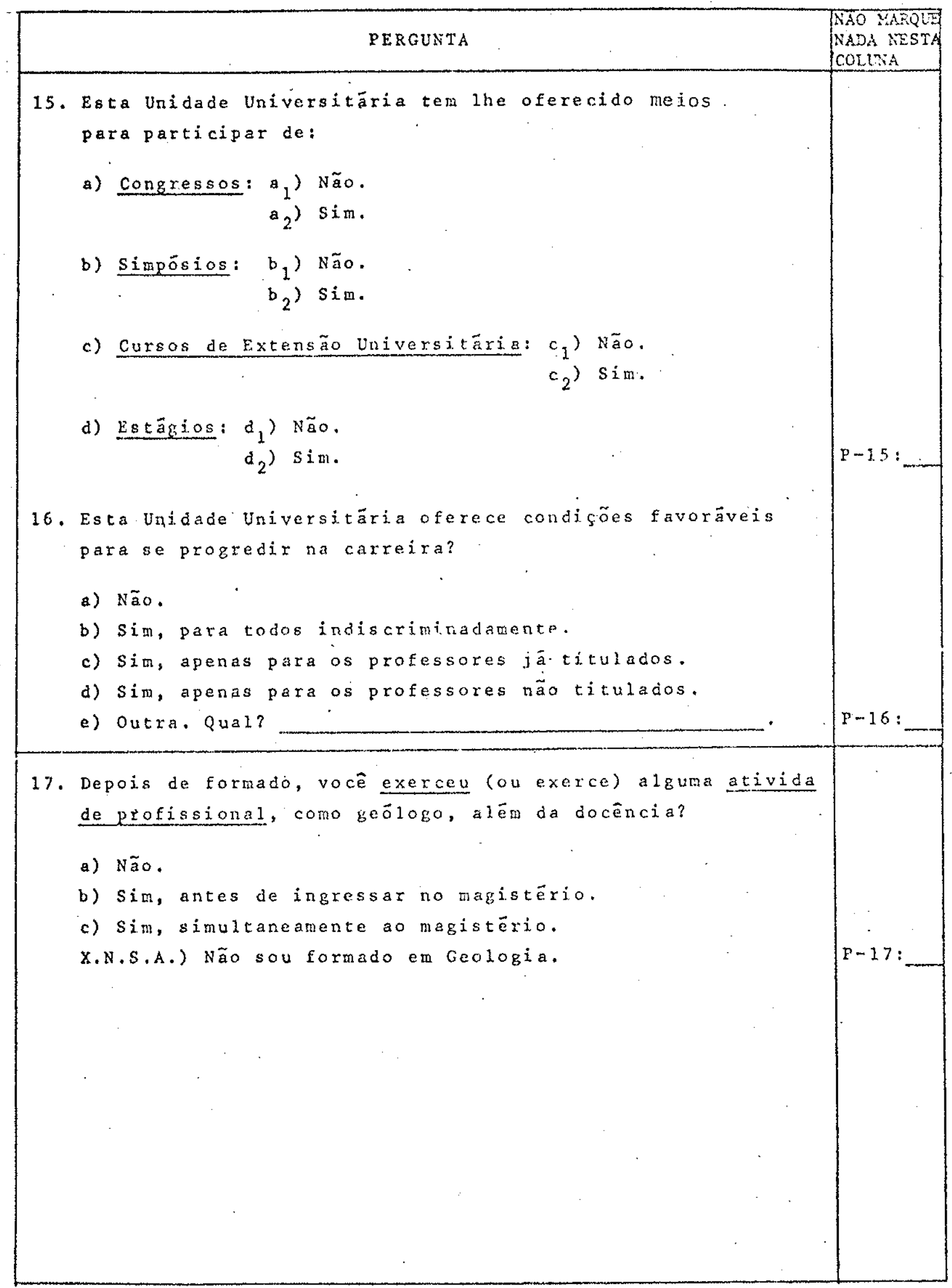




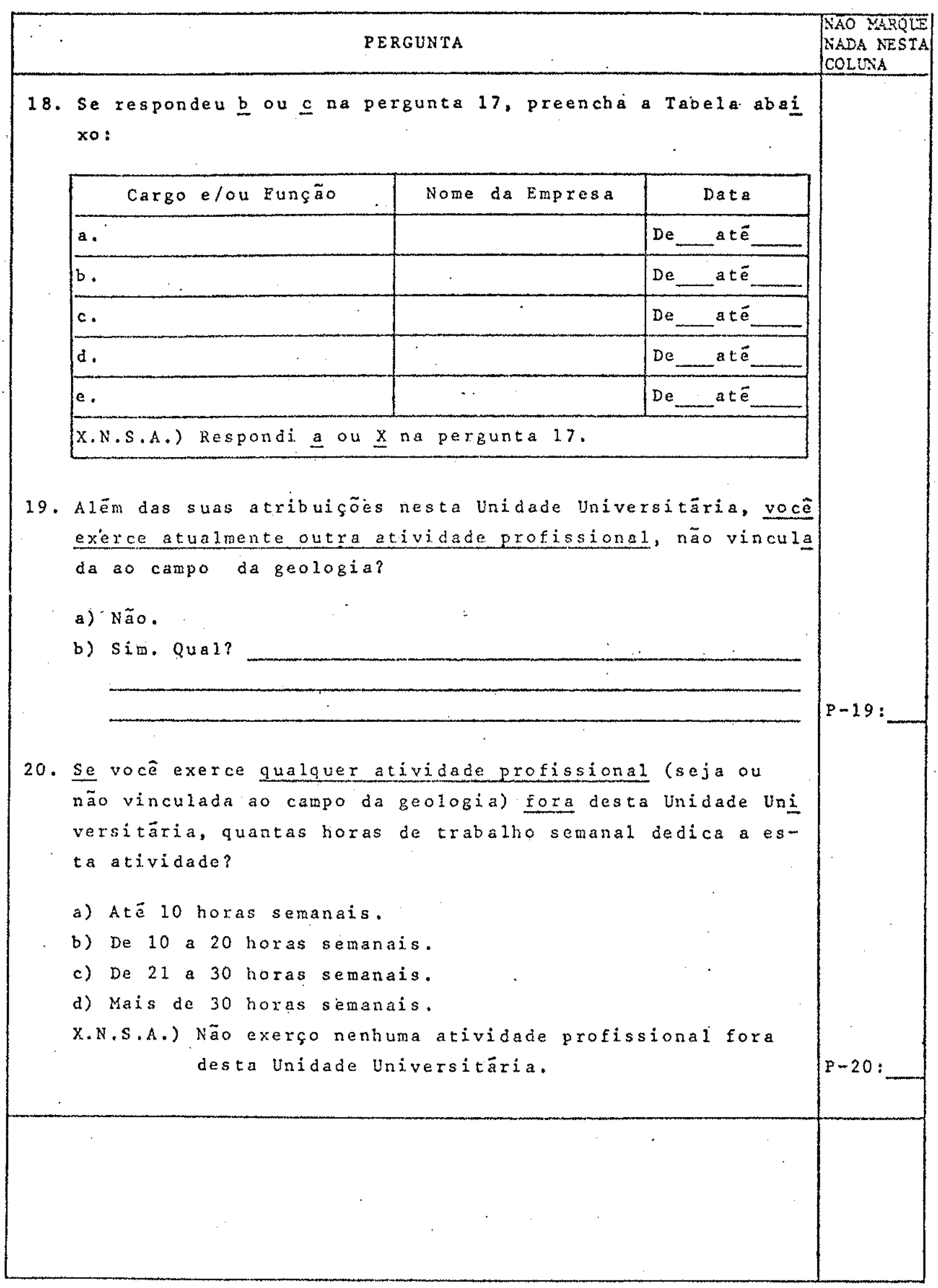




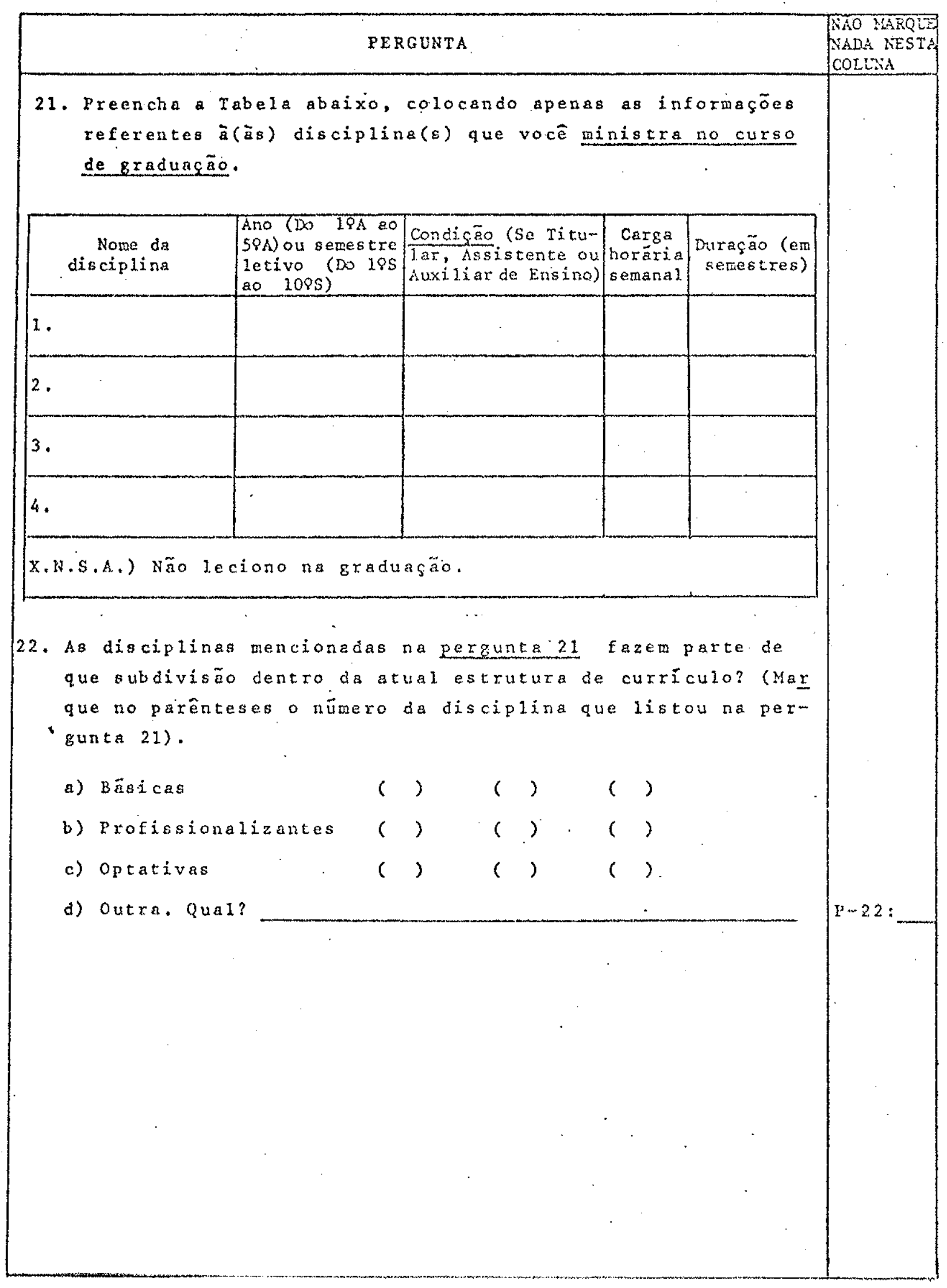




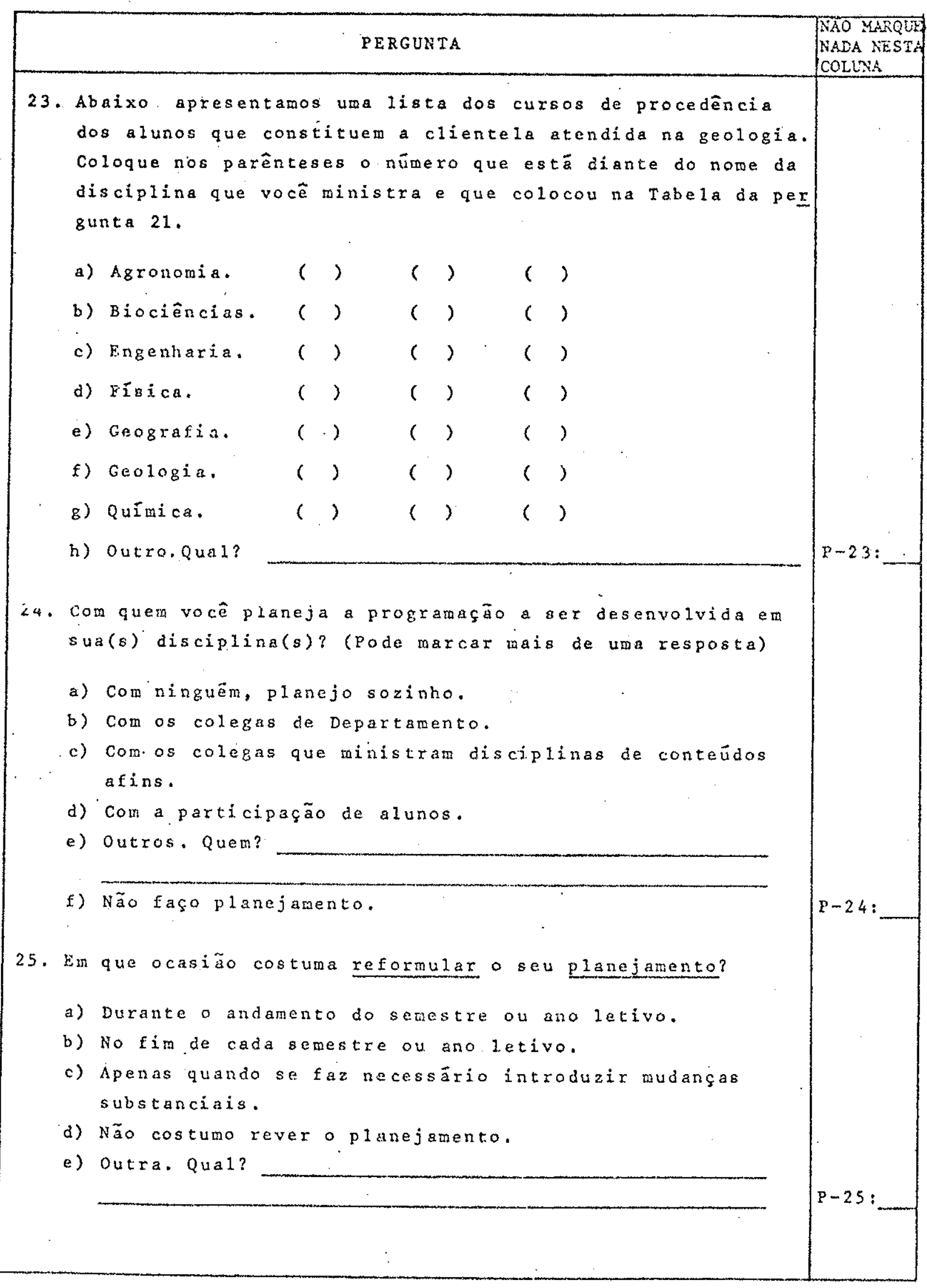




\section{PERGUNTA}

26. Em que ocasião costuma Ieformular o conteüdo do(s) programa(B) da disciplina que ministra?

a) A cada nova turma para o qual sera ministrado.

b) Em interyalos de 2 a 3 anos.

c) Näo preciaa ser revisto, pois trata de conteüdos bäsicos que säo sempre necessärios e indispensäveis.

d) Outra resposta. Qual?

27. Indique, nas tabelas que seguem, as mudanças que foram introduzidas na(s) disciplina(s), nos ultimos 5 (cinco) anos e que são de seu conhecimento.

A. Quanto à carga horaria

\begin{tabular}{|c|c|c|c|}
\hline \multirow[b]{2}{*}{ Nome da(s) disciplina(s) } & \multicolumn{2}{|c|}{ Carga horaria } & \multirow{2}{*}{$\begin{array}{l}\text { Data en que } \\
\text { ocorreu a } \\
\text { rudass }\end{array}$} \\
\hline & Le & Para & \\
\hline \multicolumn{4}{|l|}{1.} \\
\hline \multicolumn{4}{|l|}{2.} \\
\hline 3. & & & \\
\hline X.N.S.A.) Näo houve mudanças na $c$ & ia: & & \\
\hline
\end{tabular}

B. Quanto ao nümero de semestres letivos

\begin{tabular}{|c|c|c|c|}
\hline \multirow{2}{*}{ None da(s) discipling(s) } & \multicolumn{2}{|c|}{ No de semestres letivos } & \multirow{2}{*}{$\begin{array}{l}\text { Data em que } \\
\text { ocorreu a } \\
\text { rudanca }\end{array}$} \\
\hline & De & Para & \\
\hline \multicolumn{4}{|l|}{1.} \\
\hline \multicolumn{4}{|l|}{2.} \\
\hline 3.. & & $\cdot$ & \\
\hline
\end{tabular}




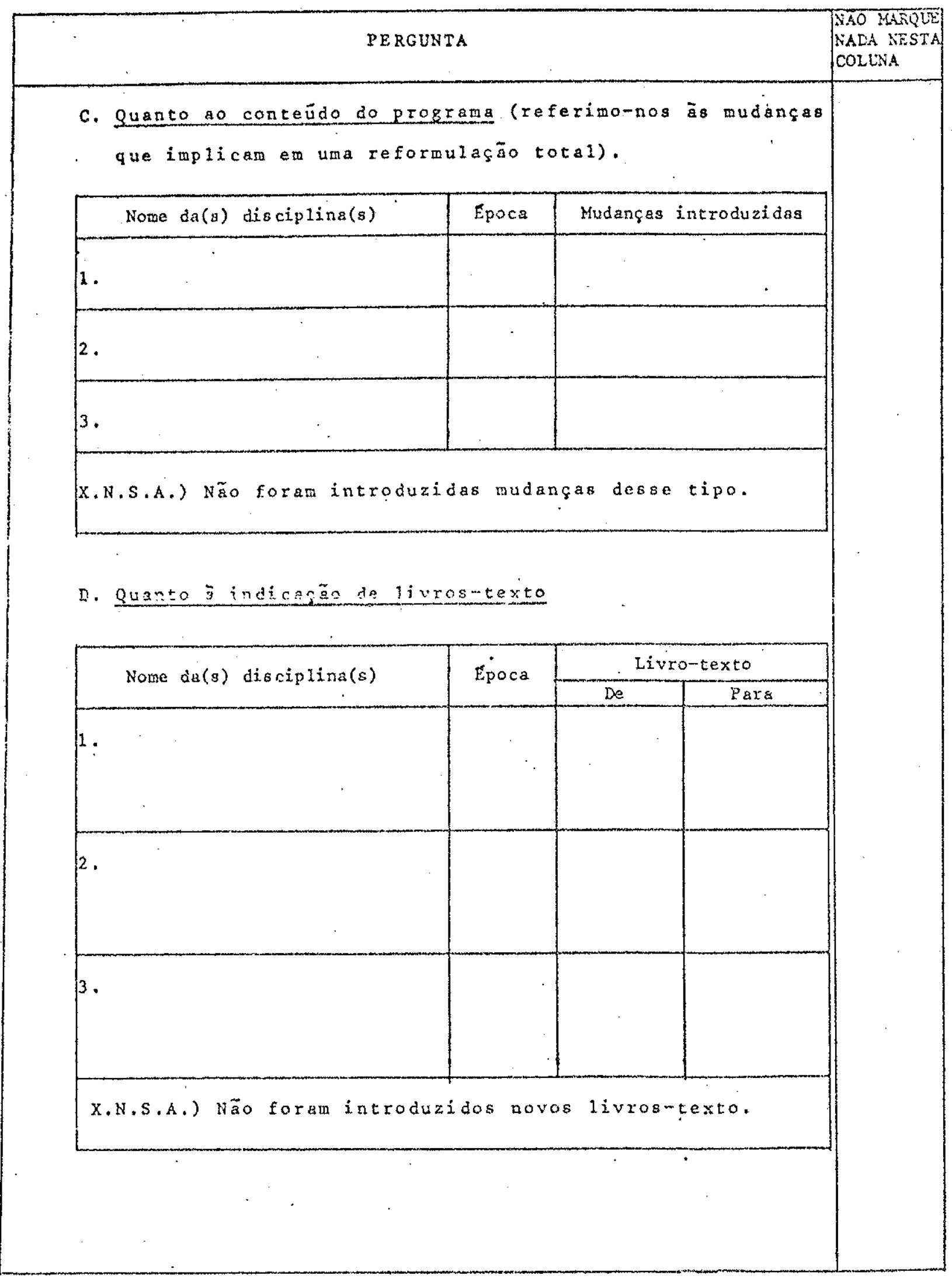


28. As mudances na carga horäria e duracão da(s) disciplina(s) forom geradab a patir: (Pode marcer mais de una resposta)

a) Da necessidade de se reestruturar o curriculo.

b) De deciã̃e interas do Departamento.

c) Da redefinisão dos objetivos do curso de geologia.

d) Da influência da câmara curricular.

e) De novas neceosidades e caracteristicas dos alunor.

f) Do influẽacia de novos projetos de perquisa.

8) Outra. Qua1?

X.N.S.A.) Näo houve mudangas de carga horäria e duraça.

Y) Näo estou informado a respeito das razóes que geraram tais mudanga.

29. As mudança ocorridas no conteüdo progaratico da (s) disciplina(B) que leciona, forani gexadas a patix: (Pode mat car mais de uma reoposta)

a) Da necegsidade de atualizaçäo do conteüdo.

b) De decisôes internas do Departzmento.

c) Da redefinişo dos objetivos do curso de geologia.

d) Da reestruturação do currículo.

e) De novas recengidades e características dos alunos.

f) Dá neceraidade de interligar o conteúdo de minhs disci plina a outras.

8) Da ineluéncia de novos projetos de pequisa.

h) Da realização de convêniog com empreans estatais e/ou privadas.

i) Outra. Qual?

X.N.S.A.) Não houve nudangas no conteỉdo prograuätico.

Y) Não estou infornado a respeito das razões que geraram tạig mudangas. 


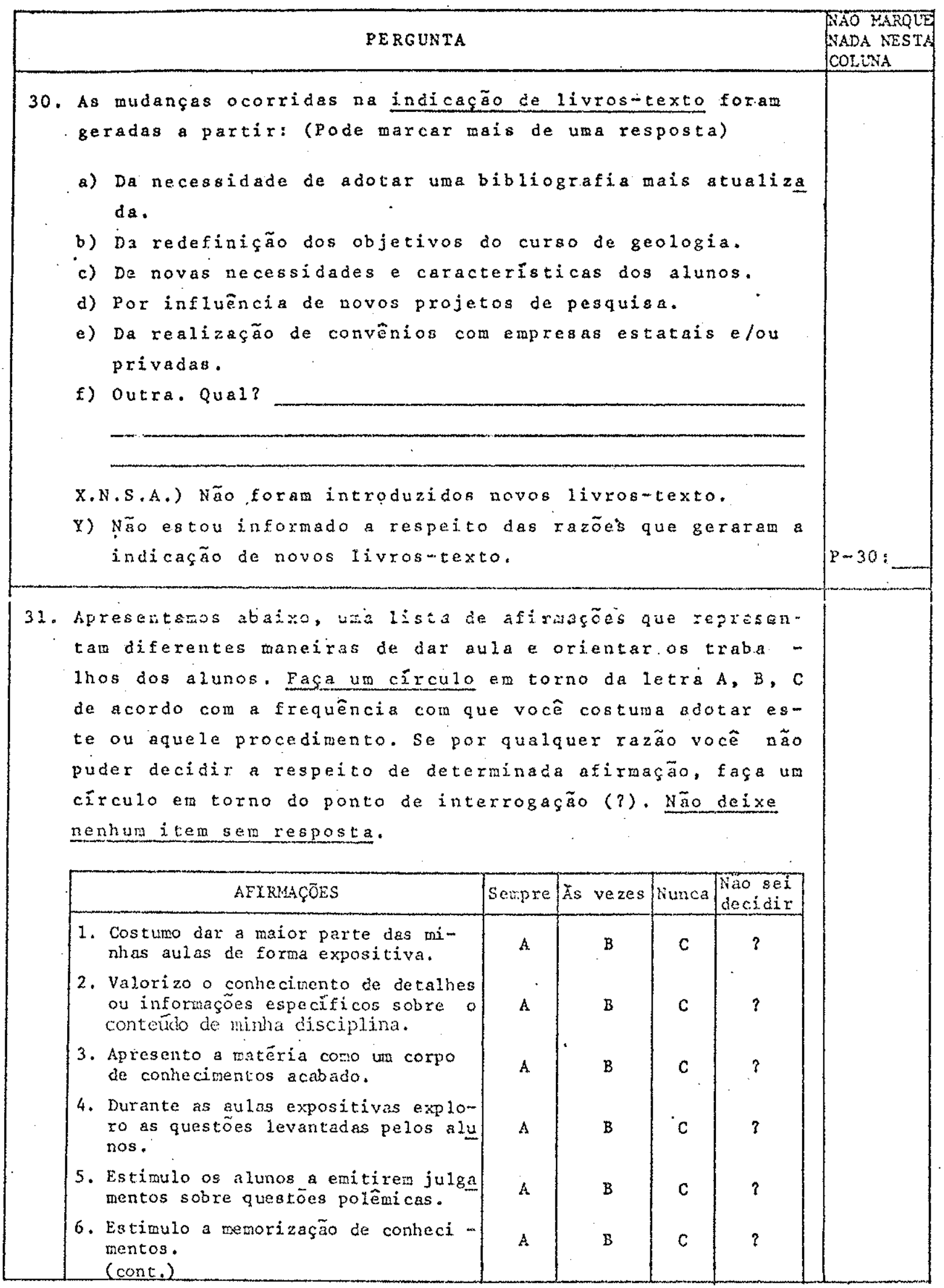




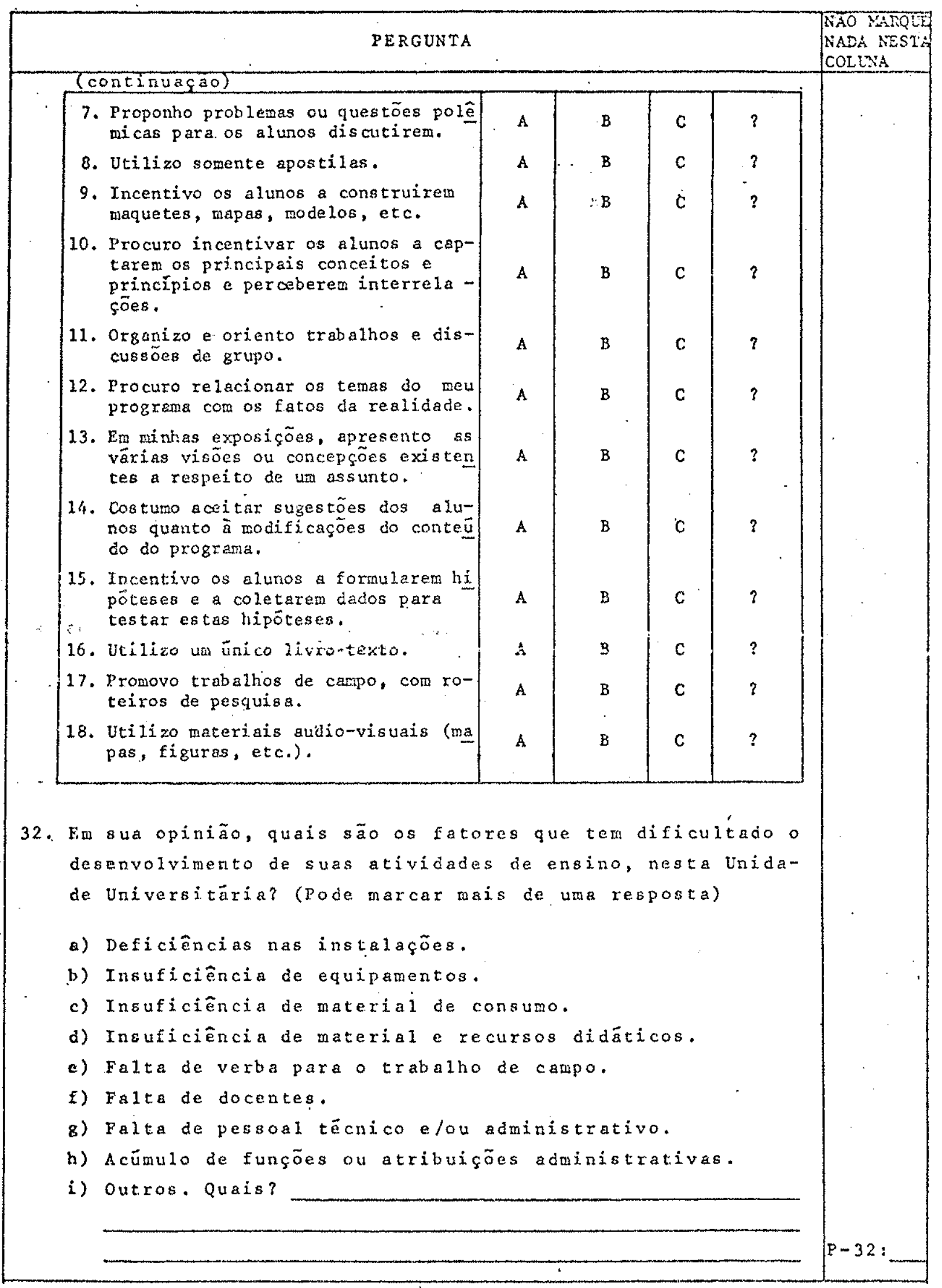




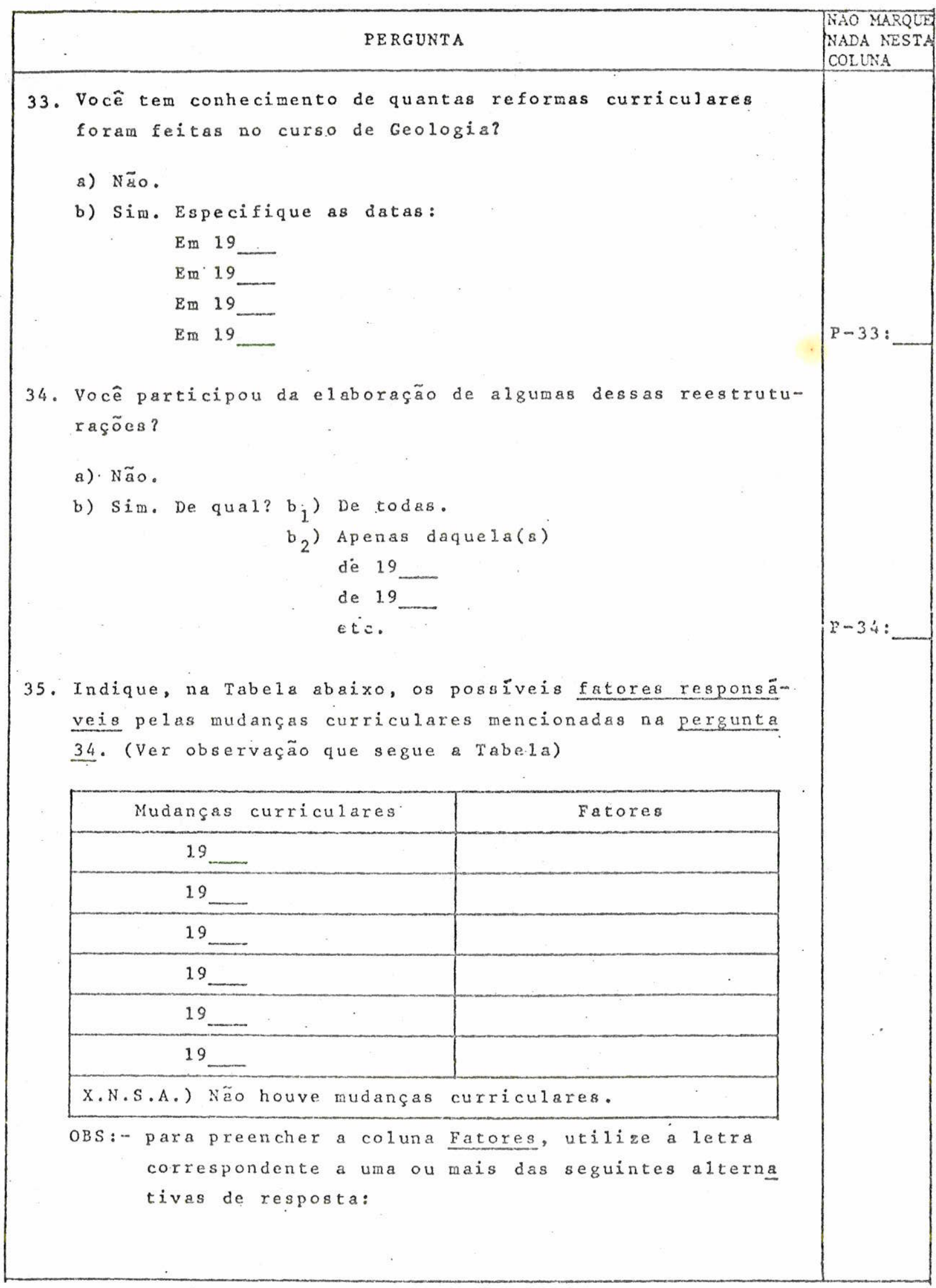


a) Dispositivos legais estabelecidos pelo Conselho Federal de Educação, NEC ou outros örgãos afins.

b) Decisões internas à Unidade Universitäia, estabelecidas pela câmara curricular ou demais niveis superio res de decisão.

c) Decisões internas ă Unidade Universitária, estabeleci das pelos Departamentos e reivindicaçóes do corpo docente, de um nodo geral.

d) Decisões internas à Unidade Universitária, relacionadas a reivindicaçōes de örgãos representantes do corpo discente, de um modo geral.

e) outros. Especifique na Tabela.

36. Se você tem conhecimento (ou participou) das reestrutura cöes pelas quais passou o curírculo do curso de geologia, faça os comentários que julgar pertinentes

A. Do currículo de 19 __ em comparaçäo ao de $29 \ldots$, penso que

B. Do curriculo de is en comparafão ao de 19 penso que

C. Do currículo de 19 em comparação ao de 19 penso que 


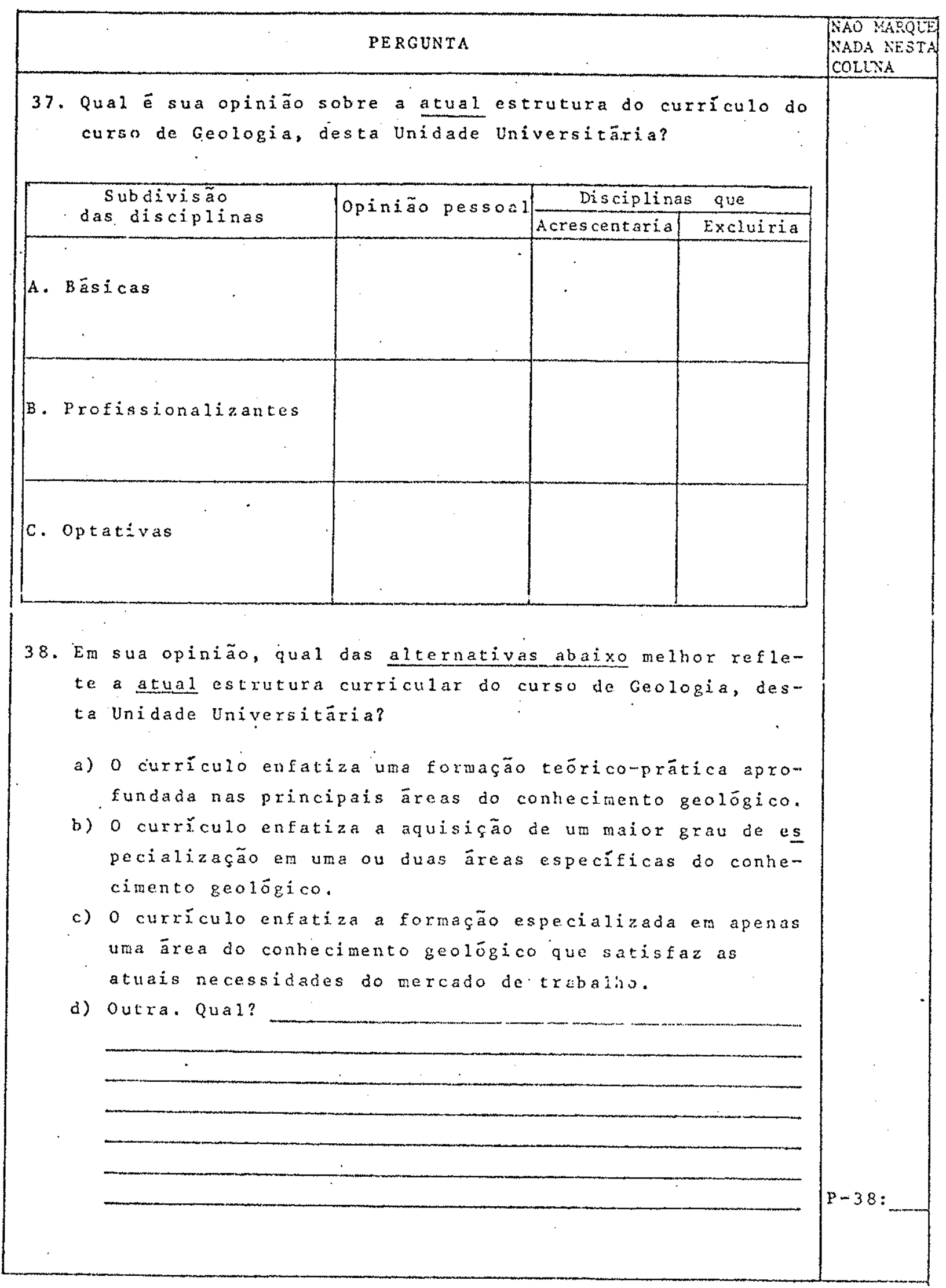




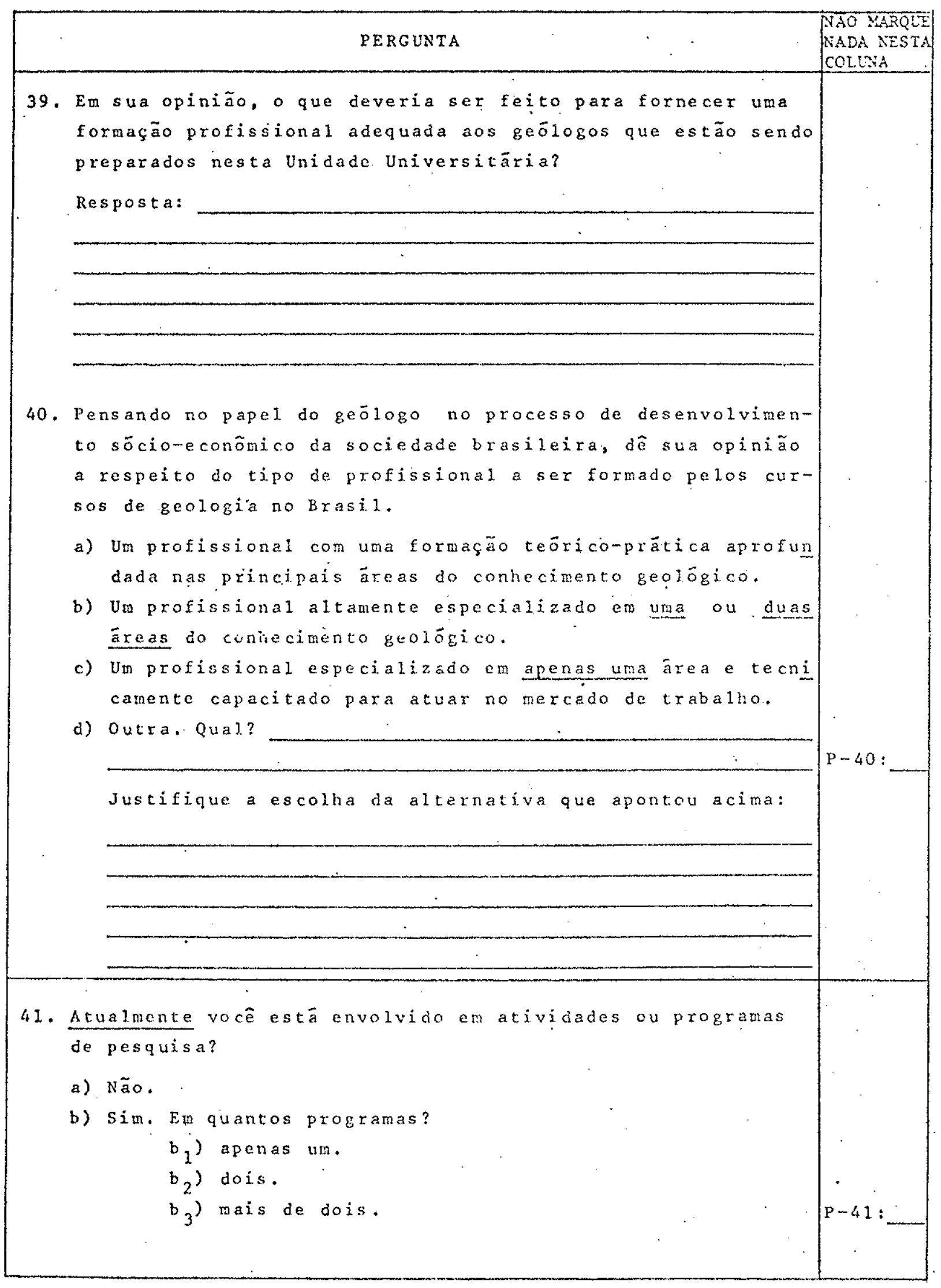




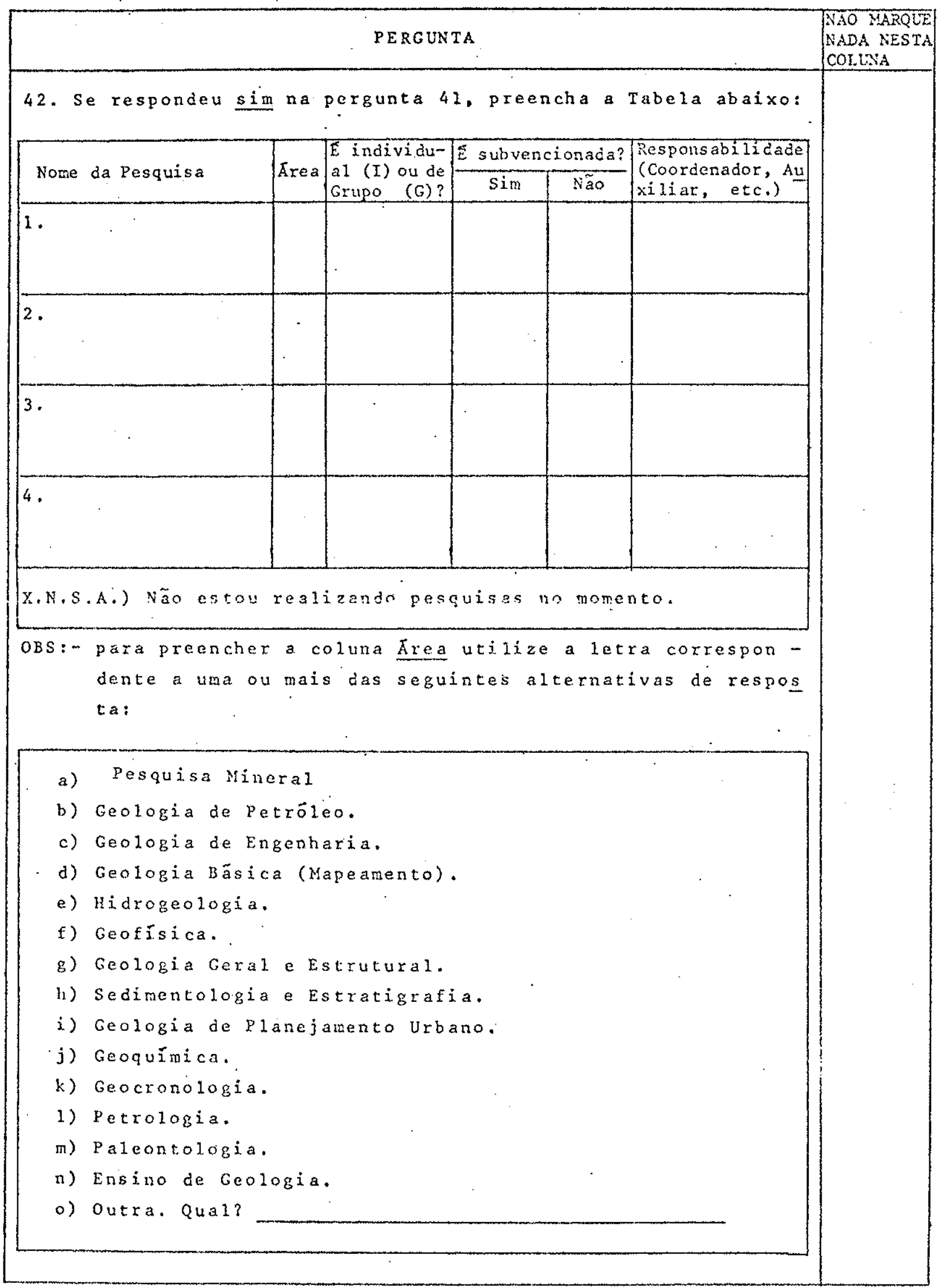




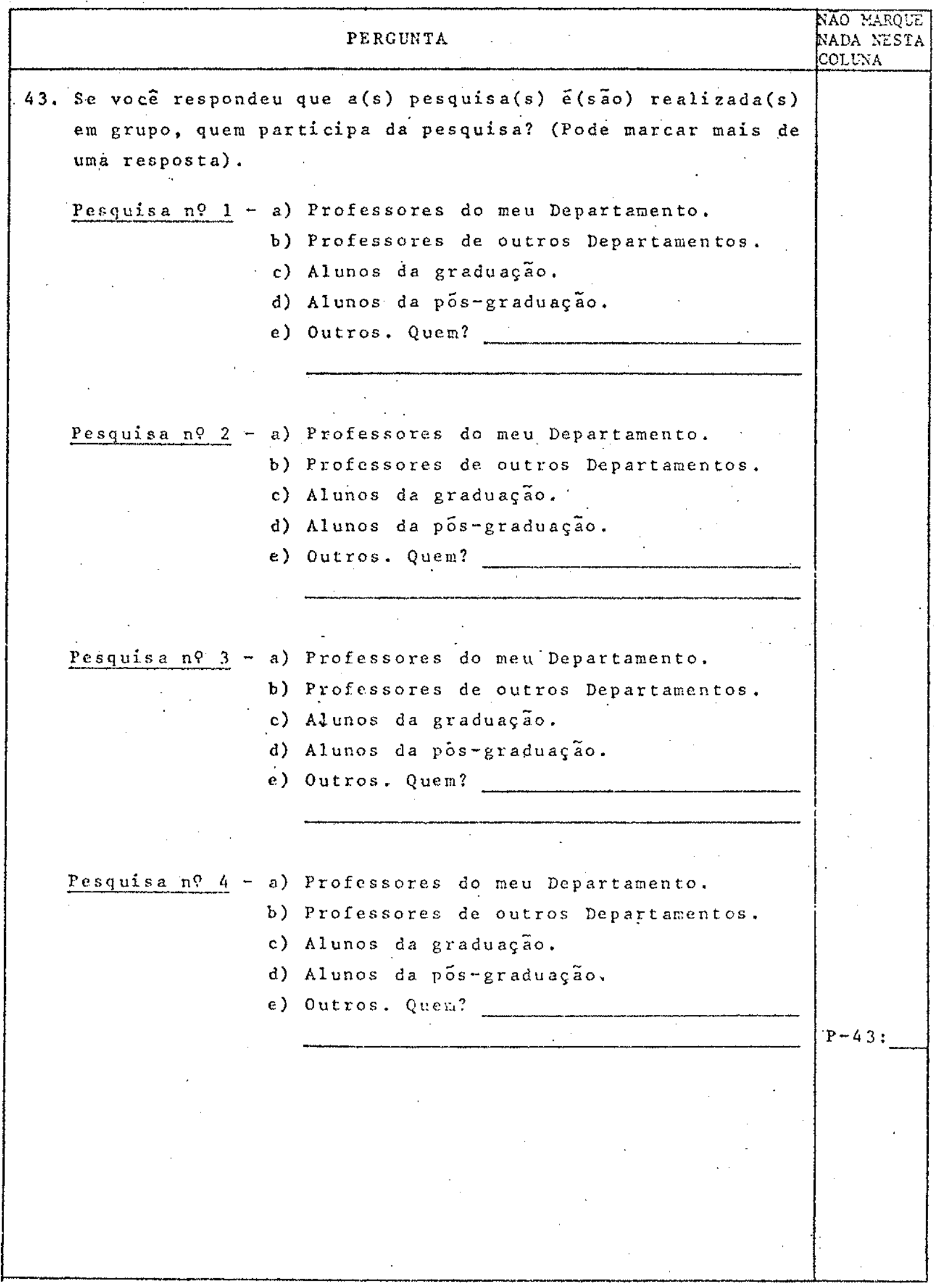




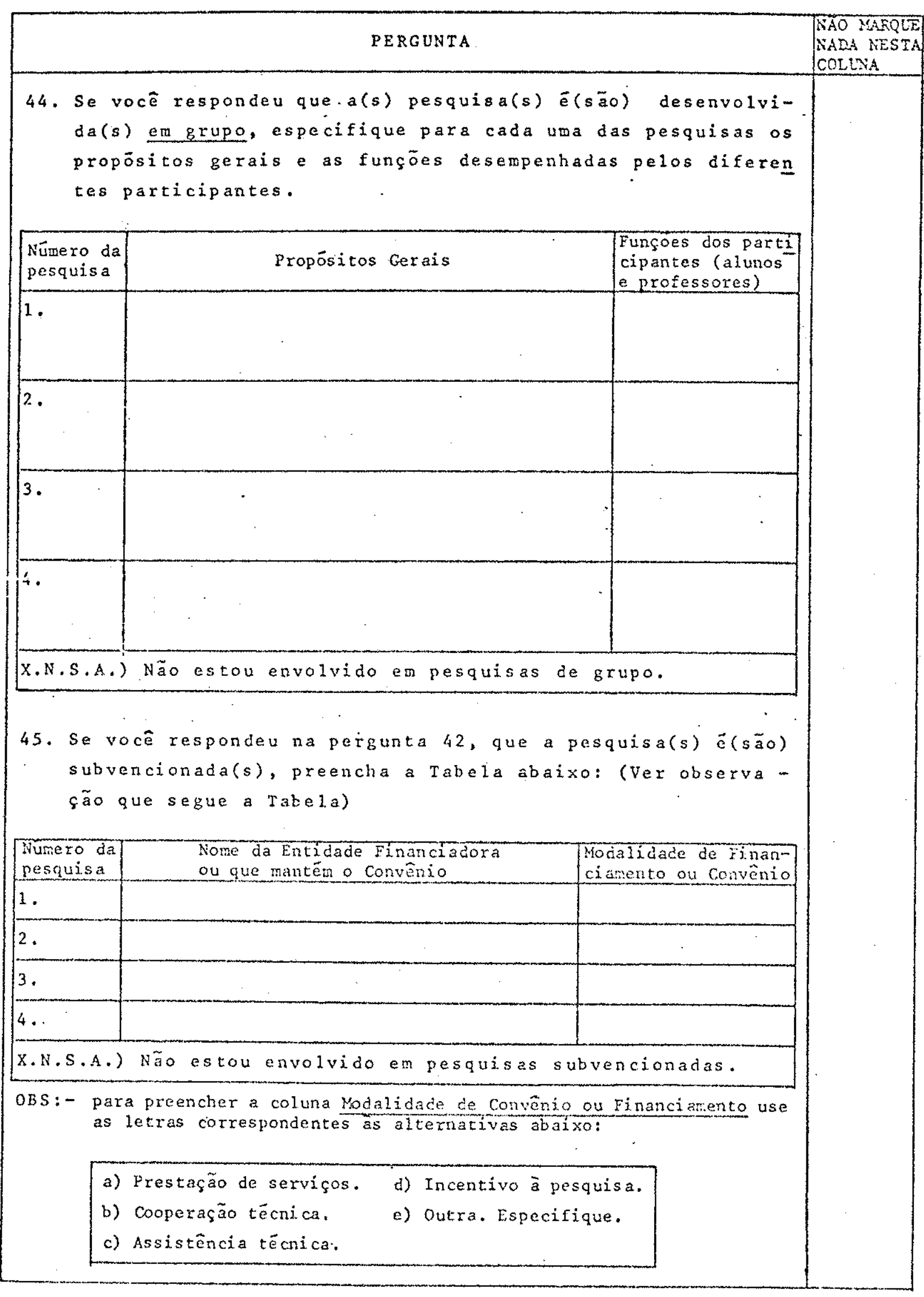




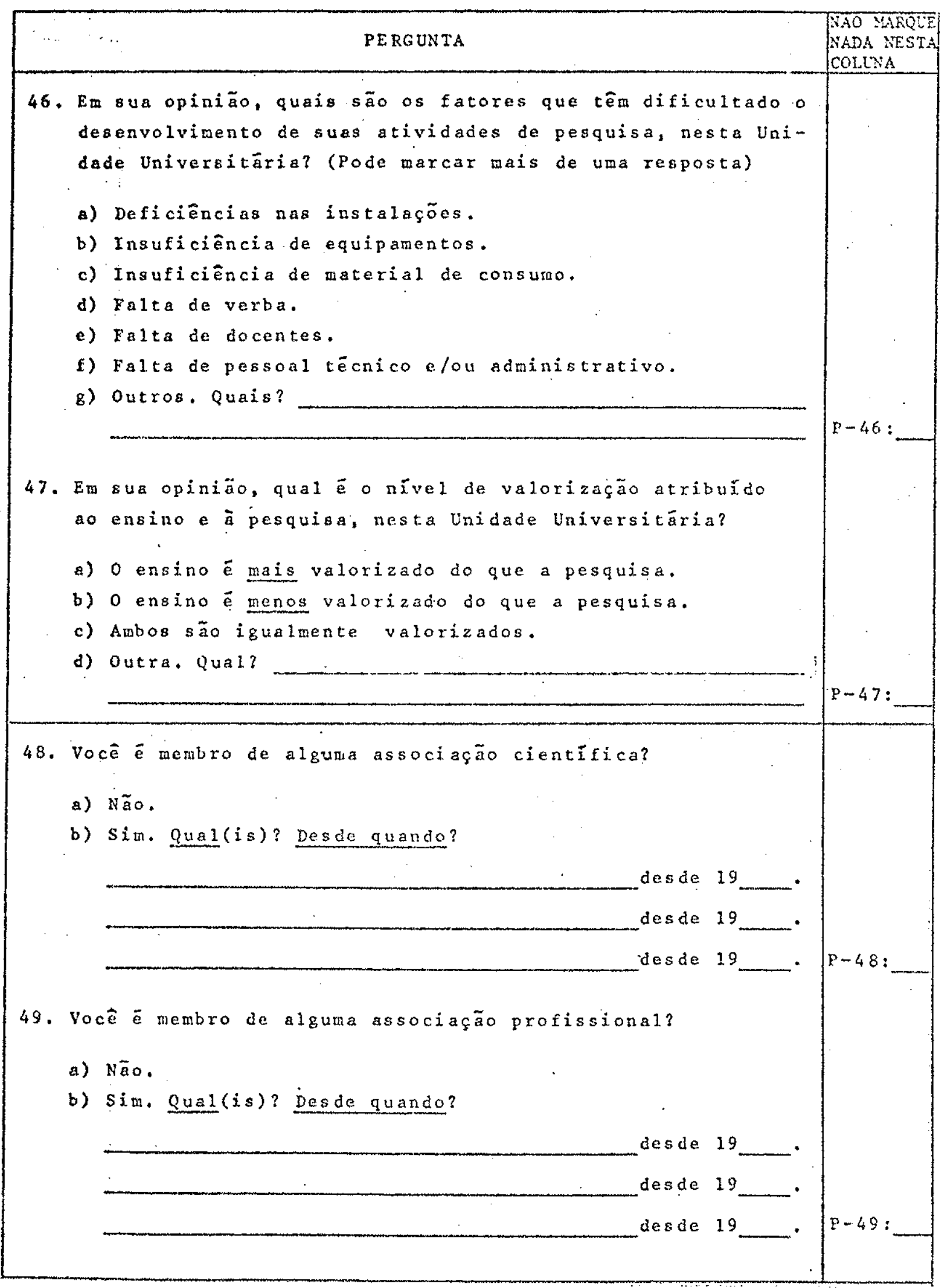




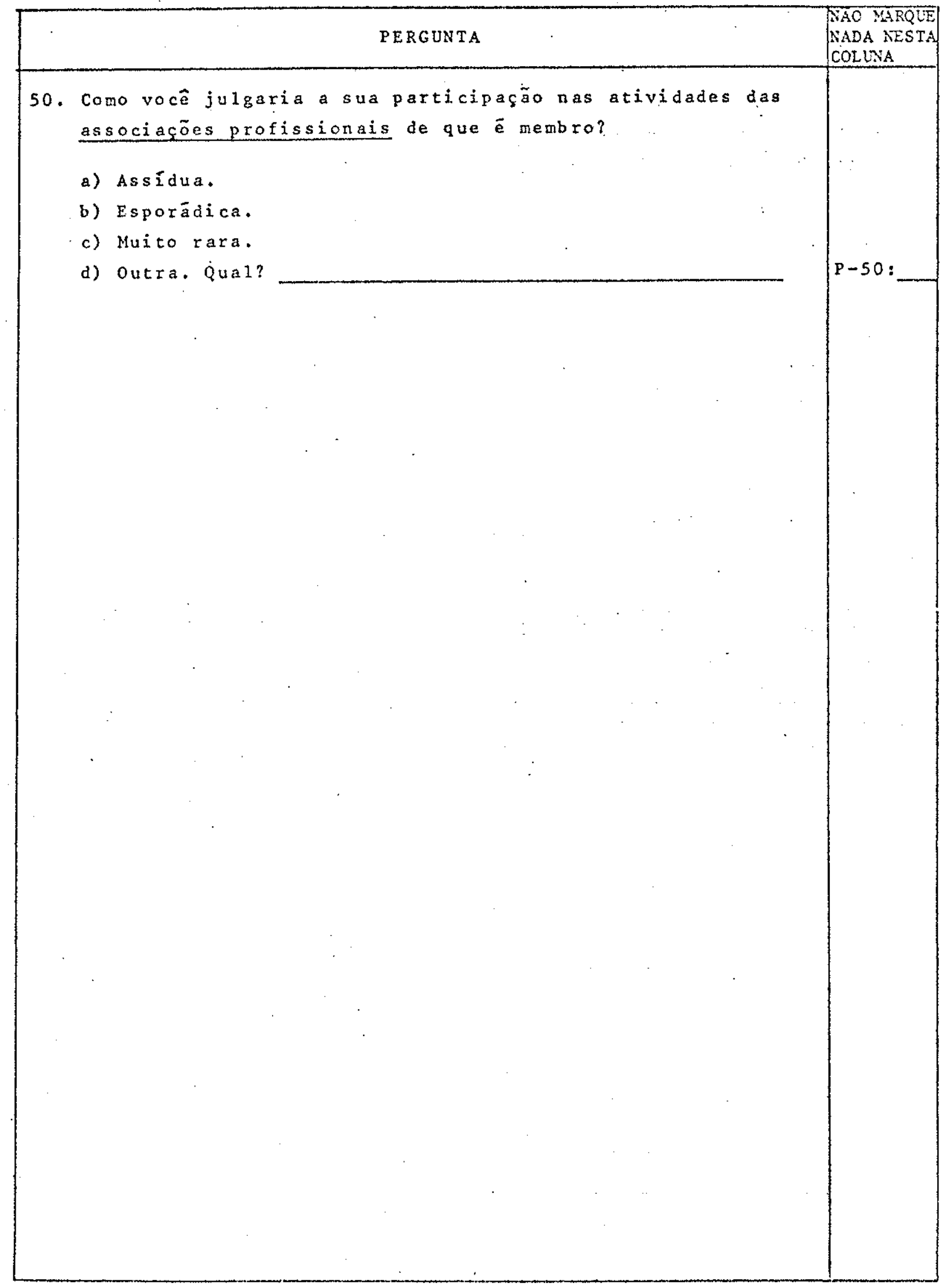




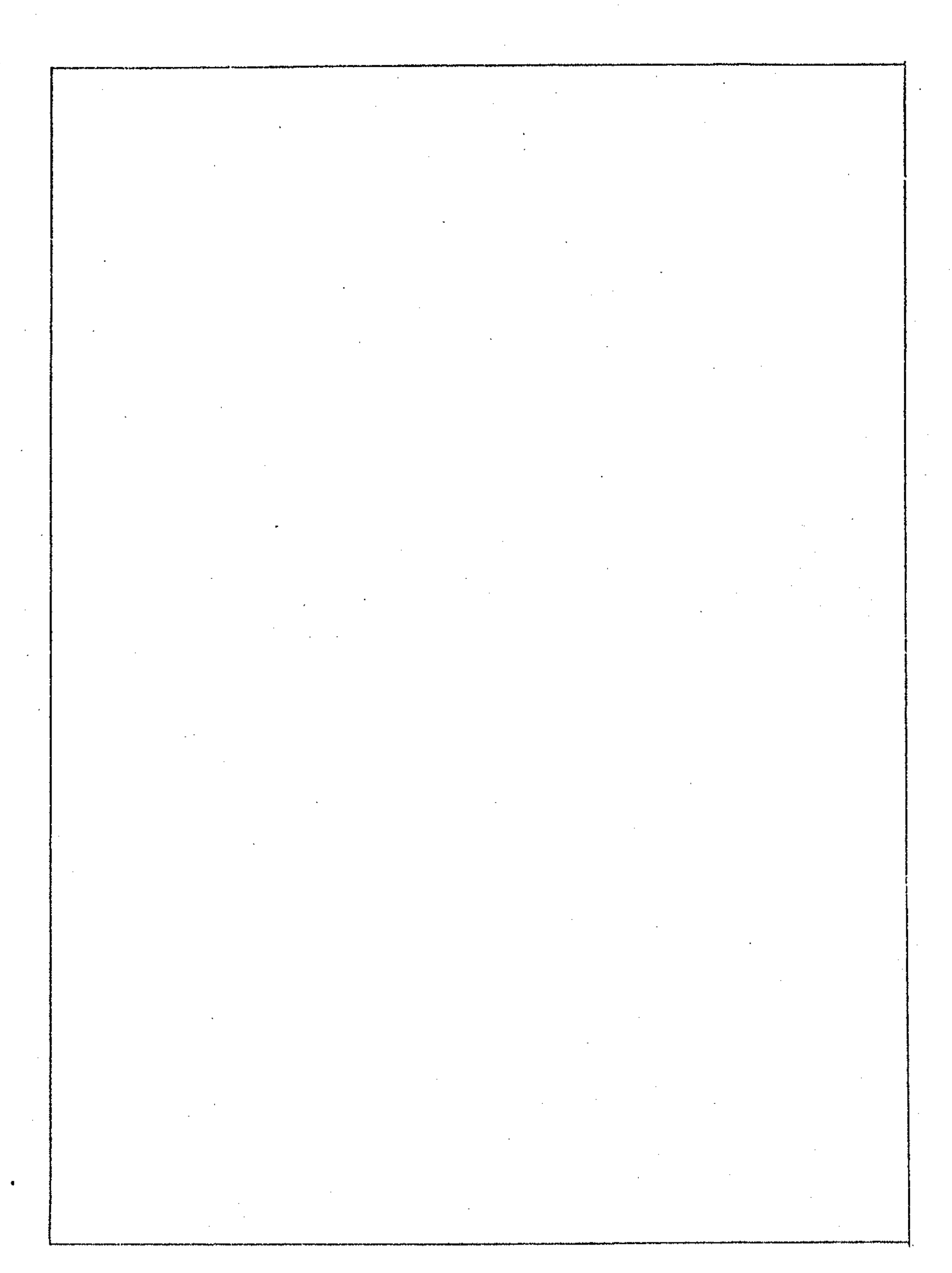


A $N E E X O 2$

INSTRUÇOES PARA APLTCAÇAO DOS QUESTIONARIOS 


\section{INSTRUCOES PARA APLICACAO DOS QUESTIONARIOS}

\section{INSTRUÇOES GERAIS}

1. Enviar carta às Unidades Universitārias onde são aplica dos os questionärios, explicando os propósitos gerais da pesquisa.

2. Avisar, com antecedencia, o Diretor da Unidade Universi täria, sobre a data provável da aplicação dos questionä rios, solicitando ao mesmo divulgar os objetivos da pes quisa entre professores e alunos sem especificar, contu do, a data da aplicação.

II. PROCEDIMENTOS PARA AMOSTRAGEM DOS ALUNOS

Como existe um numero variável de alunos em cada Uni dade Universitäria, serão descritos aqui os procedimentos gerais de amostragem a seren seguidos. Cada membro responsável pela aplícação dos questionários deverá selecionar a amostra de acordo com o procedimento geral aqui estabeleci do, adaptando-o contudo, às características de cada escola onde os questionärios serão utilizados.

1. Obter a Iista nominal de todos os alunos que ingressa ram no curso de Geologia entre o $2^{\circ}$ semestre de $1975 \mathrm{e}$ 1 ' semestre de 1978 , inclusive.

2. Relacionar o nümero de alunos ingressos, por semestre. Exemp 10:

\begin{tabular}{|c|c|c|c|c|c|}
\hline $20^{\circ}$ sem. 75 & $1 \%$ sem. 76 & $2^{\circ}$ sem. 76 & $1^{\circ}$ sem. 77 & $2^{\circ}$ sem. 77 & $1^{\circ}$ sem. 78 \\
\hline 42 & 36 & $\ldots$ & $\ldots$ & $\ldots$ & $\ldots$ \\
\hline
\end{tabular}

3. Calcular $20 \%$ do nümero de alunos de cada semestre.

4. Considerando a relação nominal dos alunos referente a ca da semestre, sortear o nümero de alunos correspondente à porcentagem estabelecida. 
5. Sortear, alēm do nümero mencionado no item anterior, mais ....: prevendo necessidade de reposição.

6. Caso o nümero de identificação do aluno seja muito extenso, substituir o nümero do computador por uma numeração de 1 a ...

7. Construir uma tabela, enviando-nos uma cópia da mesma, de modo a permitir uma visão do número de alunos por sërie ou semestre e.a composição do tamanho preciso do universo e amostra.

8. Ao dirigir-se ao local de aplicação dos questionärios, ter consjgo listas nominais nas quais deverão estar discriminados os nomes dos alunos sorteados para res ponder ao questionärio, bem como os nomes dos alunos (seguindo a ordem de sorteio) que poderão ser aciona dos caso algum dos sorteados não tiver comparecido.

E IMPRESCINDIVEL QUE ESTES PROCEDIMENTOS SEJAM SEGUTDOS RIGOROSAMENTE EM TODOS OS. CASOS.

III. PROCEDIMENTOS PARA APLICACSO DO QUESTIONARIO DO PROFESSOR

1. Fazer un levantamento do numero de professores existen te na Unidade Universitária, por Departamento ou Setor, enviando-nos uma cöpia da tabela elaborada.

Exemp10: 


\begin{tabular}{|c|c|c|c|c|c|c|}
\hline \multirow{2}{*}{$\begin{array}{l}\text { Nome do De- } \\
\text { partamento } \\
\text { ou Setor }\end{array}$} & \multicolumn{6}{|c|}{ Regime de Contratação } \\
\hline & Auxiliar & Assistente & $\begin{array}{c}\text { Assistente } \\
\text { Doutor }\end{array}$ & Adjunto & Titular & $\begin{array}{c}\text { Professor } \\
\text { Colaborador }\end{array}$ \\
\hline \multicolumn{7}{|l|}{1.} \\
\hline \multicolumn{7}{|l|}{2.} \\
\hline \multicolumn{7}{|l|}{3.} \\
\hline \multicolumn{7}{|l|}{4.} \\
\hline \multicolumn{7}{|l|}{5.} \\
\hline \multicolumn{7}{|l|}{6.} \\
\hline 7. & & & & & & \\
\hline \multicolumn{7}{|c|}{$\begin{array}{l}\text { Unidade Universitária } \\
\text { Nome do responsāvel pela aplicação }\end{array}$} \\
\hline Data & + & & & & & \\
\hline
\end{tabular}

2. Encaminhar questionários para todos os professores.

IV. APLICAÇAO E RECEBIMENTO DOS QUESTIONARIOS DOS ALUNOS

1. Reunir os alunos selecionados em uma sala.

2. Explicar os propósitos da pesquísa.

3. Distríbuir os questionários.

4. Solicitar aos respondentes para verificarem se receberam o questionário completo.

5. Jer as "instruções gerais", relacionadas na folha n: 1 do questionārio.

6. Esclarecer o preenchimento das tabelas, particularmente no que se refere à utilização das "categorias" exis tentes apōs as tabelas, em algumas questões.

7. Esclarecer que a identificaçăo do respondente è opciona1. 
8. Colocar-se à disposição para eventuais esclarecimentos, que se fizerem necessärios, durante o preenchimento.

9. Assegurar que os respondentes disporão do tempo que julgarem necessärio para o preenchimento do questionário.

10. Zelar pela individualidade das respostas (ou) prevenir aos alunos de que o questionário deve ser respondido individualmente.

11. Ao receber os questionários, conferir a folha $n^{\circ} 1$, ve rificando se todos os dados relativos à identificação foram preenchidos.

12. Numerar (de 1 a _..) os questionärios, preenchendo o es paço correspondente, na folha $n: 1$ do questionärio. Exemp 10:

\begin{tabular}{|l|l|l|l|l|}
\hline Nümero & A & 0 & 1 & 2 \\
\hline
\end{tabular}

\begin{tabular}{|l|l|l|l|l|}
\hline Nümeto & A & 0 & 2 & 6 \\
\hline
\end{tabular}

13. Elaborar uma tabela conforme modelo que segue e enviar -nos cöpia.

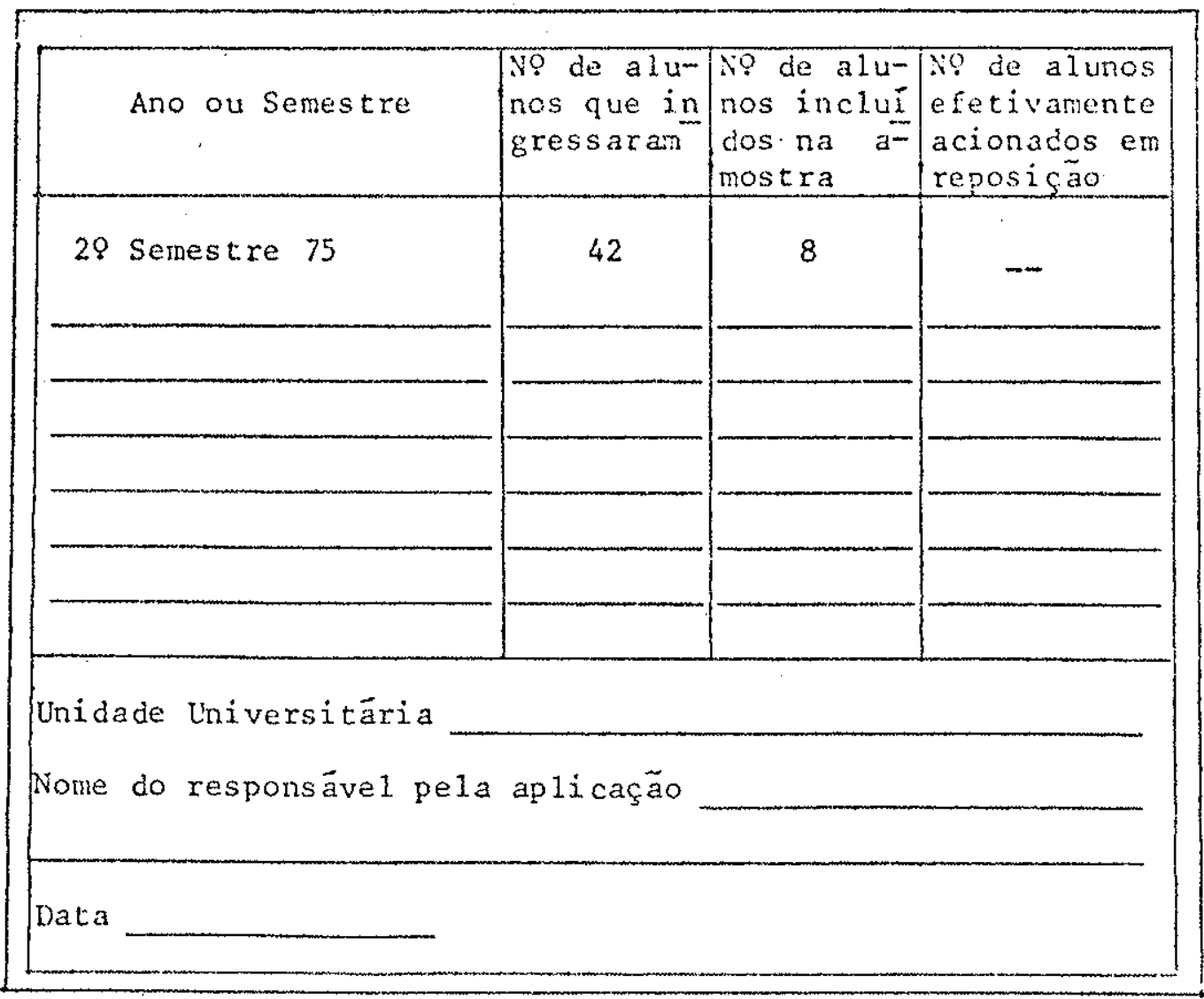


V. APLICAÇAO E RECEBIMENTO DOS QUESTIONARIOS DOS PROFESSORES

1. Apresentar, ao conjunto de professores reunidos, o propösito da pesquisa.

2. Distribuir os questionários.

3. Solicitar aos respondentes para que verifiquem se receberam o questionário completo.

4. Ler as "instruções gerais" relacionadas na folha $n$ ? 1 do questionärio.

5. Esclarecer o preenchimento das tabelas, particularmente no que se refere à utilização das "categorias" existentes apös as tabelas, em algumas questōes.

6. Esclarecer que a identificaçäo do respondente é opcio na1.

7. Ao receber os questionärios, que deverão ser entregues ao aplicador no prazo de 2 dias, conferir a folha n?. 1, verificando se todos os dados relativos à identificação foram preenchidos.

8. Numerar (de 1 a _.) os questionärios, preenchendo o espaço correspondente, na folha $n^{\circ} 1$ do questionário. Exemplo:

\begin{tabular}{|l|l|l|l|l|}
\hline Número & $\mathrm{p}$ & 0 & 3 & 2 \\
\hline
\end{tabular}

VI. PROCEDIMENTOS QUANTO AO PREENCHMMENTO DO QUESTIONARIO DA UNTDADE UNTVERSITARIA

1. Pedir ao responsavel pelo curso que encaminhe o questio närio aos indivíduos e/ou setores mais indicados para responder a cada parte do questionärio.

2. Solicitar que o questionario seja totalmente preenchido no prazo de 2 dias e devolvido ao aplicador. 
3. Rever os questionärios um dia antes de deixar a Unidade Universitāria, de modo que, em caso de necessidade, se possa fazer alguma entrevista adicional para complementar eventuais lacunas.

OBSERVAÇAO FINAL

ENCAMINHAR PESSOALMENTE TODOS OS QUESTIONARIOS DENTRO DO PRAZO PREVISTO NO CRONOGRAMA. 
$A \quad N E X X O H$

TABELAS DE CONTINGENCIA DE DUPLA E TRIPLA ENTRADA RELACOES ENTRE VARTATEIS NA SUBAMOSTRA DE PROFESSORES DAS UNIDADES UNIVERSITARIAS FEDERAIS 
TABELA $3-1$

RELAÇAO ENTRE GRUPO E REGIME DE TRABALHO NA SUBAMOSTRA DE PROFESSORES DAS UNIDADES UNIVERSITARIAS FEDERAIS - $1980^{*}$

\begin{tabular}{|l|c|c|c|c|c|c|}
\hline \multirow{2}{*}{$\begin{array}{l}\text { REGIME DE } \\
\text { TRABALHO }\end{array}$} & \multicolumn{2}{|c|}{ GRUPO A** } & \multicolumn{2}{c|}{ GRUPO B** } & \multicolumn{2}{c|}{ TOTAL } \\
\cline { 2 - 7 } & $\mathrm{N}$ & $\vdots$ & $\mathrm{N}$ & $\%$ & $\mathrm{~N}$ & $\vdots$ \\
\hline $\begin{array}{l}\text { TEMPO PARCIAL OU } \\
\text { HORA-AULA }\end{array}$ & 11 & 32,4 & 23 & 67,6 & 34 & 100,0 \\
\hline $\begin{array}{l}\text { TEMPO INTEGRAL } \\
\text { (40 horaS) }\end{array}$ & 64 & 78,0 & 18 & 22,0 & 82 & 100,0 \\
\hline DEDICACAO EXCLUSIVA & 91 & 86,7 & 14 & 13,3 & 105 & 100,0 \\
\hline TOTAL & 116 & 75,1 & 55 & 24,9 & $221^{* * *}$ & 100,0 \\
\hline
\end{tabular}

* Dados adaptados de: SOCIEDADE BRASILEIRA DE GEOLOGIA/MINISTERIO DA EDUCAÇA E CULTURA - 1981. - A Fomacão do Geölogo nas Universidades Brasileiras, um Retrato de Duas Decadas. NEC, Brasilia, 209 pp.

*GRUPO A: Professores que desenvolvem pesquisa

GRUPO B: Professores que näo desenvolvem pesquisa

***O total de professores não atingiu o total da subamostra porque un de-les näo respondeu acerca de seu regime de trabalho. 
TABELA $3-2$

RELACAO ENTRE GRUPO E EXERCICIO DE ATIVIDADES PROFISSIONAIS EXTERNAS NA SUBAMOSTRA DE PROFESSORES DAS UNIDADES UNIVERSI TARIAS FEDERAIS - 1980*

\begin{tabular}{|c|c|c|c|c|c|c|}
\hline \multirow{2}{*}{$\begin{array}{l}\text { ATIVIDADES PRO- } \\
\text { FISSIONAIS EXTERNAS }\end{array}$} & \multicolumn{2}{|c|}{ GRUPO $A^{* *}$} & \multicolumn{2}{|c|}{ GRUPO $B^{* *}$} & \multicolumn{2}{|c|}{ TOTAL } \\
\hline & $\mathrm{N}$ & $\frac{\partial}{\partial}$ & $\mathrm{N}$ & $\frac{0}{0}$ & $N$ & $\ddot{0}$ \\
\hline $\begin{array}{l}\text { EXERCE ATIVIDADES } \\
\text { EXTERNAS }\end{array}$ & 28 & 51,9 & 26 & 48,1 & 54 & 100,0 \\
\hline $\begin{array}{l}\text { NAO EXERCE ATIVIDADES } \\
\text { EXTERNAS }\end{array}$ & 135 & 82,3 & 29 & 17,7 & 164 & 100,0 \\
\hline TOTAL & 163 & 74,8 & 55 & 25,2 & $218^{k * * *}$ & 100,0 \\
\hline
\end{tabular}

* Dados adaptados de: SOCIEDADE BRASILETRA DE GEOLOGIA/MTNTSTERIO DA EDUCACAO E CULTURA - 1981. - A Formacão do Geölogo nas Universidades Brasileiras, um Retrato de Duas Decadas. MEC, Brasilia, $209 \mathrm{pp}$.

**GRUPO A: Professores que desenvolven pesquisa

GRUPO B: Professores que não desenvolvem pesquisa

***O total de professores não atingiu o total da subamostra porque alguns não responderam acerca de suas atividades profissionais externas ä Uni dade Universitáxia. 
TABELA $3-3$

RELAÇAO ENTRE GRUPO E TITULO OBTIDO NA CARREIRA UNIVERSITARIA NA SUBAMOSTRA DE PROFESSORES DAS UNIDADES UNIVERSITARIAS FEDE RAIS - $1980^{*}$

\begin{tabular}{|c|c|c|c|c|c|c|}
\hline \multirow{2}{*}{ TITULO OBTIDO } & \multicolumn{2}{|c|}{ GRUPO A* } & \multicolumn{2}{|c|}{ GRUPO B * } & \multicolumn{2}{|c|}{ TOTAL } \\
\hline & $N$ & $\%$ & $\mathrm{~N}$ & $\%$ & $\mathrm{~N}$ & $\stackrel{\circ}{a}$ \\
\hline GRADUADO & 50 & 59,5 & 34 & 40,5 & 84 & 100,0 \\
\hline MESTRE & 59 & 78,7 & 16 & 21,3 & 75 & 100,0 \\
\hline DOUTOR & 49 & 92,5 & 4 & 7,5 & 53 & 100,0 \\
\hline LIVRE-DOCENTE & 7 & 87,5 & 1 & 12,5 & 8 & $1.00,0$ \\
\hline TOTAL & 165 & 75,0 & 55 & 25,0 & $220 * *$ & 100,0 \\
\hline
\end{tabular}

*Dados adaptados de: SOCTFDADE BRASTLEIRA DE GEOLOGIA/MINISTERIO DA EDUCACAO E CULTURA - 1981 - A Formação do Geólogo nas Universidades Brasileiras, un Retrato de Duas Decadas. MEC, Brasilia, $209 \mathrm{pp}$.

**GRUPO A: Professores que desenvolvem pesquisa

GRUPO B: Professores que não desemolvem pesquisa

***O total de professores não atingiu o total da subamostra porque algums não responderam acerca de seu tîtulo. 
TABELA $3-4$

RELAÇÃO ENTRE GRUPO E TEMPO DE SERVICCO NA UNIDADE UNIVERSITARIA NA SUBANOSTRA DE PROFESSORES DAS UNIDADES UNIVERSTTARIAS FEDERAIS - $1980^{*}$

\begin{tabular}{|l|r|r|r|r|r|r|}
\hline \multirow{2}{*}{ TEMPO DE SERVIÇO } & \multicolumn{2}{|c|}{ GRUPO A* } & \multicolumn{2}{c|}{ GRUPO B* } & \multicolumn{2}{c|}{ TOTAL } \\
\cline { 2 - 7 } & N & $\%$ & $N$ & $\%$ & $N$ & $\%$ \\
\hline 2 a 5 ANOS & 28 & 56,0 & 22 & 44,0 & 50 & 100,0 \\
\hline 6 a 9 ANOS & 52 & 81,3 & 12 & 18,7 & 64 & 100,0 \\
\hline 10 a 13 ANOS & 32 & 84,2 & 6 & 15,8 & 38 & 100,0 \\
\hline 14 ANOS OU MAIS & 25 & 83,3 & 5 & 16,7 & 30 & 100,0 \\
\hline & 29 & 72,5 & 11 & 27,5 & 40 & 100,0 \\
\hline
\end{tabular}

*Dados adaptados de: SOCIEDADE BRASIUEIRA DE GEOLOGIANMTNISTERIO DA EDUCAÇA E CUI.TURA - 1981. - A Formacão do Geölogo nas Wiversidades Brasileiras, um Retrato de Duas Decadas. MC, Brasilia, 209 pp.

**GRUPO A: Professores que desenvolvem pesquisa

GRUPO B: Professores que não desenvolvem pesquisa 
TABELA 3-5

RELAÇAOO ENTRE GRUPO E PERIODO DE INICIO DE FUNCIONAMENTO DE CURSO DE GRADUACAO EM GEOLOGIA, CONTROLAN DO PELO REGIME DE TRABALHO, NA SUBAMOSTRA DE PROFESSORES DAS UNIDADES UNIVERSITARIAS FEDERAIS - 1980 *

\begin{tabular}{|c|c|c|c|c|c|c|c|c|c|c|c|c|c|c|}
\hline \multirow{3}{*}{$\begin{array}{l}\text { INICIO DE } \\
\text { FUNCIONAMENTO }\end{array}$} & \multicolumn{4}{|c|}{$\begin{array}{l}\text { TEMPO PARCIAL } \\
\text { OU HORA-AULA }\end{array}$} & \multicolumn{4}{|c|}{$\begin{array}{l}\text { TEMPO INTEGRAL } \\
(40 \text { horas })\end{array}$} & \multicolumn{4}{|c|}{$\begin{array}{l}\text { DEDICACAO } \\
\text { EXCLUSIVA }\end{array}$} & \multirow{2}{*}{\multicolumn{2}{|c|}{ TOTAL }} \\
\hline & \multicolumn{2}{|c|}{ GRUPO $A^{* *}$} & \multicolumn{2}{|c|}{ GRUPO $B^{* *}$} & \multicolumn{2}{|c|}{ GRUPO A } & \multicolumn{2}{|c|}{ GRUPO B } & \multicolumn{2}{|c|}{ GRUPO A } & \multicolumn{2}{|c|}{ GRUPO B } & & \\
\hline & $N$ & $\frac{0}{0}$ & $N$ & $\frac{0}{0}$ & $\mathrm{~N}$ & $\stackrel{0}{0}$ & $\mathrm{~N}$ & $\frac{9}{0}$ & N & $\%$ & $\mathrm{~N}$ & $\%$ & $\mathrm{~N}$ & $\%$ \\
\hline 1957 a 1965 & 8 & 38,1 & 13 & 61,9 & 45 & 88,2 & 6 & 11,8 & 64 & 94,1 & 4 & 5,9 & 140 & 63,3 \\
\hline 1970 a 1973 & 2 & 22,2 & 7 & 77,8 & 11. & 64,7 & 6 & 35,3 & 18 & 81,8 & 4 & 18,2 & 48 & 21,7 \\
\hline 1976 a 1977 & 1 & 25,0 & 3 & 75,0 & 8 & 57,1 & 6 & 42,9 & 9 & 60,0 & 6 & 40,0 & 33 & 14,9 \\
\hline TOTAL & 11 & 5,0 & 23 & 10,4 & 64 & 29,0 & 18 & 8,1 & 91 & 41,2 & 14 & 6,3 & $221^{k+k}$ & 100,0 \\
\hline
\end{tabular}

* Dados adaptados de: SOCIEDADE BRASILEIRA DE GEOLOGIAMINISTERIO DA EDUCAÇAO E CULTURA - 1981 - A Formação do Gcólogo nas Universidades Brasileiras, um Retrato de Duas Décadas. MEC, Brasília, 209 pp.

* GRUPO A: Professores que desenvolvem pesquisa GRUIO B: Professores que não desenvolvem pesqujsa

***0 total de professores não atingiu o total da subamostra porque un deles não respondeu acerca de seu regime de trabalho. 
TABELA $3-6$

RELACXO ENTRE GRUPO E PERIODO DE INICIO DE FUNCIONAMENTO DE CURSO DE GRADUAÇAO EM GEOLOGIA, CONTROLANDO PELO EXERCICIO DE ATIVIDADES PROFISSIONAIS EXTERNAS, NA SUBAMOSTRA DE PROFESSORES DAS UNIDADES UNIVERSITARIAS FEDERAIS - $1980^{*}$

\begin{tabular}{|c|c|c|c|c|c|c|c|c|c|c|}
\hline \multirow{3}{*}{$\begin{array}{l}\text { ATIVIDADES PROFISSIO- } \\
\text { NAIS EXIERNAS } \\
\text { INICIO DE } \\
\text { NUNCIONANENTO }\end{array}$} & \multicolumn{4}{|c|}{ EXERCE ATIVIDADES EXTERNAS } & \multicolumn{4}{|c|}{ NAO EXERCE ATIVIDADES EXTERNAS } & \multirow{2}{*}{\multicolumn{2}{|c|}{ TOTAL }} \\
\hline & \multicolumn{2}{|c|}{ GRUPO $A^{* *}$} & \multicolumn{2}{|c|}{ GRUPO $\mathrm{B}$ ** } & \multicolumn{2}{|c|}{ GRUPO $A^{* *}$} & \multicolumn{2}{|c|}{ GRUPO B** } & & \\
\hline & N & $\%$ & $N$ & $\%$ & N & $\%$ & $N$ & $\frac{0}{0}$ & $\mathrm{~N}^{\prime}$ & $\%$ \\
\hline 1957 a 1965 & 17 & 54,8 & 14 & 45,2 & 98 & 92,5 & 8 & 7,5 & 137 & 62,8 \\
\hline 1970 a 1973 & 7 & 43,7 & 9 & 56,3 & 24 & 75,0 & 8 & 25,0 & 48 & 22,0 \\
\hline 1976 a 1977 & 4 & 57,1 & 3 & 42,9 & 13 & 50,0 & 13 & 50,0 & 33 & 15,1 \\
\hline TOTAL & 28 & 12,8 & 26 & 11,9 & 135 & 61,9 & 29 & 13,3 & $218 *$ & 100,0 \\
\hline
\end{tabular}

* Dados adaptados de: SOCIEDADE BRASILEIRA DE GEOLOGIA/MINISTERIO DA EDUCAÇAO E CULTURA - 1981 - A Formação do Geólogo nas Universidades Brasileiras, um Retrato de Duas Décadas. MEC, Brasilia, 209 pp.

${ }^{* *}$ GRUPO A: Professores que desenvolvem pesquisa GRUlO B: Professores que não desenvolvem pesquisa

***O total de professores não atingiu o total da subamostra porque alguns não responderam acerca de suas atividades profissionais externas à Unidade Universitäria. 
TABELA 3-7

RELAÇA ENTRE GRUPO E PERIODO DE INICIO DE FUNCIONAMENTO DE CURSO DE GRADUAÇAO EM GEOLOGIA, CONTROLANDO PELO TITULO OBTIDO, NA SUBAMOSTRA DE PROFESSORES DAS UNIDADES UNIVERSITARIAS FEDERAIS - 1980*

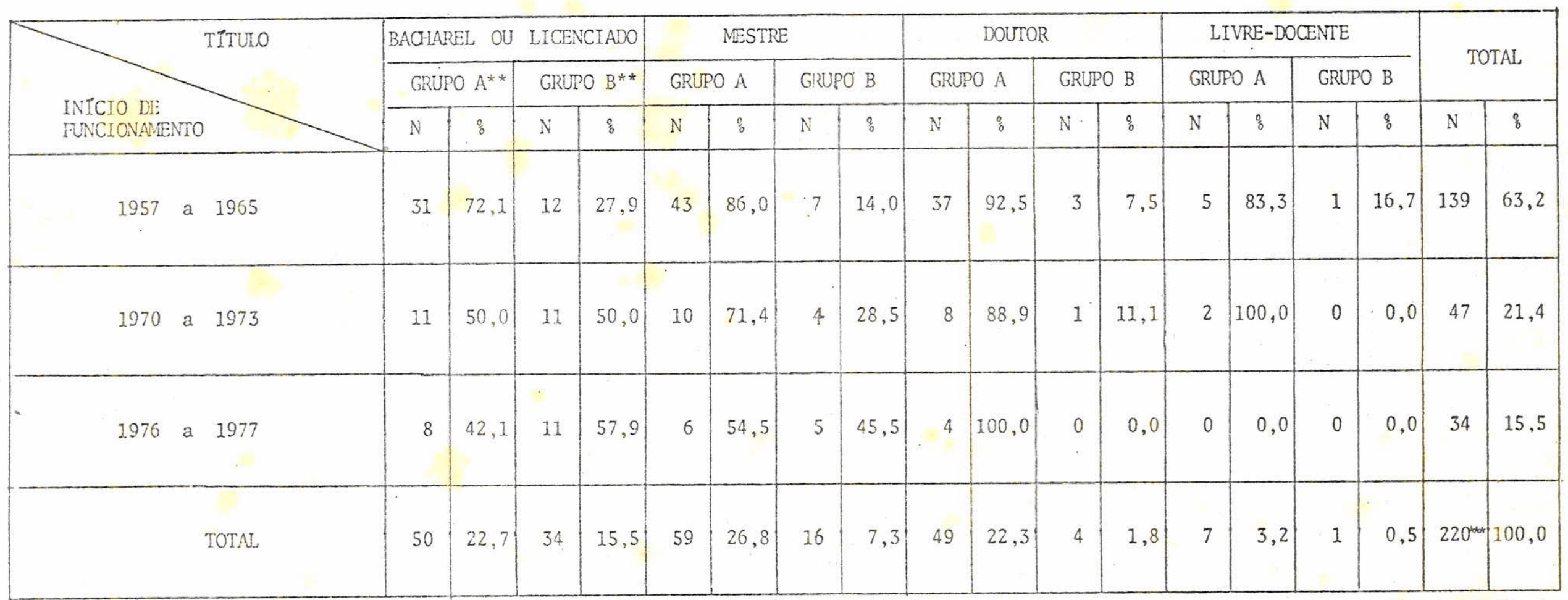

*Dados adaptados de: SOCIEDADE BRASILEIRA DE GEOLOGIA/MINISTERIO DA EDUCAÇAO E CULTURA - 1981 - A Formação do Geólogo nas Universidades Brasileiras, um Retrato de Duas Décadas. MEC, Brasília, 209 pp.

**GRUPO A: Professores que desenvolvem pesquisa

GRUPO B: Professores que não desenvolvem pesquisa

***O total de professores não atingiu o total da subamostra porque alguns não responderam acerca de seu titulo. 
TABELA $3-8$

RELACAO ENTRE GRUPO E PERIODO DE INICIO DE FUNCIONAMENTO DE CURSO DE GRADUAÇÃO EM GEOLOGIA, CONTROLANDO PELO TEMPO DE SERVIÇO, NA SUBAMOSTRA DE PROFESSORES DAS UNIDADES UNIVERSITARIAS FEDERAIS - 1980*

\begin{tabular}{|c|c|c|c|c|c|c|c|c|c|c|c|c|c|c|c|c|c|c|c|c|c|c|}
\hline \multirow{3}{*}{$\begin{array}{l}\text { TEMPO DE } \\
\text { SERVIÇO } \\
\text { INICIO DE } \\
\text { FNCIONMENTO }\end{array}$} & \multicolumn{4}{|c|}{ MENOS DE 2 ANOS } & \multicolumn{4}{|c|}{2 a 5 ANOS } & \multicolumn{4}{|c|}{6 a 9 ANOS } & \multicolumn{4}{|c|}{10 a 13 ANOS } & \multicolumn{4}{|c|}{14 ANOS OU MAIS } & \multirow{2}{*}{\multicolumn{2}{|c|}{ TOTAL }} \\
\hline & \multicolumn{2}{|c|}{ GRUPO $A^{* *}$} & \multicolumn{2}{|c|}{ GRUPO B** } & \multicolumn{2}{|c|}{ GRUPO A } & \multicolumn{2}{|c|}{ GRUPO B } & \multicolumn{2}{|c|}{ GRUPO A } & \multicolumn{2}{|c|}{ CRUPO B } & \multicolumn{2}{|c|}{ GRUPO A } & \multicolumn{2}{|c|}{ GRUPO B } & \multicolumn{2}{|c|}{ GRUPO A } & \multicolumn{2}{|c|}{ GRUPO B } & & \\
\hline & N & $\because$ & $\mathrm{N}$ & $\because$ & N & $\because$ & $\mathrm{N}$ & $\because$ & N & $\%$ & $\mathrm{~N}$ & $:$ & N & $\because$ & N & $\%$ & $N$ & $\because$ & $\mathrm{N}$ & : & $\mathrm{N}$ & $q$ \\
\hline 1957 a 1965 & 13 & 68,4 & 6 & 31,6 & 37 & 94,9 & 2 & 5,1 & 21 & 80,8 & 5 & 19,2 & 22 & 88,0 & 3 & 12,0 & 24 & 77,4 & 7 & 22,6 & 140 & 63,1 \\
\hline 1970 a 1973 & 8 & 66,7 & 4 & 33,3 & 9 & 56,3 & 7 & 43,7 & 7 & 87,5 & 1 & 12,5 & 3 & 60,0 & 2 & 40,0 & 4 & 57,1 & 3 & 42,9 & 48 & 21,6 \\
\hline 1976 a 1977 & 7 & 36,8 & 12 & 63,2 & 6 & 66,7 & 3 & 33.3 & 4 & 200,0 & 0 & 0,0 & 0 & 0,0 & 0 & 0,0 & 1 & 50,0 & 1 & 50,0 & 34 & 15,3 \\
\hline TOTAL & 28 & 12,6 & 22 & 9,9 & 52 & 23,4 & 12 & 5,4 & 32 & 14,4 & 6 & $2, ?$ & 25 & 11,3 & 5 & 2,3 & 29 & 13,1 & 11 & 5,0 & 222 & 100,0 \\
\hline
\end{tabular}

*Dados adaptados de: SOCIEDADE BRASILEIRA DE GEOLOGIA/MINISTERIO DA EDUCAÇAO E CULTURA - 1981 - A Formação do Geólogo nas Universidades Brasileiras, um Retrato de Duas Décadas. MEC, Brasília, 209 pp.

**GRUPO A: Professures que desenvolvem pesquisa

Grupo B: Professores que não desenvolvem pesquisa 